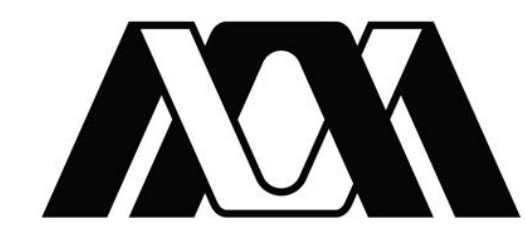

Casa abierta al tiempo UNIVERSIDAD AUTÓNOMA METROPOLITANA

\title{
La construcción de la vida laboral y la vida social en el mundo moderno. El caso de una organización inmobiliaria en Colombia
}

\section{Tesis}

Que para obtener el grado de Maestra en Estudios Organizacionales

Presenta

Marcela Prieto Rodríguez

Director de tesis

Dr. Adolfo Mir Araujo

Ciudad de México, México

Agosto 30 de 2017 


\section{ÍNDICE GENERAL}

\section{CAPÍTULO I INTRODUCCIÓN}

Pág.

6

1.1. Planteamiento del problema: La definición de las jornadas laborales en el mundo moderno

1.1.1. Las dinámicas laborales en el contexto actual

6

6

1.1.2. Los desafíos que define el nuevo contexto para las dinámicas organizacionales

Redefinición de los trabajadores en el mundo laboral y en el

1.1.3. mundo social

Desempeño de roles laborales y extra laborales a partir de las

1.1.4. jornadas laborales definidas en el mundo moderno

1.1.4.1. Pregunta general

1.1.4.2. Preguntas específicas

1.2. Justificación

1.3. Objetivos

1.3.1. Objetivo general 18

1.3.2. Objetivos específicos 18

\section{LINEAMIENTOS TEÓRICOS QUE PERMITIRÁN}

CAPÍTULO II ABORDAR EL FENÓMENO ORGANIZACIONAL A 19 ESTUDIAR

2.1. Las jornadas laborales

2.1.1. ¿Qué son las jornadas laborales? 19

2.1.2. Establecimiento de las jornadas laborales 20

2.2. La teoría de roles en el análisis de la vida social 22

2.2.1. La teoría de roles 22

2.2.2. Roles múltiples: conflicto de roles y acumulación de roles 24

2.2.2.1. Conflicto de rol: Multiplicidad de roles como fuente de estrés 24

2.2.2.2 Acumulación de rol: Multiplicidad de roles como fuente de satisfacción 26

2.2.3. La multiplicidad de roles en escenarios laborales y no laborales 28

2.2.3.1 La multiplicidad de roles generada por el escenario laboral y el escenario familiar

2.2.3.2. La multiplicidad de roles generada por el escenario laboral y otros escenarios no laborales

2.2.4. La vida social analizada desde la teoría de roles 32

2.3. La vida laboral analizada desde el Nuevo Institucionalismo 32

2.3.1. ¿Qué es el Nuevo Institucionalismo? 33

2.3.1.1. Nuevo institucionalismo sociológico 34

2.3.1.2. Nuevo institucionalismo político 35

2.3.2. Lógicas institucionales que enmarcan la dinámica organizacional 35

2.3.2.1. Las instituciones como construcciones sociales que son 36 reproducidas 
2.3.2. El proceso de institucionalización como fuente causal de patrones de comportamiento

2.3.2.3. Los mitos racionalizados

2.3.2.4. La institucionalización de la acción mediante reglas y rutinas

La adopción de prácticas institucionalizadas por parte de las

2.3.2.5. organizaciones como respuesta a las presiones institucionales para garantizar su legitimidad

23.3. El nuevo institucionalismo: teoría para analizar la definición y funcionamiento de las jornadas laborales

La teoría de roles y el nuevo institucionalismo: propuestas

2.4. teóricas pertinentes para analizar el fenómeno organizacional a estudiar

3.1. Estrategia metodológica para el estudio de caso 46

3.1.1. Elección de los instrumentos de investigación 50

3.1.2. Caracterización de las variables y su nivel de análisis 53

CAPÍTULO IV UNA APROXIMACIÓN AL OBJETO DE ESTUDIO: 57 CENTURY 21 COUNTRY

4.1. Contextualización del sector inmobiliario en Colombia 57

4.2. Red inmobiliaria Century $21 \AA$

4.3. Century 21 en Colombia 59

4.4. Relación entre Century $21 \AA$, Century 21 Colombia y C21 59

4.5. Oficina inmobiliaria objeto de estudio: C21 country 61

4.5.1. Historia de C21 Country 61

4.5.2. Quienes conforman C21 Country 62

4.5.3. Configuración de C21 Country 65

\section{ESTUDIO DE CASO: DEFINICIÓN DE LAS CAPÍTULO V JORNADAS LABORALES EN C21 COUNTRY A PARTIR DE LOS MÚLTIPLES ROLES ASUMIDOS POR SUS TRABAJADORES}

5.1. Definición de las jornadas laborales en C21 country 71

5.1.1. Elementos que inciden en la definición de las jornadas laborales desde la organización

5.1.1.1. La dinámica del mercado del sector inmobiliario 73

5.1.1.2. La asistencia a la oficina como un mandato de la organización 74

5.1.1.3. Los requerimientos de los clientes $\quad 75$

5.1.1.4. La asignación y uso de herramientas de comunicación 76

5.1.1.4.1. El celular como herramienta de trabajo de uso ilimitado $\quad 77$

5.1.1.4.2. Restricciones para el uso del celular $\quad 79$

5.1.1.4.3. El celular en la definición de los tiempos laborales y no laborales 82 
5.1. Elementos que inciden en la definición de las jornadas laborales

desde quienes conforman el equipo de trabajo

5.1.2.1. La construcción social de las jornadas laborales 84

5.1.2.2. La etapa del ciclo de vida laboral en la que se ubican 85

5.1.2.3. Experiencias laborales anteriores 86

5.1.2.4. La dinámica familiar y personal $\quad 89$

5.1.3. Construcción de la jornada laboral en C21 Country 92

5.2 La multiplicidad de roles de los trabajadores y su incidencia en la definición de las jornadas laborales

93

Roles de la vida laboral y la vida no laboral por los que transitan

5.2.1. quienes conforman el equipo de C21 Country

5.2. La multiplicidad de roles en la que están inmersos quienes conforman el equipo de C21 Country

5.2.2.1. Presencia de conflictos inter - rol en algunas personas que conforman el equipo

Roles que compiten por los mismos recursos: la sobre carga de

5.2.2.2. rol a la que están expuestas algunas personas del equipo

93

94

95

97

5.2.3. Acumulación de roles: los beneficios resultantes de transitar por múltiples escenarios

100

5.2.3. La multiplicidad de roles, elemento incidente pero no exclusivo para la definición de las jornadas laborales

La flexibilidad y la rigidez de la jornada laboral: condiciones

5.3. que pueden facilitar el desenvolvimiento de múltiples roles en el escenario laboral y no laboral

5.3.1. La rigidez del horario flexible

5.3.1.1. Definición de tiempos laborales

5.3.1.1.1. Definición de tiempos laborales en semana

5.3.1.1.2. Definición de tiempos laborales los fines de semana

5.3.1.2. Asistencia a la oficina

5.3.1.3. Elementos que hacen rígidas las jornadas laborales flexibles

5.3.2 La flexibilidad de la jornada laboral establecida por la organización

5.3.2.1. Cumplimiento de horario de trabajo

5.3.2.2. Flexibilidad en medio de la rigidez

5.3.2.3. Elementos incidentes en el paso de la rigidez a la flexibilidad Características de la flexibilidad y de la rigidez de la jornada

5.3.3. laboral que facilitan el desenvolvimiento de múltiples roles en el escenario laboral y no laboral de los trabajadores de C21 Country

Construcción de la vida social y la vida laboral en el mundo

5.4. moderno: Definición de la jornada laboral a partir de los roles asumidos en lo laboral y lo no laboral

5.4.1. A partir de la multiplicidad de roles

102

107

107

109

109

113

116

118

122

122

125

128

129

5.4.2. A partir de la institucionalización de las jornadas laborales

5.4.3. A partir de la rigidez y de la flexibilidad de las jornadas laborales

5.4.4. La vida social y la vida laboral en C21 Country ¿Se construye a partir de las jornadas laborales? 
CAPÍTULO VI REFLEXIONES FINALES

6.2. Comentarios finales 142

\section{ÍNDICE DE FIGURAS, TABLAS Y GRÁFICAS}

\section{ÍNDICE DE FIGURAS}

Figura 1. Componentes del proceso de institucionalización

Pág.

Modelo organizacional para analizar la definición de las

Figura 2. jornadas laborales de los trabajadores de una oficina 55 inmobiliaria

Figura 3. Relación entre Century $21 \AA$, Century 21 Colombia y C21 60

Figura 4. Organigrama C21 Country

66

Figura 5 Elementos que inciden en la definición de la jornada laboral en C21 Country

Figura 6 . Tendencia hacia la flexibilidad a partir de las variables de análisis

91

Figura 7. La multiplicidad de roles en C21 Country

Figura 8. Vinculación free lance: de la flexibilidad a la rigidez

Figura 9. Vinculación laboral: de la rigidez a la flexibilidad

Figura 10. Construcción de la vida social y la vida laboral en C21 Country

\section{ÍNDICE DE TABLAS}

Tabla 1. Aportes teóricos de la investigación 18

Tabla 2. Aspectos metodológicos generales $\quad 50$

Tabla 3. Marco de análisis y variables 54

Tabla 4. Información demográfica de quienes conforman C21 Country 65

Tabla 5. Mecanismos de coordinación en C21 Country 67

Tabla 6. C21 Country, una organización con configuración empresarial 69

Tabla 7. Caracterización de la población objetivo a partir de las 70

Tabla 8. Incidencia de las variables de análisis en la multiplicidad de roles

\section{ÍNDICE DE GRÁFICAS}

Gráfica 1. Rango de edad de quienes conforman C21 Country 63

Gráfica 2. Estado civil de quienes conforman C21 Country 63

Gráfica 3. Estado parental de quienes conforman C21 Country 63

Gráfica 4. Antigüedad en la empresa de quienes conforman C21 Country 64 


\section{INTRODUCCIÓN}

\subsection{PLANTEAMIENTO DEL PROBLEMA: LA DEFINICIÓN DE LAS JORNADAS LABORALES EN EL MUNDO MODERNO}

\subsubsection{Las dinámicas laborales en el contexto actual.}

A partir de las últimas décadas del siglo $X X$ y en lo que va transcurrido del siglo XXI se han ido redefiniendo las formas de organización y el rumbo del trabajo, pues las condiciones laborales prevalentes en el siglo pasado ya no son ni sostenibles ni coherentes bajo las demandas que los nuevos tiempos establecen. De acuerdo con Reygadas, "en el marco de las crisis y reajustes de los años ochenta, de la intensificación de la globalización durante los años noventa y de los diversos intentos por reorientarla en la primera década del siglo XXI, en la región se han difundido nuevas formas de organización del trabajo, se han incorporado nuevas tecnologías, se ha incrementado el empleo informal y se ha flexibilizado el empleo, el trabajo y los mecanismos de regulación laboral. En el corazón de estas transformaciones se observa una tensión: por una parte, hay un movimiento de innovación y reestructuración (...), y por otra, hay una dimensión destructiva" (Reygadas, 2011: 21).

De esta forma, en simultánea con el avance de la sociedad del conocimiento, la expansión del sector servicios y la aparición de nuevas ramas y productos, surgen, se legitiman, y se propagan los trabajos atípicos, los cuales proponen nuevos tipos de relaciones entre las empresas, los empleados y los consumidores; y por otro lado, en el marco de la globalización han proliferado los trabajos precarios es decir, "empleos inestables, sin contrato, con salarios bajos, sin prestaciones, con jornadas irregulares, a tiempo parcial o jornadas demasiado largas, con malas condiciones de trabajo, carentes de seguridad social, violatorios de los derechos laborales, con nula o reducida negociación colectiva" (Reygadas, 2011:22). Estas nuevas disposiciones para la organización del trabajo promueven la construcción de nuevas identidades, acordes con las demandas y parámetros establecidos por el modelo. Es decir, los trabajadores deben en muchos casos modificar sus maneras de trabajar, e incluso la percepción que tienen acerca de un empleo, de una empresa y de un puesto de trabajo, haciéndola compatible con las nuevas disposiciones del medio. Por tanto, tener un empleo no necesariamente implica estar trabajando de manera permanente en una jornada laboral establecida por la empresa de ocho a nueve horas diarias, de acuerdo con la normatividad, sino que se establecen largas jornadas de trabajo, jornadas a tiempo parcial, o jornadas discontinuas que los trabajadores deben cumplir a fin de garantizar su permanencia en la empresa.

Lo anterior delinea el ámbito en el que se encuentran las dinámicas organizacionales y señala algunos de los efectos que de esto se deriva; de hecho, se presenta como un elemento interesante para analizar de qué forma esas nuevas condiciones de trabajo, en particular la definición y cumplimiento de la jornada laboral, tiene relación con el desarrollo de la vida laboral y no laboral de los trabajadores. De ahí que sea necesario considerar este tema a partir de los 
ajustes que las organizaciones han debido hacer en sus dinámicas en coherencia con el contexto neoliberal, y a partir de ello, como los trabajadores de igual manera han debido modificar sus dinámicas, su identidad, su ser y su quehacer en el mundo del trabajo, incidiendo en los roles que asumen en los diferentes escenarios de vida por los que transitan.

\subsubsection{Los desafíos que define el nuevo contexto para las dinámicas organizacionales.}

Los contextos económicos y políticos referidos en las líneas precedentes generan que las organizaciones deban redefinirse para dar respuesta a las exigencias del mismo, replanteando su modo de funcionamiento y su relacionamiento, tanto interno como externo. De hecho, la idea tradicional acerca de una empresa ha debido modificarse pues ya no es habitual el escenario en el que la empresa es percibida como un espacio que propicia condiciones de estabilidad y bienestar a sus trabajadores, sino que, ahora han aparecido distintas formas de organización empresarial; por ejemplo, los grandes corporativos que desdibujan por completo la idea de la familiaridad dando preponderancia a la expansión económica, política y territorial del negocio. Aparecen además otras formas de organización como las Mypimes, que en algunos casos, paradójicamente surgen como respuesta a la desregularización generada por el modelo neoliberal - incremento de desempleo y bajos salarios -; a su vez, el modelo se encarga de invisibilizarlas y poco a poco sacarlas del mercado.

Bajo esta misma perspectiva la redefinición del mundo del trabajo ha implicado repensar la idea de los puestos de trabajo pues, ya no remite necesariamente a lo que Neffa (2010) propone como un "verdadero empleo"1, sino que el puesto de trabajo puede estar ubicado en la casa del empleado, o en cualquier otro lugar en el que él se encuentre siempre y cuando que garantice su permanente conexión con la empresa mediante el uso de dispositivos móviles y electrónicos; así la tecnología se configura como un elemento trascendental en la redefinición de las nuevas dinámicas organizacionales pues, desdibuja la preponderancia de la dimensión espacial para el cumplimiento de unas tareas y esa importancia es transferida a la dimensión temporal, de tal forma que sin importar en donde se encuentren las personas, puedan atender oportunamente las demandas del trabajo. Inclusive, también es posible pensar que en muchos casos ni siquiera existe un listado de funciones a realizar por trabajador, sino que cada vez la polivalencia y los cargos multitareas se imponen como patrón general de organización del trabajo, facilitándole a las empresas la reducción de costos laborales y creando la sensación a los trabajadores de que realizan un trabajo más

\footnotetext{
1 Neffa (2010) propone que los principales elementos de un verdadero empleo son: "trabajo asalariado regulado por la legislación en materia de contrato de trabajo (es decir subordinado directamente respecto del empleador dependiente, heterónomo, en relación de dependencia) (...) el trabajo se realiza a tiempo completo - de acuerdo con la jornada máxima legal vigente y dando lugar al pago de horas extraordinarias si fuera el caso -, dentro del ámbito físico de un establecimiento urbano ajeno a su hogar y distinto del domicilio del empleador, con un contrato de duración por tiempo indeterminado (...)" (Neffa, 2010: 44).
} 
integrado y autónomo, estimulando así su involucramiento con el mismo² (Neffa, 2010).

La jornada laboral es otro aspecto que en las organizaciones se ha resignificado en este nuevo contexto, con el propósito de dar respuesta al mismo ${ }^{3}$. Así, a pesar de que una de las preocupaciones más antiguas de la legislación del trabajo ha sido la regulación de las jornadas laborales, y que ya desde principios del siglo XIX, se reconocía que trabajar demasiadas horas constituía un peligro para la salud de los trabajadores y sus familias, actualmente en pocas empresas se trabaja ocho horas diarias, como lo establece el convenio C001 sobre las horas de trabajo de la Organización Internacional del Trabajo - en adelante OIT-; "generalmente hombres y mujeres permanecen diez y hasta doce horas en sus centros de trabajo y en consecuencia, ni a los padres ni a las madres les queda mucho tiempo para dedicarlo al hogar o a los hijos" (Debeljuh y Jáuregui, 2004: 92). De hecho como se propuso líneas atrás, Reygadas (2011), plantea entre las características de la precarización del trabajo como efecto del proceso globalizador, el establecimiento de jornadas laborales irregulares, a tiempo parcial o jornadas demasiado largas.

De acuerdo con Recio, "en años recientes la jornada laboral ha sido objeto de numerosos debates, en los cuales se ha puesto de manifiesto tanto la variedad de enfoques ideológicos y de intereses particulares que giran en torno a la misma, como la diversidad de cuestiones que confluyen en una cuestión aparentemente tan simple como la determinación del número de horas que las personas deben dedicar al empleo a cuenta de terceros" (Recio, 2002: 161). Dice el autor que este debate está ligado principalmente a tres cuestiones: Por una parte, la utilización del tiempo de trabajo como una medida para reducir o paliar el desempleo; por otra parte, la flexibilidad del tiempo de trabajo como un medio de mejora de la eficiencia productiva; y, la tercera, la reducción de la jornada laboral como mecanismo para mejorar la calidad de vida de las personas, como una forma de utilizar las mejoras de la productividad alternativa a los aumentos de renta y consumo.

\footnotetext{
${ }^{2}$ Neffa (2010) propone como característica de los trabajos atípicos o precarios la flexibilidad, e identifica varias modalidades que se han desarrollado en las organizaciones con el propósito de reducir costos, aumentar la productividad, poder introducir innovaciones tecnológicas y organizacionales para adaptarse más fácil y rápido a los cambios cuantitativos y cualitativos de la demandas, y ser más competitivos a nivel internacional. Una de estas formas de flexibilidad es la "flexibilidad interna" respecto de la organización del trabajo, en la que se observa la implementación de nuevas formas de organización como por ejemplo la movilidad entre puestos de trabajo (rotación), la polivalencia y la multifuncionalidad (ampliación de tareas, enriquecimiento de tareas) y el trabajo en equipos.

${ }^{3}$ Otra de las formas de flexibilidad que caracteriza a los trabajos precarios de acuerdo al planteamiento de Neffa (2010) es la flexibilización del tiempo de trabajo según las necesidades empresariales, en cuanto a la regularidad de la duración de la jornada según los días o las épocas del año, las condiciones para hacer horas extras, la determinación de los periodos totales o parciales de vacaciones, las pausas dentro de la jornada, la reducción de la vida activa para que las empresas puedan desprenderse de los trabajadores de mayor edad con problemas de salud, etcétera.
} 
Sin embargo, los análisis, las medidas y las políticas tanto estatales como empresariales han estado concentrados principalmente en las dos primeras cuestiones propuestas por Recio (2002), velando la complejidad de temas referentes al tercer punto, en el que analizar el tiempo y cómo éste es gestionado en la vida cotidiana habría de tener una mayor importancia, por constituir un tema fundamental en la construcción de la vida social de los trabajadores. De acuerdo con este autor, si se analiza el conjunto de la vida cotidiana de la mayoría de personas, se observa que éste se caracteriza por la realización de una enorme variedad de acciones que tienen en común el requerir una cierta cantidad de tiempo para realizarse. Junto a las actividades de trabajo mercantil mediante las cuales las personas obtienen los ingresos monetarios que les permiten subsistir en una economía de producción, realizan otras actividades con las que tratan de satisfacer otras necesidades o que resultan complementarias con la actividad mercantil; entre ellas destaca: trabajo doméstico, transporte forzado, formación, participación sociopolítica, ocio y actividades de relacionamiento. Cada una de estas actividades plantea exigencias de tiempo diferentes, en cuanto a duración y configuración; muchas de las actividades no mercantiles plantean además un cierto tipo de demandas de flexibilidad ${ }^{4}$.

De este modo, analizar las jornadas laborales únicamente como medida económica para reducir o paliar el desempleo, o como un medio de lucha para la eficiencia productiva, desconociendo la posibilidad que podrían tener éstas para mejorar la calidad de vida de las personas, es de alguna manera seguir reproduciendo las condiciones propuestas por el modelo neoliberal en el que se priorizan los aspectos económicos y cada vez se deshumanizan más los diferentes escenarios de vida, entre ellos el laboral.

\subsubsection{Redefinición de los trabajadores en el mundo laboral y en el mundo social.}

Con lo dicho hasta acá es posible afirmar que las organizaciones pueden entenderse como una "formación de la sociedad y de la cultura que siguen los parámetros de sus creadores, mantienen intercambios con el medio más allá de sus propias fronteras funcionando como caja de resonancia de los fenómenos externos e incidiendo a través de sus productos materiales y simbólicos" (Santos, 2008:105); por eso, están en la posibilidad de estructurar a las personas que las integran, y cuentan con los recursos para hacerlo; es decir, pueden influir en las formas de vida de quienes las conforman y reestructurar sus comportamientos, sus prioridades, e inclusive sus creencias de acuerdo con las necesidades de la organización y los intereses que persiguen.

\footnotetext{
${ }^{4}$ En adelante la flexibilidad será entendida como una posibilidad de adaptación al ritmo vital de situaciones que cambian con el tiempo (Recio, 2002). En caso de referirse a la característica de los trabajos atípicos y precarios propuestos por Reygadas (2011) y por Neffa (2010), se hará la aclaración correspondiente.
} 
Lo anterior, conjugado con el contexto ya descrito en el que se mercantilizan gran parte de los escenarios de la vida, desde lo macro hasta lo micro, permite identificar tres realidades respecto a las organizaciones y a quienes las conforman: El escenario económico competitivo en el que se desenvuelven las organizaciones; la competencia que se genera entre los trabajadores de las organizaciones para garantizar su permanencia en éstas; $y$, la disyuntiva frente a la que se pueden encontrar con frecuencia quienes hacen parte de la organización al entrar en conflicto los roles que desempeñan dentro y fuera de ésta.

Desde el ámbito de las organizaciones hay competencia entre ellas para sobrevivir en el mercado; entran en juego factores como el reconocimiento, la calidad y los precios de los productos o servicios ofrecidos, los costes de las materias primas e insumos para la elaboración de los productos o servicios, las estrategias de marketing implementadas, los factores diferenciadores y valores agregados, por mencionar algunos.

En segunda instancia, hay competencia entre quienes hacen parte de la organización, para permanecer dentro de ésta; las condiciones para ello se relacionan con la calidad del trabajo y los aportes realizados, el tiempo dedicado a la empresa, valores agregados que le pueda proporcionar a las labores asignadas, en resumen, en un número importante de situaciones, mantenerse en la organización está directamente relacionado con el profesionalismo y con la priorización que se le dé al trabajo respecto a otros escenarios, dedicándole gran cantidad de tiempo a la organización; pero como se verá a continuación, más allá de asuntos profesionales o laborales, también tienen preponderancia asuntos sociales de los trabajadores tales como el género y la configuración familiar. Bajo estas características se proponen imaginarios como los del "trabajador ideal", quien tiene mayores posibilidades de permanecer en la organización.

Un estudio realizado por Ruíz (2012), en una firma contable de México, pone en evidencia cómo el reconocimiento dentro de la empresa e inclusive, el mantenerse como parte de la misma, está relacionado con el tiempo que las personas le dediquen a su trabajo, la mayoría de veces renunciando a tiempos familiares, sociales y/o personales. "Las historias contadas por los entrevistados sugieren que la idea de invertir tiempo y estar físicamente presente en la oficina es más dominante que la necesidad real de trabajar largas horas para hacer el trabajo o satisfacer a los clientes. (...) La inversión de tiempo y presentismo, se utilizaron de manera informal para medir el compromiso de los empleados, la productividad y, por lo tanto, su potencial para el avance en la jerarquía. Los entrevistados, tanto femeninos como masculinos, reconocieron la necesidad de demostrar un compromiso de tiempo significativo, con el fin de ser evaluados positivamente y aumentar sus oportunidades de progreso" (Ruíz, 2012). De esta forma, el poder permanecer en una organización dependerá de la dedicación y compromiso con 
que el que los trabajadores realicen sus actividades, demostrado muchas veces con el presentismo ${ }^{5} \mathrm{y} / \mathrm{o}$ el cumplimiento de largas jornadas de trabajo.

De lo anterior se puede inferir además que el presentismo puede estar incidido por roles de género, pues debido a lo socialmente establecido, estos serán determinantes en las posibilidades de cumplimiento de los empleados a las exigencias de tiempo hechas por la organización; por lo general son los hombres quienes tienen mayores posibilidades de dar respuesta a las demandas de tiempo hechas por la organización, con respecto a las mujeres, quienes posiblemente deben atender a las demandas que se les hacen en la escena doméstica. Así se pone en evidencia la diferenciación de género que permea temas relacionados con la permanencia en una organización, y con esto, la definición de roles, posibilidades, capacidades y, comportamientos socialmente esperados para ser aceptado en la misma. Plantea Ruíz que "las prácticas y las normas de la profesión contable y la integración o la exclusión de las mujeres se ven influidos por factores sociales y los roles de género, la dinámica interna de la organización $y$, el contexto institucional (...) las mujeres que tienen éxito en organizaciones dominadas por los hombres, lo hacen mostrando características del trabajador ideal masculinizadas, suprimiendo actitudes, valores y los derechos de maternidad que las clasificarían como femeninos" (Ruíz, 2012).

De igual manera, la investigación realizada por Brumely (2014), estudia el caso de una empresa Mexicana que como parte de su proceso de modernización y adaptación a las nuevas exigencias del mercado global genera un cambio en sus políticas de trabajo, de tal forma que les garantiza a sus trabajadoras el derecho de seguir laborando después de contraer matrimonio y/o de quedar en estado de embarazo. Y, aunque de hecho esta nueva condición puede generar debate dados todos los valores culturales que se suponen implícitos en la anterior limitación, el estudio identifica cosas más allá. A partir de las entrevistas realizadas a trabajadores de los dos géneros se encontraron narrativas acerca del ya mencionado "trabajador ideal". De ahí que en las entrevistas estaba implícita la idea de equiparar el embarazo con la falta de profesionalismo y compromiso de las mujeres con su trabajo; de esta forma, la maternidad, pero no la paternidad, era un obstáculo clave para la promoción profesional (Brumely, 2014).

En resumen, los resultados de las dos investigaciones referenciadas son reiterativos en la idea de la masculinización de la mujer como condición de acceso al escenario laboral: las mujeres deben elegir entre el rol de madres y el de trabajadoras, perpetuando implícitamente la división tradicional de roles de género. La idea de masculinización se aúna con el prototipo de trabajador ideal, el cual por una parte construye y mantiene la desigualdad de género en el lugar de trabajo y por otra, legitima la idea de la economización sobre la humanización de las sociedades pues, para cumplir con los parámetros esperados para el

\footnotetext{
5 Término propuesto por Leslie A. Perlow, para referirse a la suposición de que los individuos deben estar presentes en el trabajo para tener éxito. En: Perlow, Leslie A. (1995) Putting the work back into work/family. Group and Organization Management, 20,2, 227-39.
} 
funcionamiento óptimo de la organización, - disponibilidad ilimitada de tiempo, principalmente- muchas veces los trabajadores deben comprometerse de tiempo completo en la vida laboral, dejando de lado otros espacios de socialización y esparcimiento que constituirían su vida social.

Finalmente, la tercera realidad que hace parte de la mercantilización de los escenarios de vida planteada previamente también se ubica dentro de la organización, orientada a las personas que la conforman o dirigen, quienes también están expuestos a situaciones de pugna entre sus deseos y las demandas que la organización les hace, e inclusive, se podrían agregar a este conflicto los comportamientos atribuidos socialmente a los diferentes roles que tiene cada persona de acuerdo con los escenarios en los que se desenvuelve fuera de la organización - padre, madre, hijo (a), cónyuge, hermano (a), amigo (a), vecino (a), entre otros - y, a las demandas que estos escenarios hacen, incluida la misma organización.

Estas condiciones configuran situaciones como el conflicto de roles entra la vida laboral y la vida social, la idea de la masculinización de la mujer como expresión de la presencia de conflictos entre el desarrollo personal y el laboral debido a los variados roles que se deben asumir en estos ámbitos, e incluso, la idea del trabajador ideal, la cual establece unos modos de comportamiento que inhiben la inserción en diferentes escenarios de la vida social.

\subsubsection{Desempeño de roles laborales y extra laborales a partir de las jornadas laborales definidas en el mundo moderno.}

De modo que, al observar el desarrollo de las dinámicas organizacionales actuales, y en particular el cumplimiento de funciones y la realización de las responsabilidades laborales en las empresas, industrias y organizaciones, es recurrente encontrar que las jornadas laborales y las actividades extra - laborales generan conflictos dado que, cumplir a cabalidad con las responsabilidades, exigencias y condiciones de trabajo que la organización misma determina y son asumidas por los trabajadores en su rol dentro del escenario laboral, implica descuidar otros escenarios como por ejemplo la familia, las relaciones sociales, los procesos de formación y capacitación, la participación socio - política, las actividades de ocio y esparcimiento. De esta forma, se hace visible como los diferentes escenarios propuestos por el mundo moderno generan conflictos entre los roles asumidos en la vida laboral y en la vida social.

Incluso, es posible afirmar que las nuevas formas de trabajo definidas por el mundo moderno, referenciadas antes como trabajos atípicos, generan que cada vez sea más invisible la línea que diferencia lo laboral y lo no laboral, acentuando en diversas ocasiones la aparición de conflictos entre los dos escenarios. Así que, estas nuevas formas de trabajo abren la posibilidad de definir las jornadas laborales en lo particular, y en general la dinámica laboral, de otra manera; por ejemplo, el uso de medios tecnológicos como herramientas para cumplir a cabalidad con las responsabilidades asignadas en la labor, tales como el celular y el computador, e incluso, las nuevas condiciones laborales dispuestas por la 
flexibilización laboral y precarización del trabajo, presentan un panorama, que aunque diferente al descrito previamente en el que prevalecía el presentismo en la organización como condición para mantenerse en la misma, también establece un mandato de sujeción a tiempos y espacios en los que la línea entre lo laboral y lo no laboral se desvanece cada vez más, y así como puede contribuir a acentuar el dilema entre los dos escenarios en algunas ocasiones también proporciona facilidades de armonización entre los mismos.

Desde este punto de vista es que se ha decidido realizar un estudio de caso en una organización en Colombia que hace parte de una multinacional dedicada a la compra, venta y arrendamiento de bienes raíces. La investigación en esta organización está orientada a analizar cómo se definen las jornadas laborales de los trabajadores a partir de los distintos roles que asumen en escenarios laborales y no laborales. Para ello, es pertinente tener presente variables de las personas que conforman la organización, los roles que estas asumen en los diferentes escenarios por los que transitan y las condiciones establecidas por la misma organización tales como lineamientos y herramientas de trabajo que definen la dinámica laboral que deben asumir quienes hacen parte del equipo de trabajo.

La oficina en la que se realiza la investigación para el estudio de caso está conformada por 18 personas, de las cuales 12 son agentes inmobiliarios y cumplen funciones comerciales; no tienen un horario de trabajo definido, ya que su vinculación no es laboral sino que trabajan bajo la figura de free lance ${ }^{6}$ y por tanto, no cuentan con las prestaciones de ley, no tienen una remuneración fija, sino que su remuneración es variable dependiendo de la comisión del negocio que realicen; el valor de la ganancia del negocio se establece sobre el $3 \%$ del valor total del inmueble que fue rentado o vendido; de este valor el $10 \%$ se entrega a la casa matriz de la organización, el $50 \%$ a la oficina y el $40 \%$ al agente que realizó el negocio; en caso de que el negocio haya sido realizado por dos agentes, el porcentaje de ganancia de distribuye entre los dos, es decir, $20 \%$ para cada uno.

Adicionalmente, el grupo de trabajo de la oficina lo conforman cuatro personas que cumplen funciones administrativas y de apoyo; ellas, a pesar de estar contratadas por prestación de servicios, tienen un horario de trabajo acorde con la normatividad nacional vigente de Colombia, devengan un salario mensual fijo y, cuentan con las prestaciones de ley. Las dos personas restantes tienen funciones gerenciales y a su vez son los dueños de la oficina, por tanto la definición de sus jornadas laborales y su remuneración es completamente diferente a las de las otras personas que conforman el grupo de trabajo.

\footnotetext{
${ }^{6}$ Aunque la definición de free lance será presentada más adelante, a partir de lo planteado por los entrevistados sobre este concepto, podría decirse de manera anticipada que el free lance hace referencia a un trabajador independiente cuyo trabajo realiza de manera autónoma, en términos de tiempos y espacios, y la retribución que recibe del mismo está definida no en función del tiempo empleado, sino del resultado. Igualmente, entre el free lance y la o las organizaciones que contraten sus servicios no se establece una relación laboral, sino una relación comercial de oferta y compra de servicios.
} 
Es posible pensar que la dinámica de esta oficina no versa única y necesariamente bajo la idea del ya referido "presentismo" como condición para mantenerse en la organización mediante el cumplimiento de la jornada de trabajo establecida, sino más bien, y principalmente para quienes conforman el área comercial, su permanencia en la organización dependerá de la gestión que cada persona haga de su tiempo, del uso de medios tecnológicos como el celular, y de la disposición que tenga para mostrar inmuebles y atender requerimientos de los clientes, como manera de garantizar o por lo menos buscar sus medios de subsistencia. Asimismo, es importante dimensionar los desafíos y bondades que para quienes conforman la organización plantea el uso de herramientas tecnológicas, características de las nuevas formas de trabajo, y el papel que estas tienen tanto para el cumplimiento de los objetivos del negocio, como para el desempeño de múltiples roles en el escenario laboral y no laboral. Y, además, es interesante reflexionar sobre la diferencia para configurar lo laboral y lo no laboral entre las personas de la organización que tienen la autonomía para definir sus jornadas laborales (agentes inmobiliarios), con respecto a quienes deben cumplir con el horario de trabajo establecido por la organización (personal administrativo y de apoyo).

Teniendo esto en cuenta, surgen los siguientes interrogantes que guían el desarrollo de la investigación:

\subsubsection{Pregunta general}

- ¿Cómo se definen las jornadas laborales de los trabajadores de una oficina inmobiliaria a partir de los múltiples roles que asumen en escenarios laborales y no laborales?

\subsubsection{Preguntas específicas}

- ¿Qué elementos intervienen en la definición de las jornadas laborales desde la organización y desde los trabajadores?

- ¿Qué relación existe entre el cumplimiento de la jornada de trabajo y variables como género, edad, estado civil, estado parental, tipo de trabajo realizado en la organización y tipo de vinculación?

- ¿Qué relación existe entre el uso de las nuevas tecnologías y la definición de tiempos y espacios laborales, de acuerdo con el tipo de trabajo realizado en la organización?

- ¿Cuál es la relación entre los roles asumidos por los trabajadores de la organización tanto en la vida laboral como en la vida no laboral, y la presencia de conflictos inter - rol, sobrecarga de rol y/o, acumulación de roles? 


\subsection{JUSTIFICACIÓN}

El cambio de dinámicas laborales propone un escenario en el que las relaciones laborales tradicionales son modificadas por unas relaciones atípicas y en algunas ocasiones precarias; las jornadas laborales y la definición de tiempos de trabajo, fenómenos organizaciones estudiados en esta investigación, no son ajenos a ello, inclusive estos son algunos de los aspectos característicos de las nuevas formas flexibles, dinámicas e informales de trabajo. Este fenómeno es cada vez más frecuente en las organizaciones, indistintamente de su tamaño, origen, ubicación, y responde a las demandas del mercado, de tal forma que lo laboral abarca cada vez más espacios de la vida de las personas y por tanto asuntos no laborales como la familia, el tiempo de ocio, la recreación, la capacitación quedan supeditados a éste.

Dicha situación desde hace tiempo ha generado interés en la investigadora, motivo por el cual el estudio realizado se orientó hacia este tema; desde niña veía los malabares que en ocasiones tenían que hacer papá y mamá para atender los asuntos familiares, laborales, sociales y al mismo tiempo, responder a los compromisos económicos; más adelante, y a partir de su experiencia laboral constató que esta situación no era propia o exclusiva de su familia, sino que más personas estaban insertas en esa lógica en la que lo laboral delinea la dinámica de vida en otros escenarios, implicando la modificación de patrones de comportamiento, rutinas de vida e incluso conllevando a la sobrevaloración del trabajo; así lo advirtió en dos empresas ubicadas en el sector servicios - el mismo en el que se ubica la organización objeto de estudio - cuyo personal debía trabajar por turnos, diurnos y nocturnos - empresa de seguridad privada -, y en ocasiones estar alejados de su casa para cumplir con la jornada laboral debido a que su lugar de trabajo se ubicaba en sitio remoto - empresa de preparación de alimentos para compañías mineras y petroleras - .

Es a partir de estas vivencias que más allá de entender las jornadas laborales como un mecanismo de control y productividad establecido por la organización, su definición y cumplimiento empezó a tener una connotación diferente, lo que generó interés en su estudio pues era a partir de estas que las personas determinaban el desarrollo de actividades vitales (como dormir, comer, descansar), actividades sociales (relacionamiento con familia, amigos, grupos culturales), actividades de auto cuidado (citas médicas), e incluso actividades de formación y capacitación (culminación de estudios, participación en cursos y seminarios). Así, las jornadas laborales más que indicar el cumplimiento de unos tiempos de trabajo, hacían referencia a la forma en que las personas organizaban el desarrollo de otros aspectos de su vida, ya fuera mediante la conciliación, la compatibilización o la eliminación de estos, de manera tal que el tránsito por los diversos escenarios fuera lo menos problemático posible.

De ahí que entonces sea pertinente y relevante estudiar este fenómeno en tanto incide de manera importante en las formas en las que las personas que hacen parte de la sociedad actual definen su dinámica de vida, y en las respuestas que se dan a las demandas provenientes de los múltiples escenarios por los que 
transitan. Ahora, el realizar la investigación en una organización inmobiliaria como la estudiada, más allá de la importancia que tiene ese sector empresarial para la economía colombiana, este tipo de empresa es resultado y reflejo de esas nuevas formas de organización del trabajo, - atípicas, precarias, informales, flexibles - y con ello, sus trabajadores han querido o han debido adaptarse a las mismas, en términos de tiempos, espacios, dinámicas y contratación laboral; de ahí que sea valioso analizar el fenómeno en una organización con características y dinámicas diferentes a las tradicionales, o como se menciona en un apartado anterior, que no cumpla con las condiciones de un "verdadero empleo" (Neffa, 2010).

Por otra parte, además de la importancia social que tiene esta investigación, en tanto la incidencia de los tiempos y espacios laborales definidos por la organización en el desarrollo de las actividades no laborales de los trabajadores es un tema pertinente en la época actual, esta problemática también ha generado inquietud en el ámbito académico; así lo demuestra el creciente número de estudios que se han ocupado de estas cuestiones.

Algunos de los estudios realizados se han preocupado por analizar: Cómo la irrupción de las mujeres en el mundo laboral está relacionada con la dualidad entre lo laboral y lo extra laboral (Brunet y Alarcón, 2005; Álvarez y Gómez, 2011; Moreno, 2005; Faur, 2006; Feldman et. al, 2008; Caamano, 2010), enfocándose estos análisis principalmente desde la perspectiva de género. También, cómo las exigencias del capitalismo ocasionan que las personas deban someterse a largas jornadas de trabajo para mantener su empleo dejando de lado otras facetas de su vida, llegando a crear incluso, prototipos de personas exitosas que socialmente se han establecido, quienes dedican su vida por completo al trabajo y desarrollo profesional. (Pérez y Gálvez, 2009; Rodríguez y Fernández, 2010; Ruíz, 2012; Brumely, 2014). Cómo las demandas del mercado de la fuerza laboral están generando cada vez más modificaciones en la dinámica, funcionamiento y expectativas que se tienen sobre las estructuras familiares tradicionales (Macinnes, 2005; Quintanilla, 2005; Alarcón 2012; Rhnima y Núñez, 2014).

Y, una parte importante de los estudios realizados acerca de este tema se concentra en el diseño e implementación de políticas públicas y estrategias empresariales - principalmente del sector servicios - que buscan facilitar la conciliación de los escenarios familia - trabajo primordialmente en países europeos, y algunos de los efectos que se han generado a partir de ello (Cánovas et al., 2005; Quintanilla, 2005; Mestre et al. 2012; Torns, 2011; Pasamar y Valle, 2011; Lucía - Casademunt, et. al, 2015); en este eje temático en el que se han concentrado importantes estudios es pertinente enfatizar en el realizado por Pasamar y Valle (2011), "Presiones institucionales para la conciliación de la vida profesional y personal". Estas autoras desde la perspectiva del nuevo institucionalismo sociológico plantean cómo es percibida por las empresas españolas la presión institucional respecto a la conciliación de los tiempos de sus trabajadores, relacionándola con variables personales de los directivos tales como el cargo, así como el sector en el que opera la empresa. De esta manera, las empresas en España buscan adoptar prácticas de conciliación de la vida familiar y 
laboral, de conformidad con presiones institucionales existentes en ese aspecto, para así lograr legitimidad. A partir de esta idea se concentran en analizar "en qué medida los mandatos externos que reciben las empresas para la conciliación se deben a presiones coercitivas resultantes de la legislación vigente, a presiones miméticas derivadas del grado de desarrollo de prácticas de conciliación por otras empresas, o a presiones normativas derivadas del arraigo de estos valores en la sociedad" (Pasamar y Valle, 2011:259).

Por lo anterior, si bien es cierto que el tema ha sido ampliamente estudiado desde diversas perspectivas, también se ha evidenciado que existe un vacío en la literatura que analiza la incidencia del escenario laboral en el escenario no laboral de los trabajadores pues, hay un fuerte énfasis en la familia, y en las mujeres, dejando de lado otros escenarios extra laborales o de la vida social, como por ejemplo, espacios académicos, espacios sociales, políticos y culturales, espacios de diversión y esparcimiento, o también, desconociendo la presencia de este dilema para el género masculino. De ahí que entonces la presente investigación también tenga una relevancia teórica, al intentar dar respuesta a algunos de estos vacíos evidenciados.

Estudios de este tipo son escasos en países de América Latina pues la construcción teórica al respecto se ha elaborado principalmente en países europeos y en América del Norte. Es pertinente reconocer la existencia de estudios que sobre esta temática se han realizado teniendo como base el marco teórico del Nuevo Institucionalismo; pero, a pesar de ello, por ejemplo el estudio antes citado (Pasamar y Valle, 2011), responde a analizar dinámicas de la organización respecto a presiones y condiciones externas, sin referir prácticas internas que posiblemente también incidan en el establecimiento e institucionalización de las prácticas organizacionales.

Por tanto, con esta investigación se pretende hacer algunos acercamientos iniciales para contribuir a llenar dichos vacíos teóricos, y a realizar otros aportes teóricos: 
Tabla 1. Aportes teóricos de la investigación

LLENAR VACIOS TEÓRICOS

\section{REALIZAR APORTES TEÓRICOS}

- El desenvolvimiento de roles en escenarios laborales y no laborales ha sido estudiado desde diversas perspectivas, haciendo énfasis en la familia y en el género femenino, dejando de lado otros escenarios y al posicionamiento del género masculino frente a esta problemática.

- Analizar desde la perspectiva organizacional la definición de las jornadas laborales, tanto desde la postura de la organización como la de los trabajadores, teniendo en cuenta los roles que estos últimos asumen en los escenarios laborales y no laborales por los que transitan.

- Estudios realizados sobre esta temática desde el $\mathrm{NI}$ analizan dinámicas de la organización respecto a presiones y condiciones externas, sin referir prácticas internas que también pueden incidir en el

- Conocer formas específicas bajo las cuales operan las organizaciones con características similares a la organización en la que se realizó el estudio. establecimiento y en la institucionalización de prácticas organizacionales.

- Los estudios de este tipo son escasos en países de América Latina; la construcción teórica al respecto se ha elaborado principalmente en países europeos y en América del Norte.

Fuente: Elaboración propia

\subsection{OBJETIVOS}

Teniendo en cuenta lo planteado previamente, la investigación estará orientada a:

\subsubsection{Objetivo general.}

- Explicar cómo se definen las jornadas laborales de los trabajadores de una oficina inmobiliaria a partir de los múltiples roles que asumen en escenarios laborales y no laborales

\subsubsection{Objetivos específicos.}

- Identificar elementos que intervienen en la definición de las jornadas laborales desde la organización y desde los trabajadores.

- Analizar la relación existente entre la naturaleza de la jornada de trabajo y variables como género, edad, estado civil, estado parental, tipo de trabajo realizado en la organización y tipo de vinculación de los trabajadores de la organización.

- Analizar la relación que existe entre el uso de las nuevas tecnologías y la definición de tiempos y espacios laborales, de acuerdo con el tipo de trabajo realizado en la organización.

- Analizar si los roles asumidos por los trabajadores de la organización tanto en la vida laboral como en la vida social generan conflictos inter - rol, sobrecarga de rol y/o acumulación de roles. 


\section{LINEAMIENTOS TEÓRICOS QUE PERMITIRÁN ABORDAR EL FENÓMENO ORGANIZACIONAL A ESTUDIAR}

La problemática planteada previamente es abordada desde la teoría de roles y el nuevo institucionalismo: esta última teoría proporciona elementos para analizar la existencia y definición de las jornadas laborales como parte constituyente de la estructura de la organización y la manera en que éstas inciden en el comportamiento y desarrollo de los roles sociales y laborales de los trabajadores a partir de la propuesta analítica de la teoría de roles. A continuación se presentan las herramientas conceptuales que estas dos teorías proporcionan para el análisis que se propone, no sin antes exponer de manera breve lo que se ha planteado respecto a las jornadas laborales, concepto central en la investigación.

\subsection{LAS JORNADAS LABORALES}

Jornadas laborales o jornadas de trabajo es un concepto clave en la presente investigación, dado que se analiza su definición, a partir de los roles que en el escenario laboral y no laboral asumen los trabajadores que las cumplen. De ahí que sea necesario presentar algunas conceptualizaciones que se han hecho sobre jornadas laborales, e igualmente, presentar los organismos y la reglamentación internacional y nacional - para Colombia - que las definió y las rige.

\subsection{1. ¿Qué son las jornadas laborales?}

Podría decirse que una jornada laboral es el tiempo durante el que una persona debe ejecutar la labor asignada, en un espacio determinado, a cambio del salario que recibe. En efecto, Giraldo propone que la jornada laboral, es aquel espacio de tiempo en que el trabajador pone el ejercicio de sus actividades en beneficio de un patrono. La jornada de trabajo, delimitada en su duración, representa una doble limitación para el patrono: la primera es que, al recibir la actividad del trabajador, aquel no podrá orientarla sino dentro de la esfera de la finalidad del beneficio, ya sea industrial, o comercial, etc. La segunda limitación hace referencia al poder de sujeción del patrono frente a su empleado, y no poder exigirle que su trabajo vaya más allá del límite de la jornada. De modo que, surge para el trabajador la responsabilidad de brindar toda su capacidad en el tiempo que está entregando su actividad en beneficio remunerado del patrono; así, él también tiene limitaciones en tanto debe dedicar el tiempo de su compromiso y durante él, solo podrá concretarse a lo indicado por su empleador (Giraldo, 1967:58).

Igualmente, este autor propone que al ser un espacio de tiempo la jornada no puede fijarse sino en el transcurso de un día, y que por tanto se deben considerar, dos espacios o tiempos: "(...) el día propiamente dicho y la noche. La jornada que se cumpla en el día será diurna y la que se lleve a cabo en las horas de la noche, será nocturna" (Giraldo, 1967:59).

Por otra parte, el Artículo 2 del Convenio 030 de 1930 de la OIT establece que la expresión "horas de trabajo" significa el tiempo durante el cual el personal esté a 
disposición del empleador, quedando excluidos los descansos durante los cuales el personal no se halle a la disposición del empleador. En este sentido, la jornada de trabajo o jornada laboral está definida por el número de horas que el trabajador está obligado a trabajar efectivamente.

\subsubsection{Establecimiento de las jornadas laborales.}

Como respuesta a las huelgas que vinieron tras la revolución industrial, en las que se reclamaba que la duración de las jornadas de trabajo abarcaba los siete días de la semana, excediendo las 14 horas laborales, la OIT estableció algunas disposiciones que regularan dicha situación. De acuerdo con el discurso de este organismo, mediante la definición de estos convenios "se garantiza una elevada productividad, al tiempo que se protege la salud física y mental de los trabajadores"7.

Así, por medio del convenio C001 de 1919 la OIT limitó las horas de trabajo en empresas industriales y dispuso periodos adecuados de descanso para los trabajadores. Este fue el primer convenio en materia de regulación del tiempo de trabajo, y sus disposiciones establecían que "en todas las empresas industriales públicas o privadas, o en sus dependencias, cualquiera que sea su naturaleza, con excepción de aquellas en que sólo estén empleados los miembros de una misma familia, la duración del trabajo del personal no podrá exceder de ocho horas por día y de cuarenta y ocho por semana" (Artículo 2, Convenio C001 de 1919 de la OIT).

Posteriormente, en 1930, el mismo organismo emitió el Convenio C030 de 1930, relativo a la reglamentación de las horas de trabajo en el comercio y las oficinas, sector en el que se ubica la organización objeto de estudio. El artículo tres de dicho convenio reza así: "Las horas de trabajo del personal al que le aplique el presente Convenio no podrán exceder las cuarenta y ocho horas por semana y ocho por día; o en todo caso, las horas diarias de trabajo no deben ser más de diez (Artículo 3 y artículo 6, Convenio C030 de 1930 de la OIT).

Colombia fue uno de los países que acogieron los mandatos dados por la OIT en materia de regulación del tiempo laboral. Por tanto, en el Código Sustantivo del trabajo $^{8}$, se incluye de manera extensa el tema de las jornadas laborales de la siguiente manera:

El título VI se concentra en las jornadas de trabajo. Así, en el capítulo I define algunos conceptos relacionados con éstas: plantea una diferenciación entre la jornada ordinaria de trabajo, entendida como la que convengan las partes, o a la

\footnotetext{
7 Información tomada de la Organización Internacional del Trabajo en su apartado "Temas comprendidos en las normas de trabajo, tiempo de trabajo".

${ }^{8}$ El Código Sustantivo del trabajo es el documento que en Colombia regula las relaciones de derecho individual del trabajo de carácter particular, y las de derecho colectivo del trabajo tanto oficial como particular. La finalidad de este Código es lograr la justicia en las relaciones que surgen entre empleadores y trabajadores, dentro de un espíritu de coordinación económica y equilibrio social.
} 
falta de convenio, la máxima legal; el trabajo suplementario, o de horas extras como el que excede de la jornada ordinaria, y en todo caso el que excede de la máxima legal; el trabajo ordinario y nocturno, siendo el primero el que se realiza entre las seis horas (6:00 a.m.) y las veintidós horas (10:00 p.m.); y el trabajo nocturno es el comprendido entre las veintidós horas (10:00 p.m.) y las seis horas (6:00 a.m.).

Enseguida, en el segundo capítulo de este apartado del Código, se establecen las condiciones de la jornada laboral máxima, reafirmando lo dispuesto al respecto en el convenio de la OIT; en Colombia la duración máxima de la jornada ordinaria de trabajo es de ocho (8) horas al día y cuarenta y ocho (48) a la semana, teniendo algunas excepciones relacionadas con la insalubridad o inseguridad de la labor realizada 0 , si quien la realiza es menor de edad (de 15 a 18 años); en estas situaciones la jornada laboral se reduce. En este mismo apartado se plantean las condiciones para definir jornadas laborales flexibles, las cuales deben estar distribuidas en máximo seis días a la semana con un día de descanso obligatorio; las horas de trabajo diario pueden distribuirse de manera variable durante la respectiva semana, siendo el mínimo cuatro horas continuas, y el máximo diez horas diarias sin lugar a ningún recargo por trabajo suplementario, cuando el número de horas de trabajo no exceda el promedio de 48 horas semanales, dentro de la jornada ordinaria de 6:00 a.m. a 10:00 p.m. ${ }^{9}$. Inclusive, recientemente se incluyó en el Código Sustantivo del trabajo que en las empresas con más de cincuenta (50) trabajadores que laboren cuarenta y ocho (48) horas a la semana, estos tendrán derecho a que dos (2) horas de dicha jornada, por cuenta del empleador, se dediquen exclusivamente a actividades recreativas, culturales, deportivas o de capacitación.

Habrá que analizar sin embargo, hasta dónde se está cumpliendo a cabalidad con estos parámetros definidos por la OIT para la regulación de las jornadas de trabajo, y en Colombia ratificados por el Código Sustantivo de Trabajo, o si por el contrario, el mismo contexto ha generado que excepciones definidas en estos documentos para la aplicación de la normatividad se están convirtiendo en parámetros comunes y generalizados en las prácticas laborales. Gómez y Ponce de León (2010), plantean un debate interesante respecto a si las jornadas laborales tienden a incrementarse $o$ a reducirse como resultado de los cambios producidos en el entorno organizacional. Por un lado, ponen de presente que hay una tendencia en los últimos años a incrementar sensiblemente la jornada laboral en los empleados de tiempo completo, conduciendo hacia una precarización del empleo pues, los empleados para mantener su empleo o su nivel de ingresos deben trabajar más horas. Sin embargo, plantean por otro lado que según un reporte de la OCDE (1999), ha habido una tendencia en las últimas décadas a reducir gradualmente el total de horas trabajadas al año en todos los países miembros, en parte debido a acuerdos voluntarios entre empleadores y empleados, y en parte a regulaciones gubernamentales. No obstante, en otros

\footnotetext{
${ }^{9}$ Para mayor detalle respecto a este tema se recomienda revisar Código Sustantivo del Trabajo, Colombia. Artículos del 161 al 167.
} 
países, especialmente en aquellos donde los mercados han sido desregulados y las inequidades en los ingresos se han ampliado, las jornadas laborales se han incrementado (Gómez y Ponce de León, 2010:115); este es el caso por ejemplo de Colombia y México.

\subsection{LA TEORÍA DE ROLES EN EL ANÁLISIS DE LA VIDA SOCIAL}

Tal como se ha planteado, el contexto de vida actual ha ocasionado que las personas deban desempeñar gran cantidad de roles, tanto en el mundo de lo público como en el de lo privado; ello puede generar conflicto dado que, cumplir a cabalidad con las responsabilidades, exigencias y condiciones de un escenario, puede implicar el descuido de otros, pero en otras ocasiones, la participación en múltiples escenarios puede potencializar capacidades para las personas que hacen parte de los mismos. El escenario laboral por supuesto es uno de los diversos espacios por los que las personas habitualmente transitan y por consiguiente, los roles que ahí son asumidos pueden derivar en condiciones positivas o negativas, pero además, pueden determinar su comportamiento en los otros escenarios.

De modo que, al pretender analizar cómo son definidas las jornadas laborales de una organización a partir de los múltiples roles que desempeñan los trabajadores de la misma, es importante revisar desde la teoría de roles la definición y priorización de los diversos comportamientos y funciones que estos asumen en el desarrollo de la vida cotidiana en general, y en particular, en la realización de tareas que pueden oponerse o complementarse en las diferentes circunstancias por los que transitan, a partir del cumplimiento de los tiempos y las obligaciones laborales.

\subsubsection{La teoría de roles.}

La definición del concepto Rol puede diferenciarse en dos grandes categorías. La primera, se ubica desde la perspectiva antropológico - sociológica, ésta entiende los roles como patrones normativos culturales, es decir, una agrupación de valores, actitudes y conductas que la sociedad asigna a las personas que ocupan una posición ligada a un determinado estatus social. El concepto de posición social hace referencia al lugar que ocupa una persona en el entramado de las relaciones sociales, mientras que el concepto de estatus se refiere a las funciones asignadas a la persona que ocupa dicha posición y a la valoración de esas funciones. Así, desde esta perspectiva, el rol puede definirse como la conducta que una persona asume en función de la posición que ocupa. Tomando en consideración que el concepto de rol hace referencia a una estructura social y a una jerarquía social, los roles estarían relacionados con las conductas que realizan las personas en función de su pertenencia a los grupos sociales y en función del estatus que tienen dichos grupos en la estructura social (Aritzeta y Ayestarán, 2003:61).

La segunda categoría para definir rol, de acuerdo con lo planteado por estos autores engloba la perspectiva psicosocial. Desde esta postura se han subrayado 
los contenidos cognitivos y conductas esperadas (expectativas de conducta) con relación a una posición laboral concreta. La expectativa es un constructo cognitivo que prescribe, anticipa y predice el comportamiento. Así, el concepto rol, sitúa a la persona en un contexto social determinado y en una estructura social y grupal concreta. Esto hace que la interacción personal se realice dentro de una estructura grupal e intergrupal, lo que introduce la necesidad de un aprendizaje específico de habilidades sociales para cada contexto social. Entonces, los roles reflejan los comportamientos que adoptan las personas en las diferentes posiciones sociales (Aritzeta y Ayestarán, 2003:62).

Por su parte Sarbin, importante expositor de la teoría del rol, propone que todas las sociedades se dividen en grupos y, a su vez, estos grupos están estructurados en posiciones, estatus o cargos: la posición se define como un sistema de expectativas del rol y, los roles se definen en términos de las acciones que ejercen las personas para ratificar la posición que ocupan. De esta forma podría afirmarse que rol y posición tienen una relación dialéctica, a partir de la cual se definen mutuamente. A partir de ello, este autor describió la teoría del rol en los siguientes términos:

"La teoría del rol intenta conceptualizar la conducta humana a un nivel relativamente complejo. En cierto sentido, es una teoría interdisciplinaria pues sus variables se derivan de estudios de la cultura, la sociedad y la personalidad. Las amplias unidades conceptuales de la teoría son el rol, como unidad de la cultura; la posición, como unidad de la sociedad y el sí mismo, como unidad de la personalidad" (Sarbin,1954).

En este sentido, y enmarcadas en dichas unidades conceptuales, este autor propuso tres variables principales para entender el comportamiento con relación al rol: 1) la precisión o la validez de la percepción del rol, es decir, cuan bien la persona ubica su posición con respecto a la otra; 2) la habilidad para representar un rol, en otras palabras, la efectividad de una persona para desarrollar sistemas de acciones o representar roles relacionados con posiciones; 3) la organización del sí mismo, es decir, cómo una persona se ve a sí misma, su auto concepto respecto a los roles desempeñados.

Los roles entonces son comportamientos esperados y/o asignados que se asumen a partir del estatus o la posición en la que se ubique la persona, y que están definidos por las expectativas de los individuos con los que se entra en relación y, con lo establecido socialmente por los espacios en los que se desenvuelve. Las personas regularmente asumen más de un rol, conllevando al ejercicio de múltiples roles: Las demandas por ejemplo, de la vida profesional, social, cultural o familiar hacen que una misma persona ejerza múltiples roles cuyas prescripciones son diferentes. Esta situación frecuentemente puede generar conflicto dado que los diversos roles ejercidos pueden en algún aspecto ser incompatibles; no obstante, también la multiplicidad de roles en ocasiones puede contribuir al bienestar de la persona que los ejerce. 
2.2.2. Roles múltiples: conflicto de roles y acumulación de roles.

De acuerdo con lo planteado por Guerrero la multiplicidad de roles está relacionada con la distribución de tiempo, energía y oportunidades que un individuo hace al ejercer los diversos roles que asume. El autor diferencia tres aproximaciones para el estudio de la multiplicidad de roles: a) Conflicto inter - rol, que surge cuando el comportamiento de un rol impide el desarrollo del otro, al ser incompatibles; b) Sobrecarga de rol, que se presenta cuando los roles desempeñados poseen las mismas exigencias haciendo que se compita por los recursos personales; esto advierte que un individuo puede fácilmente verse sobrecargado por la combinación de exigencias; y, c) Acumulación de roles, se define como el ejercicio de múltiples roles, permitiendo mayor interacción social y desarrollo personal; desde esta postura, los beneficios de múltiples roles se suman, de manera que las oportunidades de interacción social, desarrollo personal y autoestima aumentan (Guerrero, 2003:74). Así, los roles múltiples pueden verse como fuentes de estrés, de satisfacción o ambos.

\subsubsection{Conflicto de rol: Multiplicidad de roles como fuente de estrés}

A partir de la diferenciación propuesta por Guerrero (2003), acerca de los efectos de la multiplicidad de roles, es posible afirmar que estar frente a situaciones de conflicto inter - rol o sobrecarga de rol generará efectos negativos para quienes están inmersos en estas pues, el hecho de que hayan diferentes percepciones o expectativas sobre el rol que esa persona desempeña, ocasionará que ésta experimente un conflicto, dado que difícilmente podrá satisfacer las expectativas generadas por uno de los roles, sin rechazar las del otro.

Kahn et al. (1964, citado en Greenhaus y Beutell, 1985:77) proponen el conflicto de rol como la "ocurrencia simultánea de dos (o más) conjuntos de presiones de tal forma que el cumplimiento de un rol hace más difícil el cumplimiento de otros" (Greenhaus y Beutell, 1985:77). A partir de dicha definición, estos autores identificaron diferentes tipos de conflicto: El conflicto personal, cuando las expectativas de un individuo son incompatibles con los valores del grupo; El conflicto intro - emisor (Intra sender conflict), en el caso en que el emisor enuncie directrices contradictorias a alguien que se ve obligado a contravenir una parte de las exigencias; El conflicto inter- emisores (Inter sender conflicto), cuando dos o más emisores dirigen a un individuo demandas contradictorias; El conflicto inter roles, que nace de la presencia de dos emisores que obligan a un individuo a adaptarse a un determinado papel y le impiden adaptarse a otro.

Haciendo énfasis en el conflicto inter-roles, a propósito de la temática que se aborda en el presente documento, es posible afirmar que éste aparece cuando surgen presiones opuestas por la participación en diferentes roles. Cuando hay conflicto inter rol, las presiones de rol asociado con la pertenencia a una organización están en conflicto con las presiones derivadas de la pertenencia a otros grupos. Greenhaus y Beutell ejemplifican un conflicto inter rol, mediante el caso de un trabajador al que se le generan demandas por su rol laboral relacionadas con el cumplimiento de horas extra o llevar trabajo a casa; esta 
situación entra en conflicto con las presiones de la esposa quien le exige dar atención a los asuntos de la familia durante las horas de la noche; en este caso el conflicto inter rol surge entre el rol como trabajador y los roles de esposo y de padre (Greenhaus y Beutell, 1985:77).

De esta forma, autores como Greenhaus y Beutell (1985) y Edwards y Rothbard (2000) plantean que el conflicto inter - rol está incidido por tres componentes: "el primero se relaciona con el tiempo, sustentado en que el tiempo es un recurso muy escaso, de esta manera, cuando las personas dedican más tiempo al cumplimiento de uno de los roles, se limita la posibilidad de cumplir con las exigencias del otro, lo cual puede repercutir negativamente en el bienestar de la persona en cuanto invierte energías que sobrepasan su capacidad. El segundo, se basa en las presiones, éste se relaciona con la tensión que genera uno de los roles interfiriendo en el cumplimiento del otro. El tercero, basado en el comportamiento, es cuando un rol exige comportamientos que son incompatibles con otro u otros" (Álvarez y Gómez, 2011: 93).

Para ilustrar el primer tipo de conflicto basado en el tiempo, el estudio O'Neil, Greenberger y Marks (1994, citado en Perdigao, 2011: 45), llegó a la conclusión de que "cuando el individuo dedica gran cantidad de tiempo para el ejercicio de uno de los roles, puede ser profesional, familiar o de otro tipo, hay sentimientos de agotamiento o sobrecarga, lo que influirá en el desempeño de las otras actividades. Esta sensación de sobrecarga, asociada al desempeño de las funciones, es nombrada como uno de los principales factores responsables de desencadenar el conflicto de roles y se puede sentir tanto en el ejercicio de rol profesional, como en el ejercicio del rol de la familia, o en cualquier otro rol que desempeñe la persona, lo que dará lugar a un conflicto, del trabajo hacia la familia y/o de la familia hacia el trabajo, por ejemplo".

Sobre el segundo tipo de conflicto, es pertinente retomar a Guerrero (2003), quien sustenta la hipótesis acerca de la tensión que se genera debido a la multiplicidad de roles, a partir de ejemplos. Él ejemplifica este conflicto mediante estudios que demuestran que es menos probable que las mujeres empleadas tengan cónyuge y/o hijos que los hombres empleados, lo que ha significado que las mujeres eviten acumular roles para evitar el estrés de rol. De la misma manera, él hace referencia a la investigación de Erickson \& Klein (1981) en la que muestran que el matrimonio y los hijos reducen la probabilidad de empleo entre mujeres, lo que puede interpretarse como apoyo a una hipótesis de conflicto de inter-rol. Igualmente, Guerrero (2003) retoma a Valdez y Gutek (1987), quienes lanzaron la hipótesis de que las mujeres en trabajos especialmente exigentes tendrían menos roles que las que trabajaban en cargos con menos exigencias; ellos encontraron que cuando otros factores permanecían constantes, las mujeres gerentes estaban más propensas al divorcio y ambas (profesionales y gerentes) tenían menos hijos que otras mujeres trabajadoras.

El tercer tipo de conflicto propuesto, hace referencia a cuando los comportamientos de uno de los roles ejercidos son incompatibles con el 
desempeño de otros roles; a manera de ejemplo podría pensarse en el conflicto que se genera al pretender cumplir con las exigencias de rol que tiene el "trabajador ideal" - concepto propuesto en la parte inicial de este documento-, y cumplir con lo socialmente establecido para el rol de "la madre ideal". En este sentido, las definiciones culturales de lo que es ser una "buena madre" entran en conflicto con las definiciones culturales de la conducta que se espera del "buen trabajador", por ello muchas veces, "sobre todo la maternidad y el empleo construyen oposición. De ahí que no sea sorprendente que muchas mujeres tengan verdaderos problemas para conciliar, que se sientan culpables cuando el trabajo interfiere en sus responsabilidades familiares o que flexibilicen/ eliminen el empleo para atender a sus hijos e hijas" (Rodríguez y Fernández, 2010: 270).

\subsubsection{Acumulación de rol: Multiplicidad de roles como fuente de satisfacción}

Como se advirtió en el apartado anterior, una parte importante de la investigación sobre los roles múltiples estudia los efectos negativos que se generan en un individuo que tiene multiplicidad de roles bajo el supuesto de que éste tiene una energía y recursos limitados y por tanto, puede sentirse abrumado al asumir muchos roles. Ahora bien, a partir de los resultados de otras investigaciones realizadas acerca de los roles múltiples, se empiezan a poner en evidencia efectos positivos de dicha multiplicidad (Pietromonaco et al., 1986, Guerrero, 2003).

Plantea Guerrero (2003) que hay evidencia empírica de que los beneficios de los roles múltiples pueden observarse no solamente en mejor salud mental, sino también en la vida ocupacional. Afirma el mismo autor que a partir de algunos de los estudios realizados se ha encontrado que las mujeres que tienen rol de empleadas, esposas y madres están más satisfechas con sus trabajos que las que solamente son cónyuges y empleadas; inclusive mujeres con tres, cuatro o cinco roles tienen más autoestima y están más satisfechas con sus trabajos que las que tienen uno o dos roles. En este sentido, afirma Pietromanco et. al., que la multiplicidad de roles puede contribuir a mejorar la auto estima ya que el hecho de realizar una variedad de tareas y de interactuar con otras personas aumenta el sentido de competencia y facilita el desarrollo de una visión más rica, más compleja de sí mismo (Pietromanco et al., 1986:374).Por eso, es posible plantear, siguiendo a Guerrero (2003) que la multiplicidad de roles puede generar fuentes de experiencia y competencia que algunas veces se complementan entre sí. Entonces, desempeñarse bien en muchos roles puede aumentar los privilegios, los recursos y contactos, y mejorar la reputación social; también, aumentar la autoestima y el sentido de competencia.

De hecho, Sieber plantea que los resultados positivos de la acumulación de roles se pueden clasificar en cuatro tipos: 1) Privilegios de rol 2) Seguridad del status 3) Enriquecimiento de los recursos 4) Enriquecimiento de la personalidad.

Privilegios de rol, hace referencia a que cada rol lleva consigo ciertos derechos y privilegios. Algunos de los derechos son inherentes y están integrados en el rol y, otros son emergentes, es decir, que surgen de la interacción diaria con otras 
personas. Los primeros sirven como estímulo para decidir asumir dichos roles e incentivar su desempeño. Los segundos tienen la función de garantizar el cumplimiento del rol, especialmente cuando las demandas son altas. Los privilegios de rol son elementos institucionalizados que estipulan ciertas libertades y demandas legítimas (Sieber, 1974:570).

La seguridad del status está relacionada con la compensación que genera la tensión de la multiplicidad de roles, proporcionando numerosos soportes en caso de fallar alguno de los ámbitos de acción en los que se ubica la persona. Un individuo con una amplia gama de roles, algunos de los cuales podrían estar ubicados en grupos o círculos sociales dispares, es capaz de compensar el fracaso en cualquier ámbito social debido a la seguridad generada a partir de las otras relaciones que ha establecido. Estas relaciones son alternativas y compensatorias y pueden proporcionar afecto, apoyo moral, recursos de emergencia, e incluso la asistencia para una renovación de los esfuerzos en el rol original (Sieber, 1974:570). Es importante resaltar por ejemplo, de acuerdo con lo planteado por el autor, que la organización y los roles relacionados con el trabajo pueden ser considerados como soportes, y pueden proporcionar seguridad del status. "El hombre que se pierde a sí mismo en su trabajo puede hacerlo en respuesta al estrés personal que se genera en otras partes de su sistema social" (Sieber, 1974:573).

El enriquecimiento de los recursos se genera por los privilegios que estipulan ciertas libertades y demandas legítimas, derivadas de las relaciones sociales. $Y$ aunque estos productos no pueden considerarse como características inalienables de un rol, si pueden ser legítimamente previstas como gratificaciones habituales sin gasto adicional de esfuerzo. Algunos ejemplos de ello son: conexiones, invitaciones a reuniones sociales, una buena calificación crediticia, regalos de todo tipo, acceso a personas o a información clave, por mencionar algunos. Es así como, el mantenimiento de una amplia gama de relaciones sociales puede ser un medio necesario para adquirir y reforzar la posición y el status precisamente, porque brinda la oportunidad de elaborar una redistribución de recursos entre los roles. Otra consecuencia de la acumulación de recursos a través de múltiples roles, es que el individuo se vuelve más valioso para las personas con las que se relaciona en los roles en los que se desempeña. De esta forma, no sólo está en la posibilidad de obtener recursos y privilegios que puede usar, sino que también se convierte en un referente para las personas a su alrededor (Sieber, 1974:575).

Finalmente, la acumulación de roles además de proporcionar privilegios, soportes y recursos, puede enriquecer la personalidad y mejorar la percepción de sí mismo. De esta forma por ejemplo, la tolerancia a puntos de vista diferentes, la exposición a múltiples fuentes de información, la capacidad de adaptabilidad a las exigencias de los diversos roles, entre otros, puede beneficiar a la persona que tiene múltiples roles. De hecho, dice Sieber que "la acumulación de roles puede ser esencial para la salud mental" (Sieber, 1974:576). De igual manera dice el autor que las personas son apreciadas por poseer una gran cantidad de roles. Además de su capacidad para desempeñar múltiples roles con ciertos recursos, estas personas 
se benefician de una presunción de superioridad frente a otras. De esta forma, algunas de las tensiones derivadas de la multiplicidad de roles se pueden convertir en condiciones de prestigio social, ofreciendo así cierta compensación psíquica a quienes los desempeñan (Sieber, 1974:577).

A partir de los estudios referenciados en este apartado es posible concluir que el ejercicio de múltiples roles está relacionado con el incremento de la autoestima y el bienestar. Sin embargo, como cuestiones para tener presentes respecto a ésta afirmación Pietromonaco et al. (1986), plantean que: en primer lugar, se debe tener en cuenta la importancia y centralidad que los individuos le den a determinado rol a partir de las tareas específicas que realizan para el cumplimiento del mismo, así como el tiempo y/o el esfuerzo dedicado. En segundo lugar habrá que revisar cómo las personas que se relacionan con el desempeño de determinados roles pueden influir en la capacidad de gestionar múltiples funciones con éxito. Y, finalmente, será pertinente reflexionar si la cantidad de esfuerzo requerido por cada rol desempeñado puede ser más importante que el número de roles a desempeñar; esto teniendo en cuenta que "cuatro roles de consumo de tiempo que no se superponen pueden ser más estresantes que cuatro complementarios que requieran relativamente poco gasto de energía y tiempo" (Guerrero, 2003: 82).

\subsubsection{La multiplicidad de roles en escenarios laborales y no laborales.}

La multiplicidad de roles es entonces una característica persistente en el ser humano ya que al desenvolverse en diversos escenarios, en cada uno de estos asume un rol y, debe cumplir con los comportamientos socialmente asignados a dicho rol; más aún, la tendencia en la multiplicidad de roles puede incrementarse como respuesta a las diversas demandas establecidas por el ya descrito contexto socio - económico actual que impone el mundo moderno, al que las personas cada vez más se preocupan por ajustarse, a pesar de las maniobras que deban realizar, en tanto ello garantice su permanencia en el mismo.

Sin embargo, gran parte de la literatura existente al respecto se concentra en estudiar la multiplicidad de roles que se genera entre el escenario laboral y familiar, desconociendo que lo no laboral puede estar asociado a otros escenarios diferentes a la familia; hay una menor cantidad de estudios que se refieran a la relación trabajo - no trabajo. Por esta razón las propuestas teóricas que se han desarrollado al respecto, serán presentadas de manera independiente.

\subsubsection{La multiplicidad de roles generada por el escenario laboral y el escenario familiar}

Reflexionar acerca de la multiplicidad de roles que se genera por la participación en los escenarios laboral y familiar podría estar orientado a pensar en una relación de complementariedad en la que por ejemplo el trabajo puede ser un espacio para cumplir con las expectativas definidas en la vida familiar, y de igual manera, la familia podría ser un espacio para disipar el estrés generado por el trabajo. Sin embargo, el desarrollo de esos múltiples roles planteados por cada escenario, 
establece a la persona exigencias en diferentes sentidos y el resultado de ello dependerá en gran medida tanto de las expectativas que se generen con relación al rol en el trabajo y al rol en la familia, así como de los valores que cada persona tenga con respecto al rol que deben asumir en cada uno de estos dos escenarios.

En efecto, plantean Edwards y Rothbard (2000) que el cumplimiento de las exigencias de estos roles, puede traer recompensas extrínsecas como devengar un salario, posibilidades de desarrollo de carrera, relacionamiento con compañeros de trabajo, sostenimiento de la familia, entre otras; e intrínsecas, como el cumplimiento de objetivos, sentido de logro, por mencionar algunas. Estas recompensas generan estados de ánimo positivos, mientras su falta produce estados de ánimo negativos; estos últimos pueden estimular a: cambiar aspectos de los escenarios laborales y familiares (por ejemplo, renegociar las demandas de roles y adquirir los recursos necesarios para satisfacer las demandas), adaptarse a las condiciones en los escenarios (por ejemplo, devaluar o ignorar los aspectos decepcionantes del trabajo o la familia), o a evitar un dominio total o parcial de cualquiera de los dos escenarios (por ejemplo, pasar menos tiempo en el trabajo o con la familia). De esta forma, cuando las recompensas que resultan a partir del cumplimiento de las exigencias de los diversos roles desempeñados en estos dos escenarios generan más sentimientos negativos que positivos, podría pensarse más que en una relación de complementariedad entre escenarios, en una relación conflictiva, de oposición o de incompatibilidad.

De acuerdo con lo propuesto por Wayne et al. (2004), la investigación acerca de la relación entre el escenario laboral y el escenario familiar se ha basado casi exclusivamente en la perspectiva de la escasez, lo que sugiere que entre los roles laborales y los roles familiares se genera un conflicto inter - rol. De hecho, Greenhaus y Beutell definen el conflicto trabajo - familia como "una forma de conflicto inter - rol en la que las presiones de los roles del trabajo y la familia son incompatibles entre sí en algún aspecto" (Greenhaus y Beutell 1985:77). Es decir, que la participación en los roles del trabajo se hace más difícil debido a la participación en los roles de la familia, y lo mismo ocurre en sentido contrario. Por tanto, podría decirse de acuerdo con la literatura que los roles asumidos en el escenario laboral y en el familiar muchas veces son incompatibles dado que, el tiempo empleado al ejercicio de un rol puede dejar poco tiempo para dedicar a los otros, la tensión en un rol puede contaminar a otros, y/o, el comportamiento apropiado para un rol puede ser disfuncional a otro.

Ahora, es pertinente plantear que el conflicto trabajo - familia se produce de forma bidireccional, es decir que, puede haber una interferencia negativa del trabajo en la familia 0 , de la familia en el trabajo; sin embargo, esta doble direccionalidad del conflicto puede ser incidida y legitimada por variables como el género. En este sentido plantean Segado et al. que, "una cantidad importante de análisis apuntan a que la influencia del conflicto entre la vida laboral y la familiar está modulada por el género y el peso de los roles sociales. Una de las explicaciones más acreditadas que apoya esta influencia es la hipótesis de los límites permeables asimétricos (Pleck, 1977), la cual plantea que las relaciones no son similares en ambos sexos 
y que el conflicto del trabajo para la familia es mayor en el caso de los varones, porque hay una mayor permisividad a que el trabajo interfiera en su vida familiar. Por el contrario, las mujeres experimentan más el conflicto de la familia con el trabajo, pues las creencias respecto a sus roles son más fuertes, sobre todo si tienen hijos" (Segado, et al. 2013: 255).

Lo anterior probablemente está relacionado con el hecho de que las mujeres hacen una inversión importante de tiempo en los roles domésticos y familiares; en consecuencia, los roles masculinos de trabajo y familia requerirán de menos tiempo y energía con respecto a los femeninos en los mismos aspectos. De modo que, el género aparece como una variable determinante en el conflicto entre lo laboral y lo familiar, en cuanto define la asignación de recursos como tiempo, atención y energía a los roles definidos para cada escenario.

\subsubsection{La multiplicidad de roles generada por el escenario laboral y otros escenarios no laborales}

Como ya se planteó, gran parte de las investigaciones en estos temas suelen definir la esfera de lo no laboral o lo extra - laboral únicamente como el escenario familiar; sin embargo, como lo propone Schieman et al. (2009), eso conllevaría a pensar que los empleados que no tienen responsabilidades de atención a familia no estarían expuestos a tensiones para integrar su trabajo y las actividades no laborales. Por tanto, para efectos de esta investigación, se propone el conflicto de roles que se genera desde lo laboral no únicamente con relación a la familia, sino también a otros escenarios de desenvolvimiento social. De ahí entonces que la idea del equilibrio entre la vida laboral y la no laboral, o de la vida laboral y la vida social se plantee para indicar la necesidad que tienen las personas para armonizar estos dos ámbitos, "pensando no sólo en la compatibilidad entre el trabajo y la familia, sino incluyendo otras expectativas de roles y responsabilidades en la vida privada, como por ejemplo, el deporte, la caridad, la educación, etc." (Lucia, et. al, 2015: 63). Por tanto, en la dimensión de lo extra - laboral deberán incluirse escenarios como el hogar, la familia y los espacios de ocio (Schieman et al, 2009:966).

De acuerdo con este último autor, un supuesto en la literatura respecto a la relación de lo laboral y lo no laboral es que los trabajadores están motivados generalmente para gestionar los límites entre uno y otro escenario, de manera que puedan garantizar un equilibrio entre estos; dicho equilibrio facilitaría un alto nivel de satisfacción con el funcionamiento de los roles y una baja interferencia del trabajo en los escenarios no laborales. La mayoría de las conceptualizaciones acerca de las interferencias de un escenario sobre el otro están relacionadas con el grado de percepción que tienen los individuos acerca de la interferencia de un escenario en las atribuciones y expectativas del otro, dependiendo en parte del tiempo y energía que le demande al individuo el cumplimiento de los roles en cada uno de estos escenarios. 
En un estudio realizado por Staines y O'Connor (1980), acerca de la interferencia del trabajo en el tiempo de ocio, se afirma que la percepción de conflicto entre estos dos escenarios está claramente relacionada con las características demográficas de los trabajadores, y para diversas dimensiones del trabajo, las actividades de ocio, y la familia. La conclusión del estudio fue que el conflicto en la relación trabajo - ocio tendía a ser percibido de manera positiva cuando se tenía la posibilidad de participar en todos los principales roles de la vida (trabajo, ocio, familia), independientemente de si la participación se medía en términos conductuales (variedad de actividades, tiempo asignado) o actitudinales (significado asignado al rol). Sin embargo, el conflicto se relacionaba negativamente cuando el tiempo de ocio era afectado por la jornada de trabajo. Además, dicho conflicto se asociaba con una baja satisfacción con cada uno de los principales roles de vida.

Schieman et al. coinciden con Staines y O'Connor (1980), al plantear que el análisis del conflicto entre la vida laboral y la extra-laboral está relacionado con las características demográficas de los trabajadores; los primeros proponen por ejemplo que "condiciones como la edad, el género, el estado civil y parental, y la ocupación, pueden influir en los niveles de permeabilidad de los límites de la relación trabajo - no trabajo" (Schieman et al, 2009:967). Dicen los autores sin embargo, que no hay patrones de comportamiento claros respecto a estas condiciones. Sin embargo, ofrecen algunas descripciones con relación a dichas variables:

- Edad: Algunos estudios muestran que la edad no está asociada con las interferencias entre lo laboral y lo no laboral pero, otros encuentran que los trabajadores en edad adulta reportan los más altos niveles de interferencia. A pesar de estos resultados mixtos, hay razones teóricas sólidas para contemplar las diferencias de edad como una variable pues ésta influye en los patrones de ocupación de puestos, el significado y las condiciones de los roles de trabajo (Schieman et al, 2009:967).

- Género: Numerosos estudios documentan disparidades de género respecto a los recursos y las demandas relacionadas con el trabajo. Por ejemplo, los hombres tienden a tener mayores ocupaciones con más autonomía, autoridad, ganancias y toma de decisiones respecto a las mujeres pero también, tienden a trabajar más horas y horas extras sin previo aviso, encontrándose con entornos más nocivos y con conflictos interpersonales. En contraste, las diferencias de género en otras condiciones de trabajo, como el control por el horario, la inseguridad y la presión, son menos claras (Schieman et al, 2009:967).

- Estado civil y parental: Tener un cónyuge o pareja, e hijos genera responsabilidades que pueden crear demandas que compiten; de modo que, el estado civil y parental puede contribuir a un aprieto de tiempo para los individuos (Schieman et al, 2009:968). 
- Ocupación: Los estudios documentan que las poblaciones de individuos en ocupaciones de altas jerarquías (por ejemplo, ejecutivos, profesionales y gestores), tienden a reportar mayores niveles de interferencia entre lo laboral y lo no laboral, que sus pares en ocupaciones de bajo status. Estos patrones no son sorprendentes dado que los profesionales, en comparación con sus compañeros en ocupaciones de bajo status, están expuestos a más horas de trabajo y a más presiones. A su vez, esto contribuye a la sensación de una escasez de tiempo y la percepción de la falta de equilibrio entre la vida laboral y la no laboral (Schieman et al, 2009:969).

\subsubsection{La vida social analizada desde la teoría de roles.}

Lo visto hasta acá permite concluir entonces que efectivamente la teoría de roles y todos los aportes teóricos que se han desarrollado a partir de ésta, respecto a la relación entre lo laboral y lo no laboral, proporcionan un marco conceptual interesante y pertinente para reflexionar y analizar la definición de las jornadas laborales de los trabajadores a partir de los distintos roles que asumen en los escenarios en los que se desenvuelven.

De modo que, hacer este análisis a partir de la teoría de roles permite comprender como se estructuran los diferentes comportamientos de los individuos que hacen parte de una organización en los diversos escenarios en los que se desenvuelven (la organización, la familia, los hobbies, el ocio) y la multiplicidad de roles que ello implica. Además, abre la reflexión acerca de que dicha multiplicidad de roles necesariamente no debe ser conflictiva como tradicionalmente se ha pensado, sino que en ocasiones, dependiendo de cuestiones particulares tanto del contexto como de la persona, puede ser positiva para potencializar capacidades de los individuos. E incluso, permite plantear que dependiendo de los diversos roles que asuman las personas, y de lo positiva o negativa que pueda resultar dicha multiplicidad, es posible vislumbrar tendencias hacia la definición y cumplimiento de las jornadas laborales con determinadas características.

\subsection{LA VIDA LABORAL ANALIZADA DESDE EL NUEVO INSTITUCIONALISMO}

Así como la Teoría de roles facilita el análisis de los roles que asumen los trabajadores en los diversos escenarios por los que transitan y que inciden en la definición de las jornadas laborales, el Nuevo institucionalismo facilita el análisis de la vida laboral, reflexionando acerca de cómo se ha definido el mundo de lo laboral y cómo eso que allí está establecido incide en el mundo de lo social. De modo que, desde el nuevo institucionalismo es posible analizar el porqué de las jornadas laborales de la organización que definen el mundo laboral de sus trabajadores están definidas y reguladas de la forma en que actualmente operan y, cuáles fueron las condiciones bajo las que se establecieron las jornadas de esa manera, tanto desde la perspectiva de la dirección, como desde la perspectiva de los mismos trabajadores. Igualmente, esta corriente teórica orienta el análisis de cómo los trabajadores de la organización definen sus tiempos y espacios laborales - cumplimiento de jornada laboral y asistencia a la oficina - a partir del uso de las 
nuevas tecnologías como herramientas de trabajo, y de otras condiciones ofrecidas por la organización; y, permite reflexionar acerca de la diferencia existente entre las dinámicas laborales de quienes tienen la autonomía para definir sus jornadas laborales, con respecto a quienes deben cumplir con el horario de trabajo establecido por la organización.

\subsection{1. ¿Qué es el Nuevo Institucionalismo?}

De acuerdo con lo planteado por De la Rosa, "el nuevo institucionalismo no es un término que exprese homogeneidad teórica; más bien, representa un conjunto heterogéneo de enfoques que versan sobre las diversas relaciones entre institución y organización (o entre instituciones y organizaciones), y cuyo sustento se encuentra en nociones como individuo, actor, roles, identidades, comportamientos, reglas, regulación, construcción/constitución, ambientes, estructuras, racionalidad (limitada), costos, transacciones, entre las más destacadas" (De la Rosa, 2002: 28). Esta heterogeneidad de perspectivas con la que se constituye el nuevo institucionalismo puede constatarse inclusive en sus antecedentes, los cuales provienen de la economía, la sociología y la ciencia política, y delinean los enfoques neo institucionalistas: Nuevo Institucionalismo Económico (NIE), Nuevo Institucionalismo Político (NIP) y Nuevo Institucionalismo Sociológico (NIS).

Sin profundizar mucho en las diferencias entre uno y otro, puede decirse en términos generales que el NIE se centra en las reglas y sistemas de gobierno que se desarrollan para regular los intercambios económicos enfocándose principalmente en el nivel de la firma/estructura, esto es, los intercambios se mueven del mercado, al interior de marcos organizacionales (De la Rosa, 2002:31). EI NIP se cuestiona acerca de qué es lo que regula el comportamiento de los individuos en un ámbito organizacional; March y Olsen, autores representativos de éste enfoque, plantean que la regla es el fundamento de la institución (De la Rosa, 2002:34).

Por otra parte plantea Romero (1999), que el nuevo institucionalismo en el análisis organizacional tiene características sociológicas, al hacer énfasis en "las formas en que se estructura la acción y se hace posible el orden mediante sistemas compartidos de reglas que a la vez limitan la tendencia y la capacidad de los actores para optimizar, y privilegian algunos grupos cuyos intereses son asegurados por las sanciones y recompensas prevalecientes" (Romero, 1999:48). Así, autores como DiMaggio (1983), Jepperson (2001), Meyer (1977), Powell (1983), Rowan (1977) y Zucker (1996), siendo los más representativos del NIS, indagan acerca de qué es lo que regula la conformación de las estructuras organizacionales.

En el siguiente apartado se ahondará en el enfoque sociológico, dado que será el que guíe el análisis de la definición y funcionamiento de las jornadas laborales en el estudio de caso realizado; igualmente, se retoman algunas nociones del NIP que proporcionan un campo analítico complementario a lo planteado desde el NIS. 


\subsubsection{Nuevo institucionalismo sociológico}

La noción fundamental dentro del NIS, parafraseando a De la Rosa, es que las reglas institucionales además de que afectan las estructuras organizacionales y su desempeño las van conformando a través del tiempo por medio de la adopción de mitos racionalizados, siendo éstos, prácticas, explicaciones e historias transmitidas por la organización para reforzar su legitimación y garantizar su supervivencia; el objetivo de ello es legitimar -interna y externamente- el desempeño de la organización, haciéndola parecer racionalmente eficiente, más allá de su eficiencia real (De la Rosa, 2002: 31) ${ }^{10}$.

De acuerdo con eso, este autor identifica dos grandes áreas en las que el NIS contribuye de manera contundente al estudio de las organizaciones. Por un lado, proporciona insumos para el estudio de la construcción de campos organizacionales"11, en tanto ambientes organizacionales; "el NIS ofrece la posibilidad de estudiar al ambiente organizacional en sí mismo, y esto es relevante porque permitirá entender mejor los intersticios entre ambiente y estructura. La conformación de un campo organizacional, en tanto ambiente organizacional, permitiría entender mejor la conformación histórica de la estructura organizacional y, de esta forma, el factor histórico puede ser recuperado". (De la Rosa, 2002: 32). El otro aporte del NIS al estudio de las organizaciones tiene que ver con la noción de ambiente/contexto organizacional, en la que en el ambiente se contemplan marcos institucionales diversos, no limitándose a aspectos técnicos, sino que incluyendo también aspectos socioculturales; esto modifica la concepción de estructura organizacional que se estudia (De la Rosa, 2002: 38).

A partir de lo anterior, la pertinencia del NIS para el análisis organizacional es evidente, pues se enfoca en el estudio de las instituciones que restringen la dinámica interior de las organizaciones y del ambiente organizacional. De modo que, el NIS es apropiado por ejemplo para analizar el cambio institucional, mediante la adopción o difusión de prácticas organizativas (Powell y Dimaggio, 2001) o, para estudiar la relación entorno - estructura y organización - contexto, (Meyer y Rowan, 1977; Scott, 1995). Por ejemplo, Facin et al., (2009) desarrollaron un estudio desde el NIS para determinar la influencia de las relaciones institucionales extra-organizativas (políticas, económicas y/o sociales) en el cambio contable, destacando la cuestión de la legitimación de la empresa. $\mathrm{O}$, Pasamar y Valle (2011), hacen uso de la teoría institucional para analizar el discurso de las organizaciones para pensar en cambios orientados a la conciliación de la vida familiar y laboral.

\footnotetext{
10 Los conceptos señalados en cursiva serán abordados posteriormente con cierta profundidad en tanto proporcionan elementos valiosos para sustentar teóricamente la investigación que se presenta.

11 "La noción de campo denota la existencia de la comunidad de las organizaciones que forman parte de un sistema de significado común cuyos participantes interactúan frecuente y fatídicamente más el uno con el otro que con los actores fuera del campo" En: Scott, 2012:211.
} 


\subsubsection{Nuevo institucionalismo político ${ }^{12}$}

Así como el NIS se pregunta qué es lo que regula la conformación de las estructuras organizacionales, el NIP se pregunta qué es lo que regula el comportamiento de los individuos en un ámbito organizacional (De la Rosa, 2002:34); dicho ámbito se aloja en las instituciones políticas. Es así como March y Olsen, autores representativos de este enfoque se interesan por entender cómo funcionan estas instituciones; para ellos, "las instituciones políticas son conjuntos de reglas y rutinas relacionadas entre sí, que definen adecuadamente las acciones en términos de las relaciones entre las funciones y las situaciones" (March y Olsen, 1997: 252).

Plantea March (2002, citado en De la Rosa, 2002:33) que el NIP se relaciona con la conducta de las personas y sus procesos de toma de decisiones a partir de la acumulación de reglas a través del tiempo, las cuales le dan forma a la acción. De acuerdo con esta lógica el individuo decide y actúa no en función de un conjunto bien establecido y claro de preferencias, alternativas y consecuencias, sino a partir de su experiencia personal (situaciones pasadas), sus identidades, roles y la situación en cuestión; es decir, en una situación dada, el individuo sigue la regla más apropiada o pertinente en consecuencia con estos elementos. De esta manera, se pasa de la racionalidad a la institucionalidad pues las reglas con base en las cuales decide actuar el individuo están dadas por sus marcos institucionales interiorizados; es así como lo social, lo cultural y lo político entra en juego ${ }^{13}$.

Por lo anterior, el NIP proporciona también elementos pertinentes para analizar la definición de las jornadas laborales como proceso institucional en tanto se da relevancia a las reglas como construcciones sociales que dan sentido a la acción, y a la reducción de la incertidumbre mediante el establecimiento de rutinas organizacionales. Estas dos cuestiones plantean un marco interesante para analizar si las jornadas laborales son definidas por el ápice de la organización y/o por quienes conforman el equipo de trabajo como rutinas y reglas que minimizan la incertidumbre y garantizan el desarrollo de los procesos productivos de una manera ordenada.

\subsubsection{Lógicas institucionales que enmarcan la dinámica organizacional.}

A continuación se presentan algunos conceptos y nociones propias del nuevo institucionalismo que permiten analizar y comprender la dinámica organizacional, con la diversidad y particularidades que la constituyen.

\footnotetext{
12 Apartado construido, a partir de De la Rosa (2002) e ideas retomadas de la sesión de clase de Teoría de la Organización II, impartida por el Dr. Ayuzabet de la Rosa Alburquerque. Maestría en Estudios Organizacionales. Universidad Autónoma Metropolitana - Iztapalapa. Febrero 17 de 2016.

${ }^{13}$ Idea retomada de la sesión de clase de Teoría de la Organización II, impartida por el Dr. Ayuzabet de la Rosa Alburquerque. Maestría en Estudios Organizacionales. Universidad Autónoma Metropolitana - Iztapalapa. Febrero 17 de 2016.
} 


\subsubsection{Las instituciones como construcciones sociales que son reproducidas}

Una institución es un patrón social que revela un proceso de reproducción particular, y tiene capacidad para mantenerse automáticamente. Cuando se contrarrestan las desviaciones respecto de este patrón en forma regulada, por medio de controles reiterativamente activados, socialmente construidos -es decir, por algún conjunto de recompensas y sanciones-, se dice que un patrón está institucionalizado. Expresado de otra forma, las instituciones son esos patrones sociales que, cuando se reproducen crónicamente, deben su supervivencia a procesos sociales que se activan relativamente por sí mismos. En este sentido, las instituciones se construyen socialmente y se reproducen de manera rutinaria, funcionando como elementos relativos de ambientes restrictivos y están acompañadas de explicaciones que se dan por hecho (Jepperson, 2001: 195, 201). Así, las instituciones autorizan y controlan la acción social de manera simultánea, proporcionan acciones programadas o respuestas comunes a determinadas situaciones y al darse por hecho, son asumidas como la forma en que se hacen las cosas en determinado ambiente social, garantizando además así su persistencia en el tiempo.

De igual manera, Meyer y Rowan proponen que los elementos de las instituciones no son las normas ni los valores, sino los guiones, las reglas y las clasificaciones que se dan por hecho. Más que organizaciones concretas que producen compromisos efectivos, las instituciones son abstracciones a macro nivel, prescripciones racionalizadas e impersonales, tipificaciones compartidas, independientes de cualquier entidad particular a la que pudiera deberse una lealtad moral (Meyer y Rowan, 1977).

Por otra parte, afirma Scott que "las instituciones consisten en estructuras y actividades cognitivas, normativas y regulativas que proporcionan estabilidad y significado a la conducta social" (Scott, 1995: 33). Él identifica tres modelos contrastantes de instituciones: desde el pilar regulativo las instituciones restringen y regularizan la conducta; aquí las instituciones son entendidas como un sistema estable de reglas apoyado por la vigilancia y el poder de la sanción (Scott, 2012: 190). Desde el pilar normativo las instituciones introducen una dimensión prescriptiva, evaluativa y obligatoria dentro de la vida social; este enfoque enfatiza en como los valores y los marcos normativos estructuran las elecciones (Scott, 2012:192). Desde el pilar cognitivo, las instituciones son las reglas que constituyen la naturaleza de la realidad y el marco a través del cual el significado se construye, enfatizando así en el rol central jugado por la construcción social de significados para la formación de la conducta social ${ }^{14}$.

\subsubsection{El proceso de institucionalización como fuente causal de patrones de comportamiento ${ }^{15}$}

\footnotetext{
${ }^{14}$ Apartado construido a partir de: De la Rosa, 2002:35

15 Zucker (1977) plantea que una estructura que se ha institucionalizado es aquella que se considera como tomada por sentado por los miembros de un grupo social tan eficaz y necesaria,
} 
De acuerdo con Zucker, la institucionalización es un proceso fenomenológico por el cual algunas relaciones y acciones sociales llegan a darse por sentado y, un estado de cosas en que los conocimientos compartidos definen lo que tiene significado y las acciones que son posibles. Dice el autor que, "cuanto más alto sea el grado de institucionalización mayores serán la uniformidad generacional de los entendimientos culturales, la conservación sin un control social directo y la resistencia al cambio a través de la influencia personal" (Zucker, 2001: 150).

Tolbert y Zucker (1996) plantean que el proceso de institucionalización está dado por la habitualización, objetivación y sedimentación, que a su vez están incididos por fuerzas causales del contexto (Figura uno).

\section{Figura 1. Componentes del proceso de institucionalización}

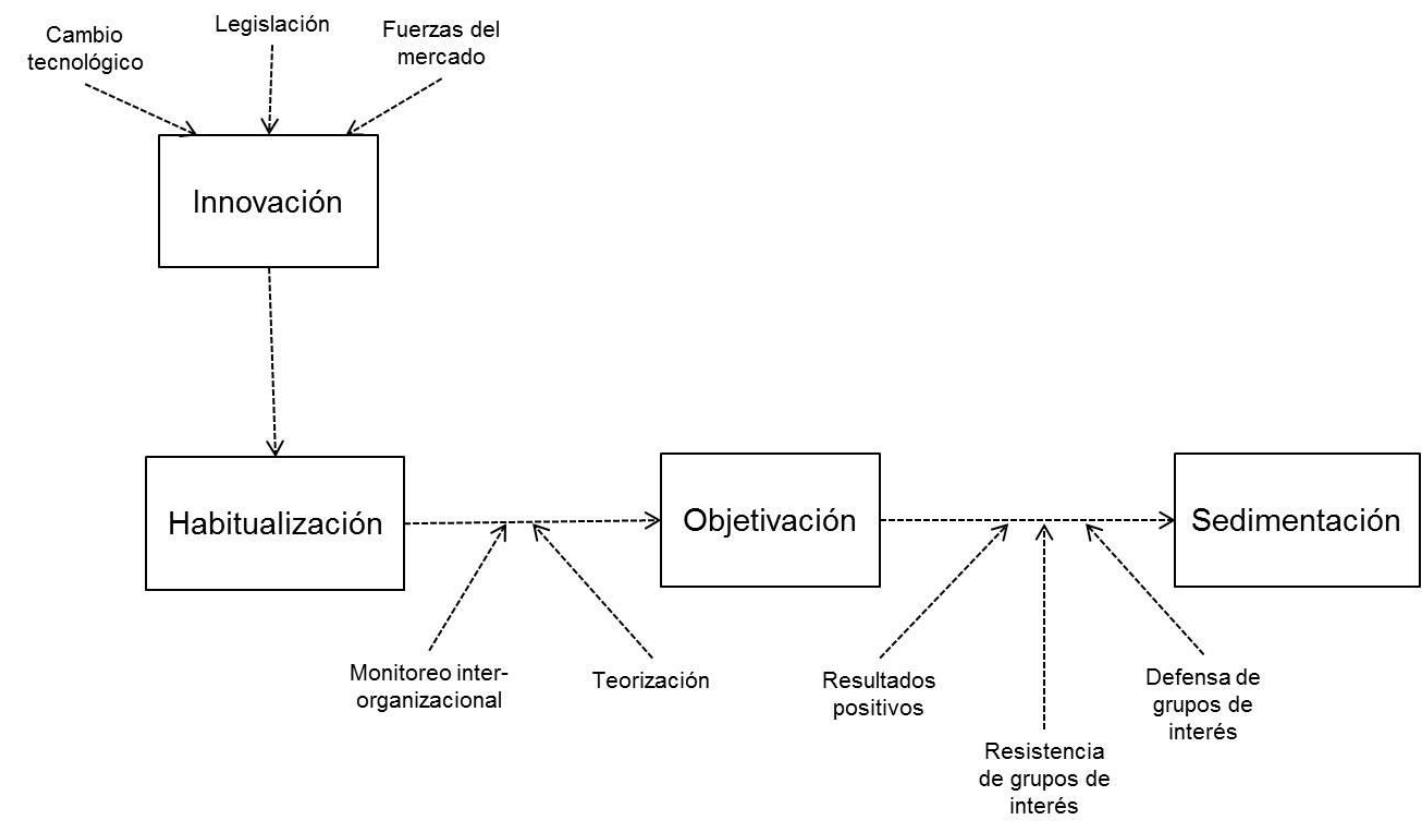

Fuente: Tolbert y Zucker (1996:182)

El proceso de habitualización "implica la generación de nuevos arreglos estructurales en respuesta a un problema organizativo específico o a un conjunto de problemas, y la formalización de tales arreglos en las políticas y procedimientos de una organización dada, o un conjunto de organizaciones que enfrentan problemas similares" (Tolbert y Zucker, 1996:181). Posteriormente, la objetivación "implica el desarrollo de algún grado de consenso social entre los tomadores de decisiones organizacionales sobre el valor de una estructura, y el aumento de la adopción de ésta por las organizaciones sobre la base de ese consenso (...) Bajo estas condiciones, cuanto más difundida se vuelve una elección dada, es más

por lo que sirve como una importante fuente causal de patrones estables de comportamiento. En: Tolbert y Zucker, 1996:179. 
probable que los individuos la vean como una opción óptima" (Tolbert y Zucker, 1996:182). Finalmente, la institucionalización completa implica la sedimentación, "un proceso que descansa fundamentalmente en la continuidad histórica de la estructura, y especialmente en su supervivencia a través de generaciones de miembros de la organización" (Tolbert y Zucker, 1996:184).

De manera similar Meyer y Rowan plantean que la institucionalización conlleva procesos por los que los procesos sociales, las obligaciones o las realidades llegan a tomar un estatus de reglas en el pensamiento y la acción sociales; estas reglas pueden tener efectos sobre las estructuras organizacionales y su cumplimiento en el trabajo técnico real, los cuales son muy diferentes a los generados por las redes de conducta y relaciones sociales que integran y rodean una organización determinada" (Meyer y Rowan, 1977:80).

Más recientemente Morgan y Hull Kristensen proponen la institucionalización, como "un proceso en el cual, a través del tiempo, los marcos regulativos, cognitivos y normativos en áreas particulares de la vida social y económica llegan a ser más consistentes y coherentes haciendo más difícil que las organizaciones se desvíen del modelo esperado de ellas" (Morgan y Hull Kristensen, 2006:1470); de esta forma los procesos de institucionalización confieren legitimidad a las organizaciones. De acuerdo con estos autores, el desarrollo de los procesos de institucionalización se orienta por las siguientes cuestiones: ¿Cuáles reglas institucionales gobiernan los campos organizacionales particulares? ¿Cómo emergen esas reglas? ¿Quiénes son los actores sociales que desarrollan, mantienen o cambian esas reglas? ¿Cómo hacen dichos actores para enganchar a otros actores en sus proyectos? ¿Cómo ocurre el cambio y cómo las nuevas reglas llegan a ser institucionalizadas?

Por lo anterior, la institucionalización establece una serie de reglas - instituciones que los individuos adoptan como formas de comportamiento y sobre todo formas de percibir la realidad al interior de las organizaciones, así como la definición de su actuación dentro de la misma organización. De igual manera, la institucionalización orienta el desarrollo de las prácticas y dinámicas organizacionales de tal forma que sean coherentes con lo que se espera de ellas en el campo organizacional en el que se ubique, de manera tal que garanticen su legitimidad.

Entonces, siguiendo a Jepperson (2001) y a De la Rosa (2002), es posible afirmar que:

"La institución representa un orden o patrón social que ha alcanzado cierto estado o propiedad; la institucionalización indica el proceso para alcanzarlo (...) una institución es un patrón social que revela un proceso de reproducción particular" (Jepperson, 2001: 203).

"La institución es un patrón a seguir; pero es seguido porque es construido socialmente. En tanto los intereses son construidos 
socialmente, son susceptibles de institucionalizarse. De esta forma la institución no sólo es construida sino construye; pero además no sólo es construida y construye, sino también regula. Así, una noción abstracta de institución e institucionalización es útil en tanto concepto que permite entender procesos de la realidad social y organizacional" (De la Rosa, 2002:33).

Así, tanto institución como institucionalización pueden entenderse como construcciones y procesos sociales, respectivamente: Las instituciones son construcciones sociales y rutinarias, cuya existencia es implícita en las organizaciones, o es transmitida por medio de procesos de socialización y, tienen la propiedad de definir lo que se debe hacer y lo que no, a partir de procesos de institucionalización.

\subsubsection{Los mitos racionalizados}

Afirman Meyer y Rowan que las sociedades modernas están llenas de reglas institucionales, las cuales funcionan como mitos que muestran varias estructuras formales como medios racionales para lograr fines deseables. Es así como muchas organizaciones reflejan marcadamente los mitos de sus ambientes institucionales, más que las demandas de sus actividades de trabajo; por tanto, los mitos no generan estructuras organizacionales formales, sino que les dan legitimidad (Meyer y Rowan, 1977:347).

En virtud de ello, los mitos tienen dos propiedades clave: "primero, son prescripciones racionalizadas e impersonales que identifican como técnicos varios propósitos sociales y especifican a manera de reglas los medios adecuados para buscar racionalmente estos propósitos (Ellul, 1964); segundo, están considerablemente institucionalizados y por tanto, en cierta medida, se hallan más allá del arbitrio de cualquier participante u organización individual" (Meyer y Rowan, 1977:343). De lo anterior es posible inferir que los mitos, al ser prescripciones racionalizadas, no son cuestionados porque crean sentido y proporcionan confianza, y en esta misma lógica, se siguen reproduciendo. Así que, prácticas como el cumplimiento de un horario, la asistencia a la oficina o incluso el uso permanente del celular para atender asuntos laborales pueden configurarse como prácticas que no son cuestionadas ni por la organización ni por los trabajadores, y que a pesar de ser prescindibles, son adoptadas y reproducidas, dado que es lo definido como legítimo en el ambiente organizacional, y además, lo establecido socialmente para la acción de trabajar, sin importar lo eficiente que esto resulte para el desarrollo del negocio. De esta forma podría decirse que el desarrollo de este tipo de prácticas proyecta una aparente eficiencia de la organización, y como consecuencia la legitima.

Meyer y Rowan (1977) proponen tres tesis respecto a los mitos racionalizados, como prácticas que al ser institucionalizadas por la organización le otorgan reconocimiento y ventajas competitivas y que en el caso estudiado, se pueden relacionar con elementos que inciden en la definición y cumplimiento de las 
jornadas laborales, o con estrategias empresariales relacionadas con su dinámica y modo de funcionamiento que dan legitimidad a la organización:

La primera es que "los ambientes y los dominios ambientales que han institucionalizado un gran número de mitos racionales generan organizaciones más formales" (Meyer y Rowan, 1977:360). Esto querrá decir por ejemplo que prácticas institucionalizadas como la asistencia a la oficina en un ambiente laboral, a pesar de no ser obligatoria y muchas veces innecesaria, da muestra de responsabilidad y compromiso con el trabajo, por lo que se adoptará como una práctica repetitiva por parte de quienes hacen parte de la organización. De igual forma el ápice de la organización abogará para que los trabajadores concurran a la oficina con el fin de poder ofrecer un buen servicio, más allá que el servicio se pueda proporcionar a través de otros medios y espacios, como se evidenciará posteriormente en el apartado del estudio de caso.

La segunda tesis se refiere a que "las organizaciones que incorporan mitos son más legítimas y exitosas y tienen más probabilidades de sobrevivir" (Meyer y Rowan, 1977:361). Así, prácticas como la definición del horario de funcionamiento de la oficina no sólo de lunes a viernes, sino también los fines de semana, hacen legítima a la organización en su ambiente organizacional, y le da posibilidades de sobrevivir en tanto ofrece las mismas condiciones de atención a clientes en términos temporales, respecto a los definidos por la competencia.

La última tesis plantea que "los esfuerzos de control organizacional, en particular en ambientes muy institucionalizados, se dedican a la conformidad ritual, tanto interna como externamente (...) Aquí la idea es que cuanto más institucionalizado esté el ambiente, más tiempo y energía dedicarán las élites organizacionales al manejo de la imagen pública y estatus de la organización, y menos dedicarán a la coordinación y administración de las relaciones particulares que van más allá de los límites de la empresa" (Meyer y Rowan, 1977:361). Con ello podría plantearse que la organización se preocupa más por implementar prácticas y estrategias con las que demuestren que ofrecen un buen servicio, en tanto les otorgan status y mejoran su imagen pública, que otras prácticas que no redunden en ello. Así por ejemplo, la definición de amplios horarios de atención, o la asignación de equipos celulares para poder atender oportunamente a los clientes será prioridad en tanto dan muestra de contar con las condiciones de ofrecer un buen servicio pero, no se preocupan porque el servicio ofrecido a los clientes sea realmente bueno, oportuno y eficiente. Sin embargo, internamente también la organización tiene la posibilidad de reforzar la importancia del cumplimiento de dichas prácticas - la asistencia a la oficina y el uso del celular - e incluso, establece formas de control sutiles que contribuyan a ello. Esto también será visible en el estudio de caso.

\subsubsection{La institucionalización de la acción mediante reglas y rutinas}

March y Olsen plantean que la acción se institucionaliza por medio de reglas y rutinas, y que ello reduce la ambigüedad. De acuerdo con lo que ellos proponen las reglas son "las rutinas, procedimientos, convenciones, papeles, estrategias, 
formas organizativas y tecnologías en torno a los cuales se construye la actividad política. Asimismo, las creencias, paradigmas, códigos, culturas y conocimiento que rodean, apoyan, elaboran y contradicen esos papeles y rutinas" (March y Olsen, 1997, 68).

El hecho de que las acciones se construyan alrededor de reglas se relaciona con que el seguimiento de las mismas proporciona confianza y seguridad de observar o desarrollar una conducta adecuada; es decir, "el cumplimiento de las reglas restringe de alguna forma la acción y la orienta a que opere de acuerdo con lo socialmente establecido, o por lo menos, a lo esperado. Sin embargo, aunque las reglas traigan consigo el orden, observamos cómo conjuntos de ellas son potencialmente ricos en conflictos, contradicciones y ambigüedades y por lo mismo producen más divergencia que conformismo, variabilidad que estandarización" (March y Olsen, 1997:90). Esto posiblemente es consecuencia de que para que las reglas sean seguidas deben crear sentido al individuo, es decir que, "la interpretación y construcción del significado es fundamental para la institucionalización de la acción y de las reglas" (De la Rosa 2012:34).

En este sentido, al estar rutinizada la mayor parte del comportamiento mediante el cumplimiento de reglas no significa que los individuos respondan automática o mecánicamente a las situaciones (March y Olsen, 1997: 90), pues muchas veces esta respuesta va a estar incidida por "la lógica de la pertinencia ${ }^{16}$. Siguiendo a De la Rosa, la institución ofrece una variedad de reglas, ante las cuales los individuos deben interpretar cuál es la más adecuada, frente a la situación en cuestión, en función de su rol o identidad. Para que las reglas sean seguidas, éstas deben hacer sentido al individuo: la interpretación y construcción del significado es fundamental para la institucionalización de la acción y de las reglas. Así, ante la ambigüedad, inestabilidad y diversidad de preferencias, la lógica de la pertinencia se erige como reguladora y constructora de la acción (De la Rosa, 2012: 34), y por tanto las reglas, más que mandatos son construcciones sociales que serán seguidas en tanto creen sentido.

Las rutinas definidas por March y Olsen consisten en "reglas de procedimiento que especifican un proceso que debe seguirse en circunstancias determinadas; pueden ser reglas de decisión, de evaluación, pueden regular tiempos adecuados para hacer tales o cuales cosas y pueden regular el cambio de reglas, pueden especificar los derechos de la oposición política". (March y Olsen, 1997:68). Así, reglas y rutinas tienen una relación dialéctica, en tanto unas definen a las otras, y viceversa: las reglas son rutinas, y las rutinas pueden ser reglas.

De modo que, "las rutinas ayudan a evitar conflictos, negocian e imponen acuerdos, mitigan la naturaleza impredecible, incorporan identidades, intereses,

${ }^{16}$ De acuerdo con una lógica de la pertinencia, los comportamientos (las creencias así como las acciones) son intencionales, pero no deliberados. Implican cumplir con las obligaciones de un papel en determinada situación, y por tanto, de intentar determinar los imperativos de mantener una posición. March y Olsen, 1997:252. 
valores y visiones del mundo individual y colectivo, limitando así la asignación de la atención, las normas de evaluación, las prioridades, las percepciones y los recursos" (Hall, 1968; Van Maanen, 1973 en March y Olsen, 1997:71). En un sentido similar Scott propone que "las rutinas reducen en gran medida la discreción de la mayoría de los participantes de forma que estos hacen menos elecciones y están más restringidos dentro de las elecciones que hacen. Las suposiciones valoradas, los marcos cognitivos, las reglas y las rutinas son los ingredientes que conducen a los individuos a comportarse de manera racional" (Scott, 2012:169). Es así que las rutinas se siguen porque establecen la forma en que se deben hacer las cosas, de manera convencional, con la seguridad de que ese comportamiento garantiza homogeneidad con el contexto y será acorde a lo establecido, aceptado y esperado.

Asimismo, Scott (2012) propone que las rutinas son portadoras de instituciones que, "recaen en un patrón de acciones que reflejan el conocimiento tácito de los actores. Hábitos profundamente arraigados y procedimientos basados en creencias y conocimientos inarticulados (Scott, 2012:209) ${ }^{17}$. Así, el cumplimiento de un horario de trabajo establece una rutina que no da cabida a enfrentarse todos los días a decidir cómo organizar su jornada laboral, y además, se adecúa a lo que socialmente se ha definido para la acción de trabajar.

2.3.2.5. La adopción de prácticas institucionalizadas por parte de las organizaciones como respuesta a las presiones institucionales para garantizar su legitimidad

Las organizaciones que se acomodan a su entorno maximizan su legitimidad e incrementan sus recursos y capacidades para mantenerse en el tiempo (Di Maggio y Powell, 1983; Scott, 2001). Como se planteó anteriormente, cuando una práctica se ha institucionalizado, la sociedad la percibe como legítima y es adoptada por las organizaciones por razones de legitimidad (Zucker, 2001). Esa adopción de prácticas consiste en el traslado del entorno a la organización de valores, estructura, estrategias y hábitos propios, generando mayor grado de homogeneidad en formas y prácticas organizativas, como resultado de la influencia de presiones institucionales; éste es el isomorfismo institucional.

DiMaggio y Powell (1983), definen el isomorfismo como un proceso limitador que obliga a una unidad en una población a parecerse a otras unidades que enfrentan las mismas condiciones ambientales (DiMaggio y Powell, 1983:108). Esta condición de similitud entre organizaciones es lo que les va a dar legitimidad y les posibilitará el incremento de sus recursos y capacidades para mantenerse en el tiempo. Con el ánimo de buscar legitimidad, las organizaciones responden a las presiones institucionales mediante: prácticas coercitivas como resultado de

17 Plantea Scott inclusive que, más que privilegiar sistemas culturales, muchos de los primeros institucionalistas visualizaron las acciones habituales, las rutinas, los procedimientos operativos estándar y un patrón de actividades similares, como las características más centrales de las instituciones. Scott, 2012:209. 
presiones formales e informales ejercidas sobre ellas por otras organizaciones de las que son dependientes, o por expectativas culturales de la sociedad en la que se desarrollan; prácticas miméticas, asociadas con las respuestas estándar que construyen las organizaciones frente a la incertidumbre, tomando como modelo a otras empresas a las que imitan; o prácticas normativas, que se relacionan con la profesionalización y el establecimiento de obligaciones sociales que determinan los comportamientos esperados de las organizaciones (Di Maggio y Powell, 1983).

En un sentido similar, Meyer y Rowan plantean que el éxito organizacional depende de otros factores aparte de la coordinación y el control eficientes de las actividades productivas; "estos factores están relacionados con el isomorfismo con las instituciones ambientales, a partir de lo cual obtienen legitimidad y recursos para sobrevivir, dado que: a) incorporan elementos que son legitimados exteriormente, más que en términos de eficiencia; b) emplean criterios de evaluación externos o ceremoniales para definir el valor de los elementos estructurales, y c) la dependencia respecto de instituciones fijadas exteriormente reduce la turbulencia y mantiene la estabilidad" (Meyer y Rowan, 1977: 348). Entonces, independientemente de su eficiencia productiva, las organizaciones que se hacen isomorfas a los ambientes institucionales en los que se encuentran, tienen más posibilidad de ser legitimadas. Por el contrario, las organizaciones que omiten elementos de estructura legitimados ambientalmente 0 que crean estructuras únicas carecen de explicaciones legítimas de sus actividades. Esas organizaciones son más vulnerables a ser acusadas como negligentes, irracionales o innecesarias (Meyer y Rowan, 1977:349).

Lo anterior deja planteado entonces que, las organizaciones adoptan prácticas institucionalizadas como respuesta a las presiones institucionales para garantizar su legitimidad pues, el no hacerlo puede ser percibido como un trance para la legitimidad de una organización, poniendo también en riesgo su capacidad de asegurar los recursos necesarios (DiMaggio y Powell, 1983). Sin embargo, es pertinente enfatizar que las organizaciones pueden responder a las presiones institucionales que el ambiente les presenta mediante la adopción de procesos isomorfos pero también, mediante elecciones estratégicas en aras de garantizar su supervivencia en el medio.

\subsubsection{El nuevo institucionalismo: teoría para analizar la definición y funcionamiento de las jornadas laborales.}

Tras el recorrido teórico propuesto, y enmarcando el tema de investigación que se pretende abordar desde el nuevo institucionalismo, es pertinente preguntarse si las jornadas laborales pueden ser entendidas como una institución o, si en cambio el proceso de definición de las mismas es la institución.

De acuerdo con Meyer y Rowan (1977), las reglas institucionales afectan a las estructuras organizacionales y su desempeño; sin embargo, no sólo las afectan sino que las van conformando a través del tiempo por medio de la adopción de mitos racionalizados. De esta manera, la estructura y los procesos organizacionales no derivan exclusivamente de una concepción racional de la 
actividad organizacional sino de una concepción institucional de las mismas; es decir, podría pensarse que la estructura y los procesos organizacionales - en este caso la definición de las jornadas laborales - no son resultado de actos racionales sino de instituciones y por eso, las estructuras organizacionales no tienen una lógica solamente racional, sino también simbólica. De ahí entonces, que el aparente buen desempeño de una organización no necesariamente es resultado de la formalización, centralización, control, sino de la adopción de prácticas institucionalizadas ${ }^{18}$.

Entonces, pensar las jornadas laborales como instituciones permite entenderlas como reglas normativas que guían la acción dentro de la vida social a través de los valores y las normas que los conforman (Scott, 1995:37). En virtud de ello, los actores se constituyen no en función de sus intereses individuales, sino en función de sus roles e identidades, que los obligan a actuar de acuerdo con ellos. No porque así deban ser las cosas, sino porque así están socialmente estatuidos sus roles e identidades (De la Rosa, 2002:35). Por tanto, las jornadas laborales podrían entenderse como algo más que la jornada ordinaria de trabajo definida por la organización, de máximo 48 horas semanales, de acuerdo con la normatividad vigente; podrían también pensarse como un mecanismo de control social que ejerce el ápice estratégico de la organización en aras de alcanzar sus objetivos de productividad y eficiencia, o como una construcción que hacen quienes conforman la organización de acuerdo a las instituciones vigentes.

\subsection{LA TEORÍA DE ROLES Y EL NUEVO INSTITUCIONALISMO: PROPUESTAS TEÓRICAS PERTINENTES PARA ANALIZAR EL FENÓMENO ORGANIZACIONAL A ESTUDIAR}

A partir de los planteamientos hechos a lo largo del documento se puede afirmar que la teoría de roles y el nuevo institucionalismo son enfoques teóricos adecuados para el desarrollo de esta investigación pues proporcionan herramientas para analizar la definición de las jornadas laborales de los trabajadores de la organización a partir de los diferentes roles que ellos asumen en su vida, tanto en el escenario social como en el laboral y, permiten conocer la naturaleza de los parámetros de funcionamiento y de la dinámica de la organización que delinean esa interrelación entre lo social y lo laboral.

Para ello, la teoría de roles proporciona herramientas teóricas y conceptuales apropiadas para entender comportamientos de los trabajadores en la organización, a partir de la diversidad de roles que asumen en lo laboral y en lo social, poniendo de presente una relación entre estos dos escenarios de vida. Por tanto, esta teoría ayudó a comprender de qué manera los roles asumidos en el mundo laboral se relacionan con los definidos por el mundo social, ya sea mediante sobre carga de rol, conflicto inter - rol y/o acumulación de roles, y cómo

\footnotetext{
18 Idea retomada de la sesión de clase de Teoría de la Organización II, impartida por el Dr. Ayuzabet de la Rosa Alburquerque. Maestría en Estudios Organizacionales. Universidad Autónoma Metropolitana - Iztapalapa. Febrero 17 de 2016.
} 
esa multiplicidad de roles en la que se desenvuelven los trabajadores incide en la definición y cumplimiento de las jornadas laborales con ciertas particularidades.

Desde la perspectiva organizacional, es importante reconocer cómo lo establecido por la organización incide en el desarrollo de la vida social de los trabajadores; esto es, las jornadas laborales; así, el nuevo institucionalismo proporciona herramientas para analizar por qué aspectos que se dan por hecho en la organización como las jornadas laborales, están definidas y reguladas de la forma en que actualmente operan, cuáles fueron las condiciones bajo las que se establecieron esas jornadas, tanto desde la perspectiva de la dirección, como desde la perspectiva de los mismos trabajadores. De igual forma, los conceptos propuestos por esta corriente teórica facilitan el análisis del comportamiento de los trabajadores respecto a la definición y al cumplimiento de las jornadas laborales, a partir de la repetición y rutinización de prácticas y el establecimiento de mitos racionalizados que conllevan a la institucionalización de las mismas por medio de acciones como el cumplimiento de un horario, la asistencia a la oficina, o el uso del celular. 


\section{METODOLOGÍA}

\subsection{ESTRATEGIA METODOLÓGICA PARA EL ESTUDIO DE CASO}

De acuerdo con el objetivo propuesto para el proceso de investigación, y en concordancia con la estructura que tiene la organización en la que se realizó el estudio de caso, se consideró importante hacer uso de instrumentos que permitieran estudiar el problema desde la perspectiva de la vida social y desde la perspectiva de la vida laboral, conociendo y analizando la postura tanto de los trabajadores de la organización como de sus directivos.

Para ello el constructivismo social proporciona una propuesta adecuada para el estudio de estos hechos sociales en tanto permite "entender al sujeto como individuo que pierde sustancialidad, convirtiéndose en un producto de los discursos sociales de los que participa y sometiéndose a constantes reconfiguraciones subjetivas" (Castellaro, 2011: 139). De acuerdo con este autor, para el constructivismo es clave la interacción social en la construcción de los saberes en tanto el conocimiento se entiende como una construcción subjetiva, dependiente de las características del observador; el sujeto es considerado como agente activo en la construcción del conocimiento; y, el conocimiento no sólo constituye un proceso activo, sino que, a su vez, es indisociable del contexto sociocultural e histórico específico que le otorga significado (Castellaro, 2011:133,134). Por ello, ubicarse desde el constructivismo social facilitará la comprensión y análisis de discursos que permean y orientan el establecimiento y desarrollo de las dinámicas a estudiar - la definición de la jornada laboral -, entendiéndolas no como algo estático, sino como hechos dinámicos producto de la construcción humana y subjetiva, enmarcadas en un contexto social y económico particular.

Siguiendo a Guba y Lincoln, los paradigmas de investigación definen para los investigadores aquello que tienen entre manos y qué cae dentro y fuera de los límites de una indagación legítima. Las creencias básicas que definen los paradigmas de indagación pueden resumirse por las respuestas que den los proponentes de determinado paradigma a tres preguntas fundamentales, que están interrelacionadas de tal modo que la respuesta que se dé a cada una de ellas, tomadas en cualquier orden, circunscribe cómo deben ser respondidas las otras. Así, la cuestión ontológica se pregunta por ¿cuál es la forma y naturaleza de la realidad y, en consecuencia, qué es lo que podemos conocer acerca de ella? La cuestión epistemológica habla sobre ¿cuál es la naturaleza de la relación entre el que conoce o el que debería conocer y lo que puede ser conocido? La cuestión metodológica se plantea ¿cómo puede el investigador (el que busca conocer) arreglárselas para averiguar si lo que él o ella cree puede ser conocido? (Guba y Lincoln: 2002, 119).

De esta forma, desde el constructivismo social la cuestión ontológica será relativista, y entonces "las realidades son comprensibles en la forma de construcciones mentales múltiples e intangibles, basadas social y 
experiencialmente, de naturaleza local y específica, y su forma y contenido dependen de los individuos o grupos que sostienen esas construcciones" (Guba y Lincoln: 2002, 128). De ahí que entonces, en la investigación realizada la cuestión ontológica es relativa a cada sujeto participante en la investigación; así que, la definición y cumplimiento de las jornadas laborales, y a partir de ello la construcción de la vida social y de la vida laboral será particular para cada persona a partir de las variables socio demográficas que la determinan y las situaciones de contexto que la inciden.

Ahora, desde este mismo paradigma la cuestión epistemológica hace referencia a lo transaccional y subjetivista. "Se supone que el investigador y el objeto de investigación están vinculados interactivamente de tal forma que los hallazgos son literalmente creados al avanzar la investigación" (Guba y Lincoln: 2002, 128). Así, para la investigación realizada el marco teórico propuesto fue un referente para el análisis de los fenómenos encontrados pero, fue en realidad la interacción con las personas investigadas y la información por ellos proporcionada a la luz de la teoría, lo que permitió comprender el fenómeno de la definición de las jornadas laborales y aportar a la construcción de conocimiento sobre el mismo.

Finalmente, respecto a la cuestión metodológica, el constructivismo la delinea como hermenéutica y dialéctica. "La naturaleza variable y personal (intra mental) de las construcciones sociales sugiere que las construcciones individuales pueden ser producidas y refinadas sólo mediante la interacción entre el investigador y quienes responden" (Guba y Lincoln: 2002, 128). Por tanto, para tener la posibilidad de conocer e interpretar esas posiciones variadas sobre el fenómeno a estudiar, en la investigación se hizo uso de técnicas que dieran posibilidad al investigador de intercambiar y analizar junto con el investigado la información por éste proporcionada.

En este marco, y teniendo como referente los supuestos epistemológicos y ontológicos que guían la investigación, el proceso de construcción de conocimiento se ubicó bajo un enfoque cualitativo pues permite estudiar relaciones sociales, analizar prácticas culturales, indagar puntos de vista frente a una situación y abordar temáticas donde la dimensión subjetiva y simbólica son decisivas (Torres, 1995). Este enfoque hace énfasis en procesos empíricos, en el estudio de cualidades en un contexto particular, busca conocer procesos subjetivos y, no tiene como función básica garantizar la verdad, sino ser utilizado de forma creativa y a la medida de cada situación, por ello, la diversidad de técnicas y estrategias que utiliza (Quecedo y Castaño, 2002:9).

De acuerdo con lo planteado por Taylor y Bogdan (1996) la investigación cualitativa produce datos descriptivos a partir de las palabras habladas o escritas de las personas, y la conducta observable. De modo que, más que un conjunto de técnicas para recoger datos, el enfoque cualitativo es un modo de encarar el mundo empírico, pues: es inductivo, dado que los investigadores desarrollan conceptos, intelecciones y comprensiones partiendo de pautas de los datos, y no recogiendo datos para evaluar modelos, hipótesis o teorías preconcebidas; 
asimismo, desde este enfoque el escenario y las personas son vistas desde una perspectiva holística, ya que no son reducidos a variables sino concebidos como un todo; los investigadores cualitativos tratan de comprender a las personas dentro del marco de referencia de ellas mismas pues, es esencial experimentar la realidad tal como otros la experimentan; el investigador cualitativo suspende 0 aparta sus propias creencias, perspectivas y predisposiciones, dándose la posibilidad de ver las cosas como si estuvieran ocurriendo por primera vez; para el investigador cualitativo todas las perspectivas son valiosas pues, este no busca la verdad sino una comprensión detallada de las perspectivas de otras personas.

El método a utilizar para el desarrollo de la investigación es el Estudio de caso, dado que su mayor fortaleza radica en que a través del mismo se mide y registra la conducta de las personas involucradas en el fenómeno estudiado. Con este método los datos pueden ser obtenidos desde una variedad de fuentes, tanto cualitativas como cuantitativas; esto es, documentos, registros de archivos, entrevistas directas, observación directa, observación de los participantes e instalaciones y objetos físicos. (Chetty, 1996 citado en Martínez, 2006:167).

Robert Yin, teórico especializado en el estudio de caso define este método como una indagación empírica que tiene los siguientes rasgos distintivos:

- Examina o indaga sobre un fenómeno contemporáneo en su entorno real

- Las fronteras entre el fenómeno y su contexto no son claramente evidentes

- Se utilizan múltiples fuentes de datos, y

- Puede estudiarse tanto un caso único como múltiples casos. (Yin, 1989:23 citado en Martínez, 2006: 174).

De esta manera, para Yin (1989, citado en Martínez, 2006: 173), la cuestión de generalizar a partir del estudio de caso no consiste en una "generalización estadística" (desde una muestra o grupo de sujetos hasta un universo), como en las encuestas y en los experimentos, sino que se trata de una "generalización analítica" (utilizar el estudio de caso único o múltiple para ilustrar, representar o generalizar a una teoría). Así, incluso los resultados del estudio de un caso pueden generalizarse a otros que representen condiciones teóricas similares. Los estudios de casos múltiples refuerzan estas generalizaciones analíticas al diseñar evidencia corroborada a partir de dos o más casos ("replicación literal") o, alternativamente, para cubrir diferentes condiciones teóricas que dieran lugar, aunque por razones predecibles, a resultados opuestos ("replicación teórica").

Sobre el estudio de caso también plantea Martínez que las investigaciones realizadas a través del método pueden ser: descriptivas, si lo que se pretende es identificar y describir los distintos factores que ejercen influencia en el fenómeno estudiado, y exploratorias, si a través de las mismas se pretende conseguir un acercamiento entre las teorías ya inscritas en el marco teórico y la realidad objeto de estudio (Martínez, 2006:171). Para la investigación realizada se hablará de una investigación exploratoria en la que se enlaza el fenómeno estudiado con la teoría de roles y el nuevo institucionalismo. 
Finalmente, respecto al estudio de caso es importante mencionar el planteamiento hecho por Antonio Barba en el prólogo del libro "Pequeñas organizaciones: complejidad y diversidad organizacional. Estudio de casos de organizaciones mexicanas" en el que plantea una reflexión sobre el estudio de caso y su importancia como herramienta metodológica para el análisis organizacional. Este autor destaca características generales del estudio de caso como método de investigación al plantear que "es un método articulador del dato y la teoría, ya que a través de éste se puede intentar crear una serie de hipótesis que en otros contextos concretos deben verificarse, lo que permite establecer un planteamiento maduro teóricamente, al mismo tiempo que adecuado en cuanto a los datos empíricos correspondientes. Por otra parte, el estudio de caso puede describir en forma exhaustiva una situación social y explicar al menos tentativamente sus múltiples factores y componentes. Constituye más bien un enfoque que enfatiza la particularidad de un problema específico cuyos límites delinean también su propio universo" (Barba, 2009:17).

Inclusive, Barba pasa de lo general a lo particular en su planteamiento respecto al uso del estudio de caso y propone algunas ventajas de emplear este método en el análisis organizacional. Estas son: "facilita al investigador la aproximación empírica para la construcción teórica; contribuye a tener un mejor conocimiento de la organización; propicia la reflexión sobre los problemas de la organización; facilita la vinculación institucional; contribuye al aprendizaje de la investigación" (Barba, 2009:19).

No obstante, a pesar de estas posibilidades, el estudio de caso ha sido una experiencia poco repetida en el ámbito mexicano, e incluso podría decirse que latinoamericano, lo que repercute en el escaso conocimiento organizacional generado en países como México o Colombia. De ahí entonces la pertinencia de hacer uso de este método en la investigación realizada, como posibilidad de incrementar el conocimiento organizacional en contextos locales.

Para el estudio de caso que se realizó, y bajo el supuesto de que la realidad social es producto humano de dimensiones no sólo subjetivas, sino también objetivas, las técnicas de recolección de información fueron diversas. Se aplicaron cuestionarios para sondear ideas generales acerca de las variables a estudiar; se llevaron a cabo entrevistas semi estructuradas, al ser un instrumento que permite recopilar información a profundidad en el contexto natural donde suceden los fenómenos; y, se realizó análisis de contenido de documentos con información acerca de las características y funcionamiento de la organización. A continuación, en la tabla dos se presenta una síntesis de los aspectos metodológicos que guiaron la investigación realizada y que fueron descritos en las líneas precedentes. 
Tabla 2. Aspectos metodológicos generales

\begin{tabular}{|c|c|c|}
\hline Paradigma & $\begin{array}{c}\text { Constructivismo } \\
\text { Social }\end{array}$ & $\begin{array}{l}\text { «Revela el significado de las formas } \\
\text { particulares de la vida social mediante la } \\
\text { articulación sistemática de las estructuras } \\
\text { subjetivas que rigen las maneras de actuar de } \\
\text { los individuos» (Ortiz, 2000: 46). }\end{array}$ \\
\hline Enfoque & Cualitativo & $\begin{array}{l}\text { Produce datos descriptivos. Es inductivo; } \\
\text { comprensión del contexto; perspectiva } \\
\text { holística; busca una comprensión detallada de } \\
\text { las perspectivas de otras personas; es } \\
\text { humanista (Quecedo y Castaño, 2002:7). }\end{array}$ \\
\hline Método & $\begin{array}{l}\text { Estudio } \\
\text { de caso }\end{array}$ & $\begin{array}{l}\text { «Estrategia de investigación dirigida a } \\
\text { comprender las dinámicas presentes en } \\
\text { contextos singulares (...) los datos pueden } \\
\text { ser obtenidos desde una variedad de fuentes, } \\
\text { tanto cualitativas como cuantitativas, con el fin } \\
\text { de describir, verificar o generar teoría» } \\
\text { (Eisenhardt, } 1989 \text { en Martínez, 2006:174). }\end{array}$ \\
\hline \multirow{3}{*}{ Técnicas } & Cuestionarios & $\begin{array}{l}\text { Técnica destinada a recoger informaciones } \\
\text { que se dan en unidades o en personas de un } \\
\text { colectivo, para después procesarlas y } \\
\text { analizarlas. Es una técnica ágil para conocer } \\
\text { datos, una vez formuladas las preguntas y } \\
\text { definidas las formas de respuesta (Briones, } \\
\text { 1996:52). }\end{array}$ \\
\hline & Entrevistas & $\begin{array}{l}\text { Conversación entre dos personas o más, } \\
\text { dirigida por el entrevistador, con preguntas y } \\
\text { respuestas, que pueden tener diversos } \\
\text { grados de formalidad. Permite recoger } \\
\text { información como datos, opiniones, ideas y } \\
\text { críticas sobre temas y situaciones específicos, } \\
\text { así como la interpretación que le dan los } \\
\text { entrevistados (Torres, 1995:30). }\end{array}$ \\
\hline & Análisis de contenido & $\begin{array}{l}\text { Análisis reflexivo de los documentos, para } \\
\text { comprender el sentido de la comunicación y } \\
\text { verificar las interrelaciones teoréticas } \\
\text { (Altheide, 1987:68 en Scribano, 2000: 129). }\end{array}$ \\
\hline
\end{tabular}

Fuente: Elaboración propia

\subsubsection{Elección de los instrumentos de investigación.}

En un primer momento del proceso de recolección de información se elaboraron y aplicaron cuestionarios generales a las 18 personas que conforman la organización para identificar variables como género, edad, estado civil, estado parental, antigüedad en la organización, posición jerárquica, tipo de trabajo realizado en la organización y el nivel de formación de quienes constituyen la oficina; a partir de estos datos fue posible obtener la información correspondiente a la dimensión: características socio - demográficas. De igual forma el cuestionario permitió conocer las características generales del trabajo que estas personas realizan: descripción del puesto, actividad laboral, jornada de trabajo, condicionamientos de la jornada de trabajo respecto a las variables antes propuestas, flexibilidad de los horarios, y lugar de trabajo; esto proporcionó un 
contexto acerca de la condición con relación a la organización y sobre la multiplicidad de roles de los trabajadores de la organización.

Finalmente, tras esta caracterización con el cuestionario fue posible indagar una cuestión más, la relación vida laboral - vida personal; esta dimensión se dividió en tres aspectos: dificultad para el desarrollo de actividades, horas dedicadas a diversas actividades y satisfacción con el tiempo dedicado. Así, respecto a la primera cuestión, se indagó si el desarrollo del rol laboral incide en el desarrollo de actividades personales o familiares, a partir de la dificultad que se generaba para: solicitar permiso para atender asuntos personales y asuntos familiares; solicitar una flexibilización en la jornada para atender asuntos familiares; solicitar disponibilidad de tiempo para atender emergencias familiares; hacer compatible el trabajo con las tareas del hogar, el cuidado de personas dependientes, actividades de autocuidado, actividades de formación y capacitación y, actividades de ocio. Frente a estos aspectos las posibilidades de respuesta eran: Siempre, casi siempre, a veces, casi nunca o nunca. Enseguida y con el propósito de analizar la relación existente entre los escenarios laborales y sociales, y los múltiples roles que de estos espacios se derivan se consideró importante conocer la distribución temporal que los trabajadores hacen para el desarrollo de diversas actividades en días laborales; de forma tal que se preguntó a las personas sobre el tiempo que dedicaban a actividades como: cumplimiento de la jornada de trabajo, desplazamiento casa - trabajo - casa, realización de las tareas del hogar, cuidado de personas dependientes, actividades familiares, actividades de auto cuidado, actividades sociales, actividades de formación y capacitación y, actividades de ocio. Respecto a estas actividades los trabajadores debían definir el tiempo dedicado, de acuerdo con los siguientes rangos: Menos de 1 hora, entre 1 y 4 horas, entre 5 y 9 horas, entre 9 y 12 horas y más de 12 horas. Finalmente, y a partir del punto anterior, se consideró valioso conocer el grado de satisfacción de las personas con la forma en que distribuyen su tiempo para la realización de dichas actividades; para esto las opciones de respuesta fueron: muy satisfecho, satisfecho, poco satisfecho e insatisfecho.

En general, a través de este cuestionario fue posible caracterizar a la población objetivo e indagar acerca de los factores que tienen que ver más propiamente con la vida laboral y que puedan relacionarse con características o condicionantes de diferentes ambientes sociales.

Ahora, a partir de los datos proporcionados por el cuestionario, se definieron temas particulares a profundizar por medio de la realización de entrevistas semi estructuradas a los trabajadores, con el propósito de indagar acerca de la construcción de la vida laboral en la que se desenvuelven y, las características de la vida social en la que participan. Por tanto, un segundo momento del proceso de recolección de información estuvo orientado a la realización de entrevistas, tanto a los trabajadores - agentes inmobiliarios y administrativos -, como a los directivos de la organización. Es importante mencionar que a pesar de que en el proceso de caracterización de la población realizado a partir del cuestionario, participaron todas las personas que hacen parte del equipo de trabajo - 18 personas-, las 
entrevistas se realizaron sólo a 16 personas dado que, dos de los agentes inmobiliarios salieron de vacaciones para el periodo de tiempo en el que se llevó a cabo este proceso, por lo que fue imposible contactarlos.

Las entrevistas que permitieron indagar acerca de la vida laboral y la vida social fueron diseñadas con una extensión determinada y se aplicaron a todas las personas que laboran en la oficina, a excepción de la Gerente. Es decir, se realizaron 15 entrevistas a trabajadores de la organización, incluido el subgerente. La entrevista se orientó a cuatro temas particulares.

Por un lado, preguntar por la rutina diaria del entrevistado, incluyendo tanto temas laborales como temas no laborales, con el propósito de conocer la dinámica de vida de las personas e identificar algunos de los roles que asumen. En la segunda parte se indagó por los espacios ocupacionales tales como la familia, el trabajo, escenarios de capacitación, de ocio y esparcimiento; con esto fue posible precisar los diferentes escenarios por los que transitan quienes conforman la organización, algunas de las relaciones que se entretejen en dichos espacios y las demandas y responsabilidades resultantes de esto. En un tercer momento se preguntó por la dinámica laboral, posibilitando la descripción de horarios de trabajo, espacios laborales, uso de herramientas de trabajo, remuneración y satisfacción laboral; estos elementos facilitaron el análisis de la vida laboral de las personas de la organización y la forma en que estos definían la forma de llevarla a cabo, a partir de mitos, rutinas, cumplimiento de reglas y el seguimiento de prácticas institucionalizadas. Finalmente, se hizo referencia a la selección de actividades y/u ocupaciones que asumen las personas; de esta forma se indagó de manera concreta por los roles desempeñados por cada persona, la prioridad que tienen unos de estos roles sobre otros, y las posibilidades de elección con las que cuentan las personas para definir el desempeño de esos roles. Con esto fue posible identificar las situaciones de multiplicidad de rol a la que están expuestas las personas, si éstas derivan de manera positiva (acumulación de roles) o negativa (sobre carga de rol, conflicto inter rol), y las cuestiones y situaciones que crean sentido para las personas entrevistadas, siendo esto la base para definir, transitar y construir su vida laboral y su vida social.

A la gerente de la oficina se le realizó una entrevista orientada a obtener información acerca de la organización y su funcionamiento: formalización, jerarquización, normatividad, centralización, tecnología empleada, división del trabajo, relación entre horarios y actividades, por mencionar algunos. Conociendo el funcionamiento de la organización se procedió a indagar cómo se implantó dicha forma de organización, qué modificaciones ha experimentado y cuáles fueron las razones que originaron dichas modificaciones.

La recolección de información para la investigación se complementó con un proceso de revisión y análisis documental como insumo para la caracterización del ambiente de la organización. En este sentido, se revisaron documentos propios de la organización como políticas, reglamentos, manuales, actas, que proporcionaron 
información acerca de las características básicas de la organización, su historia, sus proyecciones y su funcionamiento.

\subsubsection{Caracterización de las variables y su nivel de análisis.}

Con el fin de identificar y definir las dimensiones y variables de análisis, fue necesario hacer una revisión de la literatura de nuevo institucionalismo y de la teoría de roles, al constituir el marco teórico que orientó la investigación.

Así, el nuevo institucionalismo proporcionó insumos acerca de la definición de las jornadas laborales, desde la organización y desde los trabajadores, con conceptos como isomorfismo mimético, mitos racionalizados, prácticas institucionalizadas, cumplimiento de reglas y definición y seguimiento de rutinas; estos elementos orientaron el análisis de cómo los trabajadores de la organización definen sus tiempos y espacios laborales - cumplimiento de jornada laboral y asistencia a la oficina - a partir del uso de las nuevas tecnologías como herramientas de trabajo, y de otras condiciones ofrecidas por la organización, sin importar el tipo de vinculación que tengan con ésta. Por su parte, la teoría de roles permitió identificar la definición y priorización de los múltiples comportamientos y funciones que asumen las personas que conforman la organización en el tránsito de su vida laboral y su vida no laboral, resultando de esto una multiplicidad de roles que puede derivar en una condición positiva, cuando hay tendencia hacia la acumulación de roles, o en una situación negativa, al estar orientada hacia el conflicto inter rol o la sobre carga de rol; como se verá, estas situaciones inciden de manera importante en la forma en que las personas definen y cumplen las jornadas laborales.

A partir de esto, en la tabla tres se proponen entonces las siguientes dimensiones y variables de análisis: 
Tabla 3. Marco de análisis y variables

\begin{tabular}{|c|c|c|c|}
\hline DIMENSIÓN & VARIABLES & $\begin{array}{l}\text { UNIDAD DE } \\
\text { ANÁLISIS }\end{array}$ & APLICADO A \\
\hline $\begin{array}{l}\text { Características } \\
\text { socio- } \\
\text { demográficas }\end{array}$ & $\begin{array}{l}\text { - Género: hombre/ mujer } \\
\text { - Estado civil: casado / unión libre / } \\
\text { separado } \\
\text { - Estado parental: sin hijos / con } \\
\text { hijos en edad dependiente / con } \\
\text { hijos en edad independiente } \\
\text { - Trayectoria laboral: inicio / } \\
\text { finalización / jubilación }\end{array}$ & $\begin{array}{l}\text { Cuestionario de } \\
\text { caracterización }\end{array}$ & $\begin{array}{l}18 \text { personas } \\
\text { que conforman } \\
\text { la organización }\end{array}$ \\
\hline $\begin{array}{l}\text { Condiciones con } \\
\text { relación a la } \\
\text { organización }\end{array}$ & $\begin{array}{l}\text { - Tipo de trabajo: gerencial / } \\
\text { administrativo / comercial } \\
\text { - Tipo de vinculación: free lance / } \\
\text { contratación por servicios }\end{array}$ & $\begin{array}{c}\text { Cuestionario de } \\
\text { caracterización } \\
\text { Revisión } \\
\text { documental }\end{array}$ & $\begin{array}{l}18 \text { personas } \\
\text { que conforman } \\
\text { la organización }\end{array}$ \\
\hline Teoría de roles & $\begin{array}{l}\text { - Conflicto inter - rol: recurso } \\
\text { tiempo / presiones } \\
\text { comportamiento } \\
\text { - Sobre carga de rol: recurso } \\
\text { tiempo / recurso energía } \\
\text { - Acumulación de roles: privilegios } \\
\text { del rol / seguridad del status / } \\
\text { enriquecimiento de los recursos / } \\
\text { enriquecimiento de la } \\
\text { personalidad }\end{array}$ & $\begin{array}{l}\text { Entrevista semi } \\
\text { estructurada }\end{array}$ & $\begin{array}{l}11 \text { entrevistas a } \\
\text { agentes } \\
\text { inmobiliarios y } \\
\text { subgerente } \\
4 \text { entrevistas a } \\
\text { personal } \\
\text { administrativo y } \\
\text { de apoyo }\end{array}$ \\
\hline $\begin{array}{c}\text { Nuevo } \\
\text { institucionalismo }\end{array}$ & $\begin{array}{l}\text { - Institución: Patrón social / } \\
\text { prescripciones / estructuras } \\
\text { cognitivas / estructuras normativas } \\
\text { / estructuras regulativas / } \\
\text { construcción social } \\
\text { - Prácticas institucionalizadas: } \\
\text { Se da por hecho / habituación / } \\
\text { sedimentación / objetivación } \\
\text { - Mitos racionalizados: } \\
\text { prescripciones racionalizadas / } \\
\text { prácticas institucionalizadas / dan } \\
\text { legitimidad } \\
\text { - Reglas: restringen la conducta / } \\
\text { construcciones sociales procedimiento } \\
\text { - Rutinas: reglas de procida de } \\
\text { / homogeneidad a } \\
\text { comportamiento }\end{array}$ & $\begin{array}{l}\text { Entrevista semi } \\
\text { estructurada } \\
\text { Definición de } \\
\text { jornadas } \\
\text { laborales en el } \\
\text { sector inmobiliario } \\
\text { Prácticas } \\
\text { miméticas en el } \\
\text { sector inmobiliario }\end{array}$ & $\begin{array}{c}11 \text { entrevistas a } \\
\text { agentes } \\
\text { inmobiliarios y } \\
\text { subgerente } \\
4 \text { entrevistas a } \\
\text { personal } \\
\text { administrativo y } \\
\text { de apoyo } \\
1 \text { entrevista a la } \\
\text { gerente }\end{array}$ \\
\hline
\end{tabular}

Fuente: Elaboración propia

Lo anterior permitió la construcción de un modelo para analizar el fenómeno organizacional en cuestión en el que se interrelacionaron las variables y conceptos que posibilitaron dar una explicación coherente respecto al mismo. El modelo propuesto está conformado por variables relevantes de la organización y del fenómeno organizacional a estudiar, así como por las teorías que permitieron la interpretación de dichas variables en el contexto organizacional particular (Rodríguez, 2006). Con base en esto, y a partir de los elementos estructurales de 
la organización objeto de estudio, y de las posturas teóricas ya expuestas desde las cuales fue analizado el fenómeno a estudiar en dicha organización, el modelo de análisis que orientó el proceso investigativo es el siguiente:

Figura 2. Modelo organizacional para analizar la definición de las jornadas laborales de los trabajadores de una oficina inmobiliaria

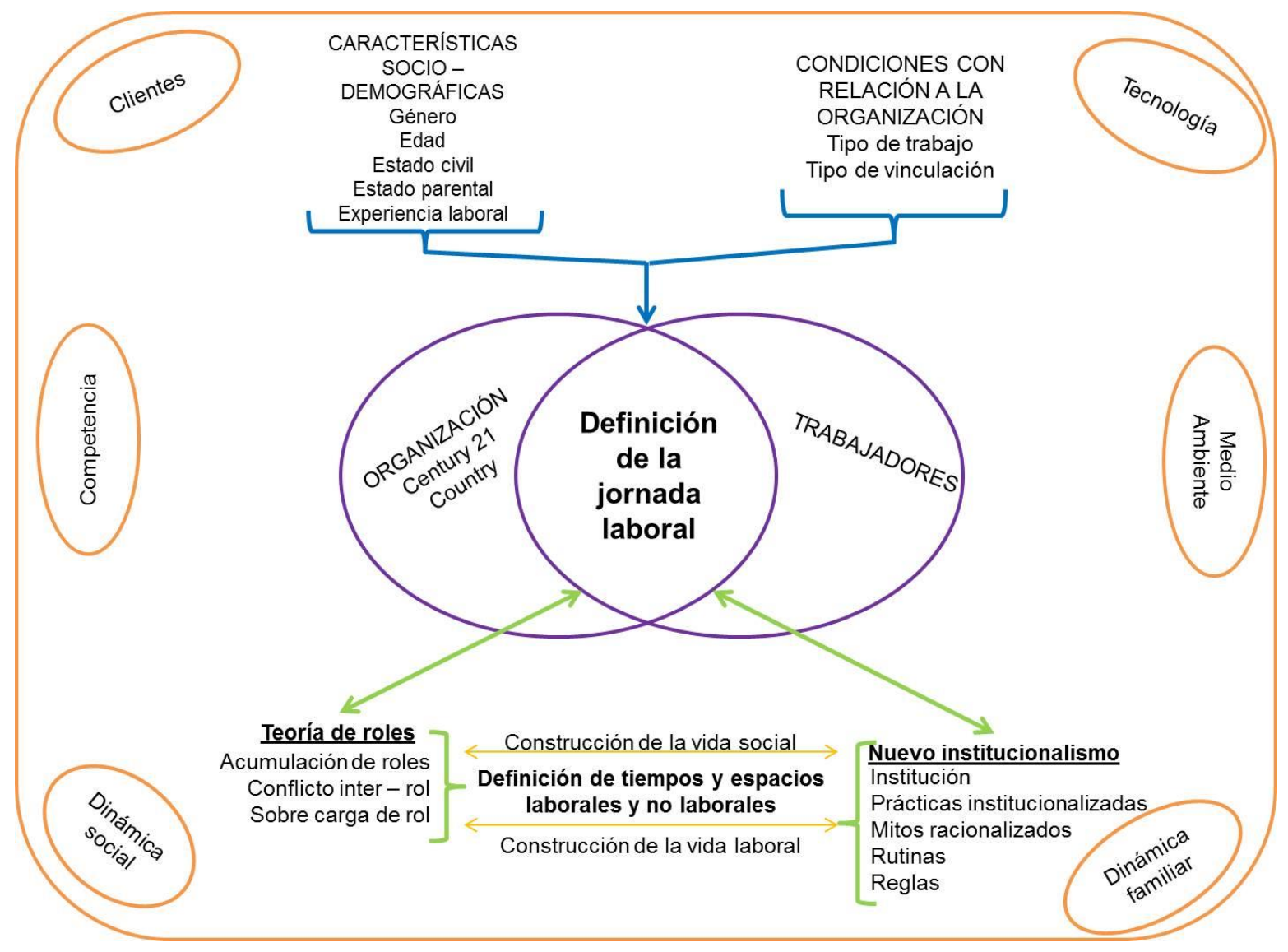

Fuente: Elaboración propia

- Los actores. En la parte central del modelo se ubica a la organización y a los trabajadores, al reconocer la incidencia de las dos partes en el desarrollo del fenómeno organizacional a estudiar, así como el impacto que el fenómeno puede generar para ellos. La organización es Century 21 Country y, los trabajadores, son las 18 personas que hacen parte de dicha organización: ápice estratégico, los agentes inmobiliarios, y el personal administrativo y de apoyo.

- El fenómeno organizacional. Como resultado de la intersección entre los dos actores principales de la organización, se ubica el fenómeno organizacional. Lo que para esta investigación interesa saber acerca del fenómeno a estudiar es de qué manera se definen las jornadas laborales de los trabajadores de una oficina inmobiliaria a partir de los distintos roles que asumen en escenarios laborales y no laborales. Esta cuestión se analiza por una lado, a partir de la condición de 
flexibilidad temporal y espacial que tienen los agentes inmobiliarios, dada la naturaleza de su vinculación con la organización y el uso que deben hacer permanentemente de herramientas tecnológicas para la dinamización del negocio; y por otro lado, a partir de la aparente rigidez de los tiempos y espacios laborales que tienen las personas que hacen parte del área administrativa de la organización. Al final además se podrá hacer una comparación con respecto a las dos situaciones, a partir de las variables que viabilizarán el desarrollo del análisis en cuestión.

- Dimensiones de análisis. En la parte superior izquierda del modelo se encuentran las variables relacionadas con las características socio demográficas de quienes hacen parte de la organización: edad, género, estado civil, estado parental, edad de los hijos y la experiencia laboral con la que cuentan las personas. En la parte superior derecha se encuentran las variables que hacen referencia a la relación de los trabajadores con la organización tales como: tipo de trabajo realizado (comercial, apoyo, administrativo) y el tipo de vinculación (freelance, prestación de servicios). Estos dos grupos de variables permitirán analizar en detalle el fenómeno organizacional en cuestión dado que se configuran como características particulares que tienen los trabajadores de la organización, y de la relación de estos con la organización y el trabajo allí realizado.

Alrededor del modelo organizacional se proponen características y elementos del entorno que tienen incidencia en la dinámica de esta organización, y específicamente, en el fenómeno en estudio: Clientes, competencia, tecnología, dinámica social de los trabajadores y dinámica familiar de los trabajadores.

- La teoría. En la parte inferior del modelo se presentan las posturas teóricas desde las cuales será estudiado el fenómeno organizacional; mediante las herramientas conceptuales que proporcionan estas teorías, es posible analizar la construcción de la vida social y la vida laboral como referente para la definición de tiempos y espacios laborales y no laborales de quienes hacen parte de la organización. En este sentido, desde la teoría de roles se retomarán conceptos como la acumulación de roles, conflicto inter - rol y sobre carga de rol y, desde el nuevo institucionalismo se recuperarán los planteamientos acerca de institución, las prácticas institucionalizadas, los mitos racionalizados, las rutinas y las reglas.

- La metodología. La investigación se realiza bajo el enfoque cualitativo, haciendo uso del estudio de caso como método. Como técnicas de recolección de información se hace uso de cuestionarios, entrevistas y revisión documental. 


\section{UNA APROXIMACIÓN AL OBJETO DE ESTUDIO: CENTRUY 21 COUNTRY}

Previo a describir la organización en la que se realizó el estudio es importante referir algunos elementos que inciden en la misma. Así, en la primera parte de este capítulo se presenta una contextualización del sector inmobiliario, en tanto es el sector en el que se ubica la organización objeto de estudio y cuyas particularidades de estructura y funcionamiento posibilitan la emergencia de ciertas condiciones involucradas con la problemática a analizar. En la segunda parte se expone la configuración de la organización misma, en un nivel macro; de modo que se hará referencia a la red de inmobiliarias Century 21 en el mundo, para finalizar con la presencia de esta organización en Colombia. En la sección final de este apartado se hace una presentación de la organización en la que se realizó el estudio de caso, Century 21 Country - en adelante C21 Country-: su historia, su configuración y funcionamiento, y una descripción demográfica de quienes hacen parte de su equipo de trabajo.

\subsection{CONTEXTUALIZACIÓN DEL SECTOR INMOBILIARIO EN COLOMBIA ${ }^{19}$.}

El sector inmobiliario hace parte del tercer sector de la economía colombiana, el sector servicios; C21 Country, se ubica en este sector, dado que su función principal es ofrecer servicios de asesoría inmobiliaria.

De acuerdo con el DANE ${ }^{20}$, en el tercer trimestre del año 2016 las actividades del sector inmobiliario generaron empleo para 1,6 millones de colombianos, y conjuntamente con los empleos generados en el sector de la construcción, representaron $13,7 \%$ del empleo total del país, y aportaron $30 \%$ de los nuevos empleos del último año. Las cifras dan cuenta de la importante y creciente contribución que hace el sector inmobiliario al desarrollo de la economía nacional.

Este crecimiento del sector posiblemente responde a la coyuntura de los últimos tiempos en la que los precios de bienes raíces son más favorables por efectos de la tasa de cambio; ahora los bienes raíces resultan $40 \%$ más baratos por efectos de la devaluación. Esta situación configura al sector inmobiliario colombiano atractivo para inversionistas extranjeros y compañías internacionales que con su incursión, dinamizan el mercado y establecen criterios para el mejoramiento de prácticas comerciales, de acuerdo con la consideración del presidente de Fedelonjas ${ }^{21}$. Es así, como a la fecha en Colombia se encuentran las cinco compañías más grandes del sector inmobiliario a nivel mundial: Coldwell Banker, Colliers y Century 21, que llegaron hace una década al país; Re/Max, que ingresó

\footnotetext{
${ }^{19}$ Apartado construido a partir de: http://www.dinero.com/edicionimpresa/negocios/articulo/perspectivas-del-sector-inmobiliario-para-2016-colombia/216505

20 EI DANE en Colombia es el Departamento Administrativo Nacional de Estadística.

${ }^{21}$ Fedelonjas es la Federación Colombiana de Lonjas de Propiedad Raíz; es una de las agrupaciones gremiales del sector inmobiliario Colombiano. Tiene 40 años de experiencia, lo que la convierte en una de las agremiaciones más antiguas y con mayor cubrimiento del territorio nacional. Información tomada de: http://www.fedelonjas.org.co/
} 
al mercado nacional hace cuatro años y, Keller Williams que hasta este año incursionó.

Sin embargo, no sólo las compañías extranjeras han activado sus planes de expansión. La creciente competencia ha llevado a que las principales firmas inmobiliarias del país estén avanzando en planes de transformación, inversión y capacitación para aprovechar las oportunidades afuera. De hecho, en los dos últimos años 153 inmobiliarias locales obtuvieron el reconocimiento como Especialistas Internacionales Certificados en la Negociación de Propiedades (CIPS) ${ }^{22}$, que les permite asesorar a inversionistas extranjeros en sus negocios de compra y renta en Colombia.

\subsection{RED INMOBILIARIA CENTURY $21 \AA^{23}$.}

El Sistema de Century 21 ® es una organización de venta de bienes raíces con presencia a nivel mundial; cuenta con más de 8.500 oficinas de ventas, autorizadas por medio de franquicias, de propiedad y funcionamiento independientes, en 64 países y territorios en todo el mundo, con operaciones internacionales en toda Europa, América, Medio Oriente y Asia. El formato de negocio de Century $21 \AA$, otorga el derecho del uso de la marca a través del sistema de franquicia para la industria inmobiliaria; es decir, la red de oficinas Century 21 son franquicias que hacen uso de la marca Century $21 \circledast$ y sus distintivos comerciales pero que, operan de manera autónoma e independiente.

Century 21 ® inició operaciones en 1971 en Estados Unidos, y en 1976 en Canadá, basando su negocio en un sistema de pequeñas compañías independientes de bienes raíces que competían contra las grandes compañías de la industria. Los fundadores de Century $21 \AA$, Art Bartlett y Marsh Fisher crearon un modelo de negocio basado en los siguientes cuatro elementos:

- Aprovechamiento de la regionalización para generar confianza dentro de los agentes independientes

- La creación de un ícono diseñado y de uso exclusivo por las franquicias Century $21 \AA$, que es la señal de jardín "poste dorado"

- El uso de la "Chaqueta dorada", que hacía de cada vendedor una valla ambulante y que lo definía como un símbolo de excelencia en el servicio.

- Se creó un Fondo Nacional de Publicidad, al cual todos los franquiciados aportarían un porcentaje del total de sus ingresos, esto permitiría una inversión considerable en medios masivos como televisión y prensa, para lograr una cobertura nacional de la marca.

Century $21 \AA$ construye la marca por medio de la imagen en las oficinas de cara al cliente final, las señales de jardín y avisos de ventana que se sitúan en las

22 CIPS: Certified International Property Specialist

23 Apartado construido a partir de la información tomada del portal corporativo de la Organización: http://www.century21colombia.com/franquicia/sistema_century.php 
propiedades que se negocian y con el atuendo de trabajo que porta cada uno de los agentes del sistema (La chaqueta dorada y la placa distintiva). Así pues, la filosofía de la organización es: que la marca trae los negocios, el sistema ayuda a mantenerlos y a través del soporte que proporcionan los agentes inmobiliarios, los negocios crecen.

\subsection{CENTURY 21 EN COLOMBIA ${ }^{24}$.}

La organización Century $21 \circledR$ en Colombia cuenta con 29 oficinas - franquiciasdistribuidas en ocho ciudades del país, con un total aproximado de 313 trabajadores, entre agentes inmobiliarios, quienes conforman el equipo de trabajo comercial, y personas del área administrativa y de soporte de cada oficina. Estas oficinas trabajan bajo los lineamientos generales de funcionamientos establecidos por Century 21 Colombia - también llamada Casa Nacional - pero operativamente lo hacen de manera independiente y autónoma.

La visión de la organización en Colombia es establecer la mayor y la más profesional red de agencias de asesoría inmobiliaria. Por su parte, la misión se orienta a prestar apoyo de consultoría, formación, gestión, tecnologías, comunicación y reclutamiento de forma que los franquiciados Century 21 Colombia se conviertan en la referencia en el mercado inmobiliario en Colombia.

Así las cosas, los valores que guían la gestión de Century 21 en Colombia, la de sus franquicias y por consiguiente, la de sus agentes inmobiliarios son el profesionalismo, el compromiso, la eficacia, la innovación, la integración y la calidad de servicio. De igual forma, la propuesta de Century 21 Colombia para los clientes, a través de sus franquicias es: "Vender o arrendar su inmueble en el menor tiempo posible, y sin complicaciones".

\subsection{RELACIÓN ENTRE CENTURY 21®, CENTURY 21 COLOMBIA Y C21 COUNTRY 25 .}

Como se planteó previamente la red de oficinas de esta compañía inmobiliaria son franquicias que hacen uso de la marca Century $21 \AA$. En este sentido, C21 Country, a pesar de ser parte de la red Century 21 , opera de manera autónoma e independiente con respecto a Century 21 Colombia y a otras franquicias que se ubican en Colombia, e incluso en Chía ${ }^{26}$. No obstante, a pesar de esta condición,

\footnotetext{
24 Apartado construido a partir de la información tomada del portal corporativo de la Organización: http://www.century21colombia.com/franquicia/sistema_century.php

25 Idem

${ }^{26}$ Chía, lugar en el que se encuentra la organización objeto de estudio es un municipio ubicado en el departamento de Cundinamarca, en Colombia. Se le conoce como "La Ciudad de la Luna", en referencia a la etimología de su nombre. El casco urbano del Municipio cuenta con un área de 17 $\mathrm{km}^{2}$ y el área total del municipio es de aproximadamente $79 \mathrm{~km}^{2}$. Chía limita al sur con el Distrito Capital de Bogotá y con el municipio de Cota; al occidente con los municipios de Tabio y Tenjo; al norte con el municipio de Cajicá y al oriente con el municipio de Sopó. Este municipio presenta una de las densidades poblacionales más altas del departamento: con 126.647 habitantes es el
} 
Casa Nacional se ejerce cierto control y se establecen directrices acordes a los parámetros definidos por la marca Century $21 \AA$ a nivel mundial. La figura tres representa la relación jerárquica entre estos tres niveles de la red Century $21 \AA$.

\section{Figura 3. Relación entre Century $21 \AA$, Century 21 Colombia y C21 Country}

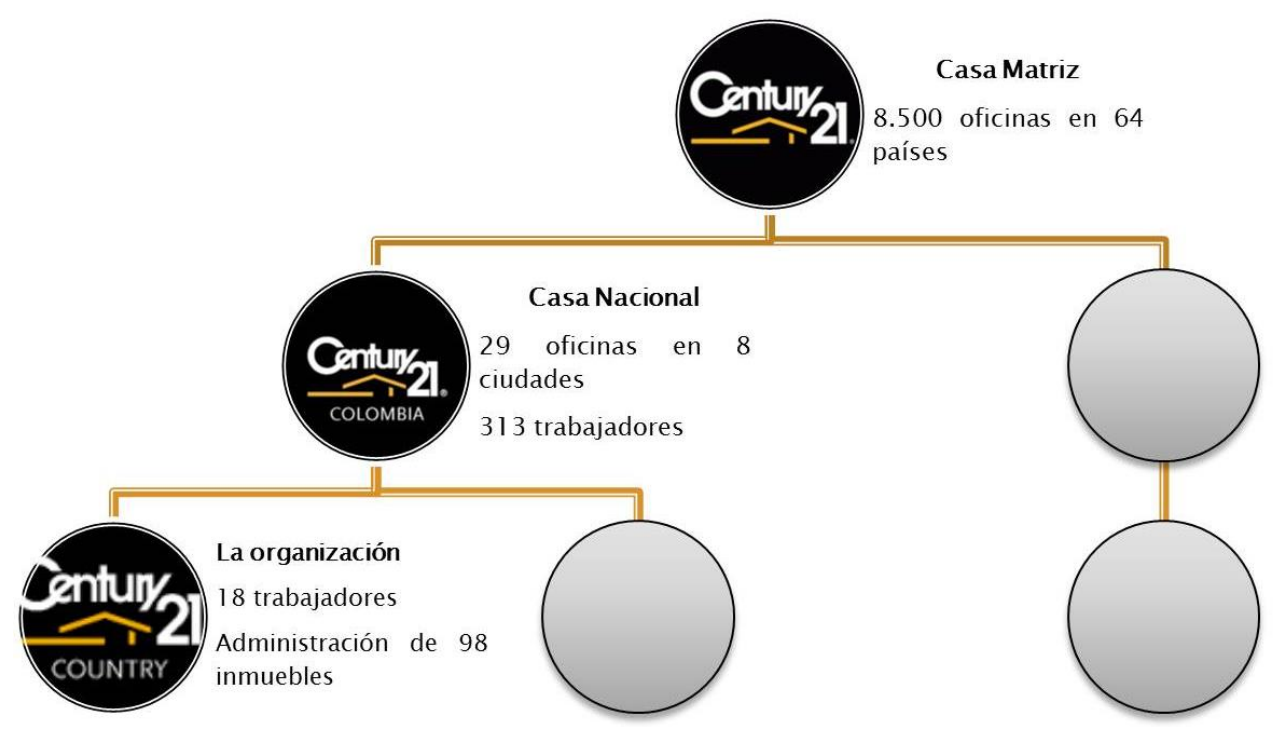

Fuente: Elaboración propia a partir de información suministrada por la organización

Así, una de las directrices dadas por Century 21 Colombia es la definición de los porcentajes para el pago de comisiones para los agentes comerciales de acuerdo con el valor del negocio realizado. Otro lineamiento que da Casa Nacional es el uso de uniformes y placas por parte de los agentes para la atención de clientes, siendo éste uno de los elementos distintivos de la marca Century $21 \AA$ a nivel mundial. Otro asunto en el que se establecen parámetros, ya no sólo desde Casa Nacional, sino desde la Casa Matriz en Estados Unidos, es el evitar establecer una relación laboral, ni con los agentes ni con las personas del área

municipio más poblado de la Sabana de Bogotá. En los últimos años Chía ha experimentado un desarrollo urbanístico considerable, en el que se destaca principalmente la construcción de residencias y conjuntos residenciales para estratos medio-altos y altos. Chía es uno de los municipios de Colombia con mayor nivel de desarrollo humano, y en Cundinamarca es el municipio con el porcentaje de personas con Necesidades Básicas Insatisfechas más bajo (7,11\%). Como en la mayor parte de los municipios de la Sabana de Bogotá, las principales actividades económicas en Chía han sido históricamente la agricultura, la floricultura y la ganadería lechera. La floricultura tiene todavía una gran importancia en la economía del municipio, pero esta se ha diversificado considerablemente en las últimas décadas y actualmente la actividad empresarial se concentra principalmente en el sector de servicios. Existen también algunas industrias, entre las que destaca la producción de derivados lácteos, y algunas manufacturas y artesanías: pintura, escultura en piedra y bronce, ebanistería, carpintería y trabajo con hierro forjado. Igualmente, la oferta gastronómica, y el turismo asociado a ella, es un sector relevante de la economía. Información tomada de: http://www.chia-cundinamarca.gov.co/ 
administrativa, sino más bien operar bajo una relación comercial vinculándolos como free lance - en el caso de los agentes-, y por prestación de servicios - para el personal administrativo y de apoyo-.

Ahora, una de las estrategias mediante las cuales Casa Nacional hace seguimiento a sus franquicias es el desarrollo bimensual de reuniones con los gerentes de oficina, a fin de, por un lado alinear procedimientos de acuerdo con lo estipulado por la Casa Matriz en Estados Unidos, y por otro, evaluar el cumplimiento de objetivos de cada una de las oficinas respecto a cierre de negocios. Así mismo, Casa Nacional tiene la posibilidad de hacer seguimiento permanente a sus franquicias mediante la plataforma de Century 21 Colombia; allí puede ver los negocios que se esperan, que se realizan o que se anulan, y en caso por ejemplo de una anulación, tiene la posibilidad de contactar al agente inmobiliario encargado 0 , incluso al propietario del inmueble, para conocer las razones por las que se eliminó de la red el negocio o el inmueble; de esta forma, Casa Nacional tiene la posibilidad de hacer un control estricto sobre la dinámica del negocio.

\subsection{OFICINA INMOBILIARIA OBJETO DE ESTUDIO: C21 COUNTRY 27}

La oficina en la que se realizó el estudio de caso es una de las 29 oficinas de Century $21 \AA$ en Colombia, previamente mencionadas; está ubicada en el Municipio de Chía, muy cerca a Bogotá, capital de Colombia. Esta oficina está operando desde el año 2010, sin embargo, durante esos seis años ha tenido diversos cambios estructurales y administrativos, los cuales inevitablemente han incidido en la configuración de su estructura y diseño.

\subsubsection{Historia de C21 Country.}

La oficina C21 Country está en funcionamiento desde el año 2010. Para ese momento la oficina era propiedad de dos socias, quienes compraron la franquicia a Century 21 Colombia. En su primer año de funcionamiento la oficina generó pérdidas; esta situación en parte fue resultado del manejo financiero y administrativo que la gerencia de ese momento le dio a la oficina. Pero también, ese estado de pérdidas fue consecuencia de la inundación que sufrió el Municipio de Chía en varias zonas ese año, debido al desbordamiento de los dos ríos que lo rodean; este desastre natural generó que el Municipio ya no fuera atractivo como lugar de residencia, ocasionando una disminución considerable de la demanda de inmuebles en esa zona, y por consiguiente, de la realización de negocios a través de la inmobiliaria.

A partir de esa situación la socias re estructuran el área administrativa de la oficina, reemplazando a la persona que en ese momento la lideraba. Es así como en Marzo de 2011 la actual gerente de la oficina se vincula a la organización como empleada. De acuerdo con lo planteado por ella en la entrevista realizada, cuando asumió su cargo como gerente, el estado financiero de la empresa mostraba una

${ }^{27}$ Apartado construido a partir de las entrevistas realizadas al área gerencial de la organización y de la revisión de documentos propios de la organización. 
pérdida cercana a los doscientos millones de pesos colombianos $(\$ 200.000 .000$ $\mathrm{COP}$. A partir de ahí implementa algunas modificaciones en el funcionamiento de la oficina en aras de impulsarla para mejorar su estado financiero; esto lo hace mediante el fortalecimiento de las estrategias de mercadeo y publicidad, la renovación del equipo de trabajo comercial y administrativo, la facilitación de herramientas de trabajo a los agentes comerciales (tales como smartphone) y, la reestructuración de la oficina mediante la creación de departamentos. Efectivamente entre el año 2011 y el año 2015 C21 Country mejoró su rendimiento económico posiblemente como resultado de la nueva administración y, del posicionamiento y reconocimiento que fue adquiriendo en Chía. Tanto así fue la recuperación que tuvo C21 Country, que en ese lapso de tiempo fue considerada por Century 21 Colombia como la segunda mejor oficina a nivel nacional dada la cantidad de negocios cerrados y, los resultados financieros entregados.

No obstante, pasados esos cinco años las socias deciden vender la franquicia, la cual fue comprada por la gerente. De esta manera, el primero de Agosto de 2015, la oficina cambia de dueños, siendo ahora propiedad de quien la lideró durante ese tiempo. Con este cambio C21 Country se convierte en una sociedad familiar pues el $50 \%$ de la propiedad de la oficina corresponde a la gerente, y el $50 \%$ restante a sus hijos, cada uno con el $25 \%$. De acuerdo con lo planteado por la gerente en la entrevista, este cambio no tuvo resonancia en el funcionamiento de la oficina pues, la dinámica que se había forjado durante los cinco años se mantuvo, así como los procedimientos ya establecidos.

\subsubsection{Quienes conforman C21 Country.}

La oficina C21 Country está conformada por 18 personas, de las cuales 12 son agentes inmobiliarios y cumplen funciones comerciales, cuatro personas conforman el área administrativa y de apoyo y, las dos personas restantes tienen funciones gerenciales y a su vez son los dueños de la oficina.

A partir de la aplicación del cuestionario de caracterización de la población que conforma C21 Country, realizada en la parte inicial de la investigación, fue posible identificar variables como género, edad, estado civil, antigüedad en la organización y el nivel de formación.

Así, en la oficina hay una preponderancia del género femenino: el 83\% de las personas que la conforman son mujeres - 15 personas- , y el $17 \%$ restante, son hombres - tres personas-. Es interesante pensar que esta situación se relaciona con las posibilidades de manejo autónomo de tiempo ofrecidas por la organización, que facilitan la armonización de la vida social y la vida laboral para las mujeres en la doble o triple jornada que en ocasiones asumen.

Respecto a la edad, el mayor porcentaje de población se encuentra entre los 51 y 60 años (33\%), seguidos de la población entre 41 y 50 años (28\%), como se observa en la gráfica uno; en el rango de edad de 18 a 20 años no se ubica ninguna persona. Por tanto podría decirse que los trabajadores de ésta organización se encuentran en la franja de adultos y adultos mayores. 


\section{Gráfica 1. Rango de edad}

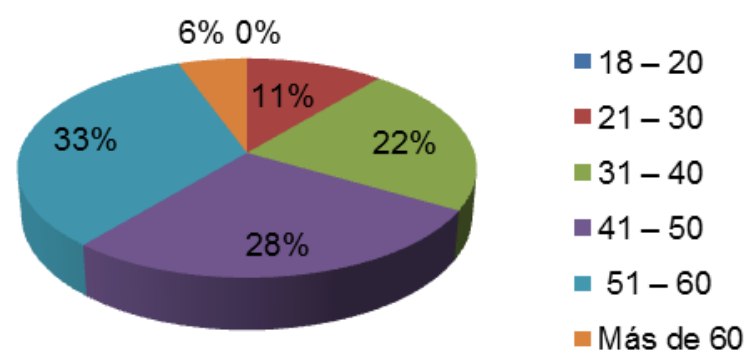

Esta característica posiblemente está relacionada con el tipo de trabajo que se realiza en la organización y las condiciones del mismo, las cuales se adecúan a las expectativas de algunas personas que se encuentran finalizando su ciclo de vida laboral o que incluso, ya están jubiladas y este trabajo es asumido como una actividad laboral no tan estricta ni demandante como otras.

Con relación al estado civil la condición predominante es casado (61\%), seguida de unión libre (22\%), y algunas personas separadas (17\%). No hay personas en situación de soltería o viudez. El $61 \%$ de las personas que trabajan en la organización tiene entre 1 y 2 hijos, el $22 \%$ entre 3 y 5 y, el $17 \%$ no tiene hijos. Estos resultados, tanto del estado civil (gráfica dos) como del estado parental (gráfica tres), permiten inferir que los trabajadores de la organización transitan necesariamente por el escenario laboral y el escenario familiar, y por tanto, están expuestos a una multiplicidad de roles como trabajadores/trabajadoras, como esposo/esposa y como padre/madre.

\section{Gráfica 2. Estado civil}

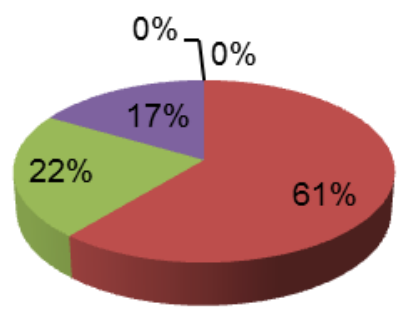

\section{Gráfica 3. Estado parental}

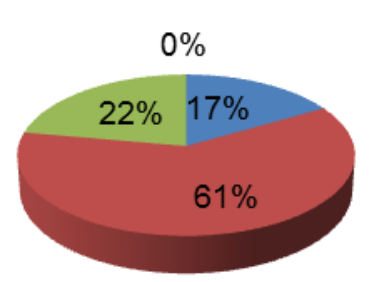

Respecto al nivel de formación, el $44 \%$ de los entrevistados cuentan con formación profesional, seguido de un $28 \%$ que tiene formación a nivel posgrado. También hay personas con nivel de formación técnica o tecnóloga en un $22 \%$ y, el menor nivel de formación es el bachillerato (6\%). Por tanto, estas características perfilan al equipo de trabajo de C21 Country como un equipo capacitado, aunque no necesariamente en el área comercial o en el sector inmobiliario. De esto es 
posible reflexionar dos cosas: Por un lado que el trabajo realizado en la organización, a pesar de no requerir mayor especialización por parte de los trabajadores, si demanda tener ciertas habilidades profesionales y laborales. Por otra parte, que la vinculación con ésta organización es consecuencia de la situación económica del país y la necesidad de ubicarse en un empleo, indistintamente de la formación y experiencia de las personas, o incluso que, dadas las condiciones laborales ofrecidas, consideraron atractivo vincularse a esta organización.

Finalmente como se presenta en la gráfica cuatro, con relación a la antigüedad en la empresa, el mayor porcentaje de trabajadores ha estado en C21 Country por más de 5 años - el 39\% - y, el menor número, que equivale al $6 \%$, lo ha hecho entre 1 y 2 años. A partir de ello podría pensarse que en general el equipo de trabajo es estable, y hay un bajo nivel de rotación de personal.

Frente a esto es importante resaltar varias cosas: Por un lado, la empresa hace 5 años inició una nueva fase liderada por la gerencia que actualmente está; desde ese momento el equipo administrativo y comercial se fue reconfigurando de acuerdo a como la nueva administración iba organizando la oficina. A partir de esto podría pensarse que en la fase de estabilización de la organización, un año después de arrancar la nueva etapa, continuó el proceso de reconfiguración y creación de cargos dentro del equipo de trabajo; de ahí que en la categoría de antigüedad en la empresa 2 a 4 años haya un porcentaje importante $-22 \%$ de la población total-. Por otro lado, un 33\% de la población dice tener de antigüedad en la empresa menos de un año. Esto posiblemente se deba al proceso de expansión en el que está la organización, a partir del cual se abrirá una nueva oficina, para la que se requiere personal administrativo y comercial capacitado. El proceso de entrenamiento de este nuevo equipo de trabajo se está realizando en la oficina estudiada.

Gráfica 4. Antigüedad en la empresa

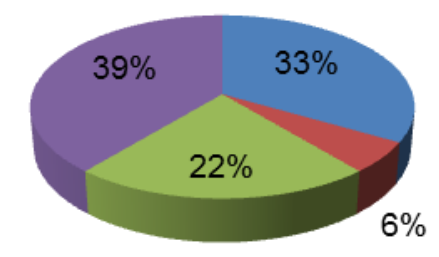

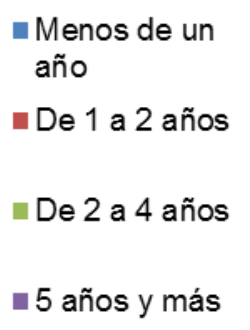

Es importante resaltar que, el tiempo de antigüedad en el cargo es muy similar al tiempo de antigüedad en la empresa, lo que permitiría inferir que no son muy frecuentes los cambios de cargo entre las mismas personas del equipo de trabajo; es decir, usualmente no se realizan movimientos en la estructura jerárquica y funcional de la organización.

A continuación, en la tabla cuatro, se presenta un resumen de la información demográfica descrita anteriormente, organizada por área de trabajo, a fin de que el lector tenga una idea más precisa de las características de quienes hacen parte de C21 Country. 
Tabla 4. Información demográfica de quienes conforman C21 Country

\begin{tabular}{|c|c|c|c|c|}
\hline VARIABLES & ÁREA & COMERCIAL & $\begin{array}{c}\text { ADMINISTRATIVA } \\
\text { Y APOYO }\end{array}$ & GERENCIA \\
\hline \multirow{2}{*}{ Género } & Femenino & 10 & 4 & 1 \\
\hline & Masculino & 2 & 0 & 1 \\
\hline \multirow{5}{*}{ Edad } & $21-30$ & 0 & 2 & 0 \\
\hline & $31-40$ & 2 & 1 & 1 \\
\hline & $41-50$ & 5 & 0 & 0 \\
\hline & $51-60$ & 4 & 1 & 1 \\
\hline & Más de 60 & 1 & 0 & 0 \\
\hline \multirow{3}{*}{ Estado civil } & Casado & 8 & 1 & 2 \\
\hline & Unión libre & 1 & 3 & 0 \\
\hline & Separado & 3 & 0 & 0 \\
\hline \multirow{4}{*}{$\begin{array}{l}\text { Nivel de } \\
\text { Formación }\end{array}$} & Bachillerato & 0 & 1 & 0 \\
\hline & $\begin{array}{l}\text { Técnico / } \\
\text { Tecnólogo }\end{array}$ & 3 & 1 & 0 \\
\hline & Pregrado & 7 & 1 & 0 \\
\hline & Posgrado & 2 & 1 & 2 \\
\hline \multirow{4}{*}{$\begin{array}{l}\text { Antigüedad } \\
\text { en la empresa }\end{array}$} & Menos de un año & 4 & 1 & 1 \\
\hline & De 1 a 2 años & 0 & 1 & 0 \\
\hline & De 2 a 4 años & 2 & 2 & 0 \\
\hline & 5 años y más & 6 & 0 & 1 \\
\hline
\end{tabular}

Fuente: Elaboración propia a partir de los cuestionarios aplicados

\subsubsection{Configuración de C21 Country.}

Mintzberg (1989), propone que la configuración de la organización permite "lograr coherencia en las características internas de la organización, para crear sinergismo entre sus procesos de trabajo y para establecer el acoplamiento con sus contextos externos, a fin de ser capaz de adaptarse a sí misma" (Mintzberg, 1989:119). Con esto, él propone siete formas diferentes de configuración ${ }^{28}$ a partir de algunos elementos que constituyen la estructura de la organización tales como los mecanismos de coordinación, la parte clave de la organización y el tipo de descentralización.

De manera preliminar, en la figura cuatro, se presenta el organigrama de C21 Country, el cual refleja parte de la configuración de la organización, y muestra su estructura vertical, el relacionamiento jerárquico y, su departamentalización,

28 Mintzberg propone siete tipos de configuraciones: Organización empresarial, organización maquinal, organización profesional, organización diversificada, organización innovadora, organización misionera, organización política (Mintzberg, 1989:127). 
además que da cuenta de las partes básicas que la constituyen ${ }^{29}$ (Minztberg, 1989). Posteriormente se plantean los otros elementos que permiten establecer bajo qué tipo de configuración se estructura C21 Country.

\section{Figura 4. Organigrama C21 Country}

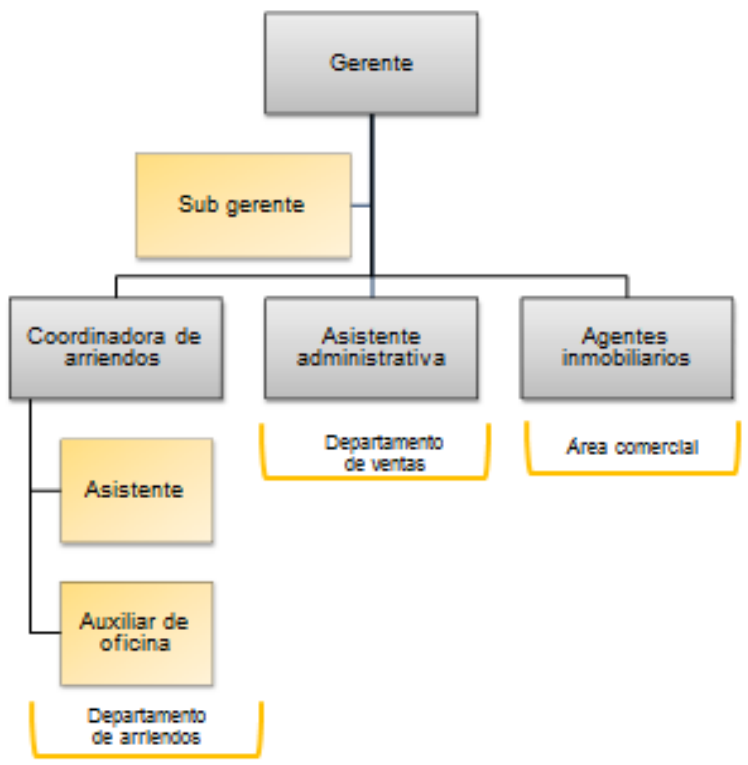

Fuente: Información documental C21 Country

Así, en la cúpula se encuentra la gerente de la oficina, quien funge como ápice estratégico de la organización; ella es quien toma las decisiones acerca del funcionamiento de la oficina tanto operativa, como administrativamente. Enseguida, hacia abajo, se ubica el sub gerente, quien constituye la línea media, "una jerarquía de autoridad entre el núcleo operativo y el ápice estratégico" (Minztberg, 1989:113); él se encarga de coordinar asuntos relacionados con el área comercial, y en caso de no estar la gerente, también asume funciones administrativas. Un nivel más abajo, y en la misma línea se encuentran los agentes inmobiliarios, la asistente administrativa y la coordinadora de arriendos; estas personas dependen directamente de la gerencia, y ocasionalmente de la subgerencia. Los agentes conforman el área comercial y constituyen el núcleo de operaciones de la organización, en tanto "realizan el trabajo básico de prestar los servicios" (Minztberg, 1989:113); a ellos les corresponde captar inmuebles para renta y venta, así como buscar clientes para dichos inmuebles; en general ellos se encargan de dinamizar todo el negocio inmobiliario de esta oficina.

${ }^{29}$ Mintzberg (1989) plantea que una organización tiene seis partes básicas: Ápice estratégico, Línea media, Núcleo de operaciones, Tecno estructura, Staff de apoyo e ideología. (Mintzberg, 1989:112) Para el caso de C21 Country se identificaron cinco de esas seis partes; no se identificó la tecno estructura, como consecuencia de su configuración empresarial que la define. 
La asistente administrativa, la coordinadora de arriendos, la asistente y la auxiliar de oficina constituyen el staff de apoyo de la organización en tanto sus funciones están orientadas a proporcionar las herramientas necesarias y a facilitar los procesos para que el núcleo de operaciones cumpla con su labor. Así, la asistente administrativa conforma el departamento de ventas; ella se encarga de facilitar a los agentes inmobiliarios lo que requieran al hacer una venta de un inmueble: elaboración de contratos, toma de seguros, entre otros trámites requeridos para tal proceso. La coordinadora de arriendos junto con la asistente y la auxiliar constituyen el departamento de arriendos; de igual manera que en el departamento de ventas, ellas se encargan de proporcionar el apoyo administrativo y operativo que requieran los agentes para la formalización de un negocio de renta y su funcionamiento: elaboración de contratos, pago de administraciones, seguimiento tanto al arrendador como al arrendatario, reparación de infraestructura en los inmuebles, entre otras labores. En el departamento de arriendos hay una jerarquía entre la coordinadora, la asistente y la auxiliar de oficina; aparentemente estas dos personas están subordinadas a la coordinadora del departamento.

Entre las diversas partes que conforman la organización, se identifican algunos mecanismos de coordinación, los cuales pueden considerarse como "los elementos más básicos de la estructura en tanto definen el modo de relacionamiento entre sus partes $\mathrm{y}$, el aglutinante que mantiene unida a la organización" (Minztberg, 1989:118). En C21 Country es posible identificar cuatro de los seis mecanismos de coordinación ${ }^{30}$ propuestos por Minztberg:

Tabla 5. Mecanismos de coordinación en C21 Country

\begin{tabular}{|c|c|c|c|c|}
\hline $\begin{array}{l}\text { Mecanismo de } \\
\text { coordinación }\end{array}$ & $\begin{array}{l}\text { Supervisión } \\
\text { directa }\end{array}$ & $\begin{array}{c}\text { Normalización de } \\
\text { habilidades }\end{array}$ & $\begin{array}{c}\text { Normalización de } \\
\text { procesos de } \\
\text { trabajo }\end{array}$ & $\begin{array}{c}\text { Normalización de } \\
\text { outpouts }\end{array}$ \\
\hline $\begin{array}{l}\text { Propuesta } \\
\text { Mintzberg }\end{array}$ & $\begin{array}{c}\text { Una persona emite } \\
\text { órdenes o } \\
\text { instrucciones a } \\
\text { otras varias cuyo } \\
\text { trabajo está } \\
\text { interrelacionado }\end{array}$ & $\begin{array}{l}\text { Los diferentes } \\
\text { trabajos se } \\
\text { coordinan en virtud } \\
\text { de la preparación } \\
\text { correspondiente } \\
\text { que han recibido } \\
\text { los trabajadores }\end{array}$ & $\begin{array}{c}\text { Alcanza la } \\
\text { coordinación } \\
\text { especificando los } \\
\text { procesos de } \\
\text { trabajo de las } \\
\text { personas que } \\
\text { desempeñan } \\
\text { tareas } \\
\text { interrelacionadas }\end{array}$ & $\begin{array}{l}\text { Logra la } \\
\text { coordinación } \\
\text { especificando los } \\
\text { resultados de } \\
\text { diferentes trabajos }\end{array}$ \\
\hline C21 Country & $\begin{array}{c}\text { Entre la gerencia y } \\
\text { el área } \\
\text { administrativa, y la } \\
\text { gerencia y el área } \\
\text { comercial }\end{array}$ & $\begin{array}{l}\text { Entre los agentes } \\
\text { comerciales }\end{array}$ & $\begin{array}{l}\text { Entre los agentes } \\
\text { comerciales y el } \\
\text { área administrativa }\end{array}$ & $\begin{array}{c}\text { Entre C21 Country, } \\
\text { C21 Colombia y } \\
\text { Century } 21{ }^{\circledR}\end{array}$ \\
\hline
\end{tabular}

Fuente: Elaboración propia a partir de Mintzberg (1989)

30 Mintzberg propone que los mecanismos de coordinación son formas como que las organizaciones pueden coordinar su trabajo: Adaptación mutua, supervisión directa, normalización de los procesos de trabajo, normalización de los outputs, normalización de las habilidades, normalización de las reglas. (Mintzberg, 1989:116). 
A partir de lo planteado hasta aquí, acerca de las partes de la organización y sus mecanismos de coordinación, es posible afirmar que C21 Country se encuentra estructurada y funciona a partir de diversos elementos que impiden encuadrarla dentro de un único tipo de configuración, de los siete definidos por Mintzberg (1989). De acuerdo con su estructura macro C21 Country responde a una organización con configuración diversificada ${ }^{31}$ pero, a partir de las características y preponderancia que tienen quienes conforman el núcleo de operaciones podría ser una organización profesional ${ }^{32}$. No obstante, dada la estructura, el proceso de toma de decisiones, las características de la líder, la conformación del equipo de trabajo, es posible definir a C21 Country como una organización con configuración empresarial, tal como se presenta en la tabla seis.

31 Mintzberg propone la organización diversificada como un conjunto de unidades semi autónomas -divisiones-, acopladas por una estructura administrativa central. "En esta estructura las divisiones tienen control de sus funciones operativas, y por tanto cada una está libre del control directo de la central, e incluso de la necesidad de coordinar las actividades con otras divisiones" (Mintzberg, 1989:181). Por su parte, la central establece los objetivos de las divisiones, vigila su rendimiento en función de esos objetivos -la coordinación entre la central y las divisiones se da mediante la normalización de los outpouts - , y mantiene contactos personales limitados con los directores de división. Podría decirse que C21 Country al hacer parte de una red multinacional de inmobiliarias se configura como una organización diversificada en tanto su relación con Casa Nacional se orienta hacia la definición de parámetros generales de funcionamiento (por ejemplo comisiones, uso de distintivos corporativos), de acuerdo con las directrices nacionales e internacionales y, al control que ejerce Casa Nacional sobre C21 Country, enfocado principalmente en el cumplimiento de objetivos - normalización de outpouts-, es decir la cantidad de negocios cerrados periódicamente. Más allá de estos elementos, C21 Country opera de manera autónoma respecto a Casa Nacional, sin tener un estrecho relacionamiento con ésta ni con otras franquicias de la marca, más que cuando se visualizan posibilidades de crecimiento para el negocio.

32 También es posible decir que C21 Country tiene una configuración como organización profesional en tanto su funcionamiento y desempeño depende en gran medida de las habilidades y conocimientos de su núcleo operativo, en este caso, los agentes inmobiliarios. Respecto a este tipo de configuración dice Mintzberg que "el núcleo de operaciones es la parte clave de la organización profesional. La única otra parte que está completamente elaborada es el staff de apoyo, pero está muy centrado en atender las actividades del núcleo de operaciones" (Mintzberg, 1989:208). Además de lo ya descrito a lo largo del documento acerca del funcionamiento de C21 Country, este planteamiento también es posible corroborarlo a partir de la entrevista realizada al Subgerente de la organización, quien dice que: "La base administrativa es la oficina, pero la empresa como tal la hace la parte comercial". Así, sin agentes comerciales C21 Country no podría funcionar, y es por esto, que las demás áreas que conforman la organización están en función de ellos. Otro asunto importante es que la organización profesional "depende de la normalización de habilidades para conseguir la coordinación, lo que se consigue fundamentalmente por medio de la preparación formal" (Mintzberg, 1989:204). En el caso de C21 Country esa normalización no es producto de la formación académica pero si, es resultado del conocimiento y experiencia que tienen los agentes inmobiliarios sobre este oficio. 
Tabla 6. C21 Country, una organización con configuración empresarial

\begin{tabular}{|c|c|c|}
\hline $\begin{array}{l}\text { ELEMENTOS DE } \\
\text { ANÁLISIS }\end{array}$ & PLANTEAMIENTO MINTZBERG & C21 COUNTRY \\
\hline El líder & $\begin{array}{l}\text { El líder de la organización es el } \\
\text { propietario }\end{array}$ & $\begin{array}{l}\text { El } 50 \% \text { de las acciones de } \mathrm{C} 21 \\
\text { Country son de la gerente, y el } 50 \% \\
\text { restante se distribuye de manera } \\
\text { equitativa entre sus dos hijos. }\end{array}$ \\
\hline $\begin{array}{l}\text { Características } \\
\text { del líder }\end{array}$ & $\begin{array}{l}\text { En esta forma empresarial es } \\
\text { absolutamente fundamental el } \\
\text { conocimiento íntimo y detallado del } \\
\text { negocio o de situaciones análogas por } \\
\text { parte del líder (Mintzberg, 1989:144). }\end{array}$ & $\begin{array}{l}\text { La gerente durante toda su vida } \\
\text { laboral se ha dedicado a la } \\
\text { comercialización de bienes raíces, } \\
\text { esto la enviste de un saber y le } \\
\text { confiere un posicionamiento respecto } \\
\text { a otras personas de la organización, } \\
\text { con relación al funcionamiento del } \\
\text { negocio. }\end{array}$ \\
\hline $\begin{array}{l}\text { Estructura de } \\
\text { la } \\
\text { organización }\end{array}$ & $\begin{array}{l}\text { La estructura de la organización } \\
\text { empresarial es simple y poco } \\
\text { elaborada; tiene poco staff, una ligera } \\
\text { división de la mano de obra y una } \\
\text { pequeña jerarquía directiva }\end{array}$ & $\begin{array}{l}\text { Existe staff que opera como área de } \\
\text { soporte para el núcleo de operaciones, } \\
\text { más que por finalidades burocráticas. } \\
\text { Hay una ligera línea media entre la } \\
\text { dirección de la organización y sus } \\
\text { áreas operativas. }\end{array}$ \\
\hline $\begin{array}{l}\text { Proceso de } \\
\text { toma de } \\
\text { decisiones }\end{array}$ & $\begin{array}{l}\text { Las decisiones relativas a la estrategia } \\
\text { y operaciones tienden a estar } \\
\text { centralizadas en el despacho del } \\
\text { director general. Esto da lugar a la } \\
\text { flexibilidad y a la adaptabilidad, dado } \\
\text { que sólo una persona tiene que actuar } \\
\text { (Mintzberg, 1989:149). }\end{array}$ & $\begin{array}{l}\text { La gerente es quien toma las } \\
\text { decisiones de la organización, } \\
\text { principalmente las estratégicas y las } \\
\text { operativas; ella define las estrategias } \\
\text { para dinamizar el negocio, la } \\
\text { vinculación de agentes comerciales, la } \\
\text { inversión en herramientas de trabajo, } \\
\text { el establecimiento de jornadas de } \\
\text { trabajo y por ejemplo, la otorgación de } \\
\text { permisos y facilidades de } \\
\text { flexibilización del tiempo. }\end{array}$ \\
\hline $\begin{array}{l}\text { Configuración } \\
\text { del equipo de } \\
\text { trabajo }\end{array}$ & $\begin{array}{l}\text { A menudo la estructura se edifica } \\
\text { alrededor de las necesidades } \\
\text { personales y la orientación del líder, y } \\
\text { la plantilla se ha llenado con personas } \\
\text { leales a él (Mintzberg, 1989:139). }\end{array}$ & $\begin{array}{l}\text { Una parte de las personas que } \\
\text { conforman el equipo de C21 Country, } \\
\text { tanto del área administrativa como } \\
\text { comercial, se han vinculado a la } \\
\text { organización más que por procesos } \\
\text { formales, por relaciones de cercanía, } \\
\text { familiaridad y amistad con la gerente. } \\
\text { Es decir, quienes conforman el equipo } \\
\text { de trabajo son familiares o amigos de } \\
\text { la gerente, otras personas fueron } \\
\text { referenciadas por conocidos, amigos o } \\
\text { familiares de ella, y una cantidad } \\
\text { reducida de trabajadores ingresaron a } \\
\text { la organización porque conocieron la } \\
\text { vacante a través de anuncios de } \\
\text { empleo y realizaron el proceso de } \\
\text { entrevista correspondiente. }\end{array}$ \\
\hline
\end{tabular}

Fuente: Elaboración propia a partir de Mintzberg (1989)

Así, lo planteado en las páginas precedentes deja ver en esencia a C21 Country, organización en la que se desarrolló la investigación, y cuyos resultados se presentan a continuación. 


\section{ESTUDIO DE CASO: DEFINICIÓN DE LAS JORNADAS LABORALES EN C21 COUNTRY A PARTIR DE LOS MÚLTIPLES ROLES ASUMIDOS POR SUS TRABAJADORES}

Con el propósito de indagar cómo se definen las jornadas laborales de los trabajadores de C21 Country a partir de los distintos roles que asumen en escenarios laborales y no laborales se realizaron entrevistas a 15 personas que hacen parte de dicha organización. Estas personas están caracterizadas a partir de variables previamente definidas para esta investigación; de la siguiente manera:

Tabla 7. Caracterización de la población objetivo a partir de las variables de análisis

\begin{tabular}{|c|c|c|c|c|c|c|}
\hline Personas & Género & Edad & $\begin{array}{c}\text { Estado } \\
\text { civil }\end{array}$ & Estado parental & $\begin{array}{c}\text { Edad de los } \\
\text { hijos }\end{array}$ & $\begin{array}{c}\text { Tipo de } \\
\text { vinculación }\end{array}$ \\
\hline Persona A & Femenino & Entre 41 y 50 & Divorciada & No tiene hijos & No aplica & Free lance \\
\hline Persona B & Femenino & Entre 51 y 60 & Casada & Entre 1 y 2 hijos & Independientes & Free lance \\
\hline Persona C & Femenino & Entre 31 y 40 & Unión libre & No tiene hijos & No aplica & Contratación \\
\hline Persona D & Femenino & Entre 21 y 30 & Unión libre & No tiene hijos & No aplica & Contratación \\
\hline Persona E & Femenino & Entre 51 y 60 & Casada & Entre 1 y 2 hijos & Dependientes & Free lance \\
\hline Persona F & Femenino & Entre 41 y 50 & Unión libre & Entre 1 y 2 hijos & Dependientes & Free lance \\
\hline Persona G & Femenino & Entre 51 y 60 & Divorciada & Entre 1 y 2 hijos & Independientes & Free lance \\
\hline Persona H & Femenino & Entre 31 y 40 & Casada & Entre 3 y 5 hijos & Dependientes & Free lance \\
\hline Persona I & Femenino & Entre 31 y 40 & Casada & Entre 3 y 5 hijos & Dependientes & Free lance \\
\hline Persona J & Femenino & Entre 51 y 60 & Divorciada & Entre 3 y 5 hijos & Independientes & Free lance \\
\hline Persona K & Femenino & Entre 51 y 60 & Casada & Entre 1 y 2 hijos & Independientes & Contratación \\
\hline Persona L & Masculino & Entre 31 y 40 & Casado & Entre 1 y 2 hijos & Dependientes & Propietario \\
\hline Persona M & Femenino & Entre 21 y 30 & Unión libre & Entre 1 y 2 hijos & Dependientes & Contratación \\
\hline Persona N & Femenino & Más de 60 & Casada & Entre 1 y 2 hijos & Independientes & Free lance \\
\hline Persona O & Masculino & Entre 41 y 50 & Casado & Entre 1 y 2 hijos & Dependientes & Free lance \\
\hline
\end{tabular}

Fuente: Elaboración propia

Estas variables facilitaron el análisis de la forma en que definen las jornadas laborales unos y otros, a partir de los distintos roles en los que se desenvuelven, identificando diferencias y similitudes, particularidades y generalidades respecto a las diversas situaciones y condiciones que inciden en ello. Así pues, las 15 personas entrevistadas tienen características diversas en términos de género, edad, estado civil, estado parental, la edad de sus hijos y el tipo de vinculación con la organización; esta heterogeneidad permitió tener un amplio panorama acerca de la incidencia de estas variables en la definición de las jornadas laborales y de la presencia de conflictos a partir de la multiplicidad que roles en la que se desenvuelven estas personas, en los escenarios de vida por los que transitan (laborales y no laborales). 
De modo que, este capítulo plantea la forma en que quienes hacen parte de C21 Country definen sus jornadas laborales a partir de los distintos roles en los que se desenvuelven, en escenarios laborales y no laborales. Para ello, en un primer apartado se hace un acercamiento a la definición de las jornadas laborales en C21 Country; se abordan los elementos que inciden en esta definición tanto desde la perspectiva de la organización como desde quienes conforman el equipo. En el segundo apartado se aborda otro elemento de análisis para conocer la forma en que se definen las jornadas laborales; esto es, los roles que asumen los trabajadores de la organización, tanto en la vida laboral como en la vida social y las situaciones positivas o negativas que de dicha multiplicidad se derivan. Enseguida, y a partir de lo planteado en las dos secciones anteriores se analizan las condiciones de flexibilidad y rigidez que caracterizan la jornada laboral de esta organización y el cumplimiento de las mismas, lo cual no es tan dúctil como pareciera, ni tan estricto como se pensaría, dado que está incidido de manera importante por los roles y las características particulares de los trabajadores de la organización. Finalmente, a partir de los elementos presentados hasta ahí, y a manera de conclusión, se realiza un breve análisis sobre cómo las personas de esta organización construyen su vida social - o en este caso familiar - y su vida laboral a partir de las jornadas laborales en las que se desenvuelven.

\subsection{DEFINICIÓN DE LAS JORNADAS LABORALES EN C21 COUNTRY}

C21 Country establece un horario de trabajo para las personas del área administrativa, quienes están vinculadas mediante contrato por prestación de servicios con la organización; este horario está definido en concordancia con las directrices de la OIT $^{33}$ acerca del tiempo laboral diario permitido. Por otra parte, los agentes inmobiliarios, al estar vinculados mediante free lance ${ }^{34}$ con la organización tienen la potestad de establecer sus horarios de trabajo a partir de sus necesidades, preferencias y los requerimientos del negocio, los cuales muchas veces coinciden con el horario estipulado por la organización.

No obstante, las jornadas laborales para quienes hacen parte de C21 Country no se limitan a dar cumplimiento a las directrices dadas por la OIT pues, en realidad están definidas por asuntos y aspectos de la vida de cada persona, relacionados con las variables ya planteadas de género, edad, estado civil, estado parental;

${ }^{33}$ Como se planteó en el marco conceptual, la OIT estipula en el convenio C030 de 1930 que en el sector comercial y de oficinas las horas de trabajo no podrán exceder las cuarenta y ocho horas por semana, distribuidas entre 8 y 10 horas de trabajo diarias.

34 De acuerdo con lo planteado en las entrevistas por la gerencia de la organización, así como por algunos agentes inmobiliarios, la vinculación bajo la modalidad free lance posibilita la flexibilidad de tiempo y espacio dado que las actividades como agentes las realizan de manera autónoma, siendo retribuidos no en función del tiempo empleado para realizar su labor -es decir que no hay obligatoriedad respecto al cumplimiento de horario o la asistencia a la oficina -, sino del resultado obtenido en su trabajo - los negocios realizados de renta y venta de inmuebles-. Así las cosas, con el free lance no se hablaría de una vinculación laboral en la que se establece una relación de subordinación desde la organización hacia los agentes inmobiliarios, sino que se haría referencia más a una relación comercial entre las partes. 
finalmente estas variables disponen condiciones para la definición de tiempos laborales, a partir de la prioridad que tenga para cada quien el trabajo, y de la etapa del ciclo de vida laboral en el que se ubiquen, de experiencias pasadas, y de la dinámica familiar en la que se desenvuelven. También la jornada laboral está definida a partir de características de la dinámica laboral relacionadas con las demandas del mercado, el tipo de vinculación con la organización, los requerimientos de los clientes, y el manejo de herramientas de comunicación como el celular y el computador. De esta forma, cada persona establece una manera diferente de trabajo, a partir de su criterio y el manejo que le da a cada uno de estos asuntos, tanto personales como laborales, incididos en gran medida por la construcción social que existe acerca de trabajar.

A continuación, en la figura cinco se presentan los elementos que tanto desde la organización, como desde la historia de vida de cada persona, se considera inciden en la definición de la jornada laboral para quienes hacen parte del equipo de trabajo de C21 Country; enseguida, se presenta una explicación sobre los mismos.

Figura 5. Elementos que inciden en la definición de la jornada laboral en C21 Country

Fuente: Elaboración propia

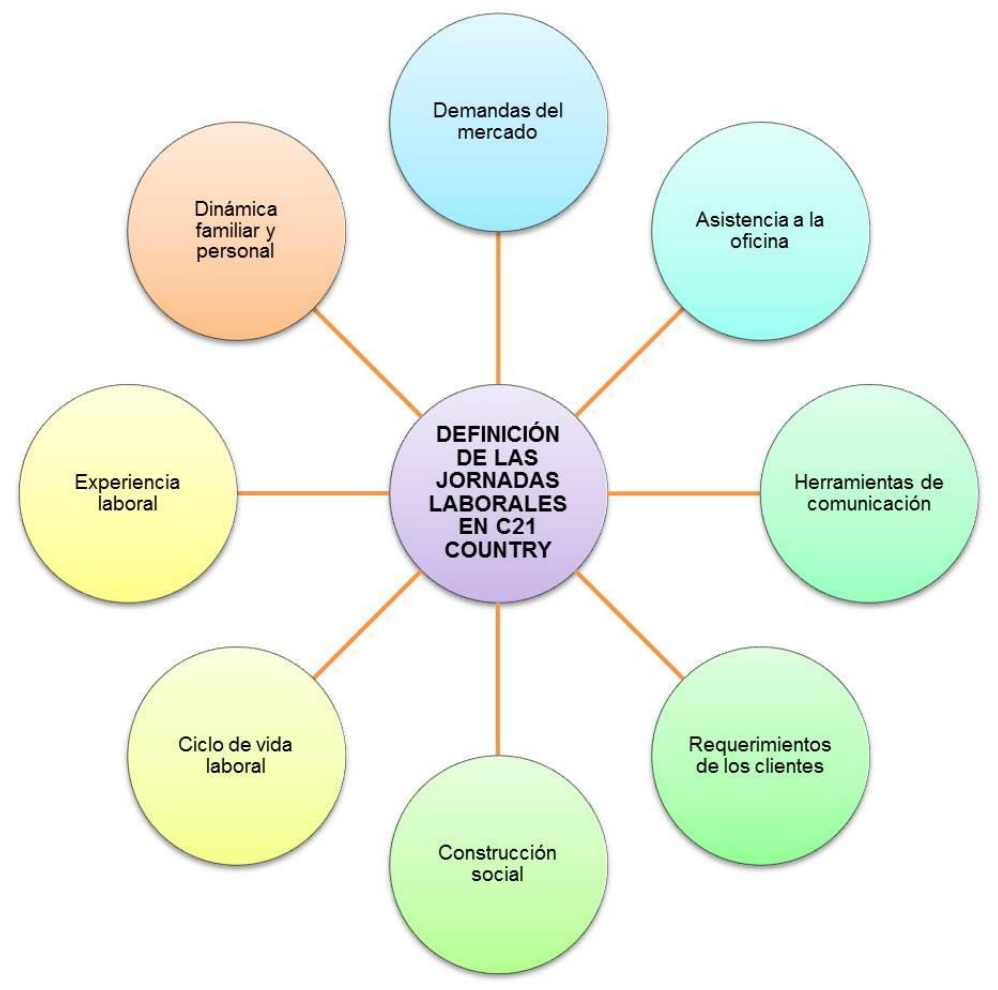

Antes de describir cada uno de estos elementos es pertinente mencionar que, algunas de estas cuestiones también inciden en que los horarios flexibles tienden hacia la rigidez en los tiempos de trabajo y que, el horario de trabajo rígido 
proporciona ciertas condiciones de flexibilidad, como se verá más adelante ${ }^{35}$. Es decir, lo que de manera anticipada se puede interpretar es que finalmente no hay una jornada laboral claramente definida ni para unos ni para otros, - sea flexible o establecida por la organización - sino que el resultado de la definición del tiempo de trabajo en esta organización resulta de cómo las personas consideren deben adecuarse para compatibilizar sus roles y sus responsabilidades familiares y laborales, desde la flexibilidad con la que cuentan algunos, y desde la rigidez aparente bajo la que se encuentran los otros. Este asunto se revisará en la parte final del capítulo.

\subsubsection{Elementos que inciden en la definición de las jornadas laborales desde la organización.}

Desde la organización se identifican algunos elementos que inciden en la definición de las jornadas laborales, relacionados no necesariamente con la legislación y los mandatos de la OIT, sino más bien con aspectos intrínsecos al negocio, y al discurso y postura de la gerencia de la organización que en algunos casos puede interpretarse como facilitadora, y en otros como controladora.

\subsubsection{La dinámica del mercado del sector inmobiliario}

La organización busca funcionar de acuerdo con la dinámica del mercado inmobiliario. A partir de lo planteado por la gerente es posible afirmar que, el establecimiento de los horarios de atención de la oficina son definidos, no sólo como respuesta a requerimientos de los clientes, sino a partir de lo establecido por otras organizaciones del sector.

"El horario de atención de nuestra oficina se ha dado según las normas establecidas por el Centro Comercial y además por el horario de atención de oficinas cercanas con servicios similares a los ofrecidos por C21 Country. Esto ha permitido prestar un servicio más competitivo y que nuestros clientes se sientan atendidos en una muy buena franja de tiempo".

De esta forma, con el propósito de ser una organización legítima respecto a su funcionamiento, C21 Country adopta prácticas miméticas respecto a los horarios de funcionamiento de la oficina, implementando lo establecido por otras organizaciones del sector inmobiliario en este sentido (Di Maggio y Powell, 1983). Esta similitud con las otras organizaciones, por lo menos en términos de tiempos de funcionamiento, le otorga legitimidad lo que en consecuencia le da más posibilidades de sobrevivir en el campo organizacional en el que se ubica, pues no habrá una condición de desventaja respecto a las otras oficinas inmobiliarias en este sentido, y en cambio, tendrá la posibilidad de incrementar sus negocios y sus resultados.

35 Esta información el lector la podrá encontrar en el apartado "La flexibilidad y la rigidez de la jornada laboral". 
Otros elementos que surgen por parte de la organización e inciden en la definición de las jornadas laborales, justificados en la dinámica del sector inmobiliario, están relacionados con el discurso manejado por la gerencia de la organización. Es pertinente recordar que las narrativas, discursos, historias e incluso políticas de la organización tienen de manera intrínseca una función controladora, con la que persuaden y le indican a los trabajadores lo que deben hacer y lo que no. "La narrativa es una pretensión presunta de verdad y corrección poderosamente persuasiva, que no suele estar sometida a la impugnación. Además de enmascarar las pretensiones de verdad persuasivas, la narrativa puede ayudar a crear una cultura de la obediencia en el lugar de trabajo al modelar los comportamientos deseados en situaciones específicas y las reglas para la aplicación de modelos" (Witten, 1997: 145).

De esta forma, temas como la asistencia a la oficina, los mandatos para la atención a los requerimientos de los clientes o el manejo de herramientas de comunicación, moldean el comportamiento, principalmente de los agentes inmobiliarios bajo la idea de que ello redundará en un mejor funcionamiento del negocio; esto podría interpretarse como una forma de control implícito que ejerce la organización desde su discurso hacia sus agentes, situación que a decir verdad no debería existir debido a la vinculación free lance que ellos tienen.

\subsubsection{La asistencia a la oficina como un mandato de la organización}

Dados los dos tipos de vinculación que existen en esta organización - vinculación laboral y vinculación free lance -, aparentemente las jornadas laborales se estructurarían de manera diferente pues, unos tendrían que asistir a la oficina permanentemente, cumpliendo el horario de trabajo establecido, mientras los otros, bajo su propio criterio definirían su dinámica de trabajo. No obstante, la organización insiste en el cumplimiento de unos tiempos y espacios de trabajo, indistintamente del tipo de vinculación, desdibujando la diferencia entre unos y otros. Así, en palabras de la gerente,

"Nuestro horario de funcionamiento debe ser cumplido a cabalidad por el personal administrativo, pues ofrecemos un servicio $y$ debemos estar dispuestos a entregarlo (...) Los agentes no tienen horario, ya que son free lance, pero aun así se les insinúa que mínimo deben venir tres veces por semana a la oficina, ya que de eso dependen sus resultados y comisiones".

Es decir, a pesar de que hay cierta diferenciación entre las jornadas de unos y otros, y que la organización es consciente de ello, al mismo tiempo procura que prácticas como la asistencia a la oficina se vuelvan un patrón común para garantizar que sí se está trabajando y que la organización cumple sus metas. Así, con la asistencia a la oficina la gerencia de la organización puede controlar la labor de quienes conforman su equipo y da pauta para estructurar una jornada laboral. Con esto posiblemente se relacione el hecho de que la gerencia de la organización promueva la realización de un comité comercial cada 15 días al que 
necesariamente deben asistir los agentes comerciales, y la obligatoriedad de "hacer planta" 36 en la oficina por parte de los agentes, tanto los días de semana, como los sábados.

Así, en C21 Country la asistencia a la oficina podría considerarse un práctica de control por parte de la organización, la cual es transmitida por ésta para estructurar una jornada laboral y así reforzar su legitimación, de modo tal que sea reconocida como una inmobiliaria que presta un buen servicio, lo que le provee reconocimiento, diferenciación y legitimidad. Entonces, indistintamente del tipo de vinculación que tienen quienes conforman el equipo, hay una insistencia por parte de la organización respecto a la necesidad de asistir a la oficina dado que eso significa para la gerencia la garantía de entregar el servicio ofrecido y obtener de ello las ganancias esperadas; de ahí que promueva la asistencia a la oficina como una necesidad, a pesar de que por ejemplo los agentes comerciales no estén en la obligación de hacerlo.

\subsubsection{Los requerimientos de los clientes}

Al ser una organización que ofrece servicios, su dinámica se define de manera importante en función de los clientes. Esto implica entonces que temas como los tiempos laborales sean definidos a partir de sus requerimientos a fin de poder dar respuesta oportunamente a las solicitudes por ellos hechas, siendo esto garantía de ofrecer un buen servicio y una estrategia de captación y retención de clientes. Es en este sentido que por ejemplo, como lo plantea la gerente, se consideró la necesidad de que la oficina funcionara los sábados contando con la presencia de agentes inmobiliarios en el lugar.

"Anteriormente los sábados no se abría la oficina, pero nos dimos cuenta que era ese día cuando la gente más llamaba y se inquietaba por resolver cuestiones del hogar; ese día lo dedican a buscar, a comprar, a programar citas; por tanto, al no funcionar la oficina los sábados se estaba perdiendo mucha clientela. A partir de eso se determinó que dos agentes deben asistir a la oficina los días sábados, cumpliendo un horario de 9:00 a.m. a 1:00 p.m. para la atención de clientes"

A pesar de que los agentes inmobiliarios no tienen la obligación de cumplir con el horario planteado por la organización, se adecúan a ese parámetro como una estrategia comercial de captación y retención de clientes pero, finalmente esta condición tiene una función de control del tiempo hacia los agentes, ocasionando que estos cumplan unos tiempos dispuestos por la organización. Además de esto,

\footnotetext{
36 La expresión "hacer planta" hace referencia a la obligatoriedad que tienen los agentes inmobiliarios de permanecer en la oficina los días sábados para atender a los clientes que allí acudan. Los horarios y los turnos de hacer planta los define la gerencia de la organización; cada sábado le corresponde a dos agentes asistir a la oficina, lo que implica que el mismo agente haga planta cada mes y medio.
} 
es pertinente resaltar que fue a causa del comportamiento y solicitudes de los clientes que se amplío el tiempo de funcionamiento de la oficina, y con ello se modificaron las jornadas laborales tanto de personas del área administrativa que deben prestar apoyo ese día, como los tiempos laborales de los agentes inmobiliarios a quienes les corresponda hacer planta, de acuerdo con orden definido por la gerencia.

Otro asunto que evidencia como los tiempos laborales se definen a partir de los requerimientos de los clientes es la vinculación free lance: esta condición bajo la cual trabajan los agentes inmobiliarios garantiza que siempre tengan disponibilidad para atender a los clientes, dado que no están regulados por ninguna normatividad acerca de límites de horas o días de trabajo, como sucedería con una vinculación laboral; en cambio, el hecho que sus ingresos dependan directamente de la cantidad de negocios cerrados genera que haya una completa disposición para concretar citas, atender llamadas o asistir a la oficina, sin restricciones aparentes.

\subsubsection{La asignación y uso de herramientas de comunicación}

Herramientas de trabajo proporcionadas por la organización, como el celular o el computador, son otro elemento que incide en la definición de las jornadas laborales, facilitando condiciones para que, a quienes les es asignado este tipo de instrumentos, tengan disponibilidad permanente para atender asuntos laborales. Así lo plantea la gerente,

"Nosotros les dimos a los agentes un celular para estar las 24 horas del día conectados con el negocio; hoy en día ésta es la herramienta de comunicación más importante, y por tanto, será éste el medio por el que los contacten los clientes".

Por tanto, el uso de herramientas de comunicación, principalmente el celular, establece una jornada laboral que trasgrede los parámetros definidos por la OIT, e incluso puede desdibujar los límites entre lo laboral y lo no laboral, planteando una jornada laboral permanente. Así lo propone la persona "B" quien reconoce la importancia de la tecnología para el éxito del negocio, pero simultáneamente identifica un problema intrínseco a su uso,

"La tecnología facilita el movimiento de mi negocio, pero a su vez, interfiere en la dinámica de mi vida y de mi familia"

Por tanto, ella establece el uso de la tecnología como herramienta esencial para el desarrollo del negocio, pero al mismo tiempo la identifica como un elemento que puede interferir en dinámicas no laborales. Es decir, debido a los beneficios en términos de eficiencia y adaptabilidad que proporciona el uso de herramientas tecnológicas, considera necesario su uso para la atención de asuntos laborales, pero a su vez es frecuente que ello interfiera en la dinámica de escenarios no laborales pues, al tener la posibilidad de recibir correos electrónicos, chats o llamadas en cualquier momento, es posible que sea no necesariamente en los 
tiempos y espacios definidos por los agentes para la ejecución de su trabajo, sino que también podrá suceder en una reunión social, en un evento familiar, o durante el tiempo que dedican a hacer ejercicio, por ejemplo.

Esto sucede principalmente con los agentes inmobiliarios, a quienes la organización les asignó un equipo celular corporativo para que a todo tiempo estén conectados con el negocio, sus clientes y las solicitudes que emerjan; es pertinente resaltar que los gastos asociados a consumo de planes de voz y datos en estos equipos es asumido por la organización. De esta situación es posible plantear algunas cuestiones preliminares:

- La primera puede leerse desde el control que la inmobiliaria quiere ejercer sobre el negocio en general y sobre sus agentes comerciales en particular pues, al proporcionarles esta herramienta de trabajo tienen cierto nivel de seguridad para que el negocio sea dinámico; en palabras cotidianas podría decirse que de esta forma los agentes "no tendrán excusas" para desatender su responsabilidad.

- Otra cuestión puede ser la relación de dependencia que la inmobiliaria busca establecer entre sus agentes y ella pues, a pesar de no existir un vínculo laboral legal, pueden establecerse estos elementos como mecanismos de influencia constitutivos de un equipo de trabajo y de un sentido de identidad y pertenencia.

- Finalmente, podría pensarse también en una actitud paternalista por parte de la organización, bajo la idea de que estas herramientas de trabajo son imprescindibles para la dinamización del negocio, pero debido a la volatilidad del mercado, y por consiguiente de la realización de negocios, los ingresos de los agentes no son estables por lo que posiblemente no todos cuentan con la posibilidad de sostener este tipo de gastos e inversiones.

En todo caso, a través de herramientas como el celular, la organización define tiempos laborales, a pesar de que no tenga la potestad de hacerlo, por lo menos no en lo que refiere a los agentes inmobiliarios, y podría pensarse que esto opera como un sistema de control por parte de la organización. Sin embargo, será en cierta medida el criterio que tenga cada agente acerca del uso de la tecnología lo que determinará sus tiempos laborales. Como se verá a continuación cada agente a partir de: su dinámica familiar, su experiencia laboral, la dependencia económica que tenga de este trabajo, su dinámica de vida en otros escenarios, la priorización que sobre estos tenga el ámbito laboral,e incluso, con la forma como es asumido este trabajo, decidirá el uso que le da a las herramientas de comunicación para resolver cuestiones laborales y definir hasta donde lo que en principio no podría sobrepasar las diez horas diarias, ocupa 12, 16 ó 24 horas.

\subsection{El celular como herramienta de trabajo de uso ilimitado}

A partir de la preponderancia que tiene el uso del celular para facilitar el establecimiento de relaciones comerciales, movilizar negocios, y en últimas para la 
legitimación de la organización, hay agentes inmobiliarios que hacen uso de éste de manera ilimitada, sin establecer condiciones ni tiempos de uso, y por tanto, ubicándose en el escenario laboral permanentemente, ya sea de manera exclusiva o alternándolo con otros escenarios de desenvolvimiento.

La persona "N" manifiesta tener una amplia disponibilidad para atender el celular; dice que contesta el celular de manera indistinta, sin tener restricción de horarios o de días, dado que considera que siempre es importante contestar a los clientes, pues cada llamada puede ser una opción para iniciar un negocio.

"Yo contesto el celular inclusive sábados y domingos y en mis horas libres no tengo problema en contestar el celular del trabajo. Es que esto es importante porque los clientes pueden ver la información por los portales inmobiliarios y llaman inmediatamente. Entonces si uno no contesta cuando suena ese celular, es posible que después se pierda el cliente. Cuando suena ese celular es porque es alguien interesado".

La persona "J" tampoco tiene límites para atender el celular en términos de horarios; es decir, no lo hace de acuerdo con los tiempos de una jornada laboral habitual, sino que tiene disponibilidad los siete días de la semana, en un horario aproximado de 16 horas, iniciando cerca de las 7:00 a.m. y finalizando cuando ella se vaya a descansar, habitualmente hacia las 11:00 p.m. Sin embargo, esta disponibilidad permanente, le genera ciertos conflictos,

"El celular es el mejor aliado que yo tengo para hacer negocios. El celular es como mi oficina, pero por eso mi jornada de trabajo es tan variable y a veces tan extensa y extenuante"

La persona " $E$ " igualmente manifiesta tener una disponibilidad permanente para atender el celular, indistintamente de la hora o el lugar en el que se encuentre. Considera de hecho que se establece hasta cierta dependencia con el celular, debido a que difícilmente puede dejarse de lado, sabiendo que en cualquier momento un cliente puede llamar para un buen negocio. En palabras de ella,

"Se vuelve uno como esclavo del tema del celular. No es fácil como en otro tipo de trabajos, acá uno no puede desconectarse del todo. Yo por ejemplo ando con el celular para arriba y para abajo. Entonces si estoy jardineando en mi casa tengo el celular siempre cerca de mí, para poder atender las llamadas que entren, y si estoy de vacaciones y estoy en la piscina, también".

De esta forma, se pone en evidencia que el uso y atención del celular como herramienta de trabajo implica que espacios no laborales sean utilizados para atender temas laborales. Pero además, considera que una condición propia de este tipo de trabajo, es estar atentos permanentemente a nuevas posibilidades de negocio; es decir, el estar atentos al celular le dará más posibilidades como 
agente de tener nuevos clientes, captar nuevos inmuebles o establecer nuevos contactos, para el desarrollo de negocios. Inclusive en lo planteado por ella en la entrevista decía que la atención al celular estaba relacionada también con un tema de responsabilidad de los agentes en cumplimiento del compromiso establecido con la inmobiliaria al aceptar ser agentes inmobiliarios pues, ello llevaba consigo brindar una excelente atención a los clientes con los que ya contaban y, a clientes potenciales.

Por lo anterior, es pertinente plantear que la asignación de celular por parte de la organización y el uso que los agentes inmobiliarios le dan al mismo, tiene relación con la idea de ofrecer a los clientes un mejor servicio mediante la atención personalizada que le proporciona cada agente, y la facilidad que igualmente los clientes tendrían para contactarlos, lo que a la final redunda en la posibilidad de hacer negocios; es decir, esto en parte estaría vinculado con la imagen de la empresa, y su posicionamiento como una empresa multinacional líder en el sector. Es así que, el uso del celular puede ser un mito racionalizado (Meyer y Rowan, 1977) para el negocio inmobiliario, que le da legitimidad a la organización. Hacer uso del celular en áreas de ventas es acorde con las funciones organizacionales socialmente definidas para hacer negocios, y por tanto, el uso del celular como herramienta de trabajo de los agentes inmobiliarios se convierte en un mito que vincula a la organización en tanto se convierte en medio para lograr los fines organizacionales (Meyer y Rowan, 1977: 344); independientemente de su posible eficacia, la asignación y uso del celular hace ver a Century 21 Country como una organización competente y con ello, adecuada, racional y moderna.

Ahora ,a partir de las características de las personas que hacen uso ilimitado del celular no es posible identificar una constante a partir de la cual se pueda relacionar esta acción con alguna de las variables revisadas en esta investigación; por tanto, no es posible plantear generalizaciones al respecto.

\subsection{Restricciones para el uso del celular}

A pesar que de manera generalizada los agentes inmobiliarios consideran que el celular es una importante herramienta de trabajo hay personas que establecen límites para el uso del mismo, incididos principalmente por presiones sociales, o por parámetros de comportamiento definidos en los otros escenarios en los que se desenvuelven. Así pues, para estos agentes la familia es quien de cierta manera ejerce control y establece restricciones para el uso del celular corporativo. La persona "B" por ejemplo plantea que no tiene un horario establecido para contestar llamadas, pero suele hacerlo entre las 7:00 a.m. y las 9:00 p.m. Inicialmente lo contestaba todo el tiempo, pero poco a poco fue restringiendo su uso sobre todo en el momento del desayuno, el almuerzo o la cena, cuando estaba compartiendo con su familia.

"Que el celular timbre y timbre es molesto para mí, por eso yo lo contestaba pero, ahí se generaba choque con mi familia, porque no era yo quien le decía a mis hijos no chateen o no contesten, sino 
ellos eran quienes me decían deja, comamos y luego devuelves la llamada".

A partir de esto, y con el propósito de no generar conflictos en su familia a causa del trabajo, restringió el uso del celular en esos momentos y, después de finalizarlos devolvía las llamadas que había recibido durante la comida. Es decir, a pesar de que el celular podría operar como un medio a partir del cual se diriman los conflictos de rol, en el caso de esta persona el uso de la tecnología para atender asuntos laborales puede ser una causante de este tipo de conflictos, en tanto no diferencia uno y otro espacio.

La persona "G" se ubica en una posición muy similar; ella tiene definidos unos tiempos para atender llamadas, pero no siempre los cumple de manera rigurosa: su idea es atender el celular desde las 8:00 a.m. hasta máximo las 7:30 p.m. u 8:00 p.m. pero también puede hacerlo por fuera de esos horarios, cuando se trata de clientes conocidos con quien ya ha realizado negocios. Aunque, ella considera que tener esa disponibilidad tan amplía para atender el celular es una práctica que debe modificar para poder disfrutar tranquilamente de espacios con su familia, y para que no se vayan a generar inconvenientes por ello. Ella dice,

"Hago uso del celular a toda hora y sé que eso lo debo modificar. Bueno ya he empezado, al menos en la hora del almuerzo ya no contesto, porque mi hija así me lo solicitó. No contesto a menos que esté esperando una llamada".

Aquí nuevamente se presenta la idea de que es la familia, en este caso la hija, quien regula el uso del celular y en últimas, quien demanda la diferenciación de los espacios laborales y los familiares. Es decir, podría suponerse que si ninguna de las dos personas referenciadas hubieran recibido ese tipo de demandas por parte de su familia respecto al uso del celular, lo seguirían utilizando de manera permanente, sin establecer límites diferentes a los tiempos de descanso requeridos en las noches.

La persona "F" plantea que a pesar de no tener establecido un horario para atender llamadas, normalmente lo hace a partir de las 7:00 a.m. y hasta las 9:00 p.m. En caso de recibir llamadas más tarde, las atiende pero únicamente para recoger datos, y al día siguiente devuelve la llamada para proporcionar la información requerida por el cliente. Considera ella que ésta es su estrategia para que el trabajo no trasgreda sus espacios de descanso, y al mismo tiempo, no pierda oportunidades de negocio. Otro asunto interesante para resaltar es, la disponibilidad que también tiene esta agente para atender el celular los domingos pues, debido a que tiene definido ese día no mostrar inmuebles, considera que contestando el celular no desatiende el negocio, pues le puede proporcionar la información requerida a quien llama, y esa persona puede ser un cliente potencial.

Ahora, contrario a lo presentado en los casos anteriores, en los que la familia pone los límites para el uso del celular, la persona "F" considera que éste es una 
herramienta muy útil que además de hacer los negocios le facilita la conciliación de tiempos entre el trabajo y la familia pues más que generarle impedimentos le facilita poder estar con su hijo y al mismo tiempo atender asuntos del trabajo, cosa que no le permitiría hacer un trabajo con horario rígido.

"El uso del celular me da muchos beneficios porque como mi prioridad además de mi trabajo es mi hijo, entonces puedo estar con él y al mismo tiempo atender el celular para resolver cosas del trabajo; ventaja que no me daría por ejemplo un horario rígido de trabajo de 8 am a 8 pm".

Así pues con esto último, más que generar interferencias, el celular es visto como una herramienta de trabajo que da posibilidades de conciliar escenarios laborales y no laborales pues, puede atender ambas cosas a la vez. Entonces, desde esta perspectiva, el celular es asumido como una herramienta que propicia que la multiplicidad de roles no genere conflicto; el uso del celular le permite armonizar roles que aparentemente podrían entrar en conflicto o podrían generar una sobre - carga de rol pues, sin tener que cambiar drásticamente su rol como mamá, puede asumir momentáneamente su rol como trabajadora; de esta forma, el celular le permite manejar de una manera armónica esa multiplicidad de roles.

De lo anterior podría deducirse que el hecho de hacer uso ilimitado del celular como herramienta de trabajo no es necesariamente un mandato de la organización, ni de la dinámica del negocio tampoco, pues el hecho de postergar su atención durante esos momentos de socialización puede suponerse no implicó la pérdida de negocios; por el contrario, esto pudo posiblemente reflejarse en una mejor convivencia en su familia, o participar en otras actividades. Por tanto, de manera preliminar es posible afirmar que el celular incide en los espacios no laborales de los agentes en la medida y de la manera que ellos lo permitan pues, establecer ciertos parámetros no necesariamente implicaría desatender el trabajo, pero posiblemente si puede contribuir a diferenciar la esfera laboral de la no laboral, que como se ha visto es frecuentemente trasgredida por la naturaleza flexible de este trabajo.

Ahora, a diferencia del grupo anterior acá si es posible identificar algunas cuestiones respecto a las variables que orientan la investigación. Las tres personas que hacen referencia al establecimiento de límites respecto al uso del celular tienen un núcleo familiar constituido: ejercen el rol de madre y en dos de los tres casos, también el de esposa. Sin embargo, la diferencia que se presenta respecto a la razón del establecimiento de límites está relacionada con la edad de los hijos: para quien el celular opera de manera positiva, en tanto le permite armonizar roles y escenario, su hijo está en una edad dependiente, es decir requiere de una acompañamiento permanente. Por su parte, las otras dos personas tiene hijos en edades independientes; de ello puede suponerse que, a pesar de no requerir siempre de la presencia materna, si es así en momentos puntuales como los de compartir en familia. 


\subsection{El celular en la definición de los tiempos laborales y no laborales}

Con base en lo planteado hasta acá es posible afirmar que hay una percepción generalizada en los agentes acerca del celular, coincidiendo en que es la principal herramienta de trabajo ya que es el medio por el cual los clientes los contactan. Para muchos el hecho de no estar atentos al celular de manera permanente implica posibilidades de perder clientes potenciales para negocios. Por cierto, la expresión "el celular es mi oficina" fue reiterada por gran parte de los agentes; esto puede generar reflexión al ponerse en relación con la rutinización que posiblemente hay detrás de la asistencia a la oficina como práctica necesaria para la realización de negocios. Es decir, si el celular es considerado como la oficina por algunos, dado que a través de ese medio se mueve gran parte de los negocios, efectivamente la asistencia a la oficina de manera diaria y permanente se haría innecesaria. Sin embargo, esto será analizado con detalle en un apartado posterior.

Es importante plantear sin embargo que esta actitud de disponibilidad permanente para la atención del celular es más prevalente para unos que para otros, pues así como hay quienes deciden no tener restricciones en el uso del celular, hay otros que si lo hacen, porque hay presión desde su entorno familiar para hacerlo, o porque a ellos les incomoda la interrupción de temas laborales en escenarios no laborales; es decir, es una decisión personal. No obstante, el primer caso se presenta en agentes comerciales, y el segundo en personas del área administrativa; esto abre una reflexión acerca de la significación que tiene el celular y su atención para unos y para otros, y la diferenciación en el comportamiento respecto a esto. Es decir, para los agentes estar atentos al celular representa posibilidades de hacer negocios y eso redundaría en recibir ingresos, por el contrario para las personas del área administrativa, atender el celular es parte de las funciones que cumplen dentro del horario de trabajo establecido, por tanto no representa ningún tipo de alteración respecto a la definición de tiempos laborales y no laborales.

De esta forma, es posible afirmar que sí hay una relación entre el uso de las nuevas tecnologías y la definición de tiempos y espacios laborales, de acuerdo con el tipo de trabajo realizado en la organización. Se puede pensar que quienes son dependientes del negocio inmobiliario, es decir, los agentes comerciales, por lo general tienen gran apertura al uso de la tecnología, en particular a la atención del celular porque consideran que ese es el principal canal por el que se movilizan los negocios. Sin embargo, en algunos casos se establecen límites en función de las rutinas y comportamientos normados en la familia, o de la prioridad que cada quién le otorga al trabajo respecto al otro escenario en el que se esté desenvolviendo, que por lo general es el familiar o en algunos casos el social. Por el contrario, quienes tienen una remuneración fija y un horario de trabajo establecido, y no dependen económicamente de los negocios, es decir, las personas del área administrativa, no se enfrentan a este dilema. 
Otro tema a resaltar referente al uso del celular como herramienta de trabajo es que puede ser que debido a éste se generen conflictos de rol, sobre carga de rol o acumulación de roles bajo la idea de la multiplicidad de roles en la que las personas que conforman la organización se desenvuelven. De acuerdo con lo planteado en este apartado, para la mayoría de trabajadores, o por lo menos para quienes establecen ciertos límites para el uso del celular, se pueden presentar conflictos de rol pues, al estar desenvolviéndose en su rol como padre o madre pueden verse interrumpidos por su rol como trabajador al atender las llamadas de celular, lo que posiblemente le genere un conflicto debido a la prioridad que le debe dar a cada uno de los roles en ese momento; por tanto, el establecer esos límites o parámetros de comportamiento funciona como un mecanismo para disuadir el conflicto que se pudiera presentar. Contrario a esto hubo un caso de una agente quien considera que el celular es un elemento de armonización de roles, que le permite asumir su rol de mamá y al mismo tiempo su rol como trabajadora; sin embargo como ya se planteó, posiblemente esto es consecuencia de la edad de su hijo.

En conclusión, el uso de herramientas como el celular tiene una implicación importante en la definición de la jornada laboral desde la organización, al ser ésta quien las proporciona para garantizar servicio permanente al cliente, y con ello, el buen funcionamiento del negocio; sin embargo, es también la postura de las personas que conforman el equipo de trabajo respecto al uso de este tipo de herramientas, un elemento que incide en la definición de las jornadas laborales pues, a partir de su criterio determinará el tiempo y el espacio óptimo para atenderlas.

\subsubsection{Elementos que inciden en la definición de las jornadas laborales desde quienes conforman el equipo de trabajo.}

De la misma manera que desde la organización se identifican algunos elementos que inciden en la definición de las jornadas laborales, a partir de quienes deben cumplirlas, es decir los trabajadores, también es posible reconocer factores que intervienen en ello; algunos de estos han sido planteados a los largo del documento, sin embargo, se hará precisión en ciertas cuestiones relacionadas con construcciones sociales y personales que contribuyen a la definición de las jornadas de trabajo desde quienes conforman el equipo de trabajo, principalmente los agentes inmobiliarios pues, en definitiva, las personas del área administrativa se adecuan a los horarios dispuestos por la organización, a excepción de cuando se presentan asuntos personales que deben ser atendidos, siendo ésta la lógica para modificar la jornada laboral y adecuar a ella su dinámica de vida y de trabajo. Estos son los elementos que intervienen en la definición de las jornadas laborales desde quienes conforman el equipo de trabajo:

\subsubsection{La construcción social de las jornadas laborales}

Tradicionalmente trabajar se ha relacionado con el asistir a un lugar específico a desempeñar la función asignada, dentro de un parámetro de tiempo determinado. Pero, con la transición del mundo moderno a la posmodernidad estas condiciones 
ya no son las únicas; de hecho, como lo plantea Reygadas (2011), los nuevos tiempos proponen unas dinámicas diferentes de trabajo, más allá del cumplimiento de tiempos y espacios, denominados por él trabajo atípicos. De cierta manera, la vinculación free lance de los agentes inmobiliarios de C21 Country se caracteriza como una de esas nuevas formas de trabajo.

No obstante, socialmente persiste la idea de trabajar bajo una dinámica convencional - o por lo menos así fue percibido en una parte importante de las personas entrevistadas -, y de alguna forma esto hace que en ocasiones haya resistencia a adecuarse a las nuevas formas de trabajo. Es decir, socialmente se ha construido una imagen del trabajo, guiada por las formas convencionales en términos de tiempo y espacio, y esto genera que a pesar de que haya posibilidad de cambio, las personas tiendan a volver a lo que ya conocen, a lo que están acostumbrados y a lo que saben que es aceptado y reconocido. De ahí que sea posible pensar la jornada laboral como una institución.

Es así que por una parte, quienes en C21 Country trabajan bajo los parámetros convencionales en su mayoría no conciben el desarrollo de su labor fuera del lugar de trabajo; hubo quienes en cambio sí plantearon ideas respecto a no cumplir horarios, y en cambio trabajar por objetivos. Por otra parte, algunos de los agentes inmobiliarios, quienes tienen la libertad de definir espacios y tiempos laborales, consideran que es necesario establecer un horario de trabajo, en ocasiones con las mismas características que las dadas por la organización, e incluso, para sentir que trabajan, asisten a la oficina todo el día. La persona "O" justifica este comportamiento bajo la idea de ser "vieja guardia",

"Yo soy de vieja guarda y entonces yo creo que uno debe estar en la oficina, en el sitio de trabajo atento a lo que pueda suceder. Uno contesta el teléfono y uno no sabe si es la llamada millonaria".

Esto quizás refleja la idea de lo habituados y rutinizados que se encuentran los individuos, que aún a pesar de tener la facilidad de decidir sobre la forma de trabajo, hay mayor inclinación por el cumplimiento de la rutina pues estas "reducen en gran medida la discreción de la mayoría de los participantes de forma que estos hacen menos elecciones y están más restringidos dentro de las elecciones que hacen" (Scott, 2012:169). De esta forma, temas como la asistencia a la oficina o el cumplimiento de un horario se convierten para algunos en una práctica diaria, con el propósito de sentir que "trabajaron", sin darse la posibilidad de hacerlo de otra manera, dadas las facilidades que para ello establece el free lance. Por tanto, podría afirmarse que los agentes inmobiliarios están institucionalizados no necesariamente por la organización sino por los procesos de socialización, de ahí la rigidez por parte de algunos con relación al cumplimento de horarios establecidos por ellos mismos, y también respecto a la asistencia a la oficina, forjando con esto su jornada laboral.

Podría decirse entonces que el cumplimento de la jornada laboral es una institución, en tanto revela un proceso de reproducción particular (Jepperson, 2001), a pesar de que se establezcan y propicien otras formas para hacerlo, y 
además porque pueden ser entendidas - las jornadas - como reglas normativas que guían la acción dentro de la vida social a través de los valores y las normas que los conforman (Scott, 1995:37); es decir, se deben establecer jornadas laborales para dar significado a la acción de trabajar, tanto desde las perspectiva de la organización como la de los agentes inmobiliarios.

\subsubsection{La etapa del ciclo de vida laboral en la que se ubican}

La organización está conformada por personas que se ubican en diferentes etapas laborales: para algunos ésta es su primera experiencia laboral, hay quienes consideran que éste será su último empleo antes de jubilarse, para otros no es el primer ni último empleo que tendrán, y para otros, la vinculación con la organización representa la posibilidad de seguir trabajando después de haber sido jubilados. Esa diversidad de posiciones respecto al trabajo, y con ello la percepción que cada uno tiene sobre el mismo, incide en el significado que éste tiene, la prioridad que le dan frente a otros escenarios, y como consecuencia, las formas de organizarlo y desarrollarlo.

Así, para quienes el trabajo tiene un papel central dado que se encuentran en una etapa laboralmente activa, las jornadas de trabajo son definidas de una manera más estricta en comparación con quienes ya están jubilados, o próximamente lo estarán. Lo que se pudo evidenciar a partir de los comentarios de la persona "O" por ejemplo, es que el trabajo es una de sus actividades centrales, y por eso establece un horario que ocupa gran parte de su día,

"Trato de armar un horario lo más normal posible: arrancar tipo 7:30 am - 8 am y estar terminando entre 6:00 y 7:00 p.m. Eso es lo que yo prefiero, para tener organizado mi trabajo".

De esta forma, lo que en principio es para él una jornada laboral flexible, se convierte en un horario de trabajo "convencional", como medida de organización de trabajo, y podría pensarse que como estrategia de negocio, para hacer captación de clientes e inmuebles, y con ello tener mayores posibilidades de recibir ingresos.

Ahora, las personas "G" y "N", son jubiladas, y tienen la facultad de definir sus jornadas laborales bajo un parámetro de flexibilidad más claro, a diferencia de sus otros compañeros pues finalmente, este trabajo no es ni la única ni la principal fuente de ingresos con la que cuentan, y lo desarrollan más como una oportunidad para sentirse activas laboralmente, lo que les da la posibilidad de no concentrarse únicamente en temas de la inmobiliaria, e inclusive, de darse el permiso de no trabajar cuando así lo deseen. Así lo plantea la persona "G",

"A pesar de que tengo horarios de trabajo "establecidos" no soy demasiado estricta con su cumplimiento. Pues, así como puedo atender a un cliente que no tiene más tiempo para una cita que 
después de las 6:00 p.m., el día que no quiero trabajar pues también me puedo dar la posibilidad de no hacerlo.

Entonces, quienes están finalizando su ciclo de vida laboral definen las jornadas laborales bajo un criterio de flexibilidad mayor, de forma que les dé la posibilidad de desarrollar otras labores de manera paralela, y su vinculación a la inmobiliaria sea solo la oportunidad de contar con un espacio de actividad, relacionamiento y percepción de ingresos adicionales. Por el contrario, quienes aún son activos laboralmente le otorgan un papel central al trabajo, posiblemente como parte de los procesos de institucionalización y las construcciones a las que ya se hizo referencia, ocasionando que las jornadas laborales, a pesar de poder ser flexibles, tengan una tendencia hacia los parámetros convencionales de funcionamiento; además, el ser laboralmente activos y constantes en el desarrollo de su labor redundará en los ingresos que reciban como comisiones de los negocios que realicen.

Por tanto, en conjunción con la etapa del ciclo laboral en el que se encuentre cada persona, la centralidad que tengan los ingresos resultantes de éste trabajo para cada quien será otro factor incidente en la definición de las jornadas laborales. Así, para quienes es su única fuente de ingresos dedicarán gran parte de su tiempo diario a temas laborales, definiendo unas jornadas laborales extensas y menos flexibles. Por el contrario, quienes reciben ingresos adicionales, como la jubilación, y no dependen únicamente de los negocios realizados en la inmobiliaria, toman ésta actividad como algo complementario, por lo que las jornadas laborales por ellos definidas funcionan, no a partir de la necesidad de estar permanentemente trabajando, sino dando cabida al desarrollo de otras actividades.

\subsubsection{Experiencias laborales anteriores}

Las experiencias que han tenido quienes conforman el equipo en trabajos anteriores son otro elemento incidente en la definición de las jornadas laborales, ya sea para modificar parámetros de comportamiento, y buscar trabajar bajo nuevas modalidades, o para seguir operando bajo la misma lógica.

Así, hubo personas en la organización para quienes las experiencias laborales anteriores fueron la causa de buscar nuevas alternativas de trabajo, en las que tuvieran la posibilidad de dejar de cumplir un horario, y en cambio, pudieran autónomamente definir sus tiempos laborales. A partir de las entrevistas realizadas fue posible conocer casos de algunas personas para quienes el cumplimiento de las jornadas de trabajo, en ocasiones excesivas, y los conflictos trabajo - familia que de allí se desencadenaron, fueron los causantes de que tomaran la decisión de buscar un trabajo con las particularidades y características de flexibilidad ofrecidas por C21 Country. Desde este punto de vista, éste trabajo es percibido como una oportunidad diferente en tanto tienen autonomía sobre sus tiempos y dinámica laboral; pueden seguir trabajando y recibiendo ingresos, sin 
dedicar todo su tiempo y energía al trabajo, sino también teniendo la posibilidad de armonizar este escenario con otros de su vida personal y familiar.

Uno de estos casos es el de la persona "I", una ingeniera civil quien durante su experiencia laboral ha estado cumpliendo largas jornadas de trabajo; su último empleo, antes de ingresar a C21 Country, le demandaba trabajar todos los días, de domingo a domingo, lo que la obligó a alejarse considerablemente de su esfera familiar y social; en este trabajo duró año y medio, pero llegó un punto en el que sentía que debía dar un giro a su vida:

"Yo, decía, tengo que buscar algo aquí en Chía de Lunes a Viernes, por mis hijas y por el tiempo para mí y para mi familia; porque pasaba con frecuencia que hacían un paseo, o alguna reunión familiar y yo no podía. Me estaba aislando de mi familia".

De esta manera, ella encuentra atractiva la propuesta de C21 Country pues, considera que le da cierta estabilidad económica, ya que los ingresos que reciba dependen en gran medida de su trabajo, y al mismo tiempo, tiene la posibilidad de alternar sus actividades con los otros roles que desempeña. De modo que, a partir de las experiencias vividas sabía qué condiciones debía tener su nuevo trabajo, por lo menos en términos de tiempo.

Un caso muy similar es el de la persona "G", quien de formación es licenciada en educación con especialización en familia y desarrollo personal; tiene 21 años de experiencia laboral en el área administrativa. En sus empleos siempre había cumplido horarios, unos más extenuantes que otros, pero por lo general le implicaban estar por fuera de su casa todo el día. A pesar de esto, ella definía estrategias para que mientras estuviera en su oficina, sus hijos también estuvieran allí, y de esta manera poder apoyarlos en la realización de tareas. Sin embargo, llegó un punto en el que se sintió demasiado saturada por los tiempos de trabajo, y decidió renunciar:

"El último año que estuve en ese trabajo, todo el mundo salió de vacaciones menos yo, porque no había alcanzado a dejar todo listo. Un día estando en la oficina me puse a pensar que eso ya no era vida, y tomé la decisión de renunciar (...) cuando yo me retiré de ese trabajo me faltaban 3 años para pensionarme, y con lo que me dieron de liquidación podía vivir ese tiempo, así que yo ya pensaba que no iba a trabajar más".

Y así fue por un tiempo pues, después de estar tres años sin trabajar sentía que necesitaba ocuparse dado que consideraba que aún tenía energía y ganas de estar en el ámbito laboral; lo que sí tenía claro era que no iba a volver a cumplir un horario, o por lo menos no tan extenuante como el que había tenido en su último trabajo

"Estaba decidida que no iba a volver a cumplir horario por lo que había vivido en mi trabajo en la Universidad. Yo ya tenía clarísimo 
que quería llegar y salir a la hora que quisiera, y justo eso fue lo que me ofreció Century"

En efecto, la propuesta de C21 Country, bajo su idea del "free lance" se adecuaba a lo que ella estaba buscando, principalmente en términos de tiempo: Trabajar sin cumplir horario, percibiendo ingresos.

La persona "O" por su parte ha tenido experiencia en docencia, en el área de sistemas y en el área comercial. Durante sus años de trabajo ha pasado por empleos diversos en los que debía cumplir una jornada intensa de trabajo que le implicaba salir muy temprano de su casa y llegar muy entrada la noche, lo mismo que dedicar fines de semana; esto lo vivió cuando estuvo vinculado a la docencia. A pesar de que le encanta esa área, sintió que era un ritmo de trabajo que lo estaba alejando de su familia y de sus proyectos personales, por tanto, decidió abrirse campo en otras áreas en las que fuera más llevadera la armonización de escenarios

"La docencia es una actividad que me gusta pero es muy desgastante. Entonces decidí cambiar de actividad e ingresé al área comercial en el sector inmobiliario".

Él considera que el hecho de haberse vinculado al área comercial, y en particular, contar con las facilidades que da C21 Country por la naturaleza del trabajo, le permitió darle un giro a su vida, no solamente por la distribución de tiempos que podía hacer entre el trabajo, la familia y otras actividades, sino también, porque le daba la posibilidad de manejar de manera equitativa con su esposa la atención de la casa y el cuidado de los hijos.

De modo que para estas personas las experiencias anteriores fueron las causantes de buscar definir una jornada de trabajo diferente, en la que no fuera necesario cumplir un horario de trabajo, dado los conflictos en los que estuvieron inmersos en la esfera laboral y familiar, y en cambio pudieran tener control sobre su propio tiempo para tener la posibilidad de manejar de la manera más armónica posible los roles por los cuales transitan diariamente. En consecuencia, la definición de la jornada laboral de estas personas en particular tiende a ser menos estricta que la de otros agentes inmobiliarios que siempre han estado trabajando bajo la modalidad free lance.

Por otra parte, algunas personas prefieren seguir trabajando como siempre lo han hecho durante su experiencia laboral. Algunos agentes inmobiliarios siempre han trabajado siendo free lance, y no imaginan trabajar de otra forma, dadas las facilidades que con ésta modalidad de trabajo tienen para el desarrollo de otras actividades y como redunda esto en sentirse satisfechos con su labor y el ritmo de vida que tienen. La persona "E" manifiesta por ejemplo que le gusta el trabajo que realiza porque no concibe desempeñar un puesto de trabajo que implique cumplir horarios, 
"En un momento de mi vida fue fácil el tema de cumplir horarios pero, en este momento no lo podría hacer; ya llevo muchos años manejando mi tiempo, sin necesidad de dar mayores explicaciones, así que no me imagino trabajando con otra dinámica"

De igual manera, hay quienes durante su trayectoria laboral han cumplido un horario de trabajo, y se sienten a gusto con ello, dado que les permite diferenciar la esfera de lo laboral y lo no laboral; tanto agentes inmobiliarios como personas del área administrativa que se encuentran en dicha situación tienden a seguir reproduciendo ese patrón de comportamiento de cumplir un horario: los primeros porque lo ven como una forma de adoptar hábitos laborales, como una estrategia para separar lo laboral y lo no laboral, o porque no imaginan una manera diferente de trabajo; los segundos porque así lo tienen establecido, y no les genera problema en tanto les permite diferenciar escenarios y a partir de ahí establecer sus dinámicas en otros espacios. Entonces, lo que se puede inferir a partir de lo anterior es que, dado que durante su trayectoria laboral estas personas han cumplido un horario, ya están habituados con ello, y no conciben una manera diferente de hacerlo; esto tiene que ver seguramente con la idea de la rutinización y la institucionalización de las jornadas laborales que más adelante se desarrollará.

\subsubsection{La dinámica familiar y personal}

La dinámica familiar de cada persona es uno de los elementos que mayor incidencia tiene en la forma que están definidas las jornadas laborales, tanto para quienes hacen parte del área administrativa, como para los agentes inmobiliarios.

Así, las personas del área administrativa por ejemplo, a pesar de que deben cumplir con el horario establecido por la organización, han tenido la posibilidad de hacer algunas modificaciones, a partir de necesidades personales y familiares puntuales. Es así como a la persona "M" la organización le dio la posibilidad de iniciar y finalizar sus labores 30 minutos antes de la hora inicialmente estipulada, a fin de que pudiera recoger a sus hijas en el colegio, y de la misma forma a la persona "D", para que pudiera retomar sus estudios. O por ejemplo, también es posible pensar en la posibilidad con la que cuentan las personas del área administrativa de solicitar permisos para asistir a citas médicas o para estar en acontecimientos familiares particulares, a los que se refiere la entrevistada "K".

Entonces, que estas personas cumplan un horario no necesariamente implica que desatienden sus asuntos personales o familiares, sino que, dada la naturaleza de esta organización tienen la posibilidad de que la jornada laboral se ajuste a la dinámica familiar o personal de cada quien, de tal forma que tengan la oportunidad de desenvolverse en esos escenarios. De este modo, la dinámica familiar y personal define ciertas pautas respecto a la adaptabilidad o maleabilidad que puede tener su jornada de trabajo, a pesar de tener un horario definido por la organización. 
Para los agentes inmobiliarios funciona igual, sólo que ya no se trata de solicitar permisos o modificar los tiempos laborales, sino de definirlos en función de sus necesidades y dinámicas personales y familiares. Así, algunos agentes inmobiliarios definen sus jornadas laborales en función del horario escolar que tengan sus hijos, de tal forma que tengan la oportunidad de dejarlos en el colegio, recibirlos cuando lleguen y de acompañarlos en el proceso de elaboración de tareas $^{37}$; o, hay otros que lo hacen en función del horario de trabajo de sus hijos y/o de su pareja ${ }^{38}$. También, hay casos en las que las jornadas laborales ocupan la mayor parte del tiempo, dado que no hay un círculo familiar o social permanente, lo que ocasiona que para la definición de los tiempos laborales no haya un referente de límite o punto de partida ${ }^{39}$.

Ahora, y como se planteará en el capítulo siguiente, además de la forma en que están vinculadas las personas con la organización, y de manera similar a como opera la multiplicidad de roles ${ }^{40}$, variables como el género, el estado civil y el estado parental también inciden de manera importante en que las personas requieran de una mayor o menor flexibilidad en las jornadas laborales. De esta forma, quienes están casados, con hijos en edades dependientes, y más aún si son mujeres, requerirán de una mayor flexibilidad en sus jornadas laborales con respecto a los hombres, o a quienes no están casados, no tienen hijos, o sus hijos no están en edades dependientes. En la figura seis se presenta la tendencia identificada en C21 Country hacia la flexibilidad, a partir de las variables de género, estado civil y estado parental.

Es posible afirmar, siguiendo a Schieman et al (2009) que, los hombres tienen menor tendencia a la flexibilidad dado que socialmente está instituido que se ubican en la esfera externa, y por tanto, las responsabilidades que asumen se relacionan más con el trabajo y una amplia disponibilidad para atender los requerimientos que de éste emerjan, generando que los espacios por los que necesariamente debe transitar sean pocos y que no requieran por tanto de mayores facilidades para moverse entre uno y otro. Las mujeres por su parte, tradicionalmente se ubican en la esfera doméstica atendiendo asuntos familiares, pero además, al incursionar al mundo del trabajo deben atender también esa esfera; esto implica que deben transitar por múltiples escenarios y por tanto, una jornada flexible les facilitará el desenvolvimiento entre esos escenarios, y otros a los que haya lugar.

Respecto al estado civil igualmente se presentan ciertas tendencias. Quienes están solteros o divorciados tienden a definir jornadas laborales menos flexibles en

\footnotetext{
37 Por ejemplo las personas "F", "H", "l" y "O".

38 Por ejemplo las personas "B", "G" y "J".

39 Por ejemplo la persona "A".

40 De manera anticipada es pertinente plantear que variables como género, edad, estado civil, estado parental y tipo de vinculación inciden en que las personas de esta organización estén más o menos propensas a enfrentar conflictos inter - rol, sobre carga de rol, o acumulación de roles. Como consecuencia de ello, se genera la necesidad de contar con condiciones laborales más o menos flexibles dependiendo de la situación de cada persona a partir de dichas variables.
} 
comparación de quienes están casados o en unión libre. Esto seguramente responde a que este tipo de relaciones establecen ciertas compromisos que crean demandas específicas, generando competencia de recursos como el tiempo (Schieman et al, 2009). De esta forma quienes tienen pareja muchas veces deben organizarse en función de la otra persona, conciliando tiempos y espacios, mientras que quienes no tienen, cuentan con mayor autonomía para definir este tipo de asuntos; de ahí que, la flexibilidad laboral propicie condiciones más favorables para la conciliación de tiempos y espacios.

Figura 6. Tendencia hacia la flexibilidad a partir de las variables de análisis

\section{Fuente: Elaboración propia}

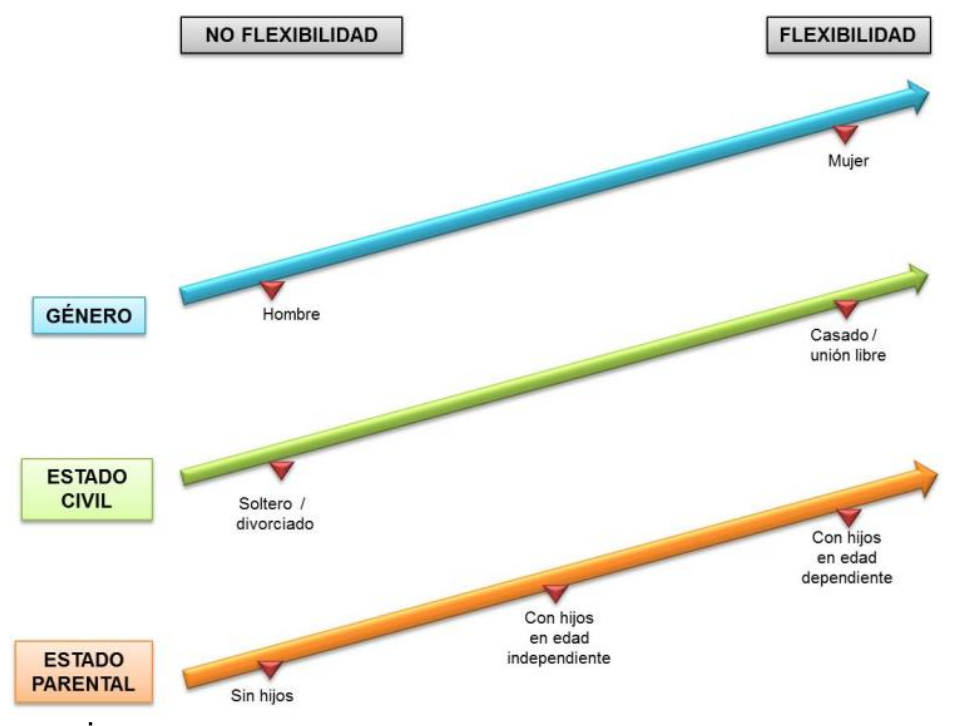

Ahora, el tener o no hijos, y el grado de dependencia de ellos también establece parámetros respecto a la necesidad de flexibilidad. De manera similar que con la pareja, los hijos implican ciertas responsabilidades y por tanto, el asumirlas adecuadamente dependerá en gran medida del tiempo que se pueda dedicar a ello (Schieman et al, 2009). De este modo, quienes tienen hijos en edades dependientes tienden a buscar una mayor flexibilidad en comparación con quienes no tienen hijos, o sus hijos ya son independientes, con el propósito de brindarles la atención y el cuidado que requieren para su desarrollo. Quienes tienen hijos en edades independientes, aunque no requieren del mismo tiempo en comparación de quienes tienen hijos pequeños, de todas formas prefieren contar con algún beneficio en términos de horarios con el fin de poder participar en una dinámica familiar armónica. Quienes no tienen hijos no se enfrentan a este tipo de asuntos, y por tanto no consideran necesario contar con una jornada laboral flexible. 


\subsubsection{Construcción de la jornada laboral en C21 Country.}

A partir de lo planteado anteriormente es posible afirmar que, aunque C21 Country tiene definidos horarios de funcionamiento de la oficina que constituyen la jornada laboral de quienes se encuentran vinculados laboralmente a la organización, y además fungen como guía para que algunos agentes inmobiliarios definan sus tiempos de trabajo, en realidad en la organización existen muchas jornadas laborales; es más, podría decirse que C21 Country cuenta con 18 jornadas laborales diferentes pues a decir verdad, cada persona que hace parte de esta organización, indistintamente del tipo de vinculación que tenga o del trabajo que realice, ha tenido la posibilidad de definir su tiempo de trabajo de acuerdo con las elementos descritos a lo largo del apartado. En este sentido, es posible plantear que en C21 Country la jornada laboral no es definida únicamente por la organización, sino también por quienes hacen parte de ella, a partir de su historia de vida.

De modo que, al proponer la existencia de 18 jornadas laborales en la organización, cada una correspondiente a una persona que conforma el equipo de trabajo, se pone en evidencia que cada individuo construye su jornada laboral o define sus tiempos laborales a partir de experiencias pasadas, de sus expectativas, de sus prioridades o de sus necesidades; es decir, no hay una jornada laboral claramente definida ni para unos ni para otros, sino que el resultado de la definición del tiempo de trabajo en esta organización emerge de cómo las personas consideran deben ajustarse para poder desenvolver sus múltiples roles y dar respuesta a sus responsabilidades familiares y laborales, desde la flexibilidad con la que cuentan algunos, y desde la rigidez aparente bajo la que se encuentran los otros. Por lo anterior, desde los estudios organizacionales será plausible hablar del constructo social de la jornada laboral.

Sin embargo, el patrón común que siguen las 18 jornadas laborales es que éstas responden a los procesos de socialización y de institucionalización de prácticas, a partir de los cuales la jornada laboral se asemeja a una rutina, que reduce la necesidad de hacer elecciones y es interiorizada. Así las cosas, la definición de las jornadas laborales está incidida por ese parámetro de rutinización e interiorización de reglas, generando que muchas veces la flexibilidad tienda a ser rígida pues, ante nuevas posibilidades de elección - en esta caso para la definición de las jornadas laborales - se tiende hacia lo conocido y hacia lo que está normado en la vida social. En virtud de ello, los agentes inmobiliarios definen sus jornadas laborales no necesariamente en función de sus intereses individuales, sino en función de los roles que asumen, y los valores y normas que estos conllevan, porque así están socialmente estatuidos (De la Rosa, 2002:35); es decir, para la definición de las jornadas laborales entra en juego tanto lo socialmente atribuido al rol de trabajador, como lo socialmente atribuido al rol de padre o madre, por ejemplo.

Por lo anterior es posible plantear que para C21 Country será más pertinente hablar de una construcción social de los tiempos laborales a partir de los elementos revisados en este apartado que inciden en ello, desde la organización y 
desde los trabajadores, más que de una definición de las jornadas laborales. Esa construcción de tiempos laborales como se ha planteado, es más o menos flexible para unos y para otros, no necesariamente como consecuencia de la vinculación laboral o de la vinculación free lance, sino más bien a partir de las variables que ubican a las personas en diversos contextos personales, sociales y laborales, que los dotan de ciertos recursos, que los exponen también a determinadas situaciones, unas más exigentes que otras, y que les asignan ciertos roles y con ellos demandas y mandatos a los cuales dar respuesta.

\subsection{LA MULTIPLICIDAD DE ROLES DE LOS TRABAJADORES Y SU INCIDENCIA EN LA DEFINICIÓN DE LAS JORNADAS LABORALES}

Conocer los diferentes espacios de desenvolvimiento de las personas que hicieron parte del estudio a partir de su rutina diaria, permitió identificar la multiplicidad de roles a la que muchas veces se enfrentan; esto facilitó el reconocimiento de algunas relaciones entre los roles asumidos por los trabajadores de la organización tanto en la vida laboral como en la vida no laboral, y la presencia de conflictos inter - rol, sobrecarga de rol y/o, acumulación de roles. Los dos primeros se presentan como situaciones problemáticas: hombres y mujeres que tienen responsabilidades en el ámbito familiar y en el ámbito laboral que para cumplir con estas requieren de los mismos recursos - por ejemplo el tiempo -; o, que de manera simultánea, están expuestos a sentimientos de agotamiento o frustración ante la imposibilidad de dar respuesta a situaciones que se desarrollan paralelamente en escenarios diferentes. En otros casos, la multiplicidad de roles se manifiesta de manera positiva, al implicar una acumulación que les permite potencializar capacidades y habilidades, relaciones sociales y espacios de desenvolvimiento, así como afianzar su auto estima y auto concepto. La jornada laboral tiene un papel importante en como derive la multiplicidad de roles pues, dependiendo de cómo estén delimitados los tiempos laborales pueden contribuir a incrementar los conflictos, o por el contrario puede facilitar la armonización de los mismos; podría suponerse incluso que, quienes tiene la posibilidad de definir su jornada laboral lo hacen a partir de los roles que desempeñan y las demandas que de allí se generen, estableciendo ciertos tiempos como laborales y otros para el desenvolvimiento en otros escenarios.

\subsubsection{Roles de la vida laboral y la vida no laboral por los que transitan quienes conforman el equipo de C21 Country.}

A partir de lo narrado por las personas que hacen parte del objeto de estudio, fue posible identificar que los roles que priman en el desarrollo diario de sus actividades se ubican en el ámbito laboral y en el ámbito familiar; por tanto, la multiplicidad de roles que define su dinámica de vida se relaciona con los roles asumidos como trabajadores de C21 Country, y como papá o mamá, esposo o esposa, e inclusive para algunos, como hijo o hija o, hermano. No se identificó la prevalencia de roles por fuera de estos dos escenarios, como en principio se hubiera pensado, tales como estudiante, o promotor social u otro que exigiría la participación en un escenario diferente a los ya planteados. Esto posiblemente puede responder a condiciones particulares que caracterizan a la población 
estudiada, principalmente referidas a la edad, al tipo de trabajo realizado y a su constitución familiar.

No obstante, a pesar de que los roles de la vida laboral y la vida no laboral para este grupo de personas se configuran principalmente entre el trabajo y la familia, fue posible evidenciar como a partir de la multiplicidad de roles resultante del desenvolvimiento en diferentes escenarios, para algunos puede implicar la presencia de conflictos inter - rol, sobre carga de roles y/o acumulación de roles. Incluso, se plantea como para algunos el tipo de trabajo realizado en Century, principalmente para los agentes inmobiliarios, contribuye a la disminución de conflictos o sobre carga de rol pero, para otros, la condición de flexibilidad de tiempos y espacios laborales, propia de la vinculación free lance, no representa ninguna posibilidad para facilitar su desenvolvimiento por los diferentes escenarios por los que transitan, sino que por el contrario, implica incrementar las responsabilidades y compromisos asumidos.

Así las cosas, para algunos el desenvolvimiento de sus roles laborales y familiares implica que cuando surge el desempeño de un rol, por ejemplo el de madre, el desarrollo de otro rol sea incompatible, por ejemplo el de trabajadora; esto es el conflicto inter - rol. Para otros, el rol de padre puede competir por los recursos personales del individuo al desempeñar su rol como trabajador, dado que poseen las mismas exigencias, lo que resulta como una sobrecarga de rol. O contrario a lo anterior, para otras personas el ejercicio de múltiples roles, como el de mamá y trabajadora en cambio de generar consecuencias negativas, permite mayor interacción social y desarrollo personal, gracias a la acumulación de roles (Guerrero, 2003). No obstante, esto no implica que sea permanente la presencia de sobrecarga, conflicto o acumulación; esto es relativo, y así como para una persona determinadas situaciones pueden generar sobrecarga en ciertos momentos, también puede resultar como una acumulación de roles, en otros; inclusive, lo que para una persona puede percibirse como un conflicto, por ejemplo el cumplimiento de la jornada laboral, para otras puede significar una acumulación, a partir de particularidades de su vida.

\subsubsection{La multiplicidad de roles en la que están inmersos quienes conforman el equipo de C21 Country.}

A continuación se analiza la multiplicidad de roles por la que transitan quienes conforman el equipo de C21 Country, desde lo positivo o lo negativo que puede resultar para cada persona el ubicarse en más de un escenario y en consecuencia, asumir más de un rol con las demandas resultantes de ello, a partir de las características particulares de cada quien, y de cómo se sitúen frente a los mandatos implícitos en el desarrollo de cada rol.

\subsubsection{Presencia de conflictos inter - rol en algunas personas que conforman el equipo}

Como se planteó anteriormente, dada la multiplicidad de roles en la que se desenvuelven quienes hacen parte del equipo de la organización, es cotidiano que 
como consecuencia de dicha condición, se presenten conflictos inter - rol para algunas personas. Así, a través de las entrevistas fue posible identificar que, efectivamente algunas personas plantean situaciones en las que se refleja un conflicto de desenvolvimiento entre el escenario laboral y el escenario familiar y entonces, el estar cumpliendo con lo socialmente establecido como trabajador o trabajadora, impide que se cumpla con lo socialmente establecido como padre o madre. Es importante resaltar dos cuestiones sobre esto: la primera de ellas es que, el conflicto inter - rol se presenta indistintamente del género, pues tanto hombres como mujeres hicieron referencia a ello. La segunda, es que es una condición más frecuente para quienes cuentan con la posibilidad de la flexibilidad de horario pues, fueron los agentes inmobiliarios quienes más alusión hicieron a ello.

Así, la persona "B" plantea que inicialmente, vincularse como agente inmobiliaria de C21 Country significó para ella la posibilidad de poder compartir con su familia y dedicarle tiempo a sus hijos; es decir, de priorizar su rol como madre y esposa. Se sintió atraída por la propuesta de flexibilidad que en términos de tiempo y espacio le ofrecía C21 Country al vincularse como free lance, debido a que le facilitaría adecuar sus jornadas de trabajo a las demandas que tenía en su rol de madre, esposa e hija. Sin embargo, lo que en un principio pareció benéfico, con el pasar del tiempo tuvo otra tendencia; lo atractivo de ser free lance posteriormente se tornó problemático dado que, su rol como agente y su rol como madre constantemente entraban en conflicto por pretender atender las dos cosas al tiempo. Es decir, ella nunca se preocupó por definir límites entre cada uno de estos escenarios -laboral y familiar-, lo que ha redundado en conflictos inter - rol pues siente que desatiende su rol como madre y esposa, que fue lo que principalmente la llevo a buscar un trabajo con tales características, por darle prioridad a los temas laborales,

"Yo en casa trato de estar muy pendiente de todos y de todo pero a veces se me olvidan cosas que me dicen mis hijos porque les pregunto algo, pero no les doy atención porque estoy pensando en el negocio, o me entra la llamada y se olvida la charla. Yo sé que es algo que debo cambiar, porque de no ser así va a llegar un momento en que mi familia se canse".

De esta forma, la persona "B" plantea una situación interesante en la que surge un conflicto inter - rol no como resultado de la flexibilidad de la jornada laboral, sino por no establecer parámetros entre uno y otro escenario y entonces, lo que en principio la motivó a vincularse a un trabajo como este - su familia -, ahora pasa a un segundo plano, pues el asumir su rol como agente inmobiliaria la obliga muchas veces a desatender su papel como madre, posiblemente como consecuencia de no tener una jornada laboral definida..

La persona "F" también hace referencia a cierto conflicto inter - rol que aparece al desenvolverse como agente comercial y como madre. Contrario al caso anterior, para ella el rol de madre interfiere en el de trabajadora, lo que le genera alguna 
incomodidad pues, a ella le gustaría estar más dedicada a su trabajo pero, a causa de su hijo y la atención que le da, debe dejar de lado su trabajo; así las cosas, se presenta otro caso en el que ser mamá y trabajadora genera conflicto.

"A mí me gustaría cambiar el horario en el trabajo para que no fuera solo en la mañana, sino todo el día pero, como tengo que esperar a que mi hijo llegue del colegio y luego ayudarle con las tareas, eso me corta el día laboral. Eso lo podría cambiar teniendo un orientador de tareas, o que mi esposo me apoyara con eso, pero a él no le gusta ni se le facilita"

De esta forma, para la persona "F" el rol que tiene prioridad es el de trabajadora, seguramente como consecuencia de su situación económica y la necesidad que tiene de cerrar negocios frecuentemente, para poder contar con los recursos necesarios para vivir; es importante recordar que ella es quien económicamente sostiene su casa, dado que el esposo no trabaja. Ahora, a partir de lo planteado por ella, su rol de trabajadora se ve interrumpido por cumplir con sus responsabilidades como madre pues, a pesar de que podría resolver algunas cosas del trabajo a través del celular, no puede programar citas con clientes, que es donde por lo general hay más posibilidades de negocio, lo que le genera cierta insatisfacción.

Contrario a esto, la persona "O" identifica en ocasiones un conflicto inter-rol al desenvolverse como padre y agente inmobiliario, priorizando por lo general su rol como padre;

"El día que haya una actividad familiar o en el colegio ese día se pierde el trabajo pues, yo antepongo mi familia al trabajo, porque no es algo que se pueda posponer. Si es necesario me apoyo en mis compañeros, en caso de que toque ir a mostrar propiedades".

Esta priorización que él hace probablemente se debe a que la esposa tiene un empleo de tiempo completo, lo que le dificultaría aún más cumplir con las citaciones del colegio; sin embargo, dado el manejo que él puede darle a sus tiempos y espacios laborales, pueden resolver ese tipo de situaciones. Ahora, es importante mencionar que esta persona no se enfrenta de manera permanente al conflicto inter - rol, seguramente como resultado de los límites que tiene establecidos en términos de tiempo y espacio para el desarrollo de sus actividades laborales y familiares, procurando que los dos escenarios no se mezclen; como se planteó anteriormente, él mismo definió su jornada laboral, en términos de tiempos y espacios. Posiblemente el hecho de establecer parámetros entre uno y otro escenario le facilita la conciliación de espacios y el desenvolvimiento armónico de sus roles, de tal forma que se relacionen mínimamente sin generar incompatibilidad; así, la condición de flexibilidad resulta positiva para la armonización de los escenarios de su desenvolvimiento social. 
Entonces, a partir del análisis acerca de la presencia de conflictos inter - rol es interesante resaltar el hecho que esta condición haya sido evidenciada únicamente en agentes inmobiliarios. Esto posiblemente se relacione con que las ventajas de la flexibilidad de tiempos y espacios laborales para conciliar y armonizar escenarios se pueden convertir en un perjuicio pues, al no establecer parámetros claros de diferenciación de escenarios será frecuente que lo laboral y lo familiar tiendan a desarrollarse de manera paralela y como resultado, se generen conflictos entre los múltiples roles que se desempeñan; por tanto, es posible afirmar que quienes no tienen definida una jornada laboral es más probable que se enfrenten a conflictos de rol, que quienes sí la tienen. También es importante subrayar que el conflicto inter - rol es preponderante en agentes del género femenino que buscaron este tipo de trabajo por las facilidades de armonización de escenarios que tendrían, a partir de la flexibilidad, pero que de acuerdo con lo planteado por ellas, redunda en un conflicto frecuente entre sus roles. Por el contrario, el entrevistado del género masculino es estricto en la definición de límites entre uno y otro escenario y, aunque se identifican situaciones de conflicto, estas son esporádicas, de suerte que cuando aparecen situaciones no rutinarias, -como por ejemplo las citaciones en el colegio- tiene la posibilidad de desenvolverse en sus diferentes roles sin un conflicto permanente.

Otro aspecto a mencionar es que las tres situaciones de conflicto inter - rol presentadas corresponden a personas con una relación marital, y dos de ellas tienen hijos en edades dependientes; esto seguramente es consecuencia de la mayor demanda que tienen sus roles conyugales y parentales respecto a personas en condiciones diferentes, generando más probabilidades de conflicto entre los roles que desempeñan.

\subsubsection{Roles que compiten por los mismos recursos: la sobre carga de rol a la que están expuestas algunas personas del equipo}

De la misma manera que el tener una multiplicidad de roles puede redundar en conflictos, también puede significar una sobre carga para quien los desempeña, dado que el desenvolvimiento en uno puede implicar exigencias muy similares al desenvolverse en otro, lo que genera cierta competencia por los recursos personales de quien se encuentra en esa posición. Así, a partir de las entrevistas realizadas fue posible identificar algunas situaciones de sobre carga de rol a las que las personas están expuestas actualmente o, lo estuvieron en otro momento, y para algunas de las cuales el trabajo en C21 Country resultó ser una posibilidad para manejar esa sobrecarga.

La persona "G" por ejemplo considera que siempre ha tenido un buen rol como mamá, a pesar de que para lograr tal condición haya tenido que sobrecargarse en algún momento de su vida para desempeñar su rol materno y su rol como trabajadora.

"Cuando mis hijos eran pequeños, yo trabajaba en la Universidad. Si mi ex - esposo estaba de viaje, entonces yo alistaba a mis hijos para 
salir al colegio a las 5:30 a.m. y a esa misma hora yo me iba para el trabajo, entonces no les quité tiempo a ellos. Por las tardes, mis hijos llegaban a las 4:00 p.m. del colegio y la ruta los dejaba en la Universidad en la que yo trabajaba. Allí estaban en mi oficina, de tal forma que yo pudiera trabajar y al mismo tiempo controlar la elaboración de sus tareas hasta que yo terminara mis responsabilidades. Pero, cuando mi ex - esposo no estaba de viaje, ya estaba en función de él y de mis hijos, así que llegaba al trabajo en la hora correspondiente e igualmente, la hora de salida procuraba que no fuera tan tarde, igual estando con mis hijos. Por eso digo que a pesar de las circunstancias siempre me he esmerado por ser una buena madre".

A partir de lo anterior, se evidencia la sobre carga de roles a la que estuvo expuesta la persona "G", quien en ese momento, al tiempo que cumplía funciones como trabajadora, se encargaba de asumir algunas de las funciones maternas relacionadas con el acompañamiento a sus hijos, de acuerdo con lo socialmente establecido para ser "una buena madre"; es decir, se preocupaba por desarrollar dos roles de manera paralela, para no poner en riesgo el ser una buena trabajadora o el ser una buena madre, aunque quizás eso implicara para ella un sobre esfuerzo que redundaría en cansancio y agotamiento. No obstante, esa condición de sobre carga actualmente ya no la percibe, debido por un lado, a que sus hijos ya son independientes y no requieren su atención de manera tal, y por otro lado, porque dada la condición de flexibilidad con la que cuenta en C21 Country, ya no debe cumplir necesariamente un horario sino, que organiza el desarrollo de actividades laborales y actividades no laborales de acuerdo a su criterio.

La persona "O" también hace referencia a una condición de sobre carga de roles como consecuencia de las demandas similares que recibe como esposo, papá y trabajador, lo que además le ha impedido retomar su rol como estudiante, por lo que ha debido postergar su proyecto de regresar a la academia:

"He intentado dos veces volver a entrar a la universidad pero ha sido imposible porque ya estaba casado y con hijos. Quizás en los próximos años cuando los niños sean más independientes lo vuelvo a intentar".

Para esta persona el desempeño de estos roles ha generado una sobrecarga, obligándolo a posponer sus proyectos académicos, en tanto las condiciones en términos de tiempo, y posiblemente de recursos económicos, sean más pertinentes para ello. Él plantea que cuando sus hijos tengan mayor independencia posiblemente pueda volver a vincularse a la Universidad; es decir que, más allá del trabajo o su rol como esposo, lo que genera la sobrecarga es el desempeño del rol de papá con respecto a los otros roles, en tanto sus hijos requieren de sus cuidados y atención en este momento. Así las cosas, el recurso que está en competencia entre el rol de papá y los otros roles es el tiempo, por 
tanto, cuando el rol de papá demande menos tiempo, podría dedicar ese recurso a otras actividades, como el estudio.

La persona "D" plantea de otra manera la sobrecarga de rol,

"Siento que tengo problemas con los múltiples roles pues, muchas veces me llevo los problemas del trabajo a la casa y viceversa. Entonces, a veces salgo muy estresada de la oficina, y al llegar a la casa estamos bien con mi esposo pero, si él dice algo que no me gusta yo discuto, afectando mi relación de pareja".

En este caso la sobrecarga de roles no está relacionada con el recurso tiempo, como en los casos anteriores sino que, se vincula más con el manejo de emociones y la energía que implica para ella estar en uno u otro escenario. Entonces, cuando las actividades de su rol como trabajadora resultan demasiado extenuantes, es posible que su rol como esposa se vea afectado, al no contar con los recursos suficientes para hacer frente a las demandas de ese rol. Ahora, posiblemente esa sobre carga no necesariamente es resultado de la carga laboral y las responsabilidades que implican su trabajo, sino quizá responda más a su poca experiencia laboral y, al proceso de aprendizaje y crecimiento que ella misma ha reconocido está viviendo. Aun así, el transitar por uno y otro escenario resulta complejo para ella en ocasiones, generando una situación negativa que impide el desempeño armónico de estos dos roles.

Así las cosas, a partir de las tres situaciones presentadas es posible decir de manera general que la sobrecarga de rol no necesariamente está relacionada con las condiciones laborales, y de manera particular con la jornada laboral, sino más bien, con la etapa de vida en la que se encuentre quien se enfrenta a la sobrecarga y las demandas generadas por los roles asumidos a partir de esto. Por ejemplo, en los dos primeros casos, la sobrecarga de rol es consecuencia de la edad de los hijos y su condición de dependencia de los padres, lo que requiere una inversión alta de recursos como tiempo y atención para el cumplimiento del rol parental; esto indudablemente ocasiona que el ejercicio de otros roles que requieren de los mismos recursos, como el de trabajador por ejemplo, generen una sobrecarga a quien los está desempeñando. Claro, éste no es el único factor que afecta pues, posiblemente pueda solventarse al contar con mayores recursos para el desenvolvimiento de cada uno de los roles, 0 al tener una menor competencia de recursos como el tiempo que cada rol requiere. En este sentido, elementos presentes, pero no determinantes, para que la sobrecarga sea mayor o menor pueden ser las condiciones del trabajo, la jornada laboral, la presencia de terceros que ayuden a solventar tal sobrecarga e incluso, la priorización que cada quien le otorgue a los diferentes escenarios por los que transita y a los roles en los que allí se desenvuelva. Otro tema a resaltar es que la sobrecarga no es una situación exclusiva del género femenino pues, uno de los agentes comerciales está expuesto a una sobrecarga de rol. 


\title{
5.2.2.3. Acumulación de roles: los beneficios resultantes de transitar por múltiples
} escenarios

Para otras personas la multiplicidad de roles ofrece beneficios relacionados con oportunidades de interacción social, desarrollo personal, e incluso, aumento de la autoestima. Esto por supuesto está directamente relacionado con factores como su etapa de vida y su dinámica familiar.

Así por ejemplo, para la persona "A" no se genera ningún conflicto entre sus roles del ámbito laboral y personal, sino que por el contrario, el desenvolvimiento en esos escenarios se complementa y es visto como positivo. Ella da prioridad a su rol como agente inmobiliaria y a partir de éste se desenvuelve en otros escenarios, inclusive su vida familiar. De esta forma, su vida laboral se interrelaciona con su vida personal, no a partir de conflictos, sino mediante la potencialización de oportunidades.

\begin{abstract}
"Yo le doy prioridad a las dos cosas; cuando hay alguna reunión familiar o social hago lo mismo que en mi trabajo. Cuando yo tengo un compromiso familiar o alguna invitación allá van las tarjetas de Century, allá va la promoción del trabajo. El trabajo va conmigo a todo lado, y voy con el trabajo a todas partes; dentro de mis actividades siempre va la Inmobiliaria".
\end{abstract}

De esta forma, podría pensarse que el desenvolverse en el escenario laboral y en el escenario social y familiar, no le genera ninguna carga negativa, sino que por el contrario, estos espacios le proporcionan mayores posibilidades de desempeño laboral, potencializando su rol como agente inmobiliaria. Esto seguramente responde a la situación particular de esta persona, quién recientemente atravesó por un proceso de divorcio y no tiene un círculo social ni familiar amplio; de esta forma, el trabajo se convierte en una "válvula de escape", en tanto escenario de desenvolvimiento a partir del cual tiene la posibilidad de empezar a tejer relaciones en otros ámbitos. Así, y en términos de lo planteado por Mayo (1972) a partir de la escuela de las Relaciones Humanas, podría afirmarse que en esta situación la organización, o en particular el trabajo, se configura para ésta persona como un nuevo espacio de integración de la sociedad ante la ruptura del núcleo familiar (Ibarra, 1994:29).

Para la persona "N" el desenvolvimiento en el ámbito laboral a partir de su rol como agente inmobiliaria le proporciona, más que conflictos o dificultades, mayores posibilidades de interacción social. Es importante señalar que ella ingresó a la oficina inmobiliaria no por necesidad laboral, dado que es jubilada, sino porque estaba buscando una actividad que le permitiera estar ocupada, sin necesidad de cumplir horarios estrictos,

"Necesito tiempo para mí y no estar todo el tiempo cumpliendo un horario a estas alturas de la vida. Ya quiero como relajarme un poco $y$ este trabajo es parte de eso; es que más que un trabajo esta es 
una actividad y una posibilidad para hacer cosas y conocer personas, para estar ocupada y actualizada".

Ella considera que el rol como agente inmobiliario le da la posibilidad de tener una mayor interacción social a la que tuviera si se quedara en su casa, pues, por un lado, vive sola, así que el rol de madre no es tan demandante para ella, e igualmente el de esposa tampoco. Y por otro lado, el desenvolverse como agente inmobiliaria además de propiciarle las posibilidades de interacción puede contribuir al aumento de su autoestima pues, le permite sentirse activa y ocupada, a pesar de haber pasado el rango de edad establecido para el desenvolvimiento en el mercado laboral.

Contrario a estas dos situaciones, en las que la multiplicidad de roles resulta positiva como consecuencia de la dinámica familiar en las que se desenvuelven, la persona " $\mathrm{H}$ " vive una experiencia completamente diferente. Para ella el rol de madre es altamente demandante, debido a la edad de sus tres hijos, y recientemente asumió el rol como trabajadora de C21 Country. Este es el primer empleo formal que ella tiene pues, anteriormente había trabajado en negocios independientes y emprendimientos propios, para tener la facilidad de cuidar a sus hijos. Sin embargo, dado que ahora dos de sus tres hijos van al colegio, sentía que tenía más posibilidades para incursionar en otros escenarios, diferentes al doméstico. Es así como se interesa por la oficina inmobiliaria, más aún a partir de las condiciones de flexibilidad de tiempo y espacio por ésta ofrecidas, pues le permiten trabajar sin desatender sus responsabilidades maternas. Pero, más allá de esa facilidad de conciliación, el estar vinculada al ámbito laboral, para ella tiene otro significado,

"Estar ahora trabajando implica que ahora me sienta estimulada y tenga la posibilidad de ampliar mi círculo social y mi espacio de vida".

Así que, como consecuencia de la flexibilidad con la que cuenta al ser agente inmobiliaria, la persona "H" puede seguir cumpliendo con su rol como mamá y esposa, y además tiene la posibilidad de sentirse laboralmente activa al asumir el trabajo en esta oficina inmobiliaria, lo que redunda para ella en una oportunidad de interacción social y desarrollo personal pues, sus escenarios de desenvolvimiento se amplían más allá del doméstico y además, tiene la posibilidad de establecer nuevas redes sociales con sus compañeros de oficina, con los clientes y con otras personas con quienes de manera directa o indirectamente se relacione a partir de su ejercicio laboral.

Por lo anterior, la multiplicidad de roles no siempre resulta ser una condición negativa intrínseca al desenvolvimiento en diversos escenarios, sino que por el contrario, dependiendo de ciertas condiciones, para algunas personas va a representar una oportunidad de crecimiento personal que además les va a dar mayores posibilidades de interacción y desarrollo. Es claro que los relatos referenciados en este apartado proceden de personas con características particulares; las primeras dos personas se ubican en un círculo social y familiar 
bastante reducido, y por tanto, los roles asumidos en esos escenarios no son tan demandantes, de tal forma que el desenvolvimiento en el escenario laboral representa una posibilidad de interacción y relacionamiento, condiciones que posiblemente se reflejen en asuntos que tienen que ver con la autoestima. Para el tercer caso, en el que si hay un marcado ejercicio de roles familiares, el desarrollo de roles laborales le da la posibilidad de desenvolverse en escenarios nuevos y diferentes, permitiéndole esto reconocer sus capacidades y habilidades, haciendo un aporte importante a su autoestima. Ahora, es posible identificar como característica común que tienen estas tres personas, que ocasiona que la multiplicidad derive en acumulación de roles, es que ellas mismas están en la posibilidad de definir su jornada laboral, lo que no las obliga a permanecer en un solo rol sino que, tienen la potestad de armonizar los escenarios en que se desenvuelven, a partir de la flexibilidad de tiempo con la que cuentan debido a su vinculación free lance.

\subsubsection{La multiplicidad de roles, elemento incidente pero no exclusivo para la definición de las jornadas laborales.}

Como se ha planteado, la diferencia acerca de cómo es interpretada la multiplicidad de roles se relaciona con algunas de las variables de análisis de la investigación. Por ejemplo, aspectos como el estado civil, el estado parental, el tipo de vinculación laboral, y con este la forma en que se estructuran las jornadas laborales, influyen en que la multiplicidad de roles tienda hacia el conflicto inter rol o la sobrecarga de rol, o por el contrario hacia la acumulación.

A continuación, en la tabla ocho, es posible observar la relación que existe entre las variables de análisis y la multiplicidad de roles a la que se enfrenta las personas que conforman la población objeto de estudio. Las condiciones en las que se marca $(X)$ son las más comunes, en las que se presenta sobre carga de rol, conflicto inter - rol o acumulación de roles; por su parte los guiones (-), indican las condiciones en las que se presume es menos probable que haya una exposición a esas formas que se derivan de la multiplicidad de roles.

De esta manera, quienes se encuentran casados y con hijos en edades dependientes tienen cierta tendencia hacia el impacto negativo de la multiplicidad de roles - conflicto inter - rol y/o sobrecarga de rol - pero, para quienes tienen pocas responsabilidades y demandas familiares, la multiplicidad de roles y en particular este tipo de trabajo, se configura como un factor positivo que los potencializa y les da seguridad - acumulación de roles-.

Ahora, contrario a lo que se pensaría, el conflicto inter -rol o la sobrecarga de rol no es exclusiva del género femenino, ni de las personas que tienen una vinculación laboral con la organización; los hombres que hacen parte del estudio también manifestaron a través de sus narraciones encontrarse en alguna de estas situaciones, y ellos no tienen un contrato laboral con la inmobiliaria, sino que están vinculados mediante free lance. Por el contrario, la acumulación de roles que resulta de la multiplicidad, sí es una postura del género femenino principalmente. 
Tabla 8. Incidencia de las variables de análisis en la multiplicidad de roles

\begin{tabular}{|c|c|c|c|c|}
\hline \multicolumn{2}{|c|}{ VARIABLES } & $\begin{array}{l}\text { Conflicto } \\
\text { Inter rol }\end{array}$ & $\begin{array}{l}\text { Sobre carga } \\
\text { de rol }\end{array}$ & $\begin{array}{c}\text { Acumulación } \\
\text { de roles }\end{array}$ \\
\hline \multirow{5}{*}{ Edad } & Entre 21 y 30 años & - & - & - \\
\hline & Entre 31 y 40 años & - & - & - \\
\hline & Entre 41 y 50 años & - & - & - \\
\hline & Entre 51 y 60 años & - & - & $\mathbf{x}$ \\
\hline & Más de 60 años & - & - & $\mathrm{x}$ \\
\hline \multirow{2}{*}{ Género } & Femenino & $x$ & $x$ & $\mathrm{x}$ \\
\hline & Masculino & $x$ & $x$ & - \\
\hline \multirow{2}{*}{$\begin{array}{l}\text { Estado } \\
\text { Civil }\end{array}$} & Casado / Unión libre & $x$ & $\mathbf{x}$ & - \\
\hline & Soltero / Divorciado & - & - & $x$ \\
\hline \multirow{3}{*}{$\begin{array}{l}\text { Estado } \\
\text { Parental }\end{array}$} & Con hijos en edad dependiente & $x$ & $x$ & - \\
\hline & Con hijos en edad independiente & - & - & $\mathbf{x}$ \\
\hline & Sin hijos & - & - & $x$ \\
\hline \multirow{2}{*}{$\begin{array}{c}\text { Tipo de } \\
\text { Vinculación }\end{array}$} & Vinculación free lance ${ }^{41}$ & $x$ & $x$ & $x$ \\
\hline & Vinculación laboral ${ }^{42}$ & - & $x$ & - \\
\hline
\end{tabular}

Fuente: Elaboración propia

Es interesante analizar por ejemplo respecto al género que tanto hombres como mujeres están expuestos a las formas negativas de la multiplicidad de roles, posiblemente como consecuencia de los diversos escenarios por los que transitan y las responsabilidades y compromisos que de estos se derivan. Sin embargo, fueron únicamente las mujeres quienes se ubicaron en una condición de acumulación; quizás esto tenga relación con la presencia mayoritariamente femenina en la población objeto de estudio, pero más allá de eso, también puede hablar de la percepción positiva que tienen algunas mujeres acerca de desempeñarse en diversas esferas, no solamente la doméstica, como tradicionalmente sucedía (Guerrero, 2003). Entonces, a pesar de lo demandante que puede ser el hecho de desenvolverse en diferentes escenarios, se considera una situación satisfactoria en tanto la multiplicidad de roles en la que se

${ }^{41}$ Como se ha planteado, la vinculación free lance no debería implicar el cumplimiento estricto de una jornada laboral, sino que cada persona está en la posibilidad de establecerla de acuerdo a su consideración.

42 Contrario a la vinculación free lance, la vinculación laboral si supone el cumplimiento de un horario de trabajo, de acuerdo con los parámetros establecidos por la organización; en este caso las personas que están vinculadas laboralmente al C21 Country, personas del área administrativa y de apoyo, deben cumplir con un horario de lunes a viernes de 8:00 a.m. a 6:00 p.m., y los sábados medio día, de acuerdo con las directrices de la gerencia. 
desenvuelven implica beneficios tales como el enriquecimiento de los recursos, o el enriquecimiento de la personalidad planteados por Sieber (1974).

Con respecto al estado civil, quienes tiene algún tipo de relación, es más común que se ubiquen en una de las formas negativas de la multiplicidad de roles, en comparación de quienes no tienen pareja. Esto responde a las responsabilidades y compromisos que se generan a partir de esta condición y, la disminución de recursos - en términos de tiempo y energía - que ello implica, lo que finalmente ocasiona que las personas se vean obligadas a sobrecargarse de responsabilidades o que estas permanentemente entren en conflicto (O'Neil, Greenberger y Marks 1994, citados en Perdigao, 2011: 45). Por su parte, las personas que no tienen pareja posiblemente tienen mayor autonomía para decidir la distribución de sus recursos, lo que les facilita que estos sean usados de forma complementaria y no competitiva.

En el caso del estado parental sucede algo similar, más aun teniendo en cuenta el nivel de dependencia que pueden tener los hijos con los padres, a partir de su edad. Quienes tienen hijos en edades dependientes posiblemente tengan una relación conflictiva de roles, o una sobre carga de rol; difícilmente de ello surgirá una acumulación de roles, dadas las demandas de tiempo y energía que implica el cuidado y atención de los hijos. Ahora bien, quienes no tienen hijos o tienen hijos con cierto nivel de independencia, comúnmente no se enfrentan a situaciones de sobre carga de rol, sino más bien a conflicto inter - rol o acumulación de roles. El conflicto inter rol en este caso se genera porque, a pesar de que no hay demandas continuas de tiempo y energía, es posible que en ocasiones estos recursos sean escasos o limitados para atender asuntos de un escenario, por estar concentrados en otros (Greenhaus y Beutell,1985). La acumulación de roles por su parte, es resultado de la disponibilidad de recursos con que cuentan las personas a partir de no estar permanentemente en función del cuidado de sus hijos. Igualmente, quienes no tienen hijos tienden más hacia los efecto positivo de la multiplicidad de roles pues, de la misma manera que quienes tienen hijos en edades independientes, tienen autonomía para decidir de qué manera y en qué proporción distribuyen los recursos con que cuentan, lo que seguramente harán en concordancia con sus preferencias y prioridades.

Es importante señalar que, los resultados del estado civil y el estado parental respecto a la multiplicidad de roles son coherentes con el planteamiento hecho por Schieman et al, (2009), quienes proponen que el tener pareja y/o hijos genera responsabilidades que pueden crear demandas que compiten (Schieman et al, 2009:968), y en consecuencia se presentan las situaciones de conflicto inter - rol 0 , sobre carga de rol.

Con relación al tipo de vinculación, quienes tienen una vinculación free lance experimentan principalmente situaciones de conflicto inter - rol y acumulación de roles mientras que, quienes están vinculados laboralmente con la organización se relacionan con la sobrecarga de rol, aunque no es una condición exclusiva pues, hubo agentes que también manifestaron cierta sobrecarga. Entonces, la 
vinculación free lance ocasiona que las personas puedan ubicarse en alguna de las tres formas de la multiplicidad de roles, dependiendo en alguna medida de las variables ya planteadas como el género, el estado civil, y el estado parental; esto posiblemente responde a la falta, escasez o invisibilidad de límites entre los escenarios por los que transitan los agentes, propios de la flexibilidad con la que cuentan, de lo que se podría interpretar que, el no cumplimiento de una jornada laboral o unos tiempos de trabajo definidos implica cierta exposición a conflictos o sobre carga de roles. Ahora, quienes están vinculados laboralmente tienen mayor exposición a la sobre carga de rol, probablemente como consecuencia de los horarios que ya están establecidos y deben cumplir, lo que genera agotamiento desde el escenario laboral, para atender asuntos de lo no laboral. Sin embargo, esto también debe revisarse en conjunto con algunas de las variables anteriores pues, no todos quienes están vinculados laboralmente sufren sobrecarga de rol.

La edad, otra de las variables de análisis no tiene una relación directa con la multiplicidad de roles, aunque es posible pensar que quienes se encuentran en una edad madura tienen mayor tendencia hacia la acumulación de roles, que hacia el conflicto o a la sobre carga, posiblemente porque son menos los espacios de desenvolvimiento por los que transitan, o están menos sujetos a estos. Por el contrario es interesante que la etapa del ciclo laboral, característica que no fue contemplada en la investigación, y sobre la que sería arriesgado plantear generalizaciones, sí tiene cierta incidencia con la multiplicidad: quienes se ubican en la parte final de su ciclo de vida laboral, o incluso quienes cuentan con otras fuentes de ingresos adicionales a éste trabajo tienen tendencia hacia la acumulación de roles; esto seguramente responde al hecho de no depender únicamente de este trabajo o de no ubicar el aspecto laboral como centro de vida facilitando el desenvolvimiento en otros escenarios, sin ocasionar conflictos o generar competencia de recursos personales para ello. Por el contrario, quienes dependen únicamente de este trabajo y se encuentran en una etapa laboral activa, son más propensos al conflicto o la sobra carga de rol.

Como se puede observar en la figura siete, para las personas que trabajan en C21 Country la multiplicidad de roles redunda en conflicto inter rol, sobre carga de rol o acumulación de roles dependiendo de variables como el género, el estado civil, el estado parental y el tipo de vinculación con la organización. Es importante resaltar que la presencia de sólo una de estas variables no implica la existencia de alguno de los fenómenos resultantes de la multiplicidad de roles, sino que es la conjunción de algunas de éstas lo que va a generar que haya más probabilidad de que emerja conflicto, sobre carga o acumulación de roles. Igualmente, es importante mencionar que la historia de cada individuo genera una interpretación diferente de sus condiciones de vida, y así, lo que para algunos puede ser agotador y representa una sobre carga de roles o un conflicto inter rol, para otros, en condiciones diferentes puede interpretarse como una acumulación de roles. 
Figura 7. La multiplicidad de roles en C21 Country

Más allá de flexibilidad o la rigidez de la jornada laboral

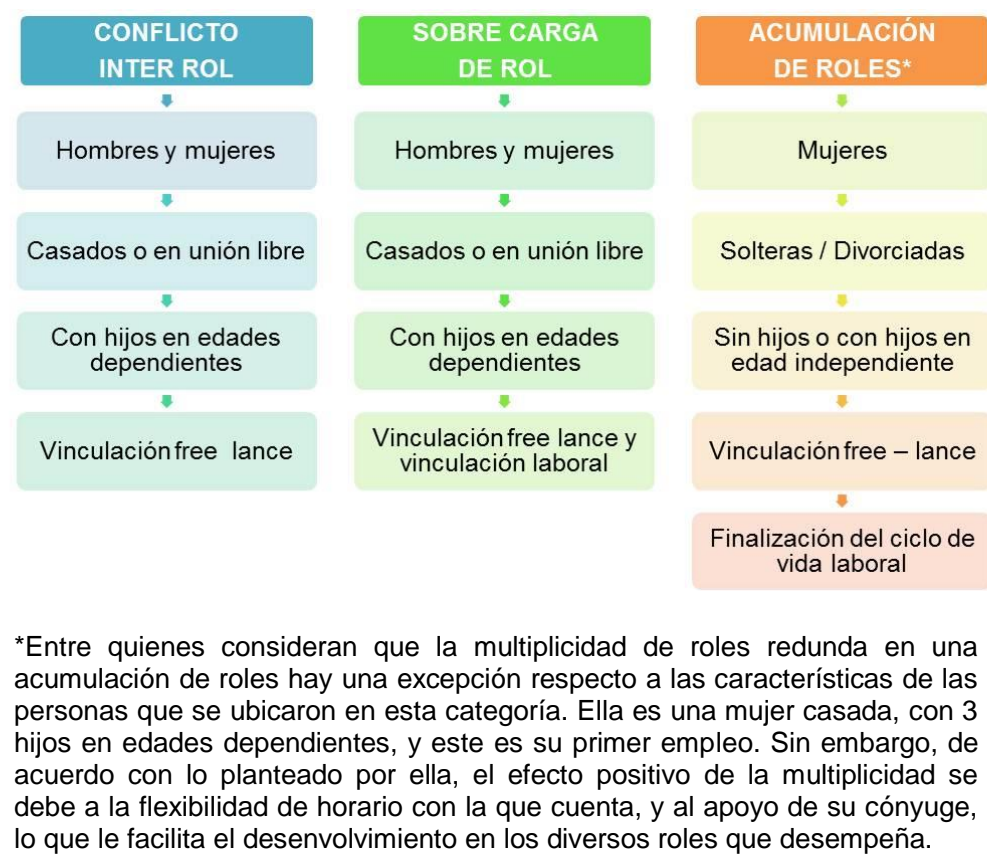

Fuente: Elaboración propia

Así, en las situaciones de conflicto y la sobre carga de rol, a partir de las características identificadas podría decirse que prevalecen los roles de esposo/esposa, madre/padre, trabajador/trabajadora entre los cuales se presenta esa relación; es decir, en estas dos situaciones el desenvolvimiento en el escenario laboral entra en conflicto con el desenvolvimiento en el escenario familiar, lo que se puede atribuir a la escasez de recursos personales como el tiempo y la energía, o al conflicto que se puede existir respecto a lo socialmente establecido para el desempeño de uno u otro rol. Por su parte en la acumulación de roles, además de la excepción evidenciada, no hay un rol conyugal específico, ni un rol materno demandante, lo que seguramente contribuirá a que no se genere una relación conflictiva entre los múltiples roles sino en cambio, que tenga un efecto positivo para quienes los desempeñan, en tanto se pueden complementar.

Entonces, a partir de los hallazgos aquí presentados es posible afirmar que contrario a lo que inicialmente se había pensado, en C21 Country el conflicto, la sobre carga o la acumulación de roles se relaciona de manera importante, pero no exclusiva con la definición flexible o rígida de la jornada laboral, consecuencia del tipo de vinculación que tienen los trabajadores con la organización; la forma como es asumida la multiplicidad de roles por la población estudiada está relacionada también con variables como el género, estado civil, y el estado parental. Ahora, la importancia que tiene la definición de la jornada laboral para el desempeño de múltiples roles se orienta a la facilidad que ésta le proporcione a las personas para que puedan conciliar espacios y tiempos; de ahí que entonces las jornadas 
busquen definirse de manera tan flexible o tan rígida como le convenga y le cree sentido tanto a la organización como a sus trabajadores.

\subsection{LA FLEXIBILIDAD Y LA RIGIDEZ DE LA JORNADA LABORAL: CONDICIONES QUE PUEDEN FACILITAR EL DESENVOLVIMIENTO DE MÚLTIPLES ROLES EN EL ESCENARIO LABORAL Y NO LABORAL}

Las jornadas laborales definidas por C21 Country, a pesar de cumplir con lo establecido por la OIT para quienes tienen una contratación directa, y de ser maleables para quienes están vinculados bajo la modalidad de free lance no necesariamente son tan estrictas como pareciera para los primeros, ni tan flexibles como se pensaría para los segundos. Es decir, lo que se pudo evidenciar a lo largo del estudio realizado, y que se plantea a continuación, es que finalmente el horario rígido establecido por la organización muchas veces es dúctil a fin de facilitar que lo laboral no obstaculice el desarrollo de algunas actividades personales y familiares; sin embargo esto no sucede siempre. Por su parte, la flexibilidad con la que cuentan los agentes inmobiliarios para definir sus tiempos y espacios laborales en ocasiones representa mayor sujeción a la vida laboral que la que tienen quienes cumplen un horario pues, deben tener disponibilidad permanente para atender y resolver solicitudes de los clientes dado que por una parte hay un acuerdo implícito con la organización de disponibilidad para la atención al cliente y por otra, sus ingresos depende exclusivamente de los negocios que realicen.

\subsubsection{La rigidez del horario flexible.}

Contraria a la dinámica de trabajo establecida por la organización para las personas del área administrativa y de apoyo, las jornadas laborales de los agentes comerciales no están definidas por la organización, sino por ellos mismos. Esto se justifica principalmente en que los agentes están vinculados a la oficina inmobiliaria bajo la modalidad free lance y por tanto, más que por el tiempo dedicado a la ejecución de sus tareas, son medidos por sus resultados, que en este caso es la realización de negocios de renta o venta de inmuebles.

Así las cosas, son los agentes inmobiliarios quienes establecen sus jornadas de trabajo, de acuerdo con la dinámica del negocio y su disponibilidad de tiempo; igualmente no necesariamente deben tener un horario de trabajo estático, ni tampoco un lugar de trabajo permanente. Habrá ocasiones en las que pueden trabajar solo en las mañanas, o solo en las tardes, o tres veces a la semana, o solo los fines de semana...o ir la oficina, trabajar desde la casa, atender visitas de clientes; en fin, existen diversas posibilidades a partir de las cuales ellos podrían definir su jornada laboral, lo que en principio se pensaría como un factor que facilita el desempeño de múltiples roles y con ello, la armonización de lo laboral y lo no laboral, dado que muchas veces las demandas laborales se pueden ajustar a las demandas personales, o viceversa.

No obstante, es interesante analizar que gran parte de los agentes inmobiliarios han definido por ellos mismos un horario de trabajo que regule su llegada y 
permanencia en la oficina, así como la atención de clientes, con las características que tendría una jornada de trabajo establecida por la organización, o por lo menos una jornada de trabajo convencional. Otros por el contrario, han establecido un parámetro de tiempo como guía para definir sus tiempos de trabajo. Esta diversidad de posiciones respecto al manejo de la flexibilidad, en cuanto a tiempos y espacios laborales, está incidida como se planteó en un capítulo anterior en gran parte por variables como género, estado civil, ciclo de vida profesional y si tienen o no personas a su cargo. De igual manera, ello redunda en la percepción resultante del desenvolvimiento en diversos escenarios, principalmente el familiar y el laboral: para algunos genera conflictos, en tanto no les permite establecer una clara diferenciación entre cada uno de esos espacios; para otros por el contrario, facilita la compatibilización, y consideran que es una opción de trabajo acertada de acuerdo al momento en el que se encuentran en su vida personal y laboral.

Antes de analizar de qué forma la flexibilidad de tiempo de trabajo propicia jornadas de trabajo rígidas, es pertinente presentar la descripción de cómo los agentes inmobiliarios definen su jornada laboral. Es necesario aclarar que con esto, de acuerdo a lo planteado por los agentes inmobiliarios a través de las entrevistas, se hace referencia al hecho de llegar a la oficina o de atender visitas de clientes, sin tomar en cuenta la revisión de correos electrónicos laborales y la atención de llamadas al celular corporativo que hacen tempano en la mañana y tarde en la noche algunos agentes ${ }^{43}$. Es decir que, los entrevistados relacionan la

43 Los agentes inmobiliarios en el cuestionario de caracterización aplicado inicialmente manifestaron que su jornada de trabajo se realizaba dentro de determinados horarios, ya fuera en la jornada definida por la organización, o en la mañana, o en la tarde. Así, en el cuestionario se les preguntó ¿En cuál de los siguientes horarios se desarrolla su jornada de trabajo? Las opciones de respuesta eran: a) Entre las 8:00 y las 12:00; b) Entre las 13:00 y las 18:00; c) Entre las 8:00 y las 18:00; d) Otro. Tras sistematizar la información se encontró que el $72 \%$ de las personas manifestaron cumplir con alguno de los horarios de trabajo propuestos y el $28 \%$ restante respondió "otro" dando como respuestas: "Todo el tiempo", "todo el tiempo de manera irregular", "en las tardes ocasionalmente empleo 1 y 2 horas", "horario irregular, unos días en la mañana y otros días en la tarde", "más de las 6:00 p.m." y, "de 5:00 a.m. a 9:00p.m."

A partir de estas respuestas, y bajo supuestos, podría pensarse que las personas que dieron las dos primeras respuestas - Todo el tiempo", "todo el tiempo de manera irregular",- así como la última, consideraron la atención del celular como parte de su jornada laboral, y por tanto se refieren al trabajo como una actividad permanente, o con una extensa jornada. No obstante, esto sólo se refleja en la respuesta de 3 personas del área comercial de las 12 que la conforman y a quienes se les aplicó el cuestionario. A razón de esto, podría pensarse que los 9 agentes inmobiliarios restantes no contemplan la atención del celular como parte de su jornada laboral o, que de acuerdo al uso que le dan no se genera una alteración o extensión de la jornada laboral definida.

Sin embargo, en el momento de la entrevista, a partir de la conversación que se entabló con cada agente, la tecnología apareció como otro elemento incidente en la definición de jornadas laborales, y a partir de eso, las personas consideraron de una manera diferente los tiempos laborales. Es decir, en un primero momento - en el cuestionario - posiblemente consideran que la tecnología es parte de su trabajo pero no lo asumen como un elemento que incida en la definición de sus tiempos laborales. Luego, tras la reflexión sobre el tema en otro contexto - la entrevista - si consideran que el uso de tecnología por lo general amplía sus tiempos y espacios laborales incidiendo en los otros espacios por los que transitan y los múltiples roles que desempeñan. En 
jornada laboral con la asistencia a la oficina o la atención personalizada de clientes, más no con actividades mediadas por la tecnología que pueden realizar desde su casa. Así, para estas personas la jornada laboral se relaciona con la atención personal de los asuntos laborales y con la asistencia a la oficina, más que con el cumplimiento de sus responsabilidades; podría decirse que esto es resultado de la habituación en la que se encuentran las personas con las jornadas laborales convencionales, y por tanto, consciente o inconscientemente las siguen reproduciendo; de ahí que las jornadas laborales, como se propuso anteriormente, puedan considerarse instituciones.

\subsubsection{Definición de tiempos laborales}

Los tiempos laborales definidos por los agentes inmobiliarios son diferentes entre ellos, respondiendo a las particularidades que surgen a partir de las variables antes mencionadas, pero aun así, algunos tienen como patrón común el adoptar ciertas características de las jornadas laborales convencionales. En este sentido, para algunos agentes es necesario establecer tiempos de trabajo estrictos, sobre todo los días entre semana, así como asistir a la oficina; para otros, esto no opera de la misma manera, y prefieren combinar espacios y tiempos laborales y no laborales.

Ahora, dada la naturaleza del negocio, los fines de semana necesariamente los agentes inmobiliarios deben trabajar pues, esos días es cuando más solicitudes reciben para visitar inmuebles o cerrar negocios por parte de los clientes; de ahí que esos días también hacen parte de sus tiempos laborales, aunque se ubiquen por fuera de los lineamientos convencionales de trabajo, y en este sentido, los agentes deben ser creativos para establecer las jornadas laborales.

\subsection{Definición de tiempos laborales en semana}

En general, los agentes comerciales de esta oficina inmobiliaria inician su jornada laboral entre las 8:00 a.m. y 10:00 a.m., y la finalizan entre las 6:00 p.m. y 7:30 p.m. No obstante, se identifican algunas particularidades y variaciones entre agentes respecto al manejo que le dan a esos lapsos de tiempo pues, hay quienes se concentran únicamente en el desarrollo de sus actividades laborales, o por el contrario, tiene la posibilidad de intercalar lo laboral y lo no laboral como una ventaja de armonización que les da este tipo de vinculación.

Entre quienes son más rigurosos con el cumplimiento de su jornada laboral se encuentran las dos personas de género masculino que hacen parte del presente estudio. Siendo que ellos cuentan con la flexibilidad de tiempo y en ocasiones hacen uso de ella, prefieren ser más estrictos con su jornada de trabajo,

este sentido, podría afirmarse que hay cierta rutinización con el uso del celular como parte de sus labores en su rol de agentes inmobiliarios, sin ser conscientes de que el uso de esta herramienta puede alterar el funcionamiento de sus tiempos laborales y no laborales. 
posiblemente porque esto no interfiere en la armonización de sus roles en los diferentes escenarios en los que se desenvuelven; por su parte, las mujeres se ubican en una posición diferente pues, son quienes más hacen uso de las bondades de la flexibilidad. Esto puede dar cuenta de los roles que tradicionalmente se han asignado a hombres y mujeres, los primeros figurando en las escenas de lo público, mientras las segundas, en el ámbito de lo privado principalmente, y ahora también en el público.

La persona "F", a pesar de que considera que la flexibilidad de tiempo y espacio le proporciona facilidades para desempeñarse en el ámbito laboral y en el familiar, prefiere definir un parámetro de horarios de trabajo, ya que eso genera hábitos laborales. De esta forma, combina las posibilidades que tiene a partir de la flexibilidad de tiempo con la definición de horarios de trabajo,

"Me gusta lo que hago porque tengo el tiempo y no tengo horario; $y$ aunque no tengo horario más me obligo a cumplir una jornada de trabajo porque el hecho que no lo haga implica que no se generen hábitos estrictos de trabajo y que por consiguiente no haya constancia: no te vuelves experta en lo que haces si no lo repites y por eso necesitas estar ahí".

De esta forma, ella considera que así no haya una jornada de trabajo establecida es importante definir tiempos de trabajo, para volverse experta en el negocio. De ahí que defina sus tiempos de trabajo de manera rigurosa, pero que al mismo tiempo le permitan armonizar lo laboral y lo no laboral. En este sentido, ella llega a la oficina entre 8:00 a.m. y 8:30 a.m., después de dejar organizadas algunas labores domésticas en su casa, y permanece en la oficina hasta la 1:00 p.m. A esa hora va a almorzar a su casa y después de esto se queda trabajando allí, revisando y dando respuesta a solicitudes de clientes por medio de correo electrónico, esto aproximadamente hasta las 4:30 p.m. que es la hora en la que llega su hijo del colegio. De igual manera, si hay alguna cita por la tarde la agenda máximo hasta a esa hora, pues en adelante prevalece su rol como madre apoyando a su hijo en la realización de tareas. Así, aunque ella tiene establecido un horario de trabajo, este funciona a partir de la dinámica y las demandas familiares que surjan, principalmente con su hijo. De modo que en este caso, la flexibilidad es un recurso pertinente para facilitar la conciliación de espacios, pero debe ser condicionada por horarios que le permitan desenvolverse en uno o en otro, de manera adecuada.

De manera similar, la persona " $E$ " considera que una de las ventajas que tiene a partir de la flexibilidad de la jornada laboral es que puede alternar tiempos y actividades laborales y no laborales,

"Llego a la oficina hacia las 9:00 a.m. hasta la 1:00 p.m. A esa hora voy a almorzar a la casa y regreso a las 2:00 p.m. a la oficina. A las 3:30 p.m. recojo a mi hijo en el colegio, lo dejo en la casa y me regreso a la oficina para estar allí hasta las 6:00 p.m. o 7:00 p.m." 
De esta forma, ella da cuenta de cómo el hecho de no tener una jornada laboral establecida, sino tener la posibilidad de ella misma definirla le da la facilidad de alternar tiempos y actividades laborales, con los no laborales, en este caso, orientados más hacia la familia. Por ejemplo ir a la oficina lo puede combinar con ir a la casa a preparar el almuerzo, recoger a su hijo en el colegio o, acompañar a su hijo o a su esposo a alguna diligencia. Dice ella que lo que más tranquilidad le da es que después de realizar sus actividades no laborales puede regresar a la oficina sin tener la presión de cumplimiento de tiempos o permisos.

Lo relatado hasta acá pone de presente por un lado el tema de la rutinización de las jornadas laborales, y como esto lleva a la institucionalización de las mismas (Scott, 2012; De la Rosa, 2002). Prácticas como cumplir un horario o asistir a la oficina hacen parte de las características de tener una jornada laboral convencional; esto genera que para los trabajadores dichas acciones se vuelvan habituales y por tanto, busquen establecer un patrón de actividades similares, conllevando así a la institucionalización de las mismas. Es por ello que, los agentes inmobiliarios definen un horario de trabajo lo más parecido posible al convencional, a pesar de tener la posibilidad de definir un horario flexible. De la misma manera, un elemento recurrente en lo planteado por estas personas es que, más allá de la definición de los horarios de trabajo, el inicio de la jornada laboral está estrechamente relacionada con la hora de la llegada a la oficina. Esto nuevamente deja ver que a partir de lo habitual que es esta práctica en el cumplimiento de la jornada laboral convencional, los agentes inmobiliarios tiendan a repetirla, así no estén obligados a hacerlo. No obstante, esto se revisará con mayor profundidad posteriormente.

Por otro lado, deja ver que, a pesar de que se supone los agentes cuentan con flexibilidad de tiempo éste es supeditado a un horario de trabajo que de manera personal definen pero además, y principalmente, a la disponibilidad que tengan los clientes para hacer las visitas a los inmuebles. Entonces, podría decirse que la flexibilidad de tiempo que dice ser el valor agregado de este tipo de contratación, por lo menos para estas personas se ve ensombrecida, no sólo por la auto definición de horarios de trabajo, sino también por la naturaleza misma del negocio, en la que el recibir ingresos depende de los negocios que hagan, y para que haya más posibilidad de cerrar negocios debe haber apertura y disponibilidad para atender al cliente de acuerdo con sus requerimientos en términos de tiempo. Entonces, ¿El horario si es tan flexible como se piensa? Realmente en estas condiciones los agentes inmobiliarios no cuentan con la flexibilidad en la jornada laboral que se hubiera considerado inicialmente pues, su tiempo lo distribuyen definiendo horarios de trabajo en función de las necesidades del negocio y sus necesidades personales y, aunque se les permite tener cierta autonomía para combinar los dos escenarios, finalmente les implica estar sujetos al cumplimiento de unos tiempos y unas demandas laborales permanentemente.

Pero, hay otros agentes comerciales que son menos estrictos con la definición de su jornada de trabajo y hacen uso de la flexibilidad que les proporciona la 
vinculación free lance para armonizar los escenarios laborales y los no laborales. Ellos procuran iniciar su jornada laboral ente 8:00 a.m. y 10:00 a.m., y dependiendo de los asuntos que tengan previstos para el día, pueden hacerlo en la oficina, desde su casa recibiendo llamadas y respondiendo correos, o atendiendo las visitas que algunos clientes pueden solicitar. De hecho, como dice la persona " $G$ ",

"Este es un trabajo relajado. No es obligación tener que trabajar todos los días, todo depende de los requerimientos que haya".

Ella por ejemplo procura iniciar su jornada entre 8:30 a.m. o 9:00 a.m., sea en la oficina o en la casa, y trabaja hasta las 12:30 del mediodía, hora en que almuerza con su hija. Cuando no tiene citas en la tarde se va para la oficina y trabaja hasta aproximadamente las 6:00 p.m. y cuando tiene citas, procura agendarlas por lo general hasta las 5:30 p.m. En la tarde cuando llega a su casa, si hay algo urgente para hacer de la oficina, como subir un inmueble a la página o llamar a clientes, lo hace aproximadamente hasta las 7:30 p.m., que es la hora en la que llega su hija de trabajar.

La persona " $\mathrm{N}$ " igualmente considera que la flexibilidad de horario que tiene en este trabajo es una excelente condición laboral para ella, pues no es necesario cumplir un horario, sino de lo que se trata es de buscar negocios y coordinar tiempos, dándole esto la facilidad de dedicarse tiempo para ella misma. En este sentido, procura llegar a la oficina entre las 9:00 a.m. y las 9:30 a.m., después de haber cumplido con su rutina matutina diaria que incluye hacer ejercicio, tomar el desayuno y dejar resueltos asuntos domésticos en su casa

"Yo considero que necesito tiempo para mí y no estar todo el tiempo cumpliendo un horario a estas alturas de la vida. Ya quiero como relajarme un poco y que este trabajo sea parte de eso".

Por lo anterior, es posible afirmar que así como hay personas para quienes a pesar de la flexibilidad con que cuentan es importante e inclusive necesario el establecimiento de horarios de trabajo y la asistencia a la oficina como escenario laboral, hay otro grupo de personas que, conscientes de las condiciones de flexibilidad de tiempo y espacio que les da su trabajo y de las ventajas y facilidades que eso representa para el desarrollo de sus actividades no laborales, hacen uso de las mismas para armonizar y priorizar sus asuntos personales sobre los laborales.

Pero además, es ineludible resaltar que justamente estas mujeres que definen sus jornadas laborales de manera flexible son jubiladas, es decir que reciben ingresos adicionales; no tienen hijos pequeños que dependan económicamente de ellas; y, tampoco son las cabezas de hogar. Por tanto, una primera relación que se evidencia es que, entre menos responsabilidades económicas y sociales, como resultado de los roles desempeñados tengan las personas, habrá mayor posibilidad de que definan los tiempos y espacios laborales de manera autónoma. 
En todo caso, lo que se percibe en general es que en la definición de los tiempos laborales para los días en semana hay una tendencia hacia la repetición del patrón de comportamiento socialmente establecido respecto a los tiempos y espacios de trabajo. Unos los hacen con mayor rigurosidad que otros, pero a fin de cuentas lo que esto deja ver es que hay una rutinización de las jornadas de trabajo a partir de condiciones espaciales y temporales que conllevan a la institucionalización de las mismas en tanto persisten como parte de un patrón de comportamiento - trabajar y como consecuencia del conocimiento tácito que los actores tienen sobre estas a partir de productos sociales y del contexto, tales como sus experiencias pasadas 0 lo socialmente establecido (Scott, 2012:206, 209).

\subsection{Definición de tiempos laborales los fines de semana}

Bajo la idea de la disponibilidad de tiempo que deben tener los agentes inmobiliarios para atender las citas solicitadas por los clientes para mostrar inmuebles, es común que este trabajo tienda a desarrollarse en gran medida los fines de semana pues, lo habitual es que los clientes trabajen entre semana, y dispongan de tiempo los otros días para considerar este tipo de asuntos. Así pues, la definición de jornadas de trabajo por parte de los agentes comerciales, no sólo opera para los días de semana, sino también para los fines de semana; y en este sentido, también es posible identificar a quienes son más estrictos con esto y quienes no, entrando a jugar en esta decisión elementos como que el fin de semana es el espacio de tiempo en el que hay mayor posibilidades de cerrar negocios, pero a su vez, son días tradicionalmente considerados de descanso, en los que el desarrollo de actividades no laborales, tienen preponderancia.

La tendencia para agendar citas los fines de semana es que el sábado es un día de mostrar inmuebles hasta las 4:00 p.m. aproximadamente, y en lo posible los domingos no se muestran inmuebles; sin embargo, debido a que este negocio depende en gran medida de la disponibilidad y solicitud de los clientes, hay unos agentes que son más flexibles con sus tiempos, dando cabida a modificaciones de este patrón, pero otros por el contrario tienen claro que es necesario diferenciar espacios y poner límite a lo laboral, con el propósito de que no interfiera en lo personal, que la mayoría de veces está más relacionado con asuntos familiares.

De acuerdo con esto, la persona "O" reafirma el hecho de que como agente inmobiliario debe contar con disponibilidad para trabajar los fines de semana, dado que es un momento en el que hay altas posibilidades de hacer negocios. La disponibilidad implica no sólo contar con el tiempo, sino también con la disposición para atender temas laborales en tiempos en los que tradicionalmente se realizan otro tipo de actividades,

"En este negocio toca trabajar cuando el cliente puede y esto implica fines de semana pues, es difícil forzar a la gente que sea en el horario de oficina. Si uno decide no trabajar los fines de semana, no se produce". 
La persona "E" igualmente considera que los fines de semana es el lapso de tiempo en el que hay mayor demanda de trabajo debido a la disponibilidad de los clientes, pero al mismo tiempo manifiesta que esos días son los que le dedica a su familia; es decir, los fines de semana tienen para ella una connotación familiar y laboral simultáneamente. Es interesante la forma en que ella resuelve esa dicotomía, pues finalmente prevalece lo laboral sobre lo familiar,

"Los fines de semana atiendo bastantes clientes; me concentro en mostrar muchos inmuebles pero no vengo a la oficina. Los sábados y los domingos estoy dedicada a mi familia pero siempre muestro; entonces busco la manera de escapármele a mi marido para ir a mostrar inmuebles cuando mis clientes lo requieren".

La idea de "escapársele al marido" deja ver la preponderancia del ámbito laboral, sobre el familiar, pero además, el conflicto que se puede generar en su familia a causa de no separar los dos escenarios. A partir de esto es importante reflexionar sobre como el trabajo desplaza otros contextos tales como el social y el familiar, y entonces, lo que podría proporcionar la flexibilidad en términos de facilitar el desenvolvimiento de múltiples roles, aquí genera un conflicto entre lo familiar y lo laboral, a causa de la disponibilidad permanente y de la flexibilidad sin límites bajo la cual trabaja esta agente inmobiliaria.

Sin embargo, también hay otros agentes que prefieren ser mucho más estrictos con la diferenciación entre lo laboral y lo no laboral los fines de semana, estableciendo límites por medio de tiempos y horarios de trabajo, que en parte respondan a la dinámica y actividades familiares. Así pues, como se planteó anteriormente, definen su horario de trabajo los sábados por ejemplo hasta medio día, hasta las 4:00 p.m. o todo el día, y el domingo por el contrario se pueden desconectar completamente del ámbito laboral, o decidir programar citas sólo muy temprano en la mañana, o hasta el mediodía.

La persona "B" "por ejemplo es consciente de la importancia que tiene trabajar los fines de semana pues, seguramente tiene más posibilidad de conseguir clientes y cerrar negocios. Bajo esa lógica, dispone los sábados para atender citas todo el día, y los domingos únicamente en la mañana, pensando que después de mediodía comparte en familia el almuerzo y actividades de descanso y esparcimiento.

"Estoy organizando dedicar el sábado a citas y el domingo sólo en la mañana, para ya después de mediodía descansar y estar en familia; el domingo por la tarde es cuando comparto con mi familia en casa, por eso prefiero dejarlo sagrado para ellos".

De manera similar la persona " $G$ " busca no programar muchas citas los sábados porque, en palabras de ella, "es un día para compartir en familia"; sin embargo, hay ocasiones en las que sí lo hace, porque a los clientes se les facilita más ese 
día, procurando que sea en la mañana, o máximo hasta las 3:00 p.m. Los domingos por lo general no programa citas, a no ser que se trate de clientes específicos a quienes les quede imposible que sea en otro momento; ella accede sólo bajo estas condiciones, dado que no es una situación que se presenta todos los domingos pero, en caso de que fuera así, dice que sería más estricta estableciendo límites para ello, pues el domingo es el día para pasar tranquila en casa con su hija, o para visitar a su mamá.

La persona " $F$ " es un poco más estricta con el horario de trabajo los fines de semana pues es el tiempo que tiene para compartir con su hijo actividades lúdicas y de esparcimiento como jugar, ir al parque, hacer ejercicio, ir a la iglesia, ver películas, entre otras. Por eso, dado que el sábado es un día importante para mostrar inmuebles procura programar citas lo más temprano posible para destinar a su familia lo que reste del día. El domingo es más estricta pues no agenda citas y en lo posible no atiende llamadas,

"Los domingos no muestro inmuebles, procuro no contestar llamadas y si alguien me escribe por el whats app respondo que les envío la información el lunes. Entonces es muy difícil que a mí me pongan una cita un domingo, y si así lo requiere el cliente le propongo que la cita sea el sábado en la mañana; tiene que ser una situación muy extrema para que yo atienda los domingos".

En este caso, contrario a los anteriores hay mayor rigurosidad en la diferenciación de tiempos; posiblemente eso responda al rol de madre que tiene esta agente, el cual es altamente demandante debido a la edad de su hijo - 7 años-. Según esto, ella prioriza su familia sobre el trabajo y hace uso de los medios tecnológicos como una herramienta de apoyo para desenvolverse en el escenario familiar sin desatender los asuntos laborales. De esta forma, debido a la edad del hijo se propone un patrón de comportamiento diferente al descrito por las personas antes mencionadas, quienes tienen hijos en edades independientes.

De igual forma la persona "L" tiene un parámetro muy claro sobre los fines de semana, dado que es el tiempo que le dedica a su familia; por eso, es muy poco el tiempo que dedica a asuntos laborales los sábados y domingos, pues considera que al dedicarse por completo al trabajo los días de entre semana, los fines de semana puede tener la posibilidad de dedicarse por completo a su familia, principalmente a su hijo.

"Los fines de semana no le dedico ni el $5 \%$ al trabajo. Si me llega un correo, lo miro, lo dejo almacenado en mi memoria y lo resuelvo hasta el lunes y si un cliente me solicita cita para fin de semana no la hago; yo trato de manifestar siempre que estoy trabajando de lunes a viernes sin horario, pero que los fines de semana son mi momento familiar, y yo le doy prioridad a eso". 
A partir de lo presentado en esta sección es posible reafirmar lo dicho en un capítulo anterior, acerca de que la familia es uno de los elementos condicionantes para definir los tiempos laborales, en este caso, los fines de semana: al desenvolverse en un núcleo familiar constituido los agentes son más estrictos con la diferenciación de espacios o por el contrario, buscan como "escaparse" de lo familiar para hacer frente a lo laboral. Inclusive, quienes tienen hijos pequeños son mucho más rigurosos con el hecho de no trabajar los fines de semana, que quienes tienen hijos en edades independientes; estos últimos, bajo ciertas condiciones especiales pueden trabajar los fines de semana. De ahí que entonces sea posible sostener que la dinámica familiar es un elemento incidente a la hora de definir las jornadas laborales.

Por otra parte, es posible afirmar que para quienes son flexibles con el tiempo de trabajo los fines de semana, la dinámica laboral define los espacios familiares en la mayoría de los casos; a pesar de que se considera el fin de semana un tiempo para compartir en familia, se prioriza el trabajo y las demandas de los clientes, y a partir de ello se definen las actividades familiares. En los casos en los que hay una estricta diferenciación de tiempos sucede lo contrario pues, los tiempos de trabajo son establecidos a partir de su dinámica familiar habitual, y salvo situaciones especiales, son modificados. En este sentido, será el criterio que tenga el agente inmobiliario para definir sus tiempos de trabajo los fines de semana lo que propiciará que se generen o no conflictos entre lo laboral y lo familiar; sin embargo, esto indudablemente está incidido por temas trascendentales como el dinero y lo relevante que sea para cada persona los ingresos que reciben a partir de los negocios realizados.

\subsubsection{Asistencia a la oficina}

Con relación a la asistencia a la oficina es recurrente la lógica de rutinización en algunos agentes, para quienes de la misma manera que es necesario establecer y cumplir un horario de trabajo, deben asistir todos los días a la oficina, así eso no sea obligatorio; es pertinente aclarar que no precisamente las mismas personas que son más estrictas con su horario, operan bajo la misma lógica para la asistencia a la oficina. Por otra parte, hay agentes que son flexibles respecto a su asistencia a la oficina, considerando que debido a la naturaleza que tiene su trabajo cuentan con la posibilidad de desarrollarlo en otros espacios como su casa, y por tanto no deben concurrir todos los días ni permanecer todo el tiempo allí. A pesar de ello, es común la percepción que tienen sobre la oficina, como un punto en el que se centraliza información, cuentan con algunas herramientas de trabajo y les da la posibilidad de captar clientes, de la misma manera que funge como un espacio de socialización e intercambio de experiencias con la gerencia de la oficina y sus compañeros de trabajo.

Quienes consideran necesario ir a la oficina todos los días lo hacen porque piensan que ese es el lugar de trabajo apropiado pues entre otras cosas, allí cuentan con diferentes herramientas que les facilitan el cumplimiento de sus responsabilidades y, porque a la oficina llegan los clientes. De hecho, la persona 
"A" va todos los días a la oficina porque siente que así cumple con su responsabilidad,

"Venir a la oficina es la responsabilidad del cumplir, de querer hacer algo. No es lo mismo quedarse en la casa que ir a la oficina, porque en la oficina ves los clientes. Yo me puedo quedar en la casa rascándome la barriga y mirando el computador, llamar y hacer la cita pero no es lo mismo, porque en la oficina puedo ver la carpeta de los clientes. Además, venir a la oficina es aprender de lo que les pasa a mis compañeras para no cometer los mismos errores".

Ella atribuye al espacio físico el desarrollo de determinadas actividades, y en este sentido cobra importancia la asistencia a la oficina en tanto indica responsabilidad y compromiso con su trabajo, además que le da la posibilidad y los recursos para desarrollarlo de manera idónea, cosa que no sucede si se queda trabajando en casa. Y bajo esta misma idea la persona "E" afirma la importancia y la necesidad de ir todos los días a la oficina a trabajar pues considera que desde su casa no puede dedicarse a cuestiones laborales dado que al llegar allá prima su rol como esposa y madre.

"Yo no funcionaría con un teletrabajo o una cosa así. Para mi es importante venir a la oficina, porque es la manera de conseguir clientes nuevos. Si yo me quedo en la casa me dedico a hacer las cosas de la casa y posiblemente conteste llamadas de clientes que ya tengo, pero no expando mi negocio".

Con lo anterior, se reitera la percepción de que la oficina es el centro de negocios y es el espacio en el que más posibilidades hay para captar nuevos clientes e inmuebles. Pero además, la oficina es definida como el espacio diferenciador entre el escenario laboral y el no laboral; es decir, ir a la oficina implica trabajar y, estar en la casa significa hacer cosas diferentes al trabajo. De modo que, es el espacio en el que se ubica la persona el que determina el rol que debe asumir o prevalecer, o lo que es lo mismo, los roles están definidos a partir de lo socialmente establecido de acuerdo con los espacios en los que se desenvuelve cada persona. Esto es coherente con lo planteado por Aritzeta y Ayerstarán (2003) al afirmar que los roles están directamente asociados a ámbitos de relación definiendo comportamientos para quienes los desempeñan a partir de tiempos y espacios diferentes. De esta forma, la asistencia a la oficina está relacionada con el cumplimiento de deberes laborales y estar en la casa representa estar en la disposición de atender otro tipo de asuntos; hay una diferenciación de roles a partir del escenario en el que su ubique la persona, en la oficina como agente y en la casa como madre y/o esposa, por ejemplo.

No obstante, otro grupo de agentes considera que el trabajo que realizan no exige necesariamente estar en la oficina, sino que por el contrario pueden realizarlo en otros espacios como su casa, haciendo uso de herramientas de trabajo como el celular y el computador; por tanto, no ven necesario el ir a la oficina todos los días, 
ni permanecer allí todo el tiempo. En efecto, hay agentes que establecen ir a la oficina 2 ó 3 veces por semana, dependiendo de las actividades personales 0 laborales que tengan previstas. Otros por el contrario, consideran que no es necesario permanecer en la oficina todo el tiempo, así que van todos los días aunque estén allí solo por momentos. No obstante, lo que es común en estas posturas es que, a pesar de no verlo necesario, de alguna manera hacen presencia en la oficina. En este sentido, la oficina sí se considera un elemento fundamental para el desarrollo de este trabajo y para el cumplimiento de una jornada laboral.

A partir de lo anterior es posible afirmar que ir a la oficina representa la posibilidad de conseguir nuevos clientes y de incrementar así las posibilidades de negocio. Pero más allá de eso, es posible reafirmar la idea planteada en un capítulo anterior acerca de que la asistencia a la oficina es un mito racionalizado en tanto socialmente está legitimado que ese es el lugar de trabajo, y la asistencia y permanencia en el mismo es señal de cumplimiento de los deberes laborales. De esta forma, la asistencia a la oficina es un mito racionalizado que da legitimidad al cumplimiento de las jornadas laborales en tanto instituciones.

De acuerdo con Meyer y Rowan (1977), los mitos racionalizados no generan estructuras organizacionales formales, sino que les dan legitimidad. En virtud de ello, una de las propiedades clave de los los mitos es que están institucionalizados y por tanto, sobrepasan cualquier consideración de los individuos. (Meyer y Rowan, 1977:343). De lo anterior es posible inferir que los mitos, al ser prescripciones racionalizadas, no son cuestionados porque crean sentido y proporcionan confianza, y en esta misma lógica, se siguen reproduciendo. Por tanto, aunque la asistencia a la oficina no es obligatoria, por lo menos no para los agentes inmobiliarios, les crea sentido en el desarrollo de su trabajo, y por eso asisten y cumplen los requerimientos de la gerencia de la organización respecto a esto sin ningún tipo de resistencia, legitimando así la jornada laboral que deben cumplir en esta organización.

\subsubsection{Elementos que hacen rígidas las jornadas laborales flexibles}

A partir de lo anterior se puede decir que, pese a la flexibilidad de la jornada laboral bajo la cual se estructura el trabajo de los agentes inmobiliarios, siendo ésta una de las principales razones por la que gran parte de ellos se vincularon a él, siguen prevaleciendo dinámicas y rutinas que se han construido alrededor del trabajo convencional, en el que hay establecidos dentro de los parámetros básicos el cumplimiento del horario, y la asistencia y permanencia en la oficina como lugar de trabajo; esto responde a la rutinización de comportamiento y a la institucionalización de prácticas laborales, como se ha planteado anteriormente.

Así, lo que en apariencia es una jornada laboral flexible en términos de tiempo y espacio, finalmente se convierte en una jornada igual o más estricta que las definidas por la organización, sujetando a quienes trabajan bajo esta modalidad no al cumplimiento de un horario fijo todos los días, pero sí a la sujeción permanente 
en el escenario laboral; es decir, la flexibilidad laboral con la que cuentan los agentes inmobiliarios muchas veces implica que siempre estén trabajando, condición que desdibuja la autonomía de tiempo propia del free lance, y que para muchos agentes fue llamativa como respuesta a la rigidez de trabajos en experiencias anteriores, dado que les daba facilidad para conciliar tiempos laborales y no laborales. Lo lamentable, como se verá más adelante, es que la sujeción resultante de esta flexibilidad también genera conflictos para el desempeño de roles laborales y familiares.

En este contexto, la flexibilidad de la jornada laboral en esta organización implica que el tiempo dedicado al trabajo sobrepase los límites que por ejemplo están definidos en un trabajo convencional, y en consecuencia, la condición de flexibilidad en cambio de proporcionar autonomía en el manejo del tiempo a quien la tiene, lo sujeta más a los temas laborales. Este paso de la flexibilidad a la rigidez se ve incidido por condiciones, tanto de la organización y el funcionamiento del negocio, como de los agentes inmobiliarios, su historia de vida y el momento particular en el que se encuentran. En la figura ocho se presentan las condiciones que delinean el camino para pasar de tener una flexibilidad en el horario de trabajo, a estar inmerso en la rigidez de los tiempos y espacios laborales.

\section{Figura 8. Vinculación free lance: de la flexibilidad a la rigidez}

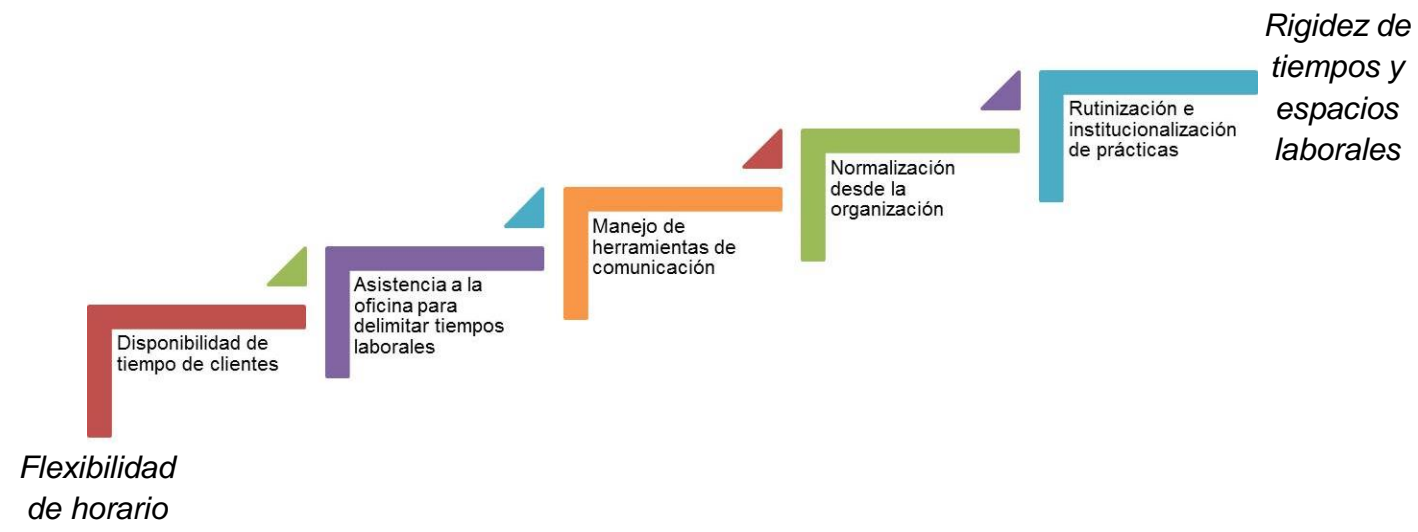

Fuente: Elaboración propia

- Disponibilidad de tiempo de clientes: Los agentes inmobiliarios están sujetos a las solicitudes de los clientes en términos de tiempo para mostrar inmuebles, o atender sus requerimientos. En ocasiones, los clientes tienen posibilidad de atender estos temas fuera de los horarios laborales tradicionales; es decir, muy temprano en la mañana, finalizando el día o los fines de semana. No obstante, hay clientes que también tienen la posibilidad de atender estos temas en tiempos laborales habituales. Esto hace entonces que la flexibilidad de horario en realidad esté sujeta a la disponibilidad de tiempo de los clientes, ya sea en los tiempos tradicionalmente laborales, o fuera de estos. 
- Asistencia a la oficina para delimitar tiempos laborales: La flexibilidad de la jornada laboral free lance es en términos de tiempo y espacio: de la misma manera que los agentes inmobiliarios tienen la potestad de definir sus tiempos de trabajo, pueden hacerlo con el espacio laboral. Así, ellos pueden trabajar desde su casa, o desde cualquier otro escenario, no necesariamente la oficina de C21 Country. Sin embargo, para muchos el asistir a la oficina representa estar trabajando, y estar fuera de ella implica que no lo están. Esto significa que para una cantidad importante de agentes el ir a la oficina se convierte en un rito que contribuye a que la flexibilidad se vuelva rígida, en tanto están sujetos a un espacio físico para el desarrollo de su labor pero además, deben hacerlo dentro de los horarios de funcionamiento de la oficina que la organización ha dispuesto.

- Manejo de herramientas de comunicación: Como se planteó en un apartado anterior ${ }^{44}$, las principales herramientas de comunicación con las que cuentan los agentes para el desempeño de su trabajo son el celular y el computador, en tanto les da la posibilidad de permanentemente atender llamadas y mensajes relacionados con su trabajo. Sin embargo, aunque en principio esto parece una ventaja para dar mayor dinamismo al negocio, puede convertirse en un elemento que les impida desconectarse del escenario laboral en tanto pueden recibir requerimientos a cualquier hora y en cualquier momento. De esta forma, la flexibilidad de la jornada laboral, mediada por el uso de estas herramientas de comunicación puede implicar la sujeción permanente al escenario laboral sin necesidad de cumplir un horario o asistir a una oficina; esto es relativo a como cada agente defina el uso de este tipo de herramientas de comunicación.

- Normalización desde la organización: A pesar de la vinculación free lance de los agentes inmobiliarios, y la flexibilidad y autonomía que de esta condición se deriva, la organización ha definido una dinámica que de cierta manera genera control sobre los agentes, a través de la cual establece cierta normalización. Por una parte los agentes deben "hacer planta" los sábados; la inmobiliaria estableció unos turnos de trabajo para esos días, a fin de garantizar que haya como mínimo dos personas del área comercial en la oficina para atender a los clientes que incrementan su demanda de estos servicios los fines de semana. Otra práctica a partir de la cual la organización normaliza la flexibilidad de la jornada laboral de los agentes inmobiliarios es el comité inmobiliario; reunión en la que deben participar todos los agentes de manera obligatoria, y se lleva a cabo los martes cada 15 días desde las 9:00 a.m. hasta la 1:00 p.m. en la oficina. Esta reunión funge como un espacio de capacitación, de direccionamiento y unificación de criterios entre la gerencia y los agentes y, de socialización de experiencias entre ellos mismos.

Entonces, debido a la vinculación free lance los agentes no tendrían la obligación de cumplir con estos parámetros definidos por la organización, podría

${ }^{44}$ El lector recordará que en la primera parte del análisis, al presentar la definición de las jornadas laborales en C21 Country, se propuso que uno de los elementos incidentes en ello, por parte de la organización es la asignación y uso de herramientas de comunicación. 
pensarse que los cumplen como estrategia de captación de clientes - planta de los sábados - , o como parte de su rutinización con hábitos laborales como resultado de experiencias anteriores - asistencia a comités-. Sin embargo, más allá de esto, es importante resaltar como estos mandatos de la organización son normalizados y, restringen aún más la condición free lance de los agentes inmobiliarios.

- Rutinización e institucionalización de prácticas: Otro elemento que puede incidir en que se desdibujen las características propias de la vinculación free lance, está relacionado con las prácticas que han sido interiorizadas por los agentes inmobiliarios a partir de experiencias laborales anteriores, o de la construcción social que hay acerca de las jornadas laborales. De esta forma, actividades como la asistencia diaria a la oficina, el establecimiento y cumplimiento de un horario laboral, la participación en reuniones y eventos que han sido normalizados por la organización están tan interiorizadas que muchas veces ni se cuestionan sino que por el contrario se introyectan como parte de la rutina de trabajo, a pesar de que no son un requerimiento para ellos, tal como si lo sería bajo otra condición de vinculación laboral.

De esta forma, los agentes se organizan a partir del discurso legitimado de las jornadas laborales, significando el trabajar a partir del cumplimiento de un horario y de asistir a la oficina. Esto es coherente con lo planteado por Scott (2012), quien afirma que los aspectos más persistentes o más institucionalizados de la conducta, son el resultado tanto de acciones pasadas, como del contexto o medio en el que ocurre esa acción en proceso (Scott, 2012:206). De esta forma, a pesar de las condiciones que les proporciona el free lance, para los agentes inmobiliarios prevalece la construcción social de las jornadas laborales, ubicándose más en un contexto laboral convencional, y desligándose del free lance en estricto sentido.

Ahora, la forma en que incidan estos elementos para que la flexibilidad de tiempo laboral se convierta en el cumplimiento de un horario de trabajo rígido dependerá del criterio de cada agente, y los límites o parámetros que defina para cada uno; esto va a estar permeado por lo que represente este trabajo para su vida, los diferentes escenarios por los que transite y los roles que allí asuma, por la dependencia económica que tenga de los ingresos recibidos a partir de esta labor, por mencionar algunos. Pero, en términos generales podría decirse que para quienes este trabajo es su única fuente de ingresos y son cabeza de familia, la disponibilidad permanente para resolver asuntos laborales será una constante, transformando lo que inicialmente sería el principal beneficio de la flexibilidad de las jornadas laborales en una problemática para el desempeño de sus roles laborales y no laborales, especialmente en el escenario familiar; sucede lo contrario para quienes reciben ingresos adicionales, o aún más, no tiene personas a su cargo, pues cuentan con mayor autonomía para definir elementos diferenciadores entre los escenarios en los que se desenvuelven. De igual manera, el facilitar el paso de la flexibilidad de la jornada laboral a la rigidez de la 
misma puede ser recurrente en los agentes que se desenvuelven en muy pocos escenarios, convirtiendo el escenario laboral en su centro de vida, o el espacio a partir del cual pueden relacionarse y tener algún tipo reconocimiento.

\subsubsection{La flexibilidad de la jornada laboral establecida por la organización.}

Quienes conforman el área administrativa de la organización están vinculadas laboralmente a la misma. Tiene definidos unos horarios de trabajo, así como el compromiso de cumplir con determinadas responsabilidades en el lapso de éste; su asistencia a la oficina es obligatoria y su permanencia en ese lugar también, a excepción de situaciones en las que por cuestiones laborales deban atender temas particulares en otro lugar. En general, esta es la dinámica socialmente aceptada y reconocida para una persona que se encuentra laborando bajo un modelo de contratación convencional, y al que por tanto, cada quien debe ajustar sus formas y modos de desenvolvimiento en otros escenarios. Entonces, para estas personas, a diferencia de los agentes inmobiliarios, la asistencia a la oficina o el cumplimiento de un horario no es un mito racionalizado, sino que hace parte de su rutina como parte del cumplimiento con su jornada laboral.

No obstante, esto que en apariencia es rígido y refleja la situación del día a día de miles de personas que hacen parte del mundo laboral, en C21 Country tiene algunos visos de flexibilidad, posiblemente atribuidos a características particulares de la configuración, estructura y funcionamiento de la organización, a características de quienes conforman el equipo de trabajo, o a ambos elementos en conjunto. A continuación se presenta la forma en que es asumida la jornada laboral por quienes deben cumplirla, las posibilidades que les proporciona la organización para que esa jornada sea manejable en función de su dinámica familiar y los elementos que se presume inciden en que la organización brinde esas facilidades.

\subsubsection{Cumplimiento de horario de trabajo}

Un asunto que incide en el desarrollo de la dinámica laboral en el marco del cumplimiento de la jornada definida por la organización es el horario, y cómo a partir de éste se estructuran y organizan los espacios para lo no laboral. El horario de trabajo definido para el personal administrativo es de lunes a viernes de 8:00 a.m. a 6:00 p.m. con una hora de almuerzo ${ }^{45}$, organizada de manera tal que sólo una de estas personas esté fuera de la oficina. Es decir, la persona "D" toma su hora de almuerzo de 12:00 m a 1:00 p.m., enseguida la toma la persona "K" y finalmente, la persona "C".

Tanto la persona "C" como la persona "K" durante la hora de almuerzo van a su casa para compartir ese espacio con sus parejas. Aunque a veces resulta problemático debido a que con el desplazamiento se reduce el tiempo establecido para almorzar, manifiestan que es un espacio valioso para regresar a casa y convivir con sus parejas. A la persona "K" le gustaría tener un poco de flexibilidad

\footnotetext{
${ }^{45}$ En el contexto colombiano el almuerzo hace referencia a la comida del mediodía.
} 
en este horario, para poder comer con tranquilidad, dada la distancia que hay entre su casa y la oficina pero, a pesar de ello considera que ésta es una posibilidad importante que les da este trabajo. De igual manera lo considera la persona "C":

"Almuerzo con mi esposo y comparto con él un rato; ese tema de ir a la casa a almorzar con él me gusta mucho porque así sea de carrera que almuerzo tengo la posibilidad de hablar y compartir con él”.

El tema de la comida presenta una situación en la que a pesar de la rigidez de la jornada laboral que cumplen, tienen la posibilidad de manejar tiempos y espacios laborales y familiares, como consecuencia de la corta distancia que hay entre la oficina y su casa. Pero, el hecho de que estas personas establezcan formas de conciliación permite pensar que finalmente se adecúan a la jornada de trabajo establecida. En este sentido, la jornada laboral se ha institucionalizado y se da por hecho, sirviendo como una fuente importante de patrones estables de comportamiento (Tolbert y Zucker,1996:179).

Respecto a la duración de la jornada, manifiestan las personas entrevistadas que por lo general los tiempos se cumplen y que son esporádicas las ocasiones en que deben quedarse más de las 6:00 p.m. para cumplir con responsabilidades laborales, y cuando deben hacerlo no es más de una hora. Esta situación es percibida como positiva, sobre todo por la entrevistada "C" quien en experiencias laborales anteriores debía cumplir con largas jornadas de trabajo, muchas veces asociado más que a la carga laboral, a la presión que generaban compañeros y jefes; es decir, anteriormente sus jornadas laborales estaban definidas, más que por horarios de trabajo, por las condiciones resultantes del presentismo ${ }^{46}$.

La persona "D" relata que aunque es muy esporádico que deba quedarse más de las 6:00 p.m., cuando eso sucede se alteran por completo todas las actividades y rutinas que ha previsto realizar después de su jornada laboral.

"A veces me da mal genio que son las 6:00 p.m. me voy a ir y me dicen que necesitan que les haga una consignación y yo voy con planes de ir al gimnasio. El problema es que si yo salgo a las 6:00 p.m. en punto, a las 8:00 p.m. en punto salgo del gimnasio y José me recoge; pero si voy a hacer un pago, un envío o una consignación estoy llegando al gimnasio a las 7:00 p.m. de la noche y toda mi rutina personal cambia, empezando porque así ya no puedo llegar a cenar con mi pareja como es costumbre y como lo acordamos los dos".

${ }^{46}$ Es pertinente recordar que el presentismo hace referencia a la suposición de que los individuos deben estar presentes en el trabajo para tener éxito. Perlow, Leslie A. (1995) Putting the work back into work/family. Group and Organization Management, 20,2, 227-39. 
Así que, a pesar de que las personas del área administrativa trabajan cumpliendo la jornada de trabajo establecida por la organización, tienen la posibilidad de armonizar espacios familiares y laborales en tanto las exigencias de tiempo laboral por lo general no exceden lo ya acordado, y a partir de eso, ellas pueden organizar sus actividades no laborales ${ }^{47}$.De modo que, hay una aceptación de la jornada laboral y a partir de ésta, las personas establecen la pauta para definir su desenvolvimiento en otros contextos; la jornada laboral marca las pautas de convivencia y comportamiento en los escenarios no laborales por los que transitan las personas, pero cuando son alteradas implica una modificación completa de la dinámica en los otros escenarios. El que se modifiquen las jornadas laborales que ya son aceptadas y se realizan rutinariamente implica que se modifique un patrón de comportamiento y con ello, quien se enfrenta a esa nueva situación debe elegir y tomar decisiones para adecuarse al nuevo panorama que se presenta. Entonces, dado que las rutinas reducen la posibilidad de elección de las personas (Scott, 2012), en tanto las cosas ya están dispuestas, al ser modificada ubica a la persona en una posición diferente, en la que debe elegir por ejemplo entre aceptar la modificación de la jornada laboral o cumplir con su rutina habitual, previendo las consecuencias que de las dos acciones se pueden derivar.

La persona " $\mathrm{K}$ " por su parte tiene una postura un tanto diferente respecto a la jornada laboral. Ella dice que por lo general durante su horario de trabajo cumple con las responsabilidades asignadas, sin excederse en la jornada y que es inusual cuando debe quedarse más de las 6:00 p.m. A pesar de esto, ella manifiesta que le gustaría, al culminar sus tareas diarias así no haya finalizado su jornada laboral, poder irse a su casa, sin necesidad de quedarse cumpliendo horario. De hecho ella plantea que en caso de tener la posibilidad de trabajar de esa manera, no le vería problema a exceder su jornada de trabajo ocasionalmente, porque de alguna manera se sentiría compensada con los días en los que pudiera salir temprano.

"A veces digo bueno ya acabe, rico que me pudiera ir para la casa. Eso sería chévere, tener tareas diarias y cuando las acabe poder irme; es decir, no tanto cumplir horario, sino estar en función del cumplimiento de actividades".

Para esta persona por ejemplo, a pesar de que aparentemente la jornada laboral no es una limitante para el desarrollo de sus actividades no laborales, y cumple sin mayor problema la jornada definida por la organización, considera innecesario el cumplir horario y piensa en cambio que sería más amable para ella trabajar bajo una modalidad en la que el rendimiento no sea medido por el "presentismo", sino por las tareas realizadas, o que quizás tuviera condiciones en las que su jornada laboral le permita incluir más actividades no laborales en su rutina de vida; respecto a esto más adelante plantea,

47 Es importante insistir en que un factor que indudablemente incide en este beneficio es la cercanía que existe entra la casa y la oficina, pues se demoran entre 15 minutos y 40 minutos. Esto implica que no deban invertir gran cantidad de tiempo en el desplazamiento, y a su vez que no les genera mayor desgaste o demanda de energía. 
"Mi jornada de trabajo ideal sería de 9:00 a.m. a 5:00 p.m. porque me daría tiempo de hacer ejercicio en la mañana, y las tardes dedicarlas a compartir con mi esposo o a comunicarme con mis hijas."

De nuevo es visible que debido a que esta persona cumple con la jornada de trabajo definida por la organización debe adaptar su ritmo de vida a esos tiempos; es decir, las rutinas deben establecerse en función de las jornadas laborales, desconociendo quizás la preponderancia que pueden tener otros escenarios de vida. Las propuestas de la persona "K" posiblemente reflejen el anhelo por hacer que aunque el trabajo sea una prioridad, no sea el elemento alrededor del cual se organicen los demás aspectos de vida. Esto inicialmente plantea la idea de modificar una institución y con ello las prácticas que la legitiman, pero ¿en qué medida una institución puede cambiar? Bajo la idea de que la institución es un patrón a seguir dado que es construido socialmente (De la Rosa, 2002:33), es posible afirmar que, una institución podrá ser modificada cuando ya no crea ni da sentido a la acción personal y colectiva ${ }^{48}$. De modo que la jornada laboral en tanto institución es cuestionada por la persona "K" porque a ella ya no le crea sentido dado que tiene otros intereses, y en su vida la prioridad ya no es el trabajo sino el escenario personal y familiar, por tanto, al interponer otros intereses, la jornada empieza a ser cuestionada y surgen interrogantes como los que se plantea ella.

Aunque con el paso del tiempo las personas cada vez están más habituadas al cumplimiento de unas jornadas laborales, y con ello se crean rutinas de vida en función de las mismas, también se identifican posturas y nuevas propuestas que plantean modos de trabajo diferentes a lo socialmente establecido, y que posiblemente pueden ser pertinentes y exitosas para algunos trabajos, en algunas organizaciones, en algunos campos organizacionales $e$ inclusive, con trabajadores con ciertas características. No obstante, en C21 Country difícilmente esto puede funcionar dado que el cumplimiento de las jornadas laborales en tanto instituciones, y la asistencia a la oficina como elemento legitimador posiciona a la organización de manera estratégica frente al mercado, frente a la competencia, frente a los clientes y frente a los mismos trabajadores; es decir, la institucionalización de las jornadas laborales crea sentido para la acción colectiva - así no lo cree para la acción individual de todos quienes conforman el equipo de trabajo - y por tanto, modificar lo ya institucionalizado le implicaría replantear los modos de funcionamiento y con ello la imagen que proyecta y por la que es reconocida.

48 Idea retomada de la sesión de clase de Teoría de la Organización II, impartida por el Dr. Ayuzabet de la Rosa Alburquerque. Maestría en Estudios Organizacionales. Universidad Autónoma Metropolitana - Iztapalapa. Febrero 17 de 2016 


\subsubsection{Flexibilidad en medio de la rigidez}

A pesar de que estas personas manifiestan cierta conformidad por la forma en que operan las jornadas laborales y como han adecuado su rutina de vida a estas, también fue posible evidenciar que hay cosas que les gustaría modificar para tener la posibilidad de atender temas no laborales en tiempos laborales, o poder organizar de mejor manera el espacio laboral y el no laboral. A partir de esta situación es posible identificar algunas condiciones de permisividad y flexibilidad que proporciona la organización en respuesta a las demandas de quienes conforman su equipo de trabajo.

Un ejemplo de esto es la situación de la persona "M"; ella trabaja en una jornada de medio tiempo: inicialmente su horario era de 8:00 a.m. a 12:00 m, pero debido a que su hora de finalización de jornada se cruzaba con la hora de salida de sus hijas del colegio, le solicitó a la gerente modificar el horario,

"Esperancita me ha dado muchas facilidades. Porque yo antes entraba a las 8:00 a.m. y salía a las 12:00 m pero era muy complicado porque las niñas salen a las 11:45 a.m. del colegio, y yo llegaba siempre a recogerlas como a las 11:55; después de un tiempo la profesora me llamó la atención. A partir de eso hablé con Esperancita a ver si podía salir más temprano. Ella me dio la opción de entrar a las 7:30 a.m. y salir a las 11:30 a.m. y así me queda muy cómodo, porque no tengo que estar corriendo".

También la persona "D" manifiesta que ante la posibilidad de retomar sus estudios en un horario nocturno, a partir de las 6:00 p.m. conversó la situación con la gerente de la oficina, quien accedió a permitirle reducir su jornada de trabajo media hora, con el fin de que pudiera cumplir con el horario de estudio,

"Yo hablé con Esperancita le dije que iba a empezar a estudiar y que el horario era de 6:00 p.m. a 10:00 p.m... Ella me dijo que no me preocupara, que me dejaba salir media hora antes para que alcanzara a llegar al lugar de estudio".

La persona "K" también hace referencia a un cambio importante respecto a su jornada laboral, pues inicialmente ella debía trabajar los sábados, situación que le generaba inconformidad y que constantemente manifestó a la gerencia de la oficina,

"A pesar de que las condiciones iniciales de empleo implicaba trabajar los sábados, siempre manifesté que no estaba de acuerdo porque me parecía que no había mucho que hacer ese día en la oficina y en cambio, ir allá, implicaba que dejara sin hacer las cosas en la casa por ir a cumplir horario, porque no era mucho lo que se hacía". 
Ante esto, la gerente le propuso que fuera los sábados cada quince días, de tal forma que un sábado iba ella y al otro sábado la gerente. Aunque esta nueva dinámica la favorecía, no se sentía completamente a gusto, porque sentía que perdía tiempo yendo a la oficina los sábados. Por esto más adelante, le propuso a la gerente que no le aumentara el salario, pero que le permitiera no ir más los sábados, y la propuesta fue aceptada.

Estas tres situaciones presentadas permiten ver como la organización se mueve entre la rigidez y la flexibilidad pues, a pesar de tener definida una jornada de trabajo que debe ser cumplida, accede a ciertas modificaciones, en este caso para facilitar el desenvolvimiento de múltiples roles, el rol como trabajadoras y los otros roles que tienen estas personas; es decir, hay una estructura rígida en apariencia, que se puede volver laxa con el fin de proporcionar condiciones que se adecúen a las demandas de quienes conforman su equipo de trabajo, dando cabida a la resolución de particularidades de la vida de cada quien, a fin de que puedan seguir haciendo parte de los diferentes escenarios sin que les generare mayor conflicto.

Dado que las jornadas laborales son constructos impuestos socialmente podría pensarse que en esta organización se flexibilizan porque no son consideradas completamente legítimas ni por la gerencia ni por el equipo de trabajo, lo que les da la posibilidad de hacerles modificaciones que se ajusten a lo que es legítimo para ellos. Es decir, en términos de Gouldner (1954) C21 Country opera bajo una burocracia bufona ${ }^{49}$, en la que no fomenta la rigidez de las jornadas laborales impuestas socialmente, aunque en principio pareciera que sí, sino que, cuando el trabajador se ha adaptado a la organización, se promueve cierta flexibilidad como resultado del acuerdo entre la gerencia y éste de tal manera que el trabajo se desarrolle bajo nuevos parámetros que sean aceptados por las dos partes.

Lo que de ello se deriva es que en general, las organizaciones no son absolutamente rígidas, de manera tal que la descripción de sus normas no necesariamente constituye la descripción de su operación real, pues en realidad las reglas son construidas socialmente (March y Olsen, 1997) y solamente las que crean sentido serán cumplidas y hablarán del comportamiento organizacional. Así que, hay reglas que están abiertas a la negociación y que sirven para obtener ciertas ventajas en el plano personal - o sea en el plano no institucionalizado como por ejemplo en este caso, reglas acerca de los tiempos laborales. Entonces, la flexibilidad ${ }^{50}$ a la regla que facilita la organización resulta del acuerdo entre los

49 Gouldner, a partir de un estudio que realiza en una empresa minera en Estados Unidos, identifica algunas de las consecuencias de querer implantar una organización burocrática. Dichas consecuencias él las denomina burocracia bufona, burocracia representativa, y burocracia centrada en los castigos. La Burocracia bufona es aquella en donde las normas y las reglas son impuestas desde afuera de la organización, por lo cual ni los jefes ni los subordinados las consideran legítimas. Gouldner, Alvin Ward (1954). Patterns of industrial bureaucracy. Patterns of industrial bureaucracy. New York, NY, US: Free Press pp. 282.

50 Es posible plantear también que esta flexibilidad habla del ambiente de la organización en el que, debido a la confianza y cercanía que hay entre quienes conforman el equipo de trabajo, no es 
trabajadores y la organización, que además posibilita la imposición de una contraprestación, o que crea un compromiso: "Sales más temprano pero llegas más temprano"; "No vienes los sábados pero no te aumento el salario".

\subsubsection{Elementos incidentes en el paso de la rigidez a la flexibilidad}

De modo que, a pesar de que la organización define una jornada de trabajo acorde con los lineamientos dados por la OIT, y en tiempos similares a otras organizaciones del sector, dadas las prácticas miméticas que la legitiman, es posible identificar condiciones y elementos que permiten transitar de la rigidez hacia la flexibilidad de las jornadas laborales, facilitándole la conciliación de tiempos laborales y no laborales a quienes se encuentran vinculados laboralmente con la inmobiliaria. En la figura nueve se representan dichos elementos:

Figura 9. Vinculación laboral: de la rigidez a la flexibilidad

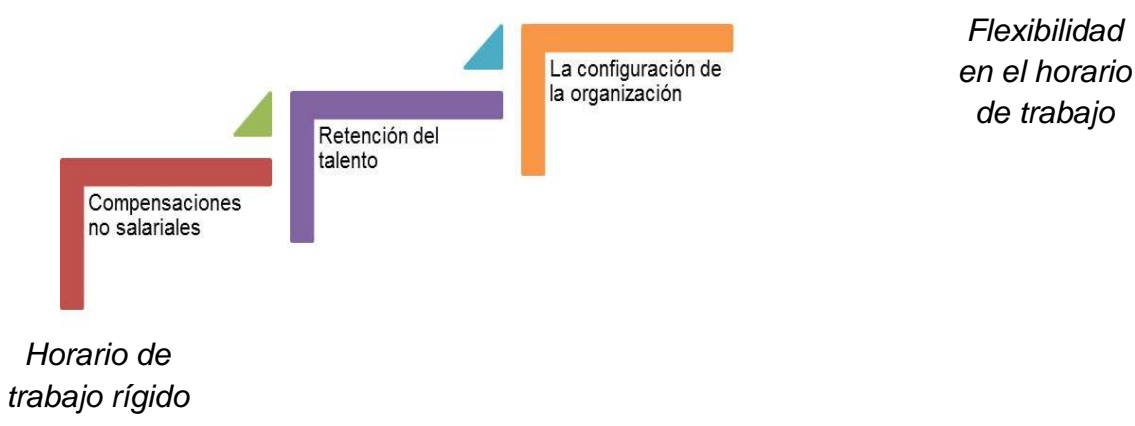

Fuente: Elaboración propia

- Compensaciones no salariales: Los salarios que ofrece la organización no son altos, hecho que puede ser compensado con recursos no económicos como el tiempo, proporcionando facilidades a los trabajadores para atender requerimientos personales en tiempos laborales. Es importante aclarar sin embargo que la organización no les concede de manera gratuita el tiempo a sus trabajadores pues, más adelante ellos deben reponer el tiempo de permiso extendiendo su jornada laboral habitual. La compensación entonces no es el tiempo en realidad, sino la facilidad que da la organización a sus trabajadores para atender asuntos particulares dentro de los tiempos laborales.

- Retención de talento: De manera similar, las facilidades que da la organización para modificar los horarios de acuerdo con los requerimientos personales de los trabajadores, o para otorgar permisos pueden ser elementos que hagan atractivo trabajar allí respecto a otros lugares, y por tanto, opera como una característica importante para considerar permanecer en dicha organización. Para la organización, es importante tener un equipo de trabajo estable de ahí que sea

necesario ser estricto con el cumplimiento de las reglas pues cuando hay confianza, seguridad y conocimiento de cómo suceden las cosas, las reglas se flexibilizan. 
permisiva y les de facilidades de flexibilización a sus trabajadores a cambio de su lealtad.

- La configuración de la organización: Como se propuso en la tabla seis, C21 Country se define como una organización con configuración empresarial, por lo que su estructura es simple, así como el proceso de toma de decisiones y el funcionamiento de la misma. Así por ejemplo, la solicitud de permisos no se convierte en un tema burocrático, sino que por el contrario, dada la cercanía de la gerencia con el equipo de trabajo, es un tema de fácil acceso, más aun sabiendo que la decisión depende de esa única persona.

Por otra parte, el hecho que el equipo de trabajo esté conformado principalmente por personas cercanas a la gerente contribuye a que se cree un ambiente de familiaridad en la organización; inclusive, la gerente en la entrevista describe la organización como una familia, y seguramente como consecuencia de ello se dan las facilidades para solicitar y adjudicar permisos de acuerdo con los requerimientos de cada persona. Es así que, quienes hacen parte de la organización - incluida la gerencia - conocen y son cercanos a situaciones de la vida personal de quienes conforman el equipo, condición que da cabida a que se otorguen permisos y facilidades para resolver asuntos de este tipo. Es por ello que la organización, bajo este parámetro de relacionamiento, es condescendiente facilitando permisos que flexibilizan la jornada de trabajo definida inicialmente por la misma.

Los elementos identificados responden principalmente a características propias de la organización. Podría plantearse que, la organización promueve este tipo de flexibilidad y permisividad con su equipo de trabajo de planta como una característica que la hace atractiva frente a otras organizaciones, dándole esto la posibilidad de mantener un grupo de trabajo estable y con ello, perpetuar la dinámica en la que se desenvuelve; esto será garantía de que sus prácticas institucionalizadas, no solo las que se relacionan con la jornada de trabajo sino en general en con su dinámica, se mantengan, en tanto seguirán siendo reproducidas por quienes conforman la organización, sin ser cuestionadas.

\subsubsection{Características de la flexibilidad y de la rigidez de la jornada laboral que facilitan el desenvolvimiento de múltiples roles en el escenario laboral y no laboral de los trabajadores de C21 Country.}

Como se pudo evidenciar con lo planteado a lo largo de este apartado, la tendencia en el comportamiento entre quienes cumplen una jornada establecida por la organización y quienes tienen la posibilidad de definirla es que los tiempos laborales responden a lo convencionalmente definido -salvo algunas excepciones-; los primeros porque así lo tienen establecido, y a partir de ahí definen sus dinámicas de vida en otros escenarios y, los segundos, porque lo ven como una manera de adoptar hábitos laborales, como una estrategia para separar lo laboral y lo no laboral, o porque no consideran una manera diferente de trabajo. 
Tal y como se ha presentado, esto da cuenta de la forma en que los individuos estamos acostumbrados a reproducir hábitos y rutinas, aun teniendo la posibilidad de modificarlas, e incluso en ocasiones, sabiendo que eso facilitaría aspectos como el desenvolvimiento de múltiples roles. Inclusive, es posible plantear que los casos en los que los agentes se organizan a partir de las facilidades de flexibilización que les da el trabajo, es debido a experiencias laborales anteriores a partir de las cuales estas personas decidieron no volver a cumplir un horario de trabajo, y coincidencialmente su etapa laboral y familiar les posibilita mantenerse en esta decisión ya que son jubilados, reciben ingresos adicionales, no son cabeza de familia, o no tienen personas dependientes a su cargo.

Por su parte, quienes cumplen la jornada laboral establecida por la oficina, consideran entonces que sus actividades no laborales deben organizarlas a partir de ese tiempo; es decir, las actividades no laborales, por ejemplo las de esparcimiento, deben ser realizadas al finalizar su jornada de trabajo, y esta situación en general no les genera conflicto; sin embargo, cuando rutinas que previamente se habían establecido en lo no laboral, son alteradas por el trabajo, sí se genera inconformidad. Esto es coherente con lo planteado por Staines y O'Connor (1980), quienes en su estudio concluyen que hay una percepción positiva con respecto a la relación entre lo laboral y lo no laboral cuando a pesar de las demandas de los diversos escenarios en los que se ubican, las personas tienen la posibilidad de participar en todos los principales roles de vida, o los considerados más importantes para cada quien, pero, hay una relación negativa cuando el tiempo no laboral es afectado por la jornada de trabajo.

A pesar de esa tendencia hacia el cumplimiento de lo socialmente establecido y de legitimar prácticas institucionalizadas, la organización en realidad no opera bajo una estructura rígida en tanto las normas son utilizadas flexiblemente. Puede decirse que la organización adopta un modelo individualizante (Nizet y Pichault, 2008), que define criterios "a la medida" de los trabajadores en el marco de acuerdos interpersonales entre estos y la organización, y de esta manera son sólo el criterio de los trabajadores y los acuerdos que establezcan con la organización los que determinan que tan rígida o que tan flexible es su jornada de trabajo, en función de los roles que desempeñen y de la compatibilización que hagan, o quieran hacer de los mismos.

Respecto a lo anterior es pertinente plantear una reflexión general acerca de las características de esta organización con relación a las posibilidades de flexibilidad de horario que proporciona a sus dos grupos de trabajo. Se puede decir que C21 Country hace uso de ciertas características propias de su dinámica, tales como la flexibilidad de tiempos trabajo, para configurarse como una opción laboral interesante para ciertos grupos poblacionales, más allá de las características comunes tales como ingresos, plan de carrera, movilidad vertical; de esta manera, la flexibilidad es un modo de tornar atractiva la organización para grupos poblacionales que tienen características particulares relacionadas por ejemplo con el género, el estado civil, el estado parental, y la trayectoria laboral. De alguna forma podría plantearse esa flexibilidad en los tiempos laborales como un salario 
emocional por medio del cual la organización retiene a quienes conforman su equipo de trabajo asegurándose contar con trabajadores con un nivel de competencia aceptable o alto (satisfactorio) y un nivel de remuneración por debajo de lo establecido en el mercado, para ese nivel de competencia; por un lado, los agentes inmobiliarios en contraparte con su vinculación free lance tienen inestabilidad salarial, y por otro lado, las personas del área administrativa tienen una asignación salarial por debajo de la remuneración del sector. De ahí que cuando la mayoría de trabajadores ponen en la balanza las condiciones laborales vs las condiciones salariales, el horario flexible se identifica como un plus que compensa dicha precariedad salarial, que en principio haría a la organización menos demandable.

Pero en definitiva, respecto al tema que principalmente nos ocupa, es posible afirmar que quienes se inclinan hacia la flexibilidad de la jornada laboral tendrían facilidades en términos de compatibilización de roles en el escenario laboral y no laboral en tanto les da la posibilidad a las personas de definir sus tiempos y espacios de trabajo a partir de sus prioridades, sin estar sujetos al cumplimiento estricto de una jornada laboral; así, cada persona tiene la posibilidad de definir lo laboral y lo no laboral de acuerdo a como lo considere. Ahora, la rigidez también facilita el desenvolvimiento de múltiples roles porque de manera estricta se diferencian tiempos y espacios laborales y no laborales, pero a la vez, la organización es permisiva frente a situaciones en las que inevitablemente chocan los dos escenarios, facilitando posibilidades de negociación de manera tal que no se genere incompatibilidad entre estos y se mantenga la diferenciación entre los mismos; esto conlleva a que en apariencia haya un pleno desenvolvimiento de cada uno de los roles - laborales y no laborales- dependiendo del escenario en el que cada persona se ubique.

Es decir que, tanto la flexibilidad de la jornada laboral como la rigidez, cada una con sus particularidades, sus pro y sus contra, dan la posibilidad de desenvolverse en múltiples roles, en el escenario laboral y el no laboral. Que esto suceda dependerá en gran medida de la exposición que tengan las personas a ciertos conflictos a partir de la multiplicidad de roles como resultado del género, la edad, el estado civil y el estado parental, pero además, de la prioridad que cada persona le conceda a los escenarios por los que transita, a partir de condiciones particulares de vida como la experiencia laboral, la preponderancia de los ingresos, la dinámica familiar, entre otros. En resumen, en esta organización, la flexibilidad de la jornada laboral y la rigidez de la misma tienden a facilitar el desenvolvimiento de múltiples roles a partir de lo que prime para cada trabajador, teniendo como referente las variables que ya se han expuesto.

\subsection{CONSTRUCCIÓN DE LA VIDA SOCIAL Y LA VIDA LABORAL EN EL MUNDO MODERNO: DEFINICIÓN DE LA JORNADA LABORAL A PARTIR DE LOS ROLES ASUMIDOS EN LO LABORAL Y EN LO NO LABORAL}

El recorrido hecho hasta este punto presenta como en C21 Country definir las jornadas laborales se configura más que como un mandato por parte de la 
organización, como una construcción social que hacen los trabajadores de la misma a partir de ciertos lineamientos establecidos por la organización y de algunas prácticas institucionalizadas por ésta y por los mismos trabajadores. De igual forma, se planteó cómo la construcción de esas jornadas laborales está incidida de manera importante por la multiplicidad de roles en la que se desenvuelven los trabajadores, pero también las variables analizadas (género, edad, estado civil, estado parental, tipo de vinculación e incluso la etapa del ciclo de vida laboral) son determinantes en ello. Finalmente, se propone que tanto la jornada laboral rígida como la flexible aportan elementos valiosos que facilitan el desenvolvimiento de múltiples roles, teniendo como referente las particularidades de vida de cada trabajador. De modo que, a partir de los elementos anteriores es posible ir un poco más allá, para analizar la forma en que las personas de C21 Country construyen su vida social y su vida laboral a partir de la rigidez o flexibilidad de las jornadas laborales en las que se desenvuelven. A continuación, en la figura diez, se sintetizan los elementos que guiarán dicho análisis.

\section{Figura 10. Construcción de la vida social y la vida laboral en C21 Country}

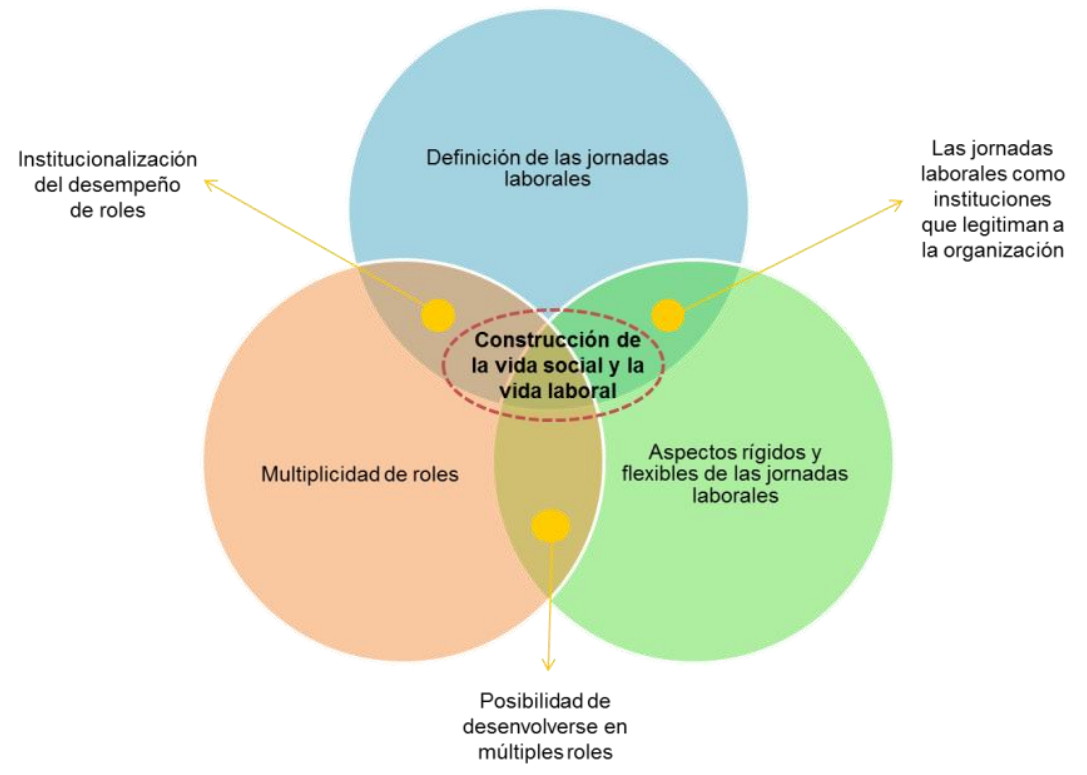

Fuente: Elaboración propia

\subsubsection{A partir de la multiplicidad de roles.}

Transitar por diferentes escenarios, e incluso por uno solo, implica asumir múltiples roles. Es así como las personas que conforman el equipo de trabajo de C21 Country hicieron referencia principalmente al escenario familiar y al escenario laboral, y con ello a su desempeño de roles como esposo/esposa, padre/madre, en algunos casos hijo/hija, y como trabajador/trabajadora. El desenvolvimiento de cada uno de estos roles responde al cumplimiento de algo institucionalizado ${ }^{51}$ :

51 Plantea Scott que las estructuras sociales son portadoras de instituciones, al basarse en expectativas como patrones, conectadas a redes de posiciones sociales, es decir, sistemas de 
comportamientos pautados socialmente que corresponden a una serie de expectativas; de modo que, el desempeño de determinado rol es coherente con ciertos comportamientos y requiere la resolución de particulares circunstancias.

Así, desenvolverse en un rol define parámetros de comportamiento que pueden complementarse o chocar con lo pautado para otro rol; de ahí que entonces la multiplicidad pueda ser negativa, generado conflicto inter - rol o sobre carga de rol, o positiva, como la acumulación de roles (Guerrero, 2003). El resultado de dicha multiplicidad de roles va a estar mediado por características propias de cada persona relacionadas con el género, el estado civil y el estado parental principalmente, pero además, por condiciones propias del ambiente en el que se desenvuelven, tanto en la esfera familiar como en la esfera laboral; por ejemplo la jornada de trabajo que cumplen, la dinámica social y familiar en la que se desenvuelven, las responsabilidades económicas que tengan. Entonces, la conjunción de estos elementos contribuyen a la construcción de la vida social y la vida laboral que hace cada persona, a partir del desarrollo simultáneo de sus roles en esos escenarios, resultando ser compatibles u opuestos.

De este modo, algunas personas tendrían mayores posibilidades de desenvolverse en múltiples roles que otras, dependiendo de características relacionadas con las variables ya mencionadas, pero finalmente construyen su vida laboral y su vida social a partir de las condiciones que el medio les ofrece, a partir de sus propios recursos y como respuesta a las demandas de los escenarios y roles en los que se desenvuelven. Es decir, los múltiples roles que estas personas desempeñan se configuran como parte de su vida social y laboral, pero la construcción que haga de cada uno de estos espacios, y la primacía que tengan los roles en uno y otro escenario depende de la forma en que cada persona se ubica frente a la situación particular a partir de sus prioridades, expectativas y recursos.

\subsubsection{A partir de la institucionalización de las jornadas laborales.}

Es posible analizar las jornadas laborales, en tanto instituciones, desde dos perspectivas:

Por un lado, las jornadas laborales operan como instituciones que dan legitimidad a la organización y por eso ésta adopta prácticas, algunas de ellas miméticas (Di Maggio y Powell, 1983), que son reconocidas en su campo organizacional y aceptadas socialmente respecto a los horarios de funcionamiento de la oficina, el uso de tecnología para el desarrollo del negocio, la flexibilización de la jornada para los agentes inmobiliarios, por mencionar algunas. Para los agentes inmobiliarios la implementación de éstas prácticas dan paso a un tipo de "autonomía controlada" (Nizet y Pichault, 2008) por parte de la organización pues,

roles. De esta manera, las estructuras constriñen y dan poder a la conducta de los actores, mediante las reglas y los sistemas de creencias codificados en roles y distinciones estructurales. Scott, 2012: 208. 
por un lado la organización promueve la iniciativa, la autodeterminación y la elección de los individuos pero por otro, los enmarca, los limita y los orienta a través de controles poderosos y sutiles tales como el celular, la participación en el comité inmobiliario, "hacer planta en la oficina". Es por ello que, la institucionalización de las jornadas laborales por parte de la organización de cierta manera limita las posibilidades con las que cuentan los agentes inmobiliarios para la definición de los tiempos laborales desde su vinculación free lance, a partir de mecanismos de sujeción que aunque en apariencia no funcionan como tal, finalmente generan que estas personas estén cumpliendo ciertos tiempos de trabajo y asumiendo determinados comportamientos que dan respuesta a ello; un ejemplo puede ser que a partir del uso de herramientas de trabajo como el celular se establecen tiempos laborales interminables.

Las personas del área administrativa por su parte cumplen una jornada laboral que se encuentra establecida por la organización, y que responde a lo adecuado dentro del campo organizacional en el que se ubica C21 Country; sin embargo, en el cumplimiento de dicha jornada entran en juego elementos de otro tipo, tales como la permisividad y la flexibilidad de la organización para el manejo de tiempos por parte de su equipo, que facilitan que el cumplimiento de dichos horarios interfiera lo menos posible en el desarrollo de actividades no laborales, haciéndola legítima para estas personas en tanto esas nuevas reglas son las que les crean sentido (March y Olsen, 1997).

Por otro lado, las jornadas laborales operan como instituciones en tanto el cumplimiento de las mismas, por parte de los agentes inmobiliarios y de las personas del área administrativa, responde a un patrón de reproducción particular (Jepperson, 2001), consecuente del comportamiento socialmente establecido de "trabajar" y de procesos de socialización. Es así que para estas personas el cumplimiento de las jornadas laborales hace parte de una rutina (Scott, 2012) que les proporciona pautas de comportamiento en el ámbito laboral, reduciendo su posibilidad - o necesidad - de elección y en cambio operando como un elemento que se da por hecho en el ámbito laboral, y que por tanto es aceptado (Tolbert y Zucker, 1996). Es decir que, sin importar el tipo de vinculación que tienen las personas que hacen parte de la organización, lo que implicaría mayor o menor autonomía para el manejo de su tiempo, hay una tendencia hacia el cumplimiento de horarios de trabajo similares a los establecidos convencionalmente, como parte de experiencias anteriores y de lo socialmente establecido; de ahí que este comportamiento se repita, se acepte y se configure como un patrón que cree sentido a la acción de trabajar.

\subsubsection{A partir de la rigidez y de la flexibilidad de las jornadas laborales.}

La organización busca que el desempeño de los roles por parte de quienes la conforman, sea lo más efectivo para ella. De modo que quienes tienen el horario flexible están vinculados con una actividad que no permite la regulación del tiempo tan estricta, pues sería irracional someterlos al cumplimiento de una jornada laboral al ser incompatible con las funciones asignadas; sin embargo, la organización establece ciertos mecanismos de control que le permiten regular el 
manejo del tiempo. En el mismo sentido, la organización requiere establecer horarios de trabajo para quienes cumplen funciones administrativas que soportan al área comercial y que deben estar disponibles en los tiempos de funcionamiento de la oficina, los cuales son establecidos a partir de prácticas miméticas; no obstante, esos horarios en apariencia rígidos son ajustados a particularidades de estas personas, que sin que impliquen la desatención del trabajo, facilite su desenvolvimiento en otros escenarios.

Ahora, cuando las personas tienen la posibilidad de definir sus jornadas laborales - los agentes inmobiliarios- lo hacen en mayor medida como una institución ya que han sido habituados y rutinizados y finalmente es algo que tiende a repetirse de manera continua; algunos otros lo hacen en función de sus experiencias de vida y de la dinámica familiar en la que se desenvuelvan, buscando no tener conflicto en el desempeño de sus roles laborales y familiares. En la otra situación, cuando hay modificaciones sobre las jornadas laborales ya definidas - personal administrativo-, no incide en igual medida la rutinización e institucionalización de prácticas laborales, sino que cobra más importancia el desenvolvimiento en diversos escenarios, y como se conjugan ciertos factores a fin de que la multiplicidad de roles que de allí se deriva sea lo menos conflictiva o genere la menor sobrecarga posible, y en cambio facilite la conciliación y el funcionamiento de una manera armónica.

Es así que, en C21 Country tanto la flexibilidad como la rigidez de las jornadas laborales pueden facilitar o complejizar el desenvolvimiento de múltiples roles; esto no depende necesariamente de lo que la organización determine, sino que será relativo a cada persona, obedeciendo a lo que para cada quien sea prioritario a partir de las variables analizadas a lo largo del documento. De ahí que entonces en esta organización las jornadas laborales sean instituciones a partir de las cuales las personas viven y deciden, dado que moldean su comportamiento; a partir de ello, las jornadas laborales se forjan como una construcción social, en tanto cada persona tiene la posibilidad de definirlas como prefiera, como le convenga y como le cree sentido, haciendo uso de la rigidez y/o de la flexibilidad sobre las que versa el funcionamiento de la organización, y de las prácticas institucionalizadas en las que se mueve.

Las características rígidas y flexibles de la jornada laboral definida por C21 Country alimentan la construcción social que cada persona hace de su jornada laboral a partir de sus necesidades, preferencias y requerimientos laborales y no laborales que de acuerdo a lo analizado, para este caso están incididos por variables como género, edad, estado civil y estado parental, y que se relacionan con asuntos igualmente individuales respecto al momento de vida en el que se encuentre cada persona, la dinámica familiar en que se desenvuelva y las expectativas laborales que tenga. 


\subsubsection{La vida social y la vida laboral en C21 Country ¿Se construye a partir de las jornadas laborales?}

Estudios recientes han planteado que como resultado del cambio en las estructuras productivas y de los mercados de trabajo es posible identificar la centralidad del trabajo en la estructuración de las relaciones humanas (De la Garza, 2010); tanto así que, el uso de la fuerza de trabajo se ha flexibilizado, modificando por ejemplo los horarios de trabajo los cuales son establecidos en función de las necesidades empresariales, y en algunos casos como consecuencia, distan de las dinámicas sociales y personales de los trabajadores. Es decir, cada vez el trabajo se ubica como la actividad central, a partir de la cual se definen posibilidades y limitantes de desenvolvimiento en otras actividades y en otros escenarios diferentes al laboral; así las cosas, se diría entonces que la tendencia en el mundo moderno es que la vida social se construya a partir y alrededor de la vida laboral.

Para el caso de C21 Country, y teniendo como base los elementos presentados y analizados a lo largo del documento, es posible plantear que no necesariamente la construcción de la vida social se hace a partir de la vida laboral, ni viceversa. Para quienes hacen parte de esta organización predomina más un escenario que el otro, dependiendo de las variables que definen a cada persona y que le proporcionan o disminuyen recursos para desenvolver los múltiples roles definidos para esos escenarios. Es decir, la construcción de la vida en estas dos esferas es particular a cada persona, desde donde cada quien se ubique, en el momento específico en el que se encuentre, a partir de su experiencia de vida, su trayectoria laboral, sus expectativas y sus prioridades. Cuando la jornada laboral es aceptada, lo más probable es que ésta defina las pautas de convivencia y comportamiento en los escenarios no laborales por los que transitan las personas pero, cuando el cumplimiento de la jornada laboral no crea sentido, las pautas de comportamiento en lo laboral son definidas a partir de otros ámbitos.

Entonces, la construcción de la vida social y la vida laboral implica que cada persona adapte y acomode lo mejor posible un escenario al otro, obedeciendo a las condiciones particulares en las que se encuentra. No obstante, esa construcción que se hace en ocasiones es mecánica dado que, hay quienes consideran no tener la potestad para decidir sobre esto, y que en cambio sólo deben dar respuesta a las demandas que desde los dos escenarios reciben; pero en definitiva, la forma en que cada persona se adecúa a ello es consecuente con lo que concibe e idea a partir de construcciones sociales que permanecen y son legítimas en los dos escenarios. Es decir, las personas moldean su comportamiento de acuerdo con lo que consideran adecuado, a partir de la construcción social que a lo largo de su vida han hecho, tanto para el escenario laboral, en particular el cumplimiento de las jornadas laborales, como para el escenario no laboral, por ejemplo la familia.

Es así que, y sin el ánimo de profundizar en discusiones que son importantes pero que no hacen parte del objetivo del presente análisis, es interesante retomar un 
planteamiento hecho por la persona " $\mathrm{H}$ " que reafirma lo anterior, al proponer que la construcción de la vida social y de la vida laboral, y el consecuente desenvolvimiento en los múltiples roles dispuestos por los escenarios en los que se ubica no depende únicamente de las facilidades que proporcionen las organizaciones respecto a los tiempos laborales, sino también, y de manera importante, de la prioridad que cada persona le dé a cada uno a partir de lo que ha construido y definido como adecuado:

"Conciliar el tiempo familiar y el laboral depende de la prioridad que cada uno tenga. Porque hay unas mamás que a los 6 meses ya están dejando a los niños en la guardería y se desentienden y se van a trabajar; para ellas su prioridad es el trabajo y su orientación profesional. Pero para mí son mis hijos; nunca me perdonaría haberlos dejado en una guardería y que crezcan y no sean los niños que yo aspire que fueran. Entonces yo prefiero sacrificarme y decir bueno, cuando sea el momento adecuado empiezo a trabajar".

Para ella, armonizar los roles laborales y los roles familiares depende en gran medida de la prioridad que los diferentes escenarios tengan para cada persona. Es decir, para quienes el trabajo sea lo principal, buscarán estrategias a través de las cuales su rol como padre o madre no interfieran en el desarrollo profesional; incluso ahora no tener hijos es tomado como una opción cada vez más frecuente por algunas personas. Pero para quienes la familia, y principalmente los hijos son lo más importante, buscan la manera de armonizar estos dos escenarios, posiblemente renunciando a su desarrollo profesional, como el caso de la persona "H", o también buscando alternativas laborales flexibles y precarias como las propuestas por ejemplo por C21 Country.

Ahora, más allá de las facilidades que den las organizaciones, o de la priorización de escenarios que plantea la persona " $\mathrm{H}$ ", es también necesario considerar las condiciones del contexto socio - económico actual pues, ya ni siquiera es cuestión de elección o de priorización el decidir salir a trabajar o quedarse cuidando a los hijos, sino cuestión de necesidad y, por más que alguien quisiera asumir su rol materno o paterno por completo, sacrificando su desarrollo laboral, no podría hacerlo por requerir de los ingresos económicos para subsistir.

Aunque este planteamiento no surge de manera directa del caso estudiado, es importante referirlo como una reflexión que resulta de las diferentes posiciones planteadas por quienes conforman la organización respecto al tiempo laboral y a los ingresos percibidos, y el análisis hecho de las mismas; sin embargo, es posible que en organizaciones con otras dinámicas de trabajo y, conformadas por una población con características socio - económicas diferentes a las que tienen quienes hacen parte del equipo $\mathrm{C} 21$ Country sean más recurrentes este tipo de dilemas entre priorización, posibilidad y necesidad de elección para la definición de la vida laboral y de la vida social. Por eso, lo más probable es que en otras organizaciones, incluso del sector inmobiliario, la definición de estos dos escenarios sea diferente. En este caso - el de C21 Country - al ser una 
construcción social, la definición de la jornada laboral y con ello la definición de la vida social y la vida laboral, no es resultado de un mandato exclusivo de la organización o del contexto, sino que es consecuencia de la conjunción particular de elementos contingenciales, organizacionales e individuales que operan de manera diferente para cada quien. Por tanto, es posible afirmar que la vida social y la vida laboral de quienes hacen parte de C21 Country se construye con incidencia de la jornada laboral, aunque no es exclusivamente a partir de dicho elemento. 


\section{REFLEXIONES FINALES}

A continuación, y a modo de reflexión a partir del análisis presentado previamente, se exponen algunas conclusiones y comentarios finales acerca del fenómeno analizado, las personas que hicieron parte de la investigación, la organización estudiada, el proceso investigativo, y en general, de las condiciones y desafíos que presenta el mundo del trabajo hoy en día, más aún, siendo visto desde los lentes de los Estudios Organizacionales.

\subsection{CONCLUSIONES}

La investigación presentada se ubica en el plano interpretativo, pues además de evidenciar el fenómeno analizado, se preocupa por ejemplificar una situación general a la que muchas personas están expuestas, indistintamente del tipo de organización en el que se ubiquen, como consecuencia de las nuevas dinámicas laborales delineadas por el modelo económico operante. De esta forma, se presentaron y analizaron restricciones temporales y espaciales que surgen a partir de la ejecución de un trabajo para el desarrollo de otro tipo de actividades en escenarios diferentes al laboral. A partir del ejercicio realizado se interpretó cómo logran las personas que hacen parte de esta organización armonizar sus múltiples roles laborales y extra laborales, con base en las demandas que cada uno de estos les hacen pero además, fuertemente incididos por el aspecto económico, que en la organización se traduce en el salario y la estabilidad laboral.

Fue posible observar que cada una de las personas que hizo parte de la investigación organiza de la forma en que más le conviene la relación entre el trabajo y la vida extra laboral: cada quien adopta una estrategia, a partir de características particulares como el género, el estado civil, el estado parental, el tipo de vinculación con la organización, el momento en el que se ubiquen dentro de su ciclo de vida laboral, y aunado con esto último, la significación que para cada uno tenga el trabajo realizado. Es así como surge el siguiente interrogante: ¿Realmente se puede ajustar el mundo laboral, o es más fácil amoldar lo no laboral a lo dispuesto por las exigencias y condiciones del trabajo?

De cierta forma, y para algunos casos, las personas tienen la posibilidad de intervenir sobre el mundo laboral, para adecuarlo a su vida no laboral; sin embargo, y en la mayoría de casos acá presentados, el ámbito de lo no laboral es el que se ajusta al laboral, y es ahí donde principalmente surgen situaciones conflictivas, ambiguas, ambivalentes, que las personas buscan resolver, mejor o peor, según las circunstancias. En este contexto cobra importancia la idea de la flexibilidad de tiempos laborales, como condición de trabajo propia de los agentes inmobiliarios de esta organización, y que en principio se pensaba facilitaba el desenvolvimiento de los múltiples roles definidos por los dos escenarios ya mencionados; pero, a partir del análisis, es posible afirmar que dicha condición no es determinante, sino que por el contrario, su aplicación es relativa a cada persona a partir de procesos de socialización, experiencias anteriores, y demandas resultantes de los roles asumidos. 
De ahí que entonces sea posible afirmar que, para el caso de estudio en particular, el concepto de horario flexible es un concepto impreciso, dado que la flexibilidad se puede lograr de diferentes maneras, inclusive a partir de la rigidez, pero principalmente, a partir de la forma como cada persona lo adecúe. Por tanto, lo que se escucha en discursos contemporáneos acerca de las bondades y ventajas de la flexibilidad de la jornada laboral es válido, principalmente para el género femenino, dado que puede facilitar la conciliación de tiempos y espacios, beneficiando a mujeres que afrontan dobles y triples jornadas; así, la flexibilidad se configura entonces como una característica atractiva, en especial para grupos poblacionales determinados. Sin embargo, esa condición de flexibilidad puede configurarse como una "trampa de la precariedad" pues finalmente en la mayoría de situaciones trae consigo condiciones de precariedad laboral que tergiversan las características del "verdadero empleo" (Neffa, 2010) a partir de una remuneración salarial inestable, inseguridad social, modificación de relaciones laborales por relaciones comerciales, establecimiento de condiciones de falsa de autonomía; de esta forma, a pesar de ser una condición que en ocasiones facilita la compatibilización de escenarios y el desenvolvimiento de múltiples roles, la flexibilidad legitima y perpetúa condiciones precarias, atípicas e inestables de trabajo, que reproducen la mercantilización de las relaciones laborales, y la adecuación de las personas a las demandas empresariales, velando sus propias necesidades y proyectos.

Por otra parte, el caso de la organización estudiada permite hablar de grupos de personas que con seguridad también se encuentran en otras organizaciones, que constantemente se enfrentan a conflictos a causa de los múltiples roles que tienen en el escenario laboral y en el no laboral y por tanto, deben ingeniárselas para definir sus jornadas laborales lo más adaptables posible a los roles que asumen en estos. De modo que, más allá de hacer referencia a la persona "A", "F" o "L", este ejercicio visibilizó la situación y la percepción de mujeres casadas, mujeres solteras, madres cabeza de hogar, padres cabeza de hogar, padres y madres con hijos pequeños, mujeres separadas, mujeres jubiladas, personas en edad joven y adulta, que se encuentran en esta organización y que muy seguramente también se hallan en otras organizaciones, respecto al desenvolvimiento de sus múltiples roles y las estrategias que muchas veces deben definir para dar cumplimiento a las demandas que cada uno les genera a partir de estas condiciones particulares de vida en las que se encuentran, y de los recursos con los que cuentan para hacer frente a las mismas.

Así, algunas personas definen diversas estrategias haciendo uso de la flexibilidad de horarios para manejar estos dos escenarios, entonces mezclan uno o varios roles en un mismo espacio con el fin de atender a las demandas de los mismos; otras se valen de la tecnología para no desconectarse de los asuntos laborales mientras atienden otras cuestiones; otras prefieren definir y cumplir por sí mismos horarios de trabajo como estrategia de diferenciación de tiempos y espacios, por mencionar algunas. Muchas de estas estrategias, como ya se dijo, están incididas por las variables propuestas de género, edad, estado civil y estado parental; no obstante, es importante recalcar que a pesar de lo determinante que pueden llegar 
a ser estas variables, las estrategias de compatibilización definidas también dependerán de la prioridad que para cada quien tenga cada uno de los roles que desempeña, de cómo se ubique frente a estos, e inclusive, del apoyo externo con el que cuente para manejarlos (cónyuge, familia extensa, instituciones).

Tampoco es posible hablar de esta situación como un caso particular de la organización estudiada, sino como un fenómeno que seguramente se puede presentar en otras organizaciones, cuyas particularidades estructurarán una manera diferente para definir las jornadas laborales, y con ello, el desenvolvimiento en múltiples roles por parte de quienes hacen parte de la organización. Por tanto, sería interesante analizar este fenómeno en organizaciones con condiciones laborales diferentes a las ofrecidas por C21 Country; por ejemplo una organización que vincule laboralmente a sus trabajadores, mediante contrato a término indefinido, con las prestaciones de ley y con estabilidad salarial; 0 , una organización con un mayor número de trabajadores; o, una organización diseñada bajo otra configuración, por ejemplo la maquinal (Mintzberg,1989); o, una organización dedicada a la producción de bienes; o incluso, en una organización con similitud de funciones, también en el sector inmobiliario, o en el sector de ventas, pero con diferencias en las características socio - demográficas de las personas que la conforman; incluso, será interesante analizar en otras organizaciones este tipo de problemáticas, en las que la participación de los trabajadores en escenarios laborales y no laborales trascienda la dicotomía trabajo - familia, y permita ver el desenvolvimiento de otros roles en espacios académicos, culturales, o políticos, por ejemplo.

Probablemente cada una de estas características propone dinámicas diferentes tanto para la organización como para quienes la conforman, y en consonancia con ello, la definición y la construcción de las jornadas laborales varía con relación a lo presentado en esta investigación. He ahí pues, un reto interesante para otros estudiosos de las ciencias sociales, inclusive para estudiosos de las organizaciones, para quienes este tema también cause interés de cara al contexto actual y/o a situaciones particulares, y quiera avanzar en la construcción de conocimiento en ese sentido; especialmente a partir de experiencias en países latinoamericanos, con el fin de contribuir a la construcción de conocimiento local. Es más, será interesante abrir otras vetas de análisis en las que se incluyan aspectos que inciden en este fenómeno, tales como el uso de la tecnología, dado que en este documento fue abordado superficialmente; sería valioso en otro estudio analizar de manera más precisa como la tecnología, al ser una herramienta cada vez más recurrente e indispensable en el mundo laboral y social incide en la definición de los tiempos laborales, el papel que tiene con respecto al desenvolvimiento de múltiples roles - facilitarlo o complejizarlo - y en definitiva, la trascendencia que tiene para la construcción y desarrollo de la vida social y laboral en el mundo moderno. Ojalá el trabajo acá presentado sea fuente de inspiración y recurso bibliográfico útil para avanzar en ese propósito. 


\subsection{COMENTARIOS FINALES}

A partir de las reflexiones presentadas anteriormente a propósito del estudio de caso realizado, es posible ir más allá del planteamiento inicial de investigación acerca de las jornadas laborales en esta organización y reflexionar sobre algunas cuestiones trascendentales para el análisis del mundo del trabajo desde una perspectiva organizacional.

El contexto actual propone unas nuevas dinámicas de trabajo y de relacionamiento en el ámbito laboral, dada la adopción de políticas que facilitaron la penetración de la lógica mercantil en el funcionamiento de las relaciones sociales y laborales, conllevando a la fragmentación y segmentación del mercado de trabajo. Esto generó presión sobre los costos salariales, lo que obligó a las empresas a cambiar su estructura para hacerlas más ágiles y flexibles, buscando nuevas formas de gestión de la producción y de la mano de obra. Así es como se da apertura a diversas modalidades de empleos, la mayoría de estos precarios, cuyas características recurrentes son la inestabilidad y la incertidumbre en tanto sus condiciones de empleo difieren de las tradicionales en las que se habla de un trabajo asalariado, regulado por la legislación en materia de contrato de trabajo; se establece una relación laboral entre el empleado y el empleador, el trabajo se realiza de tiempo completo, de acuerdo a lo legamente establecido; el contrato tiene una duración indeterminada; el empleador proporciona al empleado seguridad y prestaciones sociales; $y$, el trabajo se desarrolla en un espacio físico diferente a la domicilio del empleado o del empleador (Neffa, 2010).

No obstante, dado lo precarias que pueden definirse las nuevas formas de trabajo desde una posición objetiva, a falta de una o varias de las características ya mencionadas, si se toma en cuenta una construcción subjetiva de las mismas, posiblemente el resultado sea diferente, dado que se puede hablar de posibilidades de armonización de lo laboral y lo no laboral, por deseo u obligación, lo cual lleva implícito el reconocimiento del individuo en la organización, y con ello sus necesidades, sus pretensiones y su esencia humana.

Así, a partir del análisis propuesto es posible afirmar que el hablar de la jornada laboral también implica:

- Hablar de lo humano en tanto este aspecto está implícito en la definición de los tiempos laborales. La jornada laboral entonces no solamente debe considerarse de manera racional y cuantificable, ni como un elemento que estructura a las organizaciones y con ello las dinámicas de trabajo. A partir de la investigación realizada en C21 Country se evidenció el aspecto humano que interviene en la definición de las jornadas laborales; en esta organización las personas tienen la posibilidad de estructurar sus tiempos laborales de acuerdo con sus necesidades, intereses y prioridades; sin embargo, en organizaciones con otras particularidades y otras dinámicas por el contrario se desconocen la características de lo humano incididas por los múltiples roles y las necesidades de diferentes tipos que tienen las personas, los cuales se ven trastocados o 
ensombrecidos por el cumplimiento estricto de la jornada laboral definida. Es decir la definición y seguimiento de las jornadas laborales puede reconocer 0 desdibujar lo humano de quienes las cumplen.

- Las jornadas laborales al ser analizadas desde los Estudios Organizacionales más que una forma de normalización y/o control, son una construcción social que cada persona hace a partir de variables y particularidades como el género, el tipo de contratación, el estado civil, el estado parental, la etapa del ciclo laboral en la que se encuentre, entre otras. De modo que es posible afirmar que la jornada laboral no necesariamente es una construcción universal sino que, al ser construida socialmente da la posibilidad de que se definan múltiples jornadas en una misma organización; en el caso estudiado por ejemplo, se identifican 16 jornadas laborales, en tanto cada persona definió y reconoció lo que para ella representa la jornada y de la misma manera, como la define y la cumplen.

- C21 Country, analizada bajo los lentes críticos del modelo económico operante indudablemente es una organización que establece condiciones de trabajo precarias y atípicas para las personas que están vinculadas a ésta; Sin embargo, y sin desconocer las condiciones de precariedad del mundo del trabajo actual, el cual ha sido descrito anteriormente, también podría decirse que para la mayoría de personas que hacen parte de C21 Country esta es una "organización hecha a la medida" (Montoya, 2009) de los requerimientos de mujeres con responsabilidades familiares, madres y padres con hijos pequeños, personas que están finalizando su ciclo laboral, personas jubiladas, por ejemplo. Y, es a partir de esa condición de maleabilidad de la organización que las personas tienen la posibilidad de ir construyendo y reconstruyendo procesos organizacionales tales como las jornadas laborales, de acuerdo con sus necesidades de manera que sean pertinentes para dar respuesta a las responsabilidades y demandas que reciben de escenarios diferentes al laboral.

Parafraseando a Montoya (2009), podría decirse entonces que C21 Country tiene una estructura sólida pero su dinámica es dúctil, proporcionando cierto rango de flexibilidad para que, sin cambiar su esencia de trabajo las condiciones en las que se desarrolla el mismo se adecúen a las necesidades de las personas que la conforman. De ahí que entonces el diseño de esta organización "hecha a la medida", y en particular la definición de los tiempos laborales, esté determinada por variables como las analizadas (género, tipo de contratación, estado civil, estado parental, etapa del ciclo laboral).

- Por otra parte, desde la teoría de roles el cumplimiento de la jornada laboral puede significar sobre carga de rol, conflicto inter - rol o acumulación de roles, a partir de la multiplicidad de roles en las que se ubican las personas que conforman la organización, principalmente en el escenario familiar y en el escenario laboral, dependiendo de la condiciones sociales y personales de cada individuo que determinan la preeminencia de un rol sobre otro. Por tanto, la 
posibilidad que tienen quienes trabajan en C21 Country de definir sus tiempos laborales en algunas ocasiones contribuye a facilitar el desenvolvimiento de múltiples roles, o por lo menos a reducir ciertos conflictos; sin embargo, para otras personas esa condición de autonomía muchas veces redunda en mayores inconvenientes para el desenvolvimiento de múltiples roles dado que están incididos no solamente por las condiciones y variables propuestas, sino por procesos de socialización a partir de los cuales adoptan ciertos hábitos y rutinas, y como consecuencia, la flexibilidad de tiempos no les crea sentido como condición de desempeño en el ámbito laboral.

- A partir del nuevo institucionalismo las jornadas laborales se entienden como una construcción social que crea sentido para quienes las cumplen, de acuerdo a lo definido por ellos mismos. Sin embargo, hay procesos que inciden en la definición de las jornadas laborales, conceptualizados por esta corriente teórica: desde la organización por ejemplo, la adopción de prácticas miméticas para definir el horario de funcionamiento de la oficina, o para considerar la pertinencia de la asignación de equipos celulares a los agentes inmobiliarios, con el propósito de que permanentemente puedan atender cuestiones del negocio; es decir, para que estén trabajando a todo tiempo. $\mathrm{O}$, el establecimiento de reglas es un mecanismo de la organización para que los trabajadores se comporten de acuerdo a lo esperado por ésta; es pertinente recordar que la acción se institucionaliza por medio de reglas y rutinas (March y Olsen, 1997:90), de ahí la importancia de la definición de este tipo de controles por parte de la organización para generar en los trabajadores un comportamiento repetitivo y normado, de acuerdo con sus intereses.

Desde los trabajadores, conceptos como la rutinización de prácticas, el cumplimiento de reglas, y la definición y seguimiento de mitos racionalizados, cobran importancia en tanto son prácticas que de manera determinante inciden en la forma en que cada persona define y asume sus tiempos laborales. De modo que, hay casos en los que la asistencia a la oficina es necesaria, en tanto demuestra compromiso con el trabajo asignado; la definición de los tiempos de trabajo en condiciones similares a los horarios de funcionamiento de la oficina para unos es necesaria como estrategia de diferenciación de escenarios, y para otros, es resultado de las experiencias laborales anteriores en las que estaban habituados con el cumplimiento del horario de trabajo; el uso del celular como herramienta de trabajo para unos representa la posibilidad de conciliar tiempos y espacios laborales, y para otros significa prestar un buen servicio al cliente, de acuerdo con las políticas de la organización.

En síntesis, el nuevo contexto ofrece un abanico de posibilidades, algunas veces ambiguas en las que para obtener cierto tipo de beneficios se deben sacrificar otros; por ejemplo, la flexibilidad de tiempo a cambio de no tener un ingreso estable o de no contar con seguridad social, como en el caso de los agentes inmobiliarios de C21 Country. Sin embargo, lo hallado, analizado y expuesto a partir de esta investigación acerca de las jornadas laborales desde la perspectiva de los estudios organizacionales deja un campo de conocimiento abierto para 
seguir indagando al respecto, más aún, en un contexto socio - económico variable, volátil y cambiante como el actual, un mercado de trabajo en circunstancias volubles y precarias, un ritmo de vida cada vez más exigente y demandante, y con las características de las nuevas generaciones que de alguna forma están en sintonía con dicho dinamismo ${ }^{52}$. Todas estas condiciones complejizan el análisis de las jornadas laborales, pero el estudiarlo desde corrientes teóricas como por ejemplo la cultura y elementos como la identidad y el simbolismo, el psicoanálisis y la violencia simbólica generada desde la organización a partir del establecimiento de las jornadas laborales, o las relaciones de poder que se entretejen para y tras la definición y cumplimiento de las mismas, seguramente enriquecerán su comprensión.

Con relación al interés personal que motivó el desarrollo de la presente investigación, es importante resaltar que ésta permitió reconocer la heterogeneidad de significaciones que tienen las jornadas laborales, más allá de lo usualmente establecido. Además, amplió el campo de conocimiento sobre las mismas, incluyendo elementos omitidos o desconocidos, tales como el aspecto humano y todos los elementos que desde ahí se desencadenan e inciden en que las personas definan de una u otra forma sus tiempos de trabajo. No obstante, también abre la reflexión de los casos de quienes no están en la posibilidad de definir las jornadas, y entonces deben adecuar su vida no laboral a lo establecido por la organización generando la menor afectación posible; lo complicado del asunto es que no en todas las organizaciones existe esta posibilidad, y que muchas veces las presiones económicas tienen mayor prioridad que temas personales o familiares, por lo que los trabajadores deben resignarse a que el mundo de lo laboral desdibuje cada vez más su esencia humana, dando respuesta a las necesidades de eficiencia y productividad propias de las organizaciones definidas por el modelo económico predominante.

Por tanto, es importante proponer retos para el sector empresarial, y quienes lo lideran, dado que es urgente que las organizaciones se interesen por este tipo de problemáticas, y a partir del reconocimiento y exaltación de lo humano configuren y definan estrategias de conciliación no como una disyuntiva, sino como una posibilidad que no ponga en riesgo las condiciones de un empleo estable, y que considere tanto el reconocimiento de lo humano como de lo económico; es decir, organizaciones hechas a la medida (Montoya, 2009), de hombres y mujeres, que ofrezcan condiciones de estabilidad, seguridad y durabilidad.

\footnotetext{
52 Esto se propone en sintonía con lo planteado por Hualde Tolentino y Jurado (2014), quienes afirman que en el caso mexicano algunos jóvenes de sectores medios optan por cierto tipo de empleos flexibles e inestables pero motivantes; los llamados "trabajos independientes de segunda generación". Podría pensarse inclusive que esta es la constante en las personas de esa generación en diversos países latinoamericanos, como respuesta y mecanismo de adaptación al contexto en el que se ubican.
} 


\section{BIBLIOGRAFÍA}

- Alarcón Delgado, Irma de Lourdes (2012). "Conciliación de la vida familiar y laboral en parejas heterosexuales con intenciones de equidad de la ciudad de México". Revista de estudios de género: La ventana, ISSN 1405-9436, Vol. 4, №. 35 , págs. 58-92

-Álvarez, Adaneys y Gómez, Ingrid Carolina (2011). "Conflicto trabajo - familia, en mujeres profesionales que trabajan en la modalidad de empleo". Pensamiento psicológico No. 16. Págs. $89-106$

- Aritzeta, Aitor y Ayestarán, Sabino (2003). "Aplicabilidad Teoría Roles Belbin: Estudio Longitudinal”. Revista de Psicología General y Aplicada. Vol. 56. Págs. 61-75

- Barba Álvarez, Antonio (2009) "Reflexiones sobre el estudio de caso en el análisis organizacional" en De la Rosa Alburquerque, Ayuzabet, María Teresa Montoya Flores y Silvia Pomar Fernández (Coords.) Pequeñas Organizaciones: Complejidad y diversidad organizacional. Estudio de casos de organizaciones mexicanas, UAM y Juan Pablos Editor, pp. $13-21$

-Briones, Guillermo (1996). Metodología de la investigación cuantitativa en las ciencias sociales. Programa de especialización en teoría, métodos y técnicas de investigación social. Instituto colombiano para el fomento de la educación superior ICFES. Arfo editores e impresores Itda, pp. 1 - 205

- Brumely, Krista M. (2014), Now, We Have the Same Rights as Men to Keeps Our Jobs Gendered Perceptions of Opportunity and Obstacles in a Mexican Workplace, Gender, Work \& Organization Volume 21, Issue 3, Pp. 217 - 230

- Brunet, Icart Igansi y Alarcón, Alarcón Amado (2005). Mercado de trabajo y familia. RIPS: Revista de investigaciones políticas y sociológicas, Vol. 4 No. 2, pp. $115-129$

- Caamano Rojo, Eduardo (2010). "El teletrabajo como una alternativa para promover y facilitar la conciliación de responsabilidades laborales y familiares". Revista de Derecho de la Pontificia Universidad Católica de Valparaíso [online].N.35, pp. 79-105.

- Cánovas Montero, Ana, Rocha Sánchez, Fernando y Aragón Medina, Jorge (2005). "Las políticas de conciliación de la vida familiar y laboral de las Comunidades Autónomas". Cuadernos de relaciones laborales, Vol. 23, № 1, págs. 73-93 
- Castellaro, Mariano Andrés (2011). Definiciones teóricas y áreas de investigación propuestas desde el constructivismo en publicaciones latinoamericanas de psicología y educación presentes en la base de datos Redylac. Libertabit Revista de psicología, vol. 18, No. 2, pp. 131 - 146. Universidad de San Martín de Porres, Lima, Perú.

- De la Garza, Enrique (2010). "Hacia un concepto ampliado del trabajo. Del concepto clásico al no clásico". España. UAM - Iztapalapa y Anthropos Editorial. Capítulo I ¿Hacia dónde va el trabajo humano?, pág. 21 a 37.

- De la Rosa, Alburquerque Ayuzabet (2002). "Teoría de la Organización y Nuevo Institucionalismo en el Análisis Organizacional". Revista Administración y Organizaciones. Vol. 8. Issue 4. Págs. 13 - 44

- Debeljuh, Patricia y Jáuregui, Kety (2004) "Trabajo y familia. Hacia una cultura familiar amigable en el contexto latinoamericano". Journal of economics, finance and administrative science. ESAN - Cuadernos de difusión Vol. 16. Págs. 91 - 102

- DiMaggio, Paul J. y Walter W. Powell (1983) "The iron cage revisted: institutional isomorphism and collective rationality in organizations fields", en American Sociological Review, vol. 48, núm 2. Págs. 147 - 160

- Edwards, Jeffrey R. y Rothbard, Nancy P. (2000). Mechanisms linking work and family: clarifying the relationship between work and family constructs. The Academy of Management Review, 25, 178-199

- Facin Lavarda, Carlos Eduardo. Ripoll Feliu, Vicente Mateo. Barrachina Palanca, Mercedes (2009). "Un análisis institucional de la implicación del proceso de cambio de los SCG en la evolución de la eficiencia de las PYME". Revista Contabilidad y finanzas. Universidad de Sao Pablo. Vol. 20. Issue. 49. Págs. 126 $-141$

- Faur, Eleonor (2006). "Género, masculinidades y conciliación familia-trabajo". Nómadas, ISSN-e 0121-7550, №. 24, págs. 130-141

- Feldeman, Lya, Eleonora Vivas, Zoraide Lugli, Joanmir Zaragoza, Viviola Gómez Ortiz (2008) "Relaciones trabajo-familia y salud en mujeres trabajadoras". Salud pública de México, ISSN 0036-3634, Vol. 50, №. 6, 2008, págs. 482-489

- Giraldo Suárez, Juan de Dios (1967). “Jornada de trabajo”. Universidad Pontificia Bolivariana. Medellín, Colombia Revista Facultad de Derecho y Ciencias Políticas. No. $41-43$, pp. $56-77$ 
- Gómez Rada, Carlos Alberto y Ponce de León, Eduardo, (2010). "Modelo integrativo de la calidad de vida laboral percibida a partir de la inseguridad laboral, la jornada laboral y el salario, para hombres y mujeres trabajadores de empresas de la ciudad de Bogotá en diferentes rangos de edad". Universidad de San Buenaventura Bogotá, Colombia. Psychologia. Avances de la disciplina, vol. 4, núm. 2, julio-diciembre, 2010, pp. 113-129

- Gouldner, Alvin Ward (1954). Patterns of industrial bureaucracy. Patterns of industrial bureaucracy. New York, NY, US: Free Press pp. 282.

- Greenhaus, Jeffrey H. y Beutell, Nicholas J. (1985). Sources of conflict between work and family roles. Academy of Management Journal 10, Págs. 76 - 88

- Guba, Egon y Lincoln Yvonna (2002). Paradigmas en competencia en la investigación cualitativa. Compilacción de Denman, C y Haro J.A., Por los rincones. Antología de métodos cualitativos en la investigación social, pp. 113 145, Sonora: Colegio de Sonora.

- Guerrero, Juan (2003). "Los roles no laborales y el estrés en el trabajo". Revista colombiana de psicología. No. 12. Págs. $73-84$

- Herrera Caballero, Juan Manuel (2005). El proceso de cambio institucional. El caso del Instituto Mexicano del Petróleo. Tesis presentada para obtener el título de Doctor en Estudios Organizacionales. Universidad Autónoma Metropolitana Iztapalapa. México

- Hualde, Alfredo, Tolentino Hedalid y Jurado Mario (2014). "Trayectorias laborales en los Call Centers" en "La precariedad laboral en México. Dimensiones, dinámicas y significados". México. UAM - Cuajimalpa y El Colegio de la Frontera Norte. Introducción, pp. 221- 255

- Ibarra Colado, Eduardo (1994) "Organización del trabajo y dirección estratégica". Caracterización de la evolución de los paradigmas gerenciales" en Montaño Hirose, Luis (ed.) Argumentos sobre un debate para la modernidad. Aspectos organizacionales y económicos. México, UAM - Iztapalapa, Departamento de Economía. Serie Investigación, Núm. 13, pág. 15 - 47

- Jepperson, Ronald L. (2001) "Instituciones, efectos institucionales e institucionalismo" en Powell, Walter y Paul Di Maggio (comp.) El nuevo institucionalismo en el análisis organizacional, Fondo de Cultura Económica, Colegio Nacional de Ciencias Políticas y Administración Pública, A.C., Universidad Autónoma del Estado de México, México, pp. 193 - 215

- Lucia - Casademunt, Ana. Antonia García Cabrera. Deybbi Cuéllar Molina. (2015) "National culture, work-life balance and employee well-being in European 
tourism firms. The moderating effect of uncertainty avoidance values". Encuentros Científicos - Tourism \& Management Studies. Vol. 11, №. 1(Ejemplar dedicado a: Tourism \& Management Studies), págs. 62-69

- Macinnes, John (2005). "Diez mitos sobre la conciliación de la vida familiar y laboral". Cuadernos de relaciones laborales, Vol. 23, № 1, págs. 35-71

- March, James G. y Olsen, Johan P. (1997) El redescubrimiento de las instituciones. La base organizativa de la política, Fondo de Cultura Económica, Colegio Nacional de Ciencias Políticas y administración pública, A.C., Universidad Autónoma de Sinaloa, México.

- Martínez, Piedad Cristina (2006). "El método de estudio de caso: Estrategia metodológica de la investigación científica". Pensamiento y gestión: revista de la División de Ciencias Administrativas de la Universidad del Norte. No. 20. Págs. $165-193$

- Mestre Miquel, Joana María, Guillén Palomares, Juana y Caro Blanco, Fernanda (2012). “Abuelas cuidadoras en el siglo XXI. Recurso de conciliación de la vida social y familiar". Revista de Trabajo Social, Vol. Extra 12,_págs. 231-238

- Meyer, John W. y Brian Rowan (1977) "Institutionalized Organizations: Formal structure as myth and ceremony", en The American Journal of Sociology, vol. 83, núm 2, págs. $340-363$

- Mintzberg, H. (1989), Mintzberg y la dirección, Madrid, Días de Santos ediciones,

- Montoya Flores, María Teresa (2009) "Organizaciones hechas a la medida: configuración organizacional, mujer e identidad. El caso de una cooperativa pequeña" en De la Rosa Alburquerque, Ayuzabet, María Teresa Montoya Flores y Silvia Pomar Fernández (Coords.) Pequeñas Organizaciones: Complejidad y diversidad organizacional. Estudio de casos de organizaciones mexicanas, UAM y Juan Pablos Editor, pp. 225 - 285

- Moreno, Almudena (2005). "Empleo de la mujer y familia en los regímenes de bienestar del sur de Europa en perspectiva comparada. Permanencia del modelo del varón sustentador". Reis: Revista española de investigaciones sociológicas, No. 112 , pp. $131-164$

- Morgan, Glenn y Peer Hull Kristensen (2006) "The contested space of multinationals: Varieties of institutionalism, varieties of capitalism", en Human Relations, 59 (11): 1467-1490. 
- Neffa Julio cesar (2010) "La transición desde los verdaderos empleos al trabajo precario" en De la Garza, Enrique y Neffa, Julio Cesar (Coords.) Trabajo, identidad y acción colectiva, México, UAM - Iztapalapa, Flacso y Plaza y Valdés, pág. 43 a 80

- Nizet, Jean y Pichault Francois (2008) "De la sociología de las organizaciones a la gestión de los recursos humanos: una propuesta de marco de análisis". México, UAM - Xochimilco. Administración y Organizaciones 21, Año 11, diciembre de 2008, pág. $47-84$

- Ortiz, José Ramón (2000). Paradigmas de la investigación. UNAdocumenta, No. 14 (1) enero - junio, pp. 42 - 48

- Pasamar Reyes, Susana y Valle Cabrera, Ramón (2011). "Presiones institucionales para la conciliación de la vida profesional y personal". Cuadernos de Economía y Dirección de la Empresa. Vol. 14. Issue 4. Págs. 258 - 268

- Perdigao, Andrade María Claudia. (2011) "Work-Life Balance: condições de trabalho facilitadoras da integração do papel profissional e familiar" Revista científica Exedra. №. Extra 1(Ejemplar dedicado a: Comunicação nas Organizações). Págs. 41-54

-Pérez, Sánchez Carmen y Ana Gálvez Mozo.(2009) “Teletrabajo y vida cotidiana. Ventajas y dificultades para la conciliación de la vida laboral, personal y familiar. Revista Athenea Digital: Revista de pensamiento e investigación Social. No. 15. Págs. $57-79$

- Perlow, Leslie A. (1995) Putting the work back into work/family. Group and Organization Management, 20 ,2, 227-39

- Pietromonaco, Paula, Manis, Jean \& Frohardt-Lane, Katherine (1986). Psychological consequences of multiple social roles. Psychology of Women Quarterly, Vol 10, 373-382

- Quecedo, Rosario y Castaño, Carlos (2002). "Introducción a la metodología de investigación cualitativa”. Revista Psicodidáctica. Número 14. Págs. 5 - 39

- Quintanilla Navarro, Beatriz (2005).“ La conciliación de la vida laboral y familiar en el marco jurídico actual”. Cuadernos de relaciones laborales, Vol. 23, № 1,págs. 95-129

- Recio Andreu, Albert (2002). La jornada laboral una cuestión multiforme. En "Sindicatos y cambio económicos y sociales". Sanguineti Raymond, Wilfredo y García Laso Agustín. Universidad de Salamanca, Ediciones Universidad de Salamanca 
- Reygadas, Luis (2011), "Trabajos atípicos, trabajos precarios: ¿Dos caras de la misma moneda?", en Edith Pacheco, Enrique de la Garza y Luis Reygadas (Coordinadores), Trabajadores atípicos y precarización del empleo, El Colegio de México, México, pp. $21-45$

-Rhnima, Abdelaziz y Núñez Grapin, Juan Francisco (2014). “Articulación empleo - familia. Análisis del apoyo social como factor regulador". Ciencia_ergo-sum, Vol. 21, №. 1, 2014, págs. 9-20

- Rodríguez Menéndez, María del Carmen y Fernández García Carmen María (2010). "Empleo y maternidad: El discurso femenino sobre las dificultades para conciliar familia y trabajo.". Cuaderno de relaciones laborales, Vol. 28, No.2. Págs. $257-276$

-Rodríguez, D. (2006), Diagnóstico organizacional, México, Alfaomega, pp 34 69.

-Romero, Jorge Javier. (2001) "Estudio introductorio. Los nuevos institucionalismos: sus diferencias, sus cercanías" en Powell, Walter y Paul Di Maggio (comp.) El nuevo institucionalismo en el análisis organizacional, Fondo de Cultura Económica, Colegio Nacional de Ciencias Políticas y Administración Pública, A.C., Universidad Autónoma del Estado de México, México, pp. 7 - 32

- Ruiz Castro, Mayra (2012) "Time Demands and Gender Roles: The Case of a Big Four Firm in Mexico, Gender Work \& Organization, Volume 19, Issue 5, September, Pages $532-554$

- Santos, Noé (2008), "La institución como objeto creador de sufrimiento", Administración y Organizaciones, Año 10, No. 20, UAM - Xochimilco, pp. 103 126

-Sarbin, Theodore (1954) "Role Theory", en Handbook of social psychology. Edited by G. Lindzey. Vol. 1. Cambridge, Mass: Addision - Wesley

- Schieman, Scott. Glavin, Paul. Milkie, Melissa (2009). When Work Interferes with Life: Work-Nonwork Interference and the Influence of Work-Related Demands and Resources. American Sociological Review. Vol. 74. Issue. 6. Págs. 966 988

- Scott, Richard W. (2012). Teoría institucional y organizaciones y teoría contemporánea institucional, en Vergara, Rodolfo. Organizaciones e instituciones, BBAP y Siglo XXI, México, pp. 163-185 y 186-222. 
- Scott, Richard W. (1995) Institutions and Organizations, Sage, Thousand Oaks, London New Delhi

- Scribano, Adrian (2000). Reflexiones epistemológicas sobre la investigación cualitativa en ciencias sociales. Cinta moebio 8: 128-136

- Segado Sánchez, Sagrario. Osca Segovia, Amparo. López Peláez, Antonio. (2013) "Trabajo social con familias y conflicto familia - trabajo". Cuadernos de trabajo social. Vol. 26, No. 2. (Ejemplar dedicado a: La familia como recurso de la intervención). Págs. 253-264

-Sheehan, Joseph Green (1970).Stuttering: Research and Therapy. The University of Michigan. The University of Michigan. Harper \& Row. Págs. 424

- Sieber, Sam D. (1974) Toward a theory of role accumulation. American Sociological Review, Vol. 30, 567 - 578

- Staines Graham L y O'Connor, Pamela (1980). "Conflicts among Work, Leisure, and Family Roles". Jstore, Monthly Labor Review, pp. 35 - 40

- Taylor S. J. y Bogdan R. (1996). Introducción a los métodos cualitativos. Ediciones Paidós. 1-343.

- Tolbert, S. Pamela y Lynne G. Zucker. (1996). The institutionalization of institutional theory. En clegg, Stewart R., y cynthia hardy y Walter R. Nord. Handbook of organization studies, Sage, londres. Pp. 175-190

- Torns Martín, María Teresa (2011). Conciliación de la vida laboral y familiar o corresponsabilidad ¿El mismo discurso? RIDEG: revista interdisciplinar de estudios de género, №. 1(Ejemplar dedicado a: Familia y trabajo en la universidad ¿Conciliación o corresponsabilidad?), págs. 5-13

- Torres Carrillo, Alfonso (1995). Los enfoques cualitativos en investigación. Enfoques cualitativos y participativos en investigación social. Aprender a investigar en comunidad II. UNISUR, Bogotá D.C. Págs. 11 - 37.

-Wayne, Julie H., Musisca, Nicholas, y Fleeson, William. (2004). Considering the role of personality in the work-family experience: relationships of the big five to work-family conflict and facilitation. Journal of Vocational Behaviour, 64, 108-130

-Witten, Marsha (1997) "Narrativa y cultura de la obediencia en el lugar de trabajo", en Mumby, Dennis, Narrativa y control social. Perspectivas críticas, Amorrortu, Buenos Aires, pp. $132-160$ 
-Zucker, Lynne C. (2001) "El papel de la institucionalización en la persistencia cultural" en Powell, Walter y Di Maggio, Paul (comp.) El nuevo institucionalismo en el análisis organizacional, Fondo de Cultura Económica, Colegio Nacional de Ciencias Políticas y administración Pública, A. C., Universidad Autónoma del Estado de México, México, pp. 126-153. (1991).

\section{Fuentes de información de internet}

- Century 21 Colombia [en línea]. ¿Qué es Century 21?. 2014 [Fecha de consulta: Noviembre 18 de 2016]. Disponible en: http://www.century21colombia.com/franquicia/sistema century.php

- Chia - Cundinamarca [en línea]. Sitios de interés. 2012 Fecha de consulta: [Enero 30 de 2017]. Disponible en: http://www.chia-cundinamarca.gov.co/

- Dinero, Publicaciones Semana S.A. [en línea]. ¿Se acerca la edad dorada de las inmobiliarias en Colombia? 2015. [Fecha de consulta: Noviembre 18 de 2016], Disponible en: http://www.dinero.com/edicionimpresa/negocios/articulo/perspectivas-del-sector-inmobiliario-para-2016colombia/216505

- Federación Colombiana de Lonjas de Propiedad Raíz [en línea]. ¿Quiénes somos? 2016. [Fecha de consulta: Noviembre 18 de 2016], Disponible en: http://www.fedelonjas.org.co/

-Diario La república [en línea]. La percepción del Good Will en Colombia (Parte I). 2015. [Diciembre 6 de 2016]. Disponible en: http://www.larepublica.co/lapercepci\%C3\%B3n-del-good-will-en-colombia-parte-i 291151

- Organización Internacional del Trabajo (OIT) [en línea]. C001 - Convenio sobre las horas de trabajo (industria) de 1919. 1996 - 2016 [Junio 10 de 2016]. Disponible http://www.ilo.org/dyn/normlex/es/f?p=NORMLEXPUB:12100:0::NO::P12100 ILO CODE:C001

- Organización Internacional del Trabajo (OIT) [en línea]. C030 - Convenio sobre las horas de trabajo (comercio y oficinas) de 1930. 1996 - 2016 [Junio 10 de 2016]. Disponible en: http://www.ilo.org/dyn/normlex/es/f?p=NORMLEXPUB:12100:0::NO::P12100 ILO CODE:C030

- Secretaria del Senado de la República de Colombia [en línea]. Código Sustantivo del trabajo. 1992. [Junio 10 de 2016]. Disponible en: http://www.secretariasenado.gov.co/senado/basedoc/codigo sustantivo trabajo.h $\underline{\mathrm{tml}}$ 
LA CONSTRUCCIÓN DE LA VIDA LABORAL Y LA VIDA SOCIAL EN EL MUNDO MODERNO: EL CASO DE UNA ORGANIZACIÓN

INMOBILIARIA EN COLOMBIA

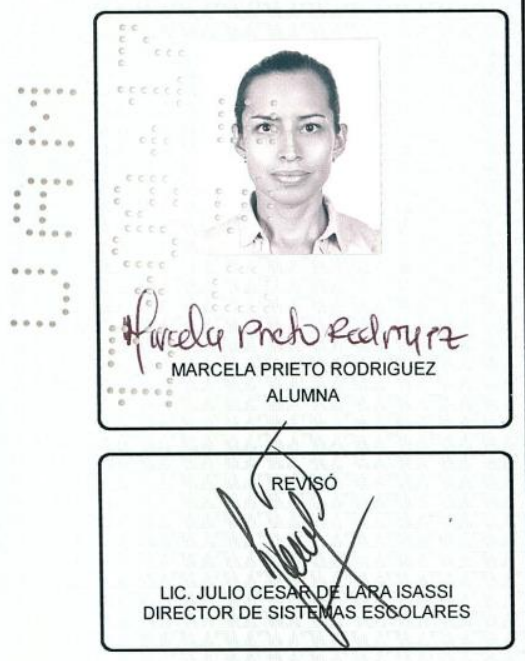

Bajo la Presidencia del primero y con carácter de Secretario el último, se reunieron para proceder al Examen de Grado cuya denominación aparece al margen, para la obtención del grado de:

MAESTRA EN ESTUDIOS ORGANIZACIONALES

DE: MARCELA PRIETO RODRIGUEZ

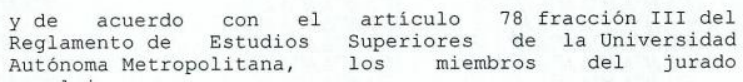
Autónoma Metropolitana, los miembros del jurado resolvieron:

\section{Aprobar}

Acto continuo, el presidente del jurado comunicó a la interesada el resultado de la evaluación $y$, en caso aprobatorio, le fue tomada la protesta.
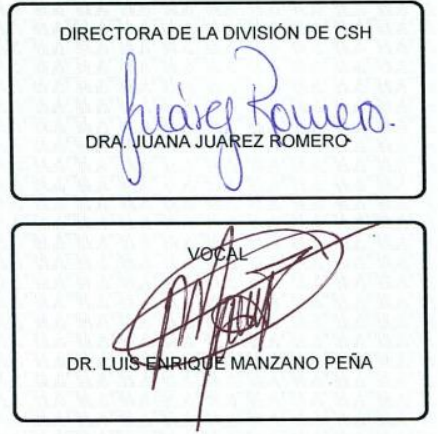

PRESIDENTE

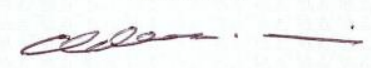

DR. ADOLFO MIR ARAUJO

SECRETARIO

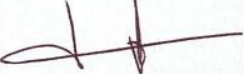

DR. LUIS MANUEL JUNCOS QUIANE 